Winfried Brömmel, Helmut König,

Manfred Sicking (Hg.)

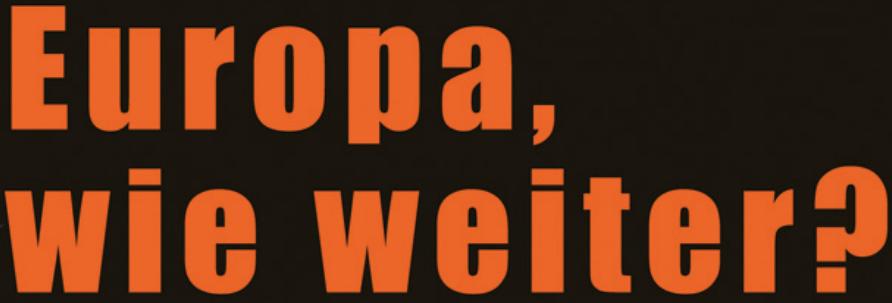

Perspektiven eines Projekts in der Krise 
Winfried Brömmel, Helmut König, Manfred Sicking (Hg.)

Europa, wie weiter? 


\section{Editorial}

Die politische Einigung Europas nach dem Ende des Zweiten Weltkriegs ist historisch einzigartig. I500 Jahre europäische Kriegsgeschichte sollen hier zu Ende kommen und zu einer dauerhaften Entfaltung der Demokratie führen. Die Suche nach geeigneten Verfahren und Institutionen bleibt jedoch schwierig. Zentrale Fragen wie die Verteilung von Aufgaben und Kompetenzen, der Ausgleich zwischen einzelstaatlichen und gemeinschaftlichen Interessen, die demokratische Legitimation sowie die Ausgestaltung der Meinungs- und Willensbildungsprozesse sind nach wie vor offen.

Europa als Ganzes ist nicht identisch mit seinen Teilen, mit den Ländern der Europäischen Union und des Kontinents. Was aber macht Europa aus? Worin bestehen seine Gemeinsamkeiten, wo verlaufen seine Grenzen, wie ist die Relation von Einheit und Vielfalt? Wie unterscheidet es sich von anderen Weltregionen, Kulturen und politischen Ordnungen?

Die Buchreihe Europäische Horizonte greift zentrale europäische Gegenwarts- und Zukunftsfragen auf und gibt politischen, ökonomischen und kulturellen Problemstellungen gleichermaßen Raum.

Die Reihe wird herausgegeben von Friedrich Jaeger, Helmut König, Claus Leggewie, Emanuel Richter und Manfred Sicking. 
Winfried Brömmel, Helmut König, Manfred Sicking (Hg.)

\section{Europa, wie weiter?}

Perspektiven eines Projekts in der Krise

[transcript $]$ 


\section{(9) $(1) \Theta$}

Dieses Werk ist lizenziert unter der Creative Commons Attribution-NonCommercial-NoDerivs 4.0 Lizenz (BY-NC-ND). Diese Lizenz erlaubt die private Nutzung, gestattet aber keine Bearbeitung und keine kommerzielle Nutzung. Weitere Informationen finden Sie unter https://creativecommons.org/licenses/by-nc-nd/4.o/deed.de/. Um Genehmigungen für Adaptionen, Übersetzungen, Derivate oder Wiederverwendung zu kommerziellen Zwecken einzuholen, wenden Sie sich bitte an rights@transcript-verlag.de

\section{(C) 2015 transcript Verlag, Bielefeld}

Die Verwertung der Texte und Bilder ist ohne Zustimmung des Verlages urheberrechtswidrig und strafbar. Das gilt auch für Vervielfältigungen, Übersetzungen, Mikroverfilmungen und für die Verarbeitung mit elektronischen Systemen.

\section{Bibliografische Information der Deutschen Nationalbibliothek}

Die Deutsche Nationalbibliothek verzeichnet diese Publikation in der Deutschen Nationalbibliografie; detaillierte bibliografische Daten sind im Internet über http://dnb.d-nb.de abrufbar.

Umschlagkonzept: Kordula Röckenhaus, Bielefeld Druck: Majuskel Medienproduktion GmbH, Wetzlar

Print-ISBN 978-3-8376-3010-7

PDF-ISBN 978-3-8394-3010-1

Gedruckt auf alterungsbeständigem Papier mit chlorfrei gebleichtem Zellstoff. Besuchen Sie uns im Internet: http://www.transcript-verlag.de Bitte fordern Sie unser Gesamtverzeichnis und andere Broschüren an unter: info@transcript-verlag.de 


\section{Inhalt}

\section{Einleitung | 7}

Winfried Brömmel/Helmut König/Manfred Sicking

Krisen, Konflikte und Solidarität.

Zur gegenwärtigen Lage der Europäischen Union | 27

Maurizio Bach

Ambivalenzen der Krise.

Währung, Konflikt und europäische Integration | 43

Georg Vobruba

Europäische Krisenpolitik auf dem Prüfstand.

Die Europäische Integration aus

wirtschaftshistorischer Sicht | 61

Werner Plumpe

Euro-Krise und internationale Finanzkrise.

Die Finanzialisierung der Wirtschaft als

politische Herausforderung für Europa $\mid 79$

Christoph Deutschmann

Die Krise der Demokratie in Europa und die Krise der Erforschung dieser Krise | 101

Thorsten Thiel 
Res Publica Europae. Ein bürgerbasiertes Konzept, die politische Integration Europas zu überdenken | 125 Ulrike Guérot

Krise und Partizipation in der Europäischen Union. Für eine neue Politik der Bürgerbeteiligung am Beispiel der Energiepolitik | 153

Jan-Hendrik Kamlage und Patrizia Nanz

Muss Europa neu begründet werden? | 177

Michael Stolleis

Verzeichnis der Autoren und Herausgeber | 195 


\section{Einleitung}

\section{WINFRIED BRÖMMEL/HELMUT KÖNIG/MANFRED SICKING}

\section{EUROPA, WIE WEITER}

Seit einem Jahrzehnt ist der europäische Integrationsprozess nicht nur ins Stocken geraten, sondern in ganz neuer Weise umkämpft und umstritten. Niemand kann gegenwärtig wissen, wie es weitergehen wird. Die Verunsicherung ist groß, die inneren und äußeren Herausforderungen türmen sich und lassen alles andere als Zuversicht aufkommen. Seit 2008 sorgt die Finanz-, Banken- und Schuldenkrise, die noch keineswegs überwunden ist, für Zwist, Unruhe und Unbehagen. Schon zuvor, im Mai 2005, scheiterte der aufwendig ins Dasein gerufene Verfassungsvertrag an den Hürden der Referenden in Frankreich und den Niederlanden. Das machte unübersehbar deutlich, wie weit sich die hochfliegenden Absichten der politischen Eliten von den Vorstellungen der Wahlbevölkerungen entfernt hatten.

Die Skepsis ist nicht gewichen, sondern nimmt stetig zu. Die Idee, mit der Einführung des Euro die Unterschiede zwischen dem Leistungsvermögen der nationalen Volkswirtschaften nach und nach anzugleichen, hat sich als Illusion herausgestellt. Die Unterschiede in der Wettbewerbsfähigkeit und in den politisch-ökonomischen Kulturen der Mitgliedstaaten sind stärker zutage getreten denn je und haben die alten gegenseitigen Klischees und Vorurteile, die lange in den Hintergrund getreten waren, revitalisiert. Die europäischen Hoffnungen der Peripherieländer Griechenland, Spanien, Portugal sind in Ernüchterung, Abwehr und Hass gegen „Brüssel“ bzw. die Geberländer des Nordens, gegen Deutschland vor allem, umgeschlagen.

Deutschland und Frankreich, ohne deren Kooperation die europäische Integration nicht vorankommen kann, liegen immer wieder im Clinch mit- 
einander. Die innere Situation in Frankreich ist besorgniserregend, das Land ist zutiefst gespalten, bei den Wahlen zum Europäischen Parlament im Jahre 2014 kam der nationalistische Front National auf die meisten Stimmen. Es ist keineswegs auszuschließen, dass die nächste Präsidentin in Paris auf den Namen Marine Le Pen hört. Aber auch in Deutschland, dem alles in allem bislang wohl integrationsfreundlichsten Land Europas, werden zum ersten Mal die integrationsfeindlichen Stimmen und Tendenzen in nennenswertem Ausmaß sichtbar und erhalten Zulauf.

Vielerorts wird die europäische Integration nicht mehr als Problemlöser für ökonomische Stagnation, Arbeitslosigkeit und Armut angesehen, sondern als deren Ursache. Und an die Stelle der in den Verträgen und offiziellen Verlautbarungen viel beschworenen europäischen Solidarität ist ein Nullsummenspiel getreten, in dem die Zugewinne der einen stets auf Kosten der anderen zustande zu kommen scheinen. Die Spaltung in Gewinner und Verlierer hat mit der Öffnung der Schere zwischen reichen und armen Ländern zu tun, also damit, dass das Versprechen stetig steigenden und immerwährenden Wohlstands nicht eingehalten werden konnte. Die Idee der Solidarität wird unter dem Klischee begraben, dass die armen Länder vollkommen selbstverschuldet in den Schlamassel geraten sind, es sich immer in der Hängematte der südlichen Sonne gemütlich gemacht haben und die reicheren Länder des Nordens dafür nun auch noch die Zeche zahlen sollen.

Die grundlegenden strukturellen Fragen und Probleme der Europäischen Integration lassen sich um drei Gesichtspunkte herum gruppieren. (1) Die soziale Dimension: Hier geht es um die Rolle Europas für die Sozial- und Wohlfahrtspolitik. Das Manko, dass die negative Integration durch das Wegarbeiten möglichst aller Art von nationalen Wettbewerbsbeschränkungen nicht im gleichen Maße von positiver Integration durch europäische Marktregulierungen kompensiert wird, ist seit langem bekannt, aber in den letzten Jahren viel deutlicher ins Bewusstsein gerückt. (2) Die politische Dimension: Sie betrifft die konstitutionelle und institutionelle Verfasstheit der Europäischen Union. Hier sind die Spannungen nicht minder groß. Die einen wollen einen großen Sprung nach vorn in Richtung einer Vertiefung und eines europäischen föderalen Staates machen, die anderen möchten am liebsten zurück in das Zeitalter der Nationalstaaten. Damit hängt das viel diskutierte Demokratiedefizit zusammen. Eine Abhilfe dieses Defizits erschien so lange nicht wirklich nötig, wie die immer wieder ins Feld geführte 
Output-Legitimation alle demokratischen Defizite auf der Input-Seite des politischen Prozesses ausreichend kompensierte. Angesichts der nachlassenden Effizienz und Wirksamkeit der Maßnahmen macht sich nun aber die alte republikanische Wahrheit geltend, dass Institutionen, die nicht durch die Zustimmung der Bevölkerungen getragen werden, sehr schnell ihre Autorität verlieren und ihre Wirksamkeit einbüßen. (3) Die internationale Dimension: Angesichts bedrückender Instabilitäten und Gewaltausbrüche an vielen Orten der Welt und angesichts der größten Flüchtlingsströme seit dem Ende des Zweiten Weltkriegs wird eine gemeinsame europäische Außenpolitik zu einer dringlichen Notwendigkeit. Das zeigen, unmittelbar vor der Haustür, die Ukraine-Krise und die neue Konfrontation mit Russland.

\section{Die soziale Dimension}

Es gehört zu den Auffälligkeiten der Diskussionen des letzten Jahrzehnts, dass sich auf der linken Seite des politischen Spektrums, die eigentlich wegen ihres Hangs zum Internationalismus gleichsam a priori für die progressive Überwindung des Nationalstaats prädestiniert ist, die Anzahl der skeptischen und ablehnenden Stimmen deutlich vermehrt hat, und zwar quer durch alle europäischen Länder (siehe die Beiträge in Hillebrand/Kellner 2014). Das liegt im Kern daran, dass der Nationalstaat bislang der einzige Rahmen geblieben ist, in dem ein einigermaßen befriedigender sozialer Ausgleich zwischen Kapital und Arbeit hergestellt werden konnte. Alle Hoffnungen, die sozialstaatlichen Errungenschaften auf der EU-Ebene weiter auszubauen bzw. mindestens zu erhalten und zu sichern, sind Makulatur geblieben. Ein soziales Europa, das erscheint jetzt mehr oder weniger als ausgemacht, wird es vorerst nicht geben. Im Gegenteil: Der Traum einer zweiten Zähmung des Kapitalismus durch die europäischen Institutionen ist zum Albtraum der neoliberalen Deregulierung und einer neuen Entfesselung des Kapitalismus verkommen (vgl. Misik 2014). Aus linker und sozialdemokratischer Sicht hat die europäische Integration die politischen und sozialen Errungenschaften der Nationalstaaten nicht gestärkt, sondern unterminiert und geschwächt. Die EU erscheint nunmehr als eine einzige große Deregulierungs- und Entdemokratisierungsmaschine (vgl. Streeck 2013), und in den Augen vieler linker und sozialdemokratischer Autoren ist dagegen nur das eine Kraut gewachsen, dass das ganze Unternehmen zurückgebaut und die einzelstaatlichen Regulierungen wieder in ihr Recht 
gesetzt werden. Kurz: Wer dem Sozialen den Vorrang vor allem anderen gibt, wem es wichtig ist, dass das untere Drittel der Gesellschaften nicht völlig auf der Strecke bleibt, der plädiert eher für die Erhaltung umfangreicher Kompetenzen auf der Ebene der Einzelstaaten als für die Übergabe weiterer nationaler Souveränitätsrechte an die Europäische Union.

An der ersten Welle der europäischen Integration nach dem Zweiten Weltkrieg waren Sozialdemokraten nicht maßgeblich beteiligt. Erst seit Ende der 1960er Jahre, als Persönlichkeiten wie Willy Brandt, Olof Palme, Bruno Kreisky entscheidenden Einfluss gewannen, schlugen sich die europäischen Sozialdemokratien mit Nachdruck auf die Seite des Integrationsprojekts. Das lag sicherlich nicht zuletzt daran, dass diese Generation von der Kriegserfahrung nachhaltig geprägt war (vgl. Bouvet 2014: 22f). Nachdem heute die Kriegsgefahr zwischen den einstmals verfeindeten Nationen dauerhaft überwunden ist und das europäische Friedensnarrativ als Begründung der Integration nicht mehr dazu angetan ist, sämtliche Bedenken in den Hintergrund zu drängen, schlägt das Pendel jetzt offenbar zurück. Zu offensichtlich ist die Tatsache geworden, dass die Entwicklung, die die europäische Integration genommen hat, dem Prinzip des sozialen Ausgleichs widerspricht. Statt von einem sozialdemokratischen Kompromiss wird Europa bestimmt von einer free-market economy under the rule of procedural law, - was eben kein sozialdemokratisches, sondern ein wirtschaftsliberales Konzept ist (vgl. Bouvet 2014: 24). Die Hoffnung, dass dieser Stand der Dinge durch eine nachholende Demokratisierung und etwa durch einen Kurswechsel der Europäischen Zentralbank in die Richtung eines linken Projekts verändert werden könnte, gilt nur noch als naiv.

Die europäische Spaltung zwischen den Geberländern des Nordens und den Schuldnerländern des Südens ist das eine, die innergesellschaftliche Spaltung zwischen denen, die vom gemeinsamen Binnenmarkt profitieren, und denen, die dabei eher unter die Räder kommen, ist das andere. Das generelle Dilemma der sozialdemokratischen Parteien in den postindustriellen Zwei-Drittel-Gesellschaften reichert sich mit einer europäischen Komponente an. An die Stelle der herkömmlichen Polarisierung zwischen links und rechts treten neue Spaltungen, die quer durch die Anhängerschaften verlaufen, auf die sich die Sozialdemokratien in den letzten Jahrzehnten gestützt haben: zwischen sozialliberalen, akademisch gebildeten und hochmobilen Milieus einerseits und den weniger gebildeten, gewerkschaftsnahen Angehörigen der unteren Mittel- und Arbeiterschicht andererseits. Die 
Akademiker unterstützen das europäische Projekt, die gering Qualifizierten stehen ihm immer fremder gegenüber, haben Probleme auf dem Arbeitsmarkt und sehen sich weitgehend schutzlos der Konkurrenz billiger osteuropäischer Wanderarbeiter ausgeliefert. Bei ihnen erzeugt das angeblich alternativlose EU-Projekt nur Angst, Missgunst und Misstrauen, sie fühlen sich entfremdet enteignet und herabgestuft. Und immer stärker erscheint auch die Sozialdemokratie in den Augen der Europaverlierer als Teil eines Modernisierungsunternehmens, das ihre Sicherheitsinteressen und Bedürfnisse untergräbt und verrät. In vielen Ländern, so sagen die Kritiker, hat die Sozialdemokratie das Gespür für diese Gefühle und Ängste verloren und versteht sich eher als Teil der ,,begabten, gebildeten, unternehmerisch veranlagten und stets mobilen Bevölkerung“ denn als Teil der wenig gebildeten traditionell sozialdemokratischen Schichten (Cuperus 2014: 37). So steht jetzt auf der einen Seite eine ,überwiegend liberale, mobile, säkulare und akademische Elite“, und auf der anderen Seite stehen Wähler, ,die mehrheitlich nicht rassistisch oder fremdenfeindlich sind, aber Stabilität in den Gemeinschaften und Engagement für das Gemeinwohl wertschätzen und glauben, dass es der immer liberaler werdenden politischen Klasse an Verständnis für sie und ihr Leben fehlt“ (Goodhart 2014: 80f).

Dieses spezifisch sozialdemokratische Dilemma zwischen Internationalismus und sozialem Ausgleich wird gegenwärtig offenbar immer mehr zugunsten des sozialen Ausgleichs aufgelöst. Das heißt dann automatisch zugleich, dass eine weitere Vertiefung der europäischen Integration, eine weitere Zentralisierung und Homogenisierung auf dieser Seite des politischen Spektrums nicht mehr auf Unterstützung rechnen kann. Angestrebt wird hier vielmehr ein maßvolleres Europa, ein Europa, das keine Union, sondern eine Gemeinschaft ist (vgl. Cuperus 2014: 40). Das ist nicht automatisch identisch mit einer vollkommen anti-europäischen Haltung, aber es markiert doch einen klaren Wandel der Präferenzen und Beweislasten: Es ist nicht mehr automatisch so, dass alles, was die europäische Integration befördert, von vornherein als der richtige Weg gilt.

\section{Die politische Dimension}

Auch der Diskurs über die konstitutionelle und institutionelle Verfasstheit der Europäischen Union hat eine neue Intensität erreicht. Aber im Unterschied zu der Diskussion über die Chancen für ein soziales Europa verlangen in der politisch-institutionellen Diskussion viele prominente Stimmen 
den großen Sprung nach vorn in die Richtung einer weiteren Vertiefung der Integration und eines europäischen Bundesstaates. Das ambitionierte Ziel besteht darin, eine föderale politische Union zu etablieren, in der das Europäische Parlament weiter gestärkt, die Europäische Kommission zu einer konstitutionellen EU-Regierung umgewandelt oder alternativ eine zentrale Regierung für die Eurozone errichtet wird.

$\mathrm{Zu}$ den Protagonisten dieser Strömung gehören der frühere belgische Ministerpräsident Guy Verhofstadt (Vorsitzender der Fraktion Allianz der Liberalen und Demokraten für Europa, ALDE) und der britische Europaparlamentsabgeordnete Andrew Duff. Beide sind engagierte Wortführer der Spinelli-Gruppe von Europaparlamentsabgeordneten, die sich für die Errichtung einer starken föderalen europäischen Regierung einsetzt. In die gleiche Richtung zielte der frühere deutsche Außenminister Joschka Fischer (2010), als er für die Gründung der ,Vereinigten Staaten von Europa“ plädierte. Die neu entstandene Glienicker Gruppe (2013) von elf deutschen Ökonomen, Politologen und Juristen trat jüngst in ähnlichem Sinn mit Vorschlägen für ein vertieftes Europa in Erscheinung. Und auch der prominente Grünen-Politiker Daniel Cohn-Bendit plädiert, gemeinsam mit Guy Verhofstadt (2012), für die langfristige Perspektive eines europäischen Bundesstaates.

Das entscheidende Argument für die Errichtung der Vereinigten Staaten von Europa lautet immer, dass nur auf diesem Wege die staatlichen Institutionen die Kompetenz und Durchschlagskraft erreichen können, die zur Bewältigung der gewaltigen Gegenwartsprobleme nötig sind. Da wir es auf der ökonomischen Seite seit den 1990er Jahren mit einer gigantischen Welle der Globalisierung und mit zunehmend transnational vernetzten Gesellschaften zu tun haben, müssen die politischen Institutionen nunmehr endlich gleichziehen, damit der Lösungsraum der Probleme wieder deckungsgleich wird mit dem Raum, in dem die Konflikte, die gelöst werden müssen, ihren Ursprung haben. Die Nationalstaaten sind per definitionem damit überfordert, transnationale Probleme zu lösen. Die politische Fragmentierung der Staatenwelt Europas muss beendet und in eine starke und wirksame transnationale Staatenunion überführt werden.

Es ist gemutmaßt worden, dass eigentlich auch die großen europäischen Volksparteien und ihre gegenwärtig führenden Politiker insgeheim diesen Bestrebungen für eine neue Stufe der Integration Europas zustimmen. Aus purem Opportunismus und aus wahltaktischer Rücksicht würden sie das 
jedoch öffentlich niemals verlauten lassen. Diese Einschätzung, die z.B. der oben bereits erwähnte Guy Verhofstadt vertreten hat (vgl. Cuperus 2014: 31f.), ist durchaus nicht von der Hand zu weisen. Das Ziel einer vollendeten europäischen Union liegt ja tatsächlich auf der Linie der mehr oder weniger realistischen, von funktionalen Zweckmäßigkeiten diktierten und angeblich alternativlosen politischen Problemlösungen, die viele der gegenwärtigen europäischen Entscheidungsträger für sich in Anspruch nehmen. Hier wird nur die funktionale Logik weitergedacht, die die Geschichte der Europäischen Integration stets bestimmt hat. Es ist oft betont worden, dass der Integrationsprozess von Anfang an im Grunde ein Elitenprojekt gewesen und als eine Art wirtschaftlicher Zweckverband von Bürokraten, Juristen und politischen Führungskräften ins Leben gerufen und getragen worden ist. Da die Versprechen von Frieden, Arbeitsplätzen und steigendem Wohlstand in den drei Jahrzehnten nach 1950 mehr oder weniger überall eingehalten wurden, widersprachen die beteiligten europäischen Bevölkerungen nicht, aber sie waren auch alles andere als Motoren, Gestalter und Antriebskräfte der Entwicklung.

Aus dieser Sicht betrachtet, wäre es zweifellos das Beste, wenn es auf diesem Pfad der technisch und funktional begründeten Integration einfach weitergehen würde. Alles kommt dann nur darauf an, die anstehenden, insbesondere die ökonomischen Probleme angemessen und professionell zu lösen. Das hat zwar eigentlich mit Politik nichts zu tun, sondern allenfalls mit Interessen und Interessensunterschieden, die man durch Expertenverhandlungen irgendwie ausgleichen und in Kompromisse überführen muss, mit denen alle Beteiligten leben können. Aber das mindert die Attraktivität diese Strategie in den Augen ihrer Befürworter nicht, sondern steigert sie. Das supranationale Regieren in Europa erscheint hier als der von Sachzwängen diktierte rationalste Weg der Handlungskoordination und der technischen Lösung von sachlichen Problemen. Europa ist sozusagen die Bühne, auf der der heimliche, aber in der Geschichte des abendländischen Denkens tief verwurzelte Wunschtraum von der Ersetzung politischen Handelns durch reine Technik in die Wirklichkeit umgesetzt werden kann.

In dieser Sicht der europäischen Dinge ergeben sich die nächsten Schritte mehr oder weniger unvermeidlich und folgerichtig aus der Einführung der Euro und der Bewältigung der Finanzkrise. Bei der Einführung des Euro bestand das Kalkül darin, dass mit ihr eine mehr oder weniger zwanglose Angleichung im Leistungsniveau der Volkswirtschaften verbunden 
sein würde. Die Deutschen waren bereit, ihre geliebte D-Mark aufzugeben, sofern die anderen Staaten einwilligten, ihre Ökonomien nach deutschem Vorbild einer strengen Überprüfung und Steuerung durch externe und von Experten festgelegte Zielvorgaben zu unterwerfen. Die gemeinsame Währung wurde gleichsam als der große leveller begriffen, der die unterschiedlichen Wirtschaftsstrukturen und -ordnungen auf ein und das gleiche Modell ausrichten würde.

Wie wir heute wissen, ging das Kalkül gründlich in die Irre. In Wirklichkeit liegen die Dinge eben doch andersherum. Das einheitliche Leistungsvermögen der Ökonomien ist die Voraussetzung für eine einheitliche Währung und nicht deren Wirkung. Einheitliche Währungen kann man also eigentlich nur dort einführen, wo das Leistungsvermögen der Volkswirtschaften bereits annähernd das gleiche Niveau aufweist. Jetzt aber, wo das Kind im Brunnen liegt, bleibt offenbar keine andere Wahl mehr, als diese Voraussetzungen in einem Akt nachholender Modernisierung mit dem entsprechenden Druck von außen herzustellen. Dazu ist es dann unvermeidlich, dass die Europäische Kommission mit mehr Kompetenzen und Rechten in der Wirtschafts- und Finanzpolitik ausgestattet wird und vor allem die Oberaufsicht über die jeweilige nationale Haushalts- und Wirtschaftspolitik an sich zieht. Als Inbegriff dieser Entwicklung kann man die sog. Troika aus EU-Kommission, Internationalem Währungsfond und Europäischer Zentralbank ansehen, die mit weitgehenden Kontroll- und Eingriffsrechten in die Politik der hilfebedürftigen Mitgliedsländer ausgestattet ist. Der nicht zu leugnende Widerspruch einer gemeinsamen Währung bei gleichzeitiger nationaler Verantwortung für Banken und Haushalte kann nun eben nur noch dadurch aufgelöst werden, dass die Währungsunion durch die Banken-, Fiskal- und Wirtschaftsunion flankiert wird. Also müssen weitere Hoheitsrechte auf die europäische Ebene übertragen werden. Auf diese Weise läuft dann alles über kurz oder lang und durch rein ökonomische Notwendigkeiten erzwungen auf die Vollendung einer politischen Union hinaus, in deren Kompetenz mit Steuerrecht, Finanzhoheit, Haushaltskontrolle und Sozialpolitik nun auch jene Bereiche fallen, die bislang in den Händen der Einzelstaaten verblieben waren. Dann ist das Ziel einer wirklich politischen Union über nationale Grenzen hinweg realisiert.

Tatsächlich hat die Eurokrise die technische Vorstellung politischen Handelns noch einmal mit großer Schubkraft versehen. Wie immer in Krisensituationen war das schnelle und entschiedene Eingreifen exekutiver 
Instanzen gefragt. Das Krisenmanagement lag und liegt in der Hand von Experten und Organen, die rasch die nötigen Schritte ergreifen und Schadensbegrenzung betreiben können. So geriet die Eurokrise zur Stunde der Notstandsregime (Scharpf) und der Expertokratie (Habermas). Einzelne nationale Regierungen haben auf diese Weise gemeinsam mit Kommission und Europäischer Zentralbank ihren Handlungsspielraum auf Kosten der nationalen Parlamente erheblich erweitert. Noch einmal ist also jene so oft in der Vergangenheit erfolgreiche Methode zum Einsatz gekommen, mit der man die Einzelstaaten immer wieder dahin bringen konnte, ,eine Integrationspolitik, die von den meisten nicht gewollt wird, als unvermeidlich zu akzeptieren" (Goodhart 2014: 86).

Es könnte aber sein, dass die Einführung des Euro und das Krisenmanagement nicht nur der Gipfelpunkt dieser technokratischen Praxis politischen Handelns gewesen sind, sondern zugleich ihren Untergang eingeleitet haben. Das liegt vor allem daran, dass die hohen Kosten, die diese Art des Handelns mit sich bringt, nun viel sichtbarer geworden sind, auf Widerstand stoßen und in lautstarken Protest umschlagen. Das stillschweigende Einverständnis der Bevölkerungen, von dem man bislang ausgehen konnte, weil alle am Ende zu den Gewinnern der Entwicklungen gehörten, ist unübersehbar von einer weit verbreiteten Ablehnung abgelöst worden. Die entpolitisierte Variante des Handelns, nach der die besten Lösungen immer von Experten ermittelt und festgelegt werden, funktioniert nur so lange, wie tatsächlich alle Beteiligten davon ausgehen dürfen, dass sie am Ende etwas davon haben. Das ist heute aber nicht mehr der Fall.

Auch die Demokratie-Lücke der europäischen Politik, von der in den akademischen und publizistischen Debatten so oft die Rede war, wird nun deutlicher wahrnehmbar. Zu ihr gehört die vertrackte Weise hinzu, in der die Unterminierung der sozialen Errungenschaften auf der europäischen Ebene mit dem institutionellen Gefüge Europas, insbesondere mit der Rolle des Europäischen Gerichtshofs (EuGH), verbunden ist. Zuletzt hat Dieter Grimm (2013) gezeigt, wie die Urteile dieses Gerichts implizit in den Rang von Verfassungsbestimmungen aufgerückt sind. Durch eine Reihe von Urteilen hat der EuGH die wirtschaftlichen Grundfreiheiten des europäischen Binnenmarkts mehr oder weniger in subjektives Recht verwandelt. Das bedeutet aber zugleich, dass die Entscheidungen über grundsätzliche Alternativen der Wirtschaftspolitik dem demokratischen Prozess weitgehend aus der Hand genommen worden sind. Es ist mithin nicht nur so, dass 
die negative Integration, also die Herstellung der Marktfreiheiten, den Vorrang hat gegenüber der positiven Integration der Regulierung. Darüber hinaus wird die negative Integration auch noch auf dem Wege der Rechtsprechung ins Werk gesetzt, die der demokratischen Kontrolle entzogen ist.

Nationale Rechtsnormen werden auf diese Weise abgeschafft, weil sie ein Hindernis für die Verwirklichung des Binnenmarkts und den Wettbewerb bilden. Was dabei jeweils als Hindernis verstanden wird, kann eng und weit definiert werden. Kommission und Gerichtshof praktizieren eine weite Auslegung und verstehen als Behinderung des freien Verkehrs von Waren, Personen, Dienstleistungen und Kapital auch jene nationalen Regeln, ,denen keinerlei wirtschaftliches oder gar diskriminierendes Motiv zugrunde liegt" (Grimm 2013: 28). Das aber führt dazu, dass zahlreiche Normen des nationalen Rechts nach und nach ihre Bedeutung verloren haben, ,,auch wenn sie legitime Schutzziele verfolgten oder sogar in Erfüllung verfassungsrechtlicher Schutzpflichten erlassen wurden“ (Grimm 2013: 28).

Allgemeiner gesagt bedeutet dies, dass die Beseitigung der nationalen Regelungen und Standards aufgrund der besonderen institutionellen Verfasstheit Europas auf rein administrativem und judikativem Weg erfolgen kann, ohne dass die politischen Organe Rat und Parlament eine Möglichkeit der Intervention haben. „Entscheidende Umgestaltungen der Wirtschaftsund Sozialsysteme der Mitgliedstaaten, der Abbau zahlreicher öffentlicher Dienstleistungen, die Beseitigung nationaler Schutznormen, die Neubestimmung des Verhältnisses von Markt und Staat sind auf diese Weise zustande gekommen“ (Grimm 2013: 29). Die positive Integration hingegen, also die Regulierung und Gestaltung der ökonomischen Strukturen durch die Setzung von Unionsrecht, die ja prinzipiell durchaus möglich wäre, verlangt ,einen politischen Akt von Kommission, Rat und Parlament, für den die Konsensschwellen hoch liegen“ (Grimm 2013: 28). Das ist ein Musterbeispiel dafür, wie es auf der europäischen Ebene möglich ist, Entscheidungen hoher politischer Relevanz ,im unpolitischen Modus“ zu fällen (Grimm 2013: 31).

Bei der Frage der möglichen Abhilfe dieses unbefriedigenden Zustands ist Grimm jedoch zögerlich. Einerseits ist klar, dass das Demokratiedefizit an der Einrichtung und Legitimation der Institutionen hängt, also mit der Konstitution und der Funktionsweise von Europäischem Parlament, Rat, Kommission, EuGH zu tun hat. Aber andererseits erschöpft es sich darin 
nicht. Die Qualität der Demokratie, so Grimm, ist stets abhängig vom $\mathrm{Zu}$ stand der Gesellschaft, in der sie existiert und in der es um die Möglichkeiten von Partizipation, Assoziation und öffentlicher Meinungsbildung geht, und damit zugleich um die Existenz von Parteien, Verbänden, Bürgerinitiativen und Medien der öffentlichen Kommunikation. Diese gesellschaftlichen Voraussetzungen der Demokratie sind aber zweifellos auf der Ebene der Mitgliedstaaten weitaus besser gegeben als auf der europäischen Ebene. Besonders fällt die Tatsache ins Gewicht, dass es keinen nennenswerten europaweiten Diskurs gibt, der diesen Namen verdient, sondern allenfalls eine „Addition von 27 nationalen Diskursen über europäische Fragen“ (Grimm 2013: 34). Alles in allem kann es diesem Argument zufolge keine wirkliche europäische Eigenlegitimation der politischen Institutionen geben. Und deswegen ist die europäische Demokratie letzten Endes allein auf die Ressource der einzelstaatlichen Legitimationszufuhr angewiesen.

An dieser Stelle geht Jürgen Habermas in seinen Interventionen in die europäischen Diskussionen einen entschiedenen Schritt weiter (vgl. zuletzt Habermas 2014). Einerseits hält Habermas die sozialen Errungenschaften, die die Einzelstaaten erreicht haben, auf der europäischen Ebene für unverzichtbar. Andererseits ist ihm zufolge aber nicht nur der weitere Ausbau des europäischen Regierens, sondern zugleich auch eine entschiedene Demokratisierung notwendig und möglich. Den von Grimm und vielen anderen immer wieder ins Feld geführten Hinweis darauf, dass es ein europäisches Volk nicht gibt und auch in Zukunft kaum geben wird, hält er eher für eine Ausrede. Zugleich rückt Habermas seine Vorstellung der europäischen Entwicklung in den anspruchsvollen Entwurf einer allgemeinen Geschichte ein, in dem die Konstitutionalisierung des Völkerrechts in weltbürgerlicher Absicht und damit eine politisch geordnete und verfasste Weltgesellschaft ins Auge gefasst werden.

Bei seinem Plädoyer für den Ausbau der Europäischen Union zu einer supranationalen Demokratie argumentiert Habermas mit der Idee einer doppelten Souveränität und entwickelt den Gedanken einer europäischen politischen Ordnung, die zweifach gestützt und legitimiert ist. Danach sind die Bürger in der supranationalen europäischen Demokratie beides zugleich: Unionsbürger und Staatsbürger. In der Rolle der Staatsbürger beharren die Europäer völlig zurecht auf ,den normativen Errungenschaften des jeweils eigenen Nationalstaates“ (Habermas 2014: 531). Diese dürfen nicht nur nicht unterschritten, sondern müssen im Gegenteil weiter entwickelt 
und über die bisherigen Grenzen hinaus ausgedehnt werden, so dass das national begrenzte Vertrauen, ,das heute in Gestalt der staatsbürgerlichen Solidarität besteht, zu der nochmals abstrakteren Form eines grenzüberschreitenden Vertrauens" (Habermas 2014: 531) weiterentwickelt werden kann. Einerseits also sollen nach Habermas die Nationalstaaten ,in der Rolle von künftigen Mitgliedstaaten als Garanten des schon erreichten Niveaus von Recht und Freiheit erhalten bleiben" (Habermas 2014: 532). Andererseits aber müssten Europas Bürger ein Interesse daran haben, dass ,die aus Nationalstaaten entstandene Union die Gestalt eines supranational handlungsfähigen Gemeinwesens annimmt, welche auf eine demokratisch legitimierte Weise effektiv handeln kann, um die heute auf die europäischen Völker eindrängenden Probleme zu lösen“" (Habermas 2014: 532).

Diese beiden Dimensionen, die sonst in den Europa-Diskussionen, besonders in den Diskussionen über ein soziales Europa und über die Möglichkeit einer europäischen Demokratie so gerne gegeneinander ausgespielt werden, will Habermas in einen Ausgleich miteinander bringen. Danach kommt für das entstehende supranationale europäische Gemeinwesen alles darauf an, dass die höhere politische Ebene die niedrigere nicht überwältigen kann. Die Frage der Letztentscheidungsbefugnis kann deswegen auf europäischer Ebene nicht wie in den herkömmlichen Vorstellungen eines Bundesstaates durch Hierarchisierung gelöst werden, sondern nur dadurch, dass ,die heterarchische Beziehung zwischen den Mitgliedstaaten und der Föderation aufrechterhalten bleibt" (Habermas 2014: 532). Das bedeutet, dass die Komponente und Kategorie des Bundes in einer für Europa neuen Weise ganz ernst genommen und durchdacht werden muss.

Mit diesen Überlegungen greift Habermas einen Diskussionsstrang über Europa auf, der im Rekurs auf spezifisch republikanische politiktheoretische Positionen nach einem Ausweg aus den verschiedenen Sackgassen der europäischen Entwicklung sucht und in jüngerer Zeit deutlicher vernehmbar geworden ist. Die Argumente für ein republikanisches Europa zielen im Kern in zwei Richtungen. Zum einen spielt das Modell des Bundes eine große Rolle, mit dem an die Stelle eines rigiden Einheitsstaates das Prinzip des Regierens in Umgebungen der Verschiedenheit, der Pluralität und der Vielfalt gesetzt wird. Heterogenität gilt hier nicht als Zumutung und Belastung, als etwas, das zugunsten von Homogenität, Identität und Ähnlichkeit überwunden werden muss, sondern als Ausweis einer besonderen Qualität, die erhaltens- und schützenswert ist. An die Stelle differenzloser Einheits- 
vorstellungen treten Figuren des behutsamen Umgangs mit dem Fremden und mit Unterschieden. Neben und gegen die rationalistisch-liberalen Kategorien von Effizienz, Konsens und berechenbarer Rationalität, die immer in der Nähe funktionalistischer Bestimmungen stehen, treten die republikanischen Bestimmungen von Kontingenz, Konflikt, Verschiedenheit und die Absage an hierarchische und durch Souveränitätsanmaßungen gespeiste Ordnungsmodelle. Auf diese Weise wird der politische Raum für Meinungen und Gegenmeinungen, für die Vielfalt von Perspektiven, für das Austragen von Kontroversen weit geöffnet (vgl. Thiel 2012: 196ff, 232ff).

Die andere Richtung, mit der sich die republikanischen Konzepte auseinandersetzen, betrifft die Frage nach dem europäischen demos. Der Hinweis darauf, dass auch in den Nationalstaaten das einheitliche WirBewusstsein erst nach einem langen und aufwendigen Prozess entstanden ist, mit dem auch Habermas (2014: 530f) gern operiert, hilft hier nur begrenzt weiter. Der Hinweis vermag zwar deutlich zu machen, dass die politische Gemeinschaft der Nation keine natürliche Größe, sondern etwas Artifizielles und Erzeugtes ist. Aber damit hört dann der Modell- und Vorbildcharakter des Nationalbewusstseins auch schon auf. Denn nirgendwo operieren die nationalen Mythen und Narrative mit politischen Größen, immer stützen sie sich auf vorgeblich natürliche Substanzen, auf die Ähnlichkeit und Gleichheit von Herkunft, Sprache, Sitten, Schicksal, Gedächtnis oder, wie bei Carl Schmitt (1932: 33), auf die Freund-Feind-Unterscheidung ,im Sinne einer seinsmäßigen Ursprünglichkeit“".

In der republikanischen Idee eines europäischen „Wir“ ist dagegen nicht die natürliche Gegebenheit ausschlaggebend, sondern die Verbundenheit, die dadurch entsteht, dass man gemeinsam ein Vorhaben realisieren möchte. Dieses „Wir“ ist keine natürliche oder historische Substanz, keine vorgegebene, durch Kultur, Herkünfte und Schicksalsschläge bereits existierende Größe, die man nur noch finden müsste, sondern eine Größe, die durch gemeinsame Absichten und Vorhaben, durch den Austausch und im Akt des Austausches von Perspektiven, Meinungen und Positionen erst entsteht. Nicht im Einschmelzen der Unterschiede realisiert sie sich, sondern in ihrer Anerkennung und Legitimierung.

\section{Die internationale Dimension}

Schon seit dem 11. September 2001 war klar, dass die liberale Vision vom Ende der Geschichte und vom dem Übergang in ein Zeitalter, in dem die 
Realisierung von Menschenrechten, Multikulturalität, Minderheitenschutz und Gleichberechtigung der Geschlechter die einzige Aufgabe ist, die noch erledigt werden muss, eine vollkommene Illusion ist. Das 21. Jahrhundert macht dort weiter, wo das 20. Jahrhundert aufgehört hat: mit blutigen Kämpfen, Kriegen und wahnwitziger Irrationalität. Die weltpolitischen Konflikte und Zerreißungen in Syrien, Irak und im Nahen Osten sind beängstigend. Im subsaharischen Afrika verbreiten mordende Milizen Angst und Schrecken, die Konfrontation mit Russland und der Krieg in der Ostukraine drohen sich zu einem Flächenbrand zu erweitern. Hinzu kommt das Problem der Flüchtlinge, bei dem in skandalöser Weise immer wieder die europäischen Menschenrechtsstandards unterminiert werden und die Europäische Union eine menschenverachtende Abschottungspolitik betreibt.

Europa muss zu diesen weltpolitischen Konflikten eine Haltung finden, die seinen Prinzipien entspricht. Das gilt gegenwärtig insbesondere für den Ukraine-Konflikt und die kaum verhohlene kriegerische Aggression, die Russland dort praktiziert. Einerseits war die ukrainische Revolution des Euromaidan ein weithin sichtbares Zeichen für die überragende Attraktivität, die Europa als Raum der Freiheit, des Rechts und des sozialen Ausgleichs nach wie vor in vielen Regionen der Welt genießt. Andererseits war und ist die Europäische Union mehr oder weniger rat- und hilflos gegenüber dem Einsatz der Gewalt, mit dem das Russland Putins gegenüber seinem Nachbarstaat und früheren Partner auftritt, einen Teil des Territoriums annektiert und dann mit den Mitteln hybrider Kriegführung die massive Destabilisierung dieses souveränen Staates betreibt.

Damit nicht genug. Es wird immer klarer, dass das gegenwärtige Russland nicht nur die Ukraine destabilisieren, gefügig machen und in sein Einflussgebiet integrieren, sondern darüber hinaus die gesamte europäische politische Nachkriegs-Ordnung zerstören möchte. Dafür sucht und findet Putin Verbündete bei den populistischen, nationalistischen und anti-europäischen Parteien und Gruppierungen, die, wie der Front National in Frankreich, die Auflösung von Eurozone und Europäischer Union fordern. Nach Marine Le Pen wird die Europäische Union zusammenbrechen wie die Sowjetunion seinerzeit zusammengebrochen ist, weil die europäischen Bevölkerungen die Kontrolle sowohl über die Volkswirtschaften und Währungen wie über die Zuwanderung in ihr Territorium preisgegeben haben. Aber auch auf der linken Seite des politischen Spektrums findet Putin Verständnis und Unterstützung für seine gegen Europa gerichtete aggressive Politik 
und für seine Ordnungsvorstellungen, die immer unverhohlener diktatorische Züge annehmen.

Europa kommt weniger denn je daran vorbei, eine eigene internationale und außenpolitische Rolle ins Auge zu fassen und eine internationale Handlungsfähigkeit mit einer eigenen Handschrift anzustreben, in der die Durchsetzung des Völkerrechts, die Sicherung der internationalen Friedensordnung und die soft power der Verhandlungsdiplomatie von ausschlaggebender Bedeutung sind. Freilich kann man in der neuen Konfrontation auch einen Glücksfall für Europa sehen. Nichts hilft der inneren Geschlossenheit so sehr wie ein äußerer Feind, gegen den man sich zur Wehr setzen muss. Das ist genau das Muster, mit dem das Russland Putins gegenwärtig gegenüber der Ukraine und Europa operiert und damit alle inneren Widersprüche und Schwächen seines Regimes zu kaschieren versucht. Aus vielen Beispielen wissen wir, dass das kurzfristig funktionieren, auf die Dauer jedoch nicht gutgehen kann. Aber Europa kann nicht abwarten und dabei zusehen, dass sich diese Erfahrung erneut bewahrheitet. Es muss zu diesen Entwicklungen im Osten eine eigene Haltung entwickeln und sich auf andauernde Konflikte mit Russland einrichten.

\section{Die BeiträGE des Bandes}

Die Beiträge dieses Bandes gehen im Kern auf eine Vortragsreihe zurück, die die Veranstaltungsinitiative Europäische Horizonte im Mai 2014 in Aachen veranstaltet hat. Einige Vorträge konnten nicht in die Publikation übernommen werden, einige Beiträge sind neu hinzugekommen. Es versteht sich, dass hier nur ein kleiner Ausschnitt der gegenwärtig drängenden europäischen Konflikte und Fragen angesprochen werden kann.

Für Maurizio Bach ist die gegenwärtige Malaise Europas eine soziologische Parabel für eine tief verwurzelte Steuerungs- und Kontrollillusion moderner Gesellschaften. In einem Rückblick zeigt er, dass durch die Gründung Europas als institutionelle Konstruktion vor allem die Entscheidungs- und Kompromisswilligkeit der Mitgliedstaaten sichergestellt werden sollte. Die Europäische Union sei kein demokratisch legitimierter Staat sondern vielmehr ein supranationales Verhandlungs- und Rechtssystem, das unbestreitbare Erfolge der bisherigen europäischen Integration hervorbrachte. Jedoch hätten die Binnenmarktpolitik und mit ihr die Währungsunion 
eine Spirale von ungewollten und unerwünschten Effekten in Gang gesetzt. Er betrachtet die Währungsunion als einen schweren politischer Fehler des europäischen Einigungsprozesses. Für eine tragfähige Weiterentwicklung der Europäischen Union kommt nach seinem Dafürhalten nur eine Konkretisierung und institutionelle Ausformung der Leitidee der europäischen Solidarität in Frage. Europa müsse als Solidargemeinschaft neu begründet werden.

Georg Vobruba skizziert in seiner Analyse, warum Krisen im modernen sozialwissenschaftlichen Denken als offene Konstellationen konzipiert werden. Er beschreibt die Hauptcharakteristika der Eurokrise und unterscheidet dabei zwischen Geld und Währungen, um die sozialen Implikationen der Krise zeigen zu können. Aufbauend auf der Schilderung komplexer Konfliktkonstellation geht es bei Vobruba um die These, dass in der Eurokrise Konflikte gesellschaftsbildend wirken, wenn sie sich in einem Rahmen abspielen, der von allen Konfliktparteien akzeptiert werden oder doch hingenommen werden muss. Abschließend greift er das Problem von Krisen als sozial offene Konstellationen noch einmal auf und legt dar, dass die Europäische Integration kein teleologischer Prozess ist, der objektiven historischen Gesetzmäßigkeiten folgt.

Werner Plumpe untersucht die wirtschaftlichen Integrationsleistungen in der nach dem Zweiten Weltkrieg erfolgten Europäisierung. Letztere sei, so seine These, nach 1945 vor allem deswegen möglich gewesen, da Europa zu diesem Zeitpunkt bereits integriert gewesen sei. Deswegen sei die Europäisierung Westeuropas eine Folge und nicht die Voraussetzung für die nach dem Zweiten Weltkrieg erfolgten Integrationsprozesse. Plumpe argumentiert, dass der europäische Wirtschaftsraum bereits vor 1914 spezielle arbeitsteilige Strukturen besaß, die seit der zweiten Hälfte des 19. Jahrhunderts institutionalisiert worden sind. Die europäische Integration definiert Plumpe als ein politisches Projekt vor dem Hintergrund einer speziellen ökonomischen Situation. Die Währungsunion von 1992, eingeführt aus dem „Geist der multilateralen, gegenseitigen Kontrolle zur Ermöglichung wirtschaftlicher Kooperation", habe allerdings an die Stelle der Kooperation autonomer Akteure eher ein Zwangssystem der Anpassung gesetzt. Plumpe spricht in diesem Zusammenhang von einem „Risikospiel“, dessen Ausgang völlig offen sei.

Christoph Deutschmann diskutiert verschiedene Ansätze zur Erklärung der Euro-Krise und setzt sich kritisch mit gängigen Thesen auseinander, die 
Schuldenkrise sei vor allem auf die Widersprüche in der institutionellen Konstruktion der europäischen Gemeinschaftswährung oder auf Rationalitätenfallen demokratischer Politik zurückzuführen. Seines Erachtens liegt in dem jahrzehntelangen Prozess der „Finanzialisierung“, der nicht nur in Europa, sondern auch in den USA und anderen OECD-Ländern die Polarisierung der Einkommens- und Vermögensverteilung vorangetrieben und zum Aufbau eines beträchtlichen Überhangs an nicht einlösbaren Vermögensforderungen geführt habe. Die demokratische Politik sei mit der Herausforderung konfrontiert, tragfähige Wege zum Abbau der überhöhten Vermögensforderungen zu finden - eine Herausforderung, die ein (mindestens) europaweit koordiniertes Vorgehen verlange.

Krisendiagnosen sind für Thorsten Thiel stets politisch. Wer von einer Krise spricht oder schreibt, wolle zum Handeln anregen, weil die Situation als untragbar erachtet wird. Der Autor fragt sich jedoch, ob die Diagnose der Krise der Demokratie in Europa, so wie sie heute gestellt wird, tatsächlich Handlungsanreize schafft und Alternativen denkbar werden lässt. Dazu beschreibt er die zunehmende Spezialisierung der Europaforschung und deren Folgen für die Rolle Politischer Theorie. Anschließend skizziert er, wie sich die Diagnosen europäischer Demokratie inhaltlich ausdifferenziert haben und arbeitet heraus, worin nach seiner Ansicht die konzeptionelle Erschöpfung des Diskurses besteht. Abschließend plädiert Thiel für ein alternatives Theoretisieren und damit verbunden einen anderen öffentlichen Diskurs über Europa.

Ulrike Guérot spricht sich in ihrem Artikel dafür aus, die bislang vorherrschende polarisierende Debatte über ,mehr oder weniger“ Europa zu überwinden. Es gelte das Augenmerk von einer Diskussion über die vertikale Struktur - Europa vs. subsidiäre Nationalstaaten - in eine horizontale Struktur zu bringen, um Europa gemeinsam zu einer andersartigen europäischen Demokratie zu gestalten. Das europäische Projekt solle den europäischen Bürgerinnen und Bürgern als Souverän des Prozesses zurück gegeben werden. Dazu bedürfe es des Nachdenkens über die Ausgestaltung eines europäischen Zwei-Kammern-Systems, damit Entscheidungen über gemeinsame Prioritäten der EU-Bürgerinnen und Bürger durch eine ,,verschränkte“ Legislative getroffen werden und eine „Res Publica Europae“ für das europäische Gemeinwohl demokratisch einstehen könne. Dieses Konzept einer transnationalen europäischen Demokratie, jenseits von 
nationalen Grenzen, sei letztlich die Lösung der augenblicklichen Malaise Europas.

Ausgehend von der derzeitigen Lage betrachten Jan-Hendrik Kamlage und Patrizia Nanz die derzeitige Krise der suprastaatlichen Institutionen der EU als eine umfassende Legitimationskrise, die das politische Projekt der EU im Ganzen zu Fall bringen kann. Ohne ausreichende Akzeptanz bei den Bürgerinnen und Bürgern sei die Union am Ende zum Scheitern verurteilt. Lange Zeit galt die Einbeziehung organisierter Interessen durch Konsultationsmechanismen als Lösung für das demokratische Defizit der EUKommission. Die Autoren fordern jedoch ergänzende dialogorientierte Bürgerbeteiligungsverfahren über zentrale europäische Fragen auf lokaler, regionaler, nationaler und transnationaler Ebene. Abschließend stellen sie die Europäische Energiepolitik als Experimentierfeld einer institutionalisierten partizipativen Demokratie vor.

Michael Stolleis stellt in seinem Beitrag das selbstverständlich gewordene Ensemble von Grundprinzipien des öffentlichen Rechts als wirksamen Kern Europas vor: Die Basis bilden die Tradition der aristotelischen Politik, die antike Staatsliteratur, das neuzeitliche Natur- und Völkerrecht und die Grundgedanken der Verantwortlichkeit der europäischen Obrigkeiten für eine gerechte Sozialordnung. Hierauf ruht nach Stolleis die europäische Idee des Rechts- und Verfassungsstaats, der auch ein der Gerechtigkeit verpflichteter Sozialstaat ist. Unser ideenpolitisches Reservoir und unser kultureller Resonanzraum bildeten dafür den Hintergrund. Jedoch genüge es nicht, die erprobten Elemente zu besitzen, sondern sie müssen ständig erneuert werden. Vielleicht brauche Europa eine gewisse Erschütterung, um zu erfassen, was wir an diesem einzigartigen politischen Zusammenschluss haben. Der Autor macht abschließend Vorschläge, wie Europa an die neuen Bedingungen angepasst werden kann.

\section{LITERATUR}

Bouvet, Laurent (2014): Eine fortschrittliche Vision von Europa, in: Ernst Hillebrand/Anna Maria Kellner (Hg.), Für ein anderes Europa. Beiträge zu einer notwendigen Debatte, Bonn.

Cohn-Bendit, Daniel/Verhofstadt, Guy (2012): Für Europa. Ein Manifest, München. 
Cuperus, René (2014): Gegen ein Einheitseuropa. Euro-Realisten in der Klemme zwischen radikalen Föderalisten und Anti-EU-Extremisten, in: Ernst Hillebrand/Anna Maria Kellner (Hg.), Für ein anderes Europa. Beiträge zu einer notwendigen Debatte, Bonn.

Fischer, Joschka (2010): Die Vereinigten Staaten von Europa, in: Bertelsmann-Stiftung (Hg.), Europa wagen, Gütersloh.

Glienicker Gruppe (2013): Mobil, gerecht, einig. Die Glienicker Gruppe elf deutsche Ökonomen, Politologen und Juristen - entwerfen ein neues Europa, in: Die Zeit 43. 25. Oktober.

Goodhart, David (2014): Eine neue Abmachung zwischen EU und Nationalstaaten, in: Ernst Hillebrand/Anna Maria Kellner (Hg.), Für ein anderes Europa. Beiträge zu einer notwendigen Debatte, Bonn.

Grimm, Dieter (2013): Zum Stand der demokratischen Legitimation der Europäischen Union nach Lissabon, in: Nabila Abbas/Annette Förster/Emanuel Richter (Hg.), Supranationalität und Demokratie, Wiesbaden 2015.

Habermas, Jürgen (2014): Warum der Ausbau der Europäischen Union zu einer supranationalen Demokratie nötig und wie er möglich ist, in: Leviathan 42.4 .

Hillebrand, Ernst/Kellner, Anna Maria (Hg.) (2014): Für ein anderes Europa. Beiträge zu einer notwendigen Debatte, Bonn.

Misik, Robert (2014): Haben wir den falschen Götzen angebetet?, in: Ernst Hillebrand/Anna Maria Kellner (Hg.), Für ein anderes Europa. Beiträge zu einer notwendigen Debatte, Bonn.

Schmitt, Carl (1932): Der Begriff des Politischen. Text von 1932 mit einem Vorwort und drei Corollarien, Berlin 1963.

Streeck, Wolfgang (2013): Gekaufte Zeit. Die vertagte Krise des demokratischen Kapitalismus, Berlin.

Thiel, Thorsten (2012): Republikanismus und die Europäische Union. Eine Neubestimmung des Diskurses um die Legitimität europäischen Regierens, Baden-Baden. 



\section{Krisen, Konflikte und Solidarität}

\section{Zur gegenwärtigen Lage der Europäischen Union}

MAURIZIO B ACH

Die Europäische Union ist momentan in keiner guten Verfassung. „Krise“ ist die zur beherrschenden Zustandsbeschreibung geworden: Staatsschuldenkrise, Eurokrise, Legitimationskrise, Strukturkrise der EU lauten die gängigen Schlagworte zur Zeitdiagnose. Wenn die Beobachtung Niklas Luhmanns zutrifft, dass die Politik aufgrund systemischer Überforderung und begrenzter rationaler Problemlösungsfähigkeit, eine „Präferenz für unlösbare Probleme“ entwickelt, über die nur mehr unter Vortäuschung einer Lösbarkeit der Probleme, mithin folgenlos geredet werden kann (vgl. Luhmann 2000: 247), dann wäre die gegenwärtige Krisenpolitik der Europäischen Union das beste empirische Beispiel dafür. Vorherrschend ist hierbei jedenfalls der Eindruck des reinen Tagesmanagements, des Spielens auf Zeit, der Externalisierung der ökonomischen und sozialen Kosten der Eurorettung in die südlichen Gesellschaften sowie derjenige einer Überdeckung der geringen Problemlösungsfähigkeit der Europäischen Union durch politische Rhetorik. Die gegenwärtige Malaise Europas erweist sich als eine soziologische Parabel für die tief verwurzelten Steuerungs- und Kontrollillusionen moderner Gesellschaften und ihrer politischen Eliten. Ein Hauptkennzeichen der Krisen Europas ist, dass sie einer sozialen Eigendynamik unterliegen, deren Ursachen letztlich in den Widersprüchen und Paradoxien des europäischen Institutionensystems begründet sind. Die Dilemmata, in welche die Europäische Union kumulativ hineingeraten ist, kann der supranationale Verband durch die eigenen Entscheidungsverfahren und Steue- 
rungsinstrumente vermutlich nicht mehr auflösen - institutionelle Selbstblockierung ist die Konsequenz.

In Anbetracht dieser Lage gilt es, die Strukturen der Europäischen Union besser zu verstehen. Wie funktioniert Europa? Worauf gründeten seine historischen Erfolge? Worin liegen die Schwierigkeiten und Grenzen des zugrunde liegenden Integrationsmodells? Welche Ursachen hat die gegenwärtige Krise des europäischen Projekts? Wie steht es um die Zukunftschancen der Europäischen Union? Diesen Fragen soll im Folgenden aus einer institutionensoziologischen Perspektive nachgegangen werden.

\section{Die EUROPÄISCHE VEREINIGUNG: EIN INSTITUTIONENEXPERIMENT}

Mit dem Begriff „Europa“ verbinden sich ganz unterschiedliche Vorstellungen. Europa wird als geographischer Raum oder als kulturelle Einheit, als ökonomisches und politisches Machtgebilde oder auch als ,europäische Gesellschaft" gedacht. Ein tragfähiger Konsens über die Einheit und Gestalt Europas, über dessen sog. „Finalität“ existiert bis heute nicht. Den verschiedenen Europabildern mangelt es an Klarheit und Eindeutigkeit. Aber eine geschichtsmächtige Konkretisierung erfuhr die Idee eines vereinten Europas dann doch, und zwar in der Institutionengestalt der Europäischen Union und ihrer Vorläuferorganisationen, der Europäischen Gemeinschaft für Kohle und Stahl (EGKS) oder der Europäischen Wirtschaftsgemeinschaft (EWG).

Die Katastrophe des Zweiten Weltkrieges motivierte hellsichtige politische Köpfe diesseits und jenseits des Atlantiks dazu, darüber nachzudenken, wie sich in Zukunft der Frieden in Europa dauerhaft sichern ließe. Einer dieser Vorreiter war Jean Monnet (1888-1979), ein Unternehmer und parteienunabhängiger politischer Intellektueller und Organisator mit langjähriger Erfahrung im Völkerbund (vgl. Duchêne 1994). Monnet konzipierte eine originelle Institutionenarchitektur, die einzigartig ist in der bisherigen Geschichte politischer Institutionen. Bis heute ist es dieses Organisationsmodell, das dem Projekt der europäischen Einigung Stabilität und Kohärenz verleiht. Allerdings gibt es mittlerweile Anzeichen dafür, dass dieses neuartige politische Gebilde an Grenzen stößt, nicht zuletzt aufgrund der Besonderheiten seiner Struktur. 
Betrachten wir zunächst die Institutionenstruktur: Das Konzept Monnets enthält im Kern zwei strategische Komponenten: Zum einen basiert es auf dem Prinzip der funktionalen Integration, d.h. der schrittweisen Ausdehnung des europäischen Handlungsfeldes von begrenzten Politikfeldern (Montanindustrie, Zoll, Markt) auf weitere interdependente Bereiche (Arbeitnehmerwanderung, Ausbildung, Gesundheitsschutz, Beschäftigungs- und Konjunkturpolitik etc.). Dieses sollte schließlich aufgrund rein funktionaler Sachzwänge, also kumulativ in einer politischen Union der europäischen Staaten münden. Als zweites Grundelement sah Monnet die Institutionalisierung eines neuartigen politischen Organisationsprinzips vor: „Supranationalität““. Sein Modell zielte damit auf die Schaffung eines Konfliktrahmens jenseits der Nationalstaaten. Im Zentrum des europäischen Konfliktrahmens steht eine „dritte Instanz“, die weitgehende Autonomie besitzt, den Mitgliedstaaten übergeordnet ist und zugleich über eigene Befugnisse verfügt. Dieses Organ hieß ursprünglich „Hohe Behörde“; heute nennt man es Kommission.

Was versprachen sich die Gründungsväter von dieser institutionellen Konstruktion? Sichergestellt werden sollte vor allem die Entscheidungsund Kompromisswilligkeit der Mitgliedstaaten. Nicht die Staaten, sondern das supranationale Organ sollte die inhaltlichen Integrationsziele definieren, den Mitgliedstaaten Vorschläge für eine Weiterentwicklung unterbreiten und deren Umsetzung überwachen. Mit dieser Übertragung von Souveränität auf das nach eigenem Recht agierende supranationale Organ sollte eine nachhaltige Loslösung der europäischen Ziele von den nationalen Interessen und Bürokratien erreicht werden. Gleichzeitig wurde damit eine eigene Handlungs- und Rechtsebene für die europäische Ebene geschaffen, bei der vor allem auch der Rechtsetzung des Europäischen Gerichtshofs eine zunehmend bedeutende Rolle zukommt. Die Mitgliedstaaten verpflichteten sich damit zur Abkehr von nationalen Egoismen und zur Kooperation übergeordneter Ziele. Gleich Odysseus banden sie sich an den Schiffsmast der neuen europäischen Institutionen und des supranationalen Rechts, um den Sirenen der Nationalstaaten nicht (mehr) zu erliegen. Daran wird deutlich, dass europäische Integration in erster Linie ein Experiment der Institutionenpolitik war und ist. Europäische Politik hängt wesentlich von politischen Entscheidungen ab und von der Handlungsfähigkeit der neu gebildeten supranationalen Institutionen. Die Einzigartigkeit und Attraktivität des europäischen Modells ist vor allem darin begründet, dass eine verbindliche 
und kontinuierliche Kooperation der Mitgliedstaaten so institutionalisiert wurde, dass Rückfälle in reine nationale Interessenpolitik ebenso erschwert werden wie ein Bruch von paktierten Beschlüssen.

Auch wenn die Kommission im Verhältnis zur intergouvernementalen Ebene heute deutlich schwächer erscheint als noch vor der Krise, bleibt sie doch nach wie vor der zentrale Motor der Integration. Das liegt vor allem an der Übertragung des Vorschlagsrechts in der Gesetzgebung auf sie. Dies führte zu einer historisch beispiellosen und folgenreichen Trennung der Vorschlagskompetenz von der Beschlusskompetenz. Beim Ministerrat, dem Organ der Mitgliedsregierungen, verbleibt die Letztentscheidung über die Richtlinien und Verordnungen der Europäischen Union, also die Beschlusskompetenz. Aber die Erarbeitung der inhaltlichen Gesetzesvorlagen obliegt nach wie vor nahezu ausschließlich der Kommission. Sie hat das Initiativmonopol im Gesetzgebungsprozess. Dadurch wird letzterer inhaltlich von der supranationalen Agentur, ihren Fachbürokratien und Generaldirektionen ausgearbeitet. Das hat eine gravierende Konsequenz: Die Europapolitik trägt stark technokratische Züge, und sie wird gewissermaßen in einem „unpolitischen Modus“ (vgl. Grimm 2013) vollzogen. Dies erweist sich allerdings auf der anderen Seite auch als eine ihrer wesentlichen Erfolgsvoraussetzungen, denn der „unpolitische Modus“ entlastet vom schwierigen Prozess der Konfliktvermittlung und Interessenaggregation unter den Bedingungen demokratischer Partizipation und parlamentarischer Kontrolle in den Mitgliedstaaten. Der legislative Prozess in der EU basiert somit in erster Linie auf dem Zusammenwirken der zwischenstaatlichen Ebene (Ministerrat) auf der einen Seite und der supranationalen Ebene (Kommission) auf der anderen Seite.

Welche Rolle spielt dabei das Europäische Parlament? Das Europäische Parlament wird in bestimmten Politikfeldern zwar einbezogen, ist jedoch in die zentrale Willensbildung und Entscheidungsfindung der EU nur relativ schwach eingebunden. Dies obwohl es aus direkten Wahlen in den europäischen Ländern hervorgeht und damit als demokratisch legitimiert gelten kann (vgl. Bach 2014). Das Europaparlament verfügt weder über eine originäre parlamentarische Gesetzgebungsbefugnis, noch vermag es den Rat oder die Kommission effektiv zu kontrollieren. Daran ändert auch die durch den Lissabon-Vertrag (2007) ermöglichte Wahl des Kommissionspräsidenten und das erforderliche Zustimmungsvotum zur personellen Zusammensetzung der Kommission nicht viel. Das Europäische Parlament entscheidet 
lediglich mit „negativer Wirkung“, was allerdings mit echter Parlamentsmacht wenig gemein hat.

Die Unterschiede der Europäischen Union im Vergleich mit den bekannten staatlichen und insbesondere demokratischen politischen Systemen liegen auf der Hand. Zwar finden sich in ihrer Organstruktur alle Grundelemente politischer Ordnungen - demokratische Legitimation, Legislativkompetenzen, personelle und finanzielle Ressourcen -, welche in ein Gefüge von checks and balances, d.h. der wechselseitigen Kontrollen und des Ausgleichs eingebettet sind. Aber die Art ihrer institutionellen Verortung entspricht nicht annähernd dem üblichen Modell parlamentarischer Demokratien. So lässt sich der europäische Staatenverband mit herkömmlichen Kategorien der Verfassungslehre nicht angemessen beschreiben.

Als Zwischenresümee kann somit festgehalten werden: Die Europäische Union ist kein Staat und weit davon entfernt demokratisch legitimiert zu sein. Es ist ein supranationales Verhandlungs- und Rechtssystem eigener Art, ein sui generis-Gebilde. Das muss man aber nicht unbedingt negativ beurteilen. Im Gegenteil: Die unbestreitbaren Erfolge der bisherigen europäischen Integration sind nicht zuletzt auf diese einzigartige Kombination von Verhandlungsregime, Supranationalität und Rechtsintegration im sog. „europäischen Mehrebenensystem“ zurückzuführen. Eines ausgeprägten europäischen Bewusstseins auf Seiten der Bürger bedurfte es daher lange Zeit nicht. Die europäische Institutionenbildung geht der Bewusstseinsbildung voraus. Europa wurde politisch und ökonomisch vor allem durch die Bindekräfte der institutionellen und rechtlichen Integration geeint. Das Fehlen einer „europäischen Identität“ wurde erst später zum Problem (vgl. Viehoff/Segers 1999, Lepsius 2000).

\section{Die EU IN DER KRISE: Paradoxe Effekte und soziale KonflikTe}

Die skizzierten Systemmerkmale des supranationalen Institutionenverbandes sind aber auch für Fehlentwicklungen des europäischen Integrationsprojektes verantwortlich. Auf die Folgen der Politikverflechtung und auf das Legitimationsdefizit wurde bereits hingewiesen. Aber auch die Binnenmarktpolitik und mit ihr die Währungsunion - lange Zeit die Paradepferde der Wirtschaftsintegration - haben eine Spirale von ungewollten und 
unerwünschten Effekten in Gang gesetzt. Das wurde aber erst im Verlauf der Euro- und Staatsschuldenkrise offensichtlich.

Zunächst setzte die Binnenmarktpolitik, die Mitte der 1980er Jahre unter der Kommissionspräsidentschaft Jacques Delors' eingeleitet wurde, eine erwartete und allseits begrüßte Erfolgsspirale der Europäisierung in Gang. Die Europäische Union hat immer mehr Funktionsbereiche der Gesellschaft einer Regulierung unterworfen. Zugleich erfuhren die Befugnisse der Kommission eine Ausweitung. Zunehmend wurden auch wirtschaftsfremde Bereiche der Brüsseler Regulierungspolitik unterworfen, wie etwa die Studentenmobilität, der Umweltschutz oder die Vorratsdatenspeicherung (vgl. Haltern 2007).

Von der Aufhebung der Binnengrenzen im internationalen Wirtschaftsverkehr und von der Schaffung eines großen Binnenmarktes erwarteten die Regierungen ein nachhaltiges Wirtschaftswachstum und als Folge davon eine allgemeine und greifbare Wohlstandsmehrung, und zwar für alle. Die später hinzugekommene gemeinsame Währung sollte die monetären Kosten im europäischen Binnenhandel senken, eine europaweite Preistransparenz schaffen und dadurch ein reibungsloses Funktionieren des Binnenmarktes sicherstellen. Es wurden mithin vor allem positive Wohlfahrtseffekte und Kostenersparnisse in Aussicht gestellt. Doch das ist nur die eine, die glänzende Seite der Medaille.

Wie sieht die andere Seite aus? Verbreitet ist die Kritik, die europäische Wirtschaftspolitik betreibe die Entfesselung der negativen Seiten des Kapitalismus, insbesondere einen Abbau von Sozialstandards in den Mitgliedstaaten. Entscheidend sind die in der EU angestoßenen Prozesse der Marktbildung und Deregulierung. Stichwort: Neoliberale Wirtschafts- und Sozialpolitik (vgl. Streeck 2012). Dabei gibt es freilich Gewinner und Verlierer. Insbesondere schwächere Marktsegmente und Standorte mit veralteten Industrien geraten verstärkt unter Druck, etwa die Landwirte, die Stahlindustrie, die öffentlichen Unternehmen oder die Staatsangestellten. Als Folge davon gibt es eine wachsende Kluft zwischen jenen, die sich aufgrund ihrer Qualifikationen und Wettbewerbsfähigkeit auf den europäischen (und globalen) Märkten behaupten können einerseits, und jenen, die zu Marktverlierern und zu Outsidern des Arbeitsmarktes werden andererseits. $\mathrm{Zu}$ letzteren gehören insbesondere niedrig qualifizierte Arbeitnehmer, solche mit veralteten Qualifikationen und ältere Menschen, aber auch ganze Bevölkerungsgruppen, ja Gesellschaften, soweit sie in der Peripherie des 
europäischen Wirtschaftsraumes, in strukturschwachen Regionen oder Krisenstaaten leben.

Freilich gibt es nicht nur Verlierer der europäischen Marktpolitik, es gibt auch Gewinner. Die neuen grenzüberschreitenden Möglichkeiten des Konsums, des Tourismus, der Mobilität, die Einführung europäischer Normen in vielen Lebensbereichen (z.B. bei der Gleichstellung der Geschlechter), die Entwicklung einer europäischen Infrastruktur des Transports und der Kommunikation und nicht zuletzt der europäische Studentenaustausch führten zu spürbaren Verbesserungen der Arbeitschancen und Lebenslagen von unterschiedlichen Bevölkerungsschichten. So ist auch unbestreitbar, dass sich die Volkswirtschaften von Beitrittsländern im Zuge ihrer Umstrukturierung und Modernisierung in ihrer ökonomischen Produktivität, den Einkommensverhältnissen und der Beschäftigung mittel- und langfristig den Entwicklungsniveaus der Länder des ökonomischen Zentrums annähern. Das gilt in besonderem Maße für die neuen mittelost- und osteuropäischen Länder. Damit nimmt die ökonomische und soziale Konvergenz in der Europäischen Union tendenziell zu.

Allerdings gibt es auch Entwicklungen, die den Konvergenz- und Kohäsionsversprechen des europäischen Verbandes entgegenwirken und diese sogar Lügen strafen. Um diese Zusammenhänge richtig verstehen zu können, ist es sinnvoll, Europa einmal aus dem Blickwinkel der Peripherien, also aus der Perspektive der südlichen Krisenländer zu betrachten und damit eine gesamteuropäische Sichtweise einzunehmen.

Die sich wechselseitig verstärkenden Krisen der letzten fünf Jahre brachten viele strukturelle Probleme des europäischen Verbandes überraschend ans Licht. Besonders die Staatsschuldenkrise und die Euro-Krise offenbarten dabei auch die Mitverantwortung der Europäischen Union für die entstandene Malaise. In der Krise hat sich das europäische Mehrebenensystem faktisch zu einem blockierten System entwickelt. Die EU ist in einem Teufelskreis verstrickt, der rationale Lösungen erschweren oder gar verhindern kann. Die EU ist also selbst Teil des Krisengeschehens und zugleich einer der wichtigsten Krisenherde. Sie ist das Problem, nicht mehr die Lösung. Denn die Euro-Krise erweist sich als eine Strukturkrise der europäischen Vergesellschaftung (vgl. Illing 2013). Wo liegen die Ursachen?

Um diese Frage beantworten zu können, muss man die Währungsunion in den Fokus nehmen. Meine These lautet: Die Währungsunion war ein politischer Fehler, vielleicht der folgenreichste des europäischen Eini- 
gungsprozesses. Manche Beobachter halten den Euro sogar für ein „frivoles Experiment“ (Streeck 2012), weil mit ihm leichtfertig und mit ruinösen Konsequenzen der gesellschaftliche Zusammenhalt und Frieden in Europa aufs Spiel gesetzt wurde.

Mit der Einführung des Euro ist nicht nur ein Prozess der vermutlich irreversiblen Entparlamentarisierung in den Mitgliedstaaten der Europäischen Union eingeleitet worden. Auch ging immer mehr wirtschaftspolitische Steuerungsmacht auf technokratische Agenturen mit einem hohen Grad an politischer Autonomie, wie der Europäischen Zentralbank und der Kommission, über. Letztere sind von demokratischen Prozessen weitgehend entkoppelt. Deren Politik ist unabhängig von Wahlausgängen. Früher war das gut für die Integration; heute wird es zunehmend zum Fallstrick.

Aber das kardinale Problem des europäischen Währungsverbandes ist das Abwertungsverbot, d.h. der mit festen Wechselkursen notwendig verbundene Verzicht, vom Instrument der Abwertung Gebrauch zu machen, um Außenhandelssalden zu beeinflussen und um negative Effekte unterschiedlicher Produktivitätsfortschritte einzelner Länder abzufedern. Deshalb verschärfte sich als unmittelbare Folge der Währungsunion die soziale Ungleichheit in den ärmeren Mitgliedstaaten. Zudem kam es zu einem Matthäus-Effekt der Ungleichheit im europäischen Sozialraum: „Wer hat, dem wird gegeben, wer wenig hat, dem wird auch noch das genommen, was er hat." Entgegen dem Versprechen des Europäischen Binnenmarktes, unter gleichen Wettbewerbsbedingungen ein beständiges ökonomisches Wachstum für alle Mitgliedsländer zu erzielen, bewirkte gerade die Europäisierung der nationalen Währungen im Endeffekt das Gegenteil: Nach einem anfänglichen Wachstumsschub in den früheren Weichwährungsländern (niedrigen Durchschnittszinsen) verfestigte sich wieder das historische Muster der sozio-ökonomischen Spaltungslinien in Europa. Mit anderen Worten: Die strukturell seit jeher privilegierten, wettbewerbs- und exportstarken Industriegesellschaften des Nordens stehen den wettbewerbsschwachen Problemländern des Südens gegenüber. Vor allem die starken Ökonomien profitieren vom System unveränderlicher Wechselkurse. Sie konnten ihre beherrschende Marktstellung ausbauen, was in anhaltend Exportüberschüssen zum Ausdruck kommt. Letztere flossen teilweise in die südlichen Importländer wieder zurück, allerdings in Form von Krediten zu Absicherung von deren Zahlungsfähigkeit (vgl. Scharpf 2012). 
Die mediterranen Volkswirtschaften haben gleichsam ein doppeltes Nachsehen: Einerseits finanzieren sie über ihren Schuldendienst das nordeuropäische Bankensystem mit und tragen damit wesentlich zur Stabilität des Beschäftigungsmarktes und zur ökonomischen Prosperität der Länder Nordeuropas bei. Andererseits verlieren sie selbst immer mehr an Wettbewerbsfähigkeit auf dem Binnenmarkt, geraten in die Staatsschuldenfalle und in eine zunehmend prekäre ökonomische sowie soziale Lage.

Unter den Bedingungen eines einheitlichen Währungsregimes sehen sich die peripheren Länder somit gezwungen, zu dem einzig verbliebenen Mittel zu greifen, um auf den extremen Wettbewerbsdruck zu reagieren: die innere Abwertung. Das bedeutet: Die Währungsunion verurteilt die Regierungen dieser Staaten dazu, Rationalisierungen zu fördern, einen systematischen Abbau von Sozialstandards, die Flexibilisierung der Arbeitsmärkte, niedrigere Löhne, längere Arbeitszeiten sowie eine höhere Erwerbsbeteiligung zu betreiben.

Doch die Ausgangsausstattung der Länder war immer schon ungleich. Aus historischen und sozialstrukturellen Gründen konnten sie schon vor der Verwirklichung des Binnenmarktes mit den viel wettbewerbsstärkeren Ökonomien des Zentrums nicht Schritt halten. Sie hatten nie auch nur die leiseste Chance, ihren Entwicklungsrückstand aufzuholen. Im Gegenteil: Als Folge der Deregulierung, der offenen Grenzen für Güter und des engen Währungskorsetts verschlechterten sich mit dem Binnenmarkt und der Währungsunion die Wettbewerbschancen der Peripherie weiter. Damit verfestigte sich eine historische Pfadabhängigkeit und eine unaufhaltsame Abwärtsspirale der sozialen Ungleichheit in Europa (vgl. Bach 2014a).

Unter den Krisenbedingungen des vergangenen halben Jahrzehnts führten die Dilemmata und Paradoxien der Währungsunion somit zu massiven sozialen Verwerfungen. Die europäischen Geldgeber (EU, EZB, IWF) bürden den Empfängerländern als Gegenleistung für Hilfskredite und Haftungsgarantien einschneidende Reformen auf, die mit hohen sozialen Folgekosten und einer weiteren Schwächung ihrer Wettbewerbsfähigkeit verbunden sind. Das führt zu einer Verschärfung der politischen Konflikte in den betroffenen Ländern. Extreme politische Gruppierungen und populistische Parteien bestimmen immer mehr die politische Agenda (SYRIZA, Cinque Stelle, Le Pen etc.).

Aber auch die Beziehungen der Mitgliedstaaten des supranationalen Verbandes untereinander gestalten sich zunehmend konflikthaft. Auf eine 
für die Europäische Union neuartige Weise kommen wieder Machtdifferenziale und vor allem Machtrhetorik ins Spiel. Europa wird dadurch auf eine neue Weise politisiert. So sehen sich die mediterranen Länder in der Krise einem europäischen Machtkartell unterworfen. Dieses setzt sich aus supranationalen Technokraten und Überschussländern zusammen. Das führt unweigerlich zu einer Spaltung der Europäischen Union; es konterkariert zudem die Einheits- und Kohäsionsbestrebungen der Europäischen Union.

Somit bewirkt selbst die EU-Rettungspolitik eine sich selbst verstärkende Misere in den Empfängerstaaten. Die Konsolidierungsstrategie unter Konditionalitäten zementiert die politische Abhängigkeit der Peripherie vom Zentrum. Die mediterranen Krisenländer sind jetzt auf Gedeih und Verderb auf die „Hilfsmaßnahmen“ der europäischen Instanzen angewiesen. Sie haben ihre wirtschafts- und währungspolitische Souveränität längst an die europäische Ebene abgetreten. Das spitzt intern die Verteilungskonflikte zu und blockiert die Handlungsfähigkeit der Regierungen. Gerade dem, was für eine erfolgreiche Modernisierungsstrategie unverzichtbar wäre - Zeit für Reformen und stabile politische Verhältnisse - wird durch die Krisenbewältigungsstrategie der Europäischen Union entgegengewirkt.

Dieser dramatische Abwärtssog, in den die peripheren Länder mit der Währungsunion geraten sind, verstärkte sich paradoxerweise durch das Krisenmanagement der Europäischen Union. Konnten die sozialen Konflikte lange Zeit noch in der Latenz gehalten werden, so explodierten sie in den südlichen Mitgliedstaaten, als die Angst vor der Staatsinsolvenz sich verbreitete, sich eine dauerhafte Rezession und massive Wohlstandsverluste für breite Schichten der Gesellschaft einstellten. Das Krisenmanagement der Europäischen Union schlug damit direkt und ohne Abfederung auf die betroffenen Gesellschaften durch; die Staatsschulden- und Euro-Krise verwandelte sich rasch in eine allgemeine Gesellschaftskrise. Das durch die Europäische Union, die Europäische Zentralbank und den Internationalen Währungsfonds ins Werk gesetzte Krisenmanagement vermochte zwar kurzfristig die Liquiditätsengpässe der betroffenen Mitgliedstaaten zu überwinden (und die Risikoaufschläge für Kredite zu senken), führte aber aufgrund der den Empfängerländern auferlegten Spar- und Reformkonditionalitäten zu einer beispiellosen innergesellschaftlichen Konfliktverschärfung.

Die Ungleichheitsdynamik, die vor Krisenausbruch üblicherweise in nationalen Konflikt- und Auslegungsarenen ausgetragen wurde, gewinnt da- 
durch eine neue, eine europäische Dimension. Immer häufiger kommt es auch in der breiteren Öffentlichkeit zu transnationalen Vergleichen der Sozialstrukturen, der Einkommens- und Vermögenslagen sowie der Sozialstandards. Zudem wird erstmals in einem nennenswerten Umfang die Europäische Politik als Zurechnungseinheit für Wohlstandsverluste bzw. -gewinne von sozialen Gruppen adressiert. In diesem Zusammenhang kann von einer neuen Qualität und Dynamik der Europäisierung der sozialen Ungleichheit gesprochen werden. Die Ungleichheit hat mittlerweile eine genuin europäische Dimension angenommen und sprengt damit den nationalstaatlichen Deutungs- und Konfliktrahmen (vgl. Heidenreich 2014).

\section{EUROPÄISCHE SOLIDARITÄT}

Die Ausweitung der Staatsschuldenkrise durch das als Rettungspolitik camouflierte Austeritätsprogramm führte, wie wir sahen, zu einer tiefgreifenden Gesellschafts- und Legitimationskrise der Europäischen Union (vgl. auch Touraine 2010). Umso dringlicher stellt sich die Frage, wie die Dilemmata und Paradoxien, in welche die Euro-Krise die Europäische Union verstrickt hat, aufgelöst werden können. Eine tragfähige Zukunftsperspektive für das europäische Integrationsprojekt kann nach Lage der Dinge derzeit weder mit dem Euro, noch ohne den europäischen Währungsverband entwickelt werden. Das ist das Grunddilemma. Dass die Zukunftsfähigkeit der Europäischen Union ebenso wenig durch eine rélance des 2005 gescheiterten Verfassungsprojekts wieder hergestellt werden kann, liegt ebenso auf Hand. Das käme in der jetzigen Lage einer ,politischen Herkulesaufgabe“ (Streeck 2013: 243) gleich. Dennoch kann, wie die Geschichte lehrt, Zukunftsfähigkeit für den europäischen Verband erfolgversprechend nur durch geeignete Institutionenpolitik erreicht werden.

Wie sollten nun aber die Weichen gestellt werden, damit dem drohenden Zerfall der Europäischen Union entgegengewirkt werden kann? Für eine Überwindung des derzeit struktur- und krisenbedingt ,blockierten Systems“ und für eine tragfähige Weiterentwicklung der Europäischen Union kommt nach meinem Dafürhalten nur ein Weg in Frage: eine Konkretisierung und institutionelle Ausformung der Leitidee der europäischen Solidarität (vgl. Lepsius 2013, S. 251). Europa muss als Solidargemeinschaft neu begründet werden. Das ist freilich alles andere als ein einfaches Unterfan- 
gen: Transnationale Solidarität effektiv zu verwirklichen, ist äußerst schwierig. Dazu fehlt es meist an den gesellschaftlichen Voraussetzungen, an einem europäischen Wir-Gefühl und entsprechenden Loyalitäten, die eine Umverteilung von Ressourcen tragen und rechtfertigen könnten (vgl. Beckert et al. 2004).

Aber andererseits ist eine Solidaritätsnorm längst fester Bestandteil des europäischen Vertrags- und Rechtssystems. Sie gilt sogar als eines der zentralen Prinzipien des Gesellschafts- und Gleichheitsskripts der Europäischen Union. So heißt es in Art. 3 des EUV: Die Europäische Union ,bekämpft soziale Ausgrenzung und Diskriminierungen und fördert soziale Gerechtigkeit und sozialen Schutz“. Und weiter: „Sie fördert den wirtschaftlichen, sozialen und territorialen Zusammenhalt und die Solidarität zwischen den Mitgliedstaaten." Bisher findet die europäische Solidarität vor allem in den Struktur- und Kohäsionsfonds ihren institutionellen Ausdruck. Allerdings dominieren dabei immer noch die einzelstaatlichen und regionalen Interessen, insbesondere der Nettozahler-Länder. Letztere sind stets darauf bedacht sind, ein juste retour sicherzustellen, mithin eine Kompensation der geleisteten Einzahlungen durch entsprechende Rückflüsse.

Die Krise hat nun manifest werden lassen, dass sich gesellschaftliche Einheit und Konvergenz in sozialstruktureller Hinsicht in Europa nicht allein mittels Marktbildung, Deregulierung und einigen wenigen, zudem finanziell unterausgestatteten Struktur- und Kohäsionsfonds erreichen lässt. Ebenso wenig taugen, wie wir sahen, die Hilfsmaßnahmen für insolvenzgefährdete Mitgliedstaaten im Rahmen des ESM dazu, die zunehmende Ungleichheit in Europa zu bewältigen. Auch wenn mittlerweile der mit Abstand größte Gläubiger die Europäische Zentralbank ist, die indirekt über den unbegrenzten Aufkauf von Staatsanleihen und verlängerten Kreditlaufzeiten eine Zinssubventionierung betreibt und damit die zukünftige Transferunion (auf Kosten der Steuerzahler) bereits vorwegnimmt, kann diese Form von „europäischer Solidarität“ nicht ausreichend sein. Sie entspricht der „eigennützigen Hilfe“ (Vobruba 2007: 21) oder auch - zugespitzter formuliert - einer „Solidarität als Strafe“, welche „die Bürger eines zahlungsunfähig gewordenen Staates für ihre früheren Regierungen in Gesamthaftung nimmt" (Streeck 2012: 137). Die durch die Krise erfolgte Europäisierung der Ungleichheitsfrage zeigt somit ein höchst ambivalentes Gesicht. Einerseits hat sich die Europäische Union zu einem neuen transnationalen Vergleichs- und Zurechnungsrahmen für sozioökonomische Dispa- 
ritäten entwickelt. Andererseits geht bisher damit noch keine nennenswerte Verschiebung der Solidaritätshorizonte vom nationalen auf den europäischen Rahmen einher. Ganz im Gegenteil: Die neuen Ungleichheiten unterhöhlen nicht nur die Einheits- und Kohäsionsprogrammatik, sondern auch den europäischen Solidaritätsgedanken.

Es erhebt sich daher die Frage: Welche Art von Solidarität ist mit dem europäischen Einigungsgedanken am besten zu vereinbaren? Eine Solidarität als Ausdruck des nationalen Eigennutzes und der Markt- und Vertragsbeziehungen, wie sie den Hilfskrediten für Griechenland und dem Europäischen Stabilitätsmechanismus zugrunde liegt? Das entspricht dem Marktmodell der Integration, „Marktgerechtigkeit“ ist das zugrunde liegende Prinzip. Unterstützung können die Schwachen dann allerdings nur erwarten, wenn zugleich die Starken, in erster Linie die Banken oder die Überschussländer, davon profitieren. Oder sollte es darum gehen, eine echte europäische Solidarität zu verwirklichen, mithin eine Solidarität als sozialmoralisches Projekt, als ein Projekt der europäischen Gesellschaftswerdung? Das ist außerordentlich schwierig. Aber in Anbetracht der gesellschaftlichen und politischen Risiken der Marktintegration, die bisher ohne europäische Sozialintegration voranschritt, ist ein Umdenken wohl unverzichtbar.

Überfällig ist eine breite Diskussion über die Kriterien von europäischer Solidarität. Die Frage der ,sozialen Gerechtigkeit“ darf nicht mehr allein eine Domäne der Nationalstaaten bleiben. Auch die sozialen Probleme haben, wie ich zu zeigen versucht habe, längst eine europäische Dynamik gewonnen. Parallel zur faktischen Europäisierung der sozialen Ungleichheit muss deshalb der Diskurs über Kriterien sozialer Gerechtigkeit ebenfalls auf das europäische Niveau gehoben werden. Ohne dass die wohlhabenden und wettbewerbsstarken Mitgliedstaaten im Namen Europas Opfer bringen, wird aber keine wirkliche europäische Solidarität zu realisieren sein. Die Transferunion existiert faktisch bereits. Es geht jetzt darum, den Mut zu entwickeln, dies den Bürgern auch offen einzugestehen und die Europäische Union damit solidaritätsfähig zu machen, kognitiv und praktischpolitisch. Sie solidaritätsfähig machen, heißt sie zukunftsfähig machen. Vielleicht ließe sich damit die Union auch den Bürgern wieder näher bringen. 


\section{LITERATUR}

Bach, Maurizio (2013): Europäische Integration. Zwischen Markt und Solidarität, in: Stefan Hradil (Hg.), Deutsche Verhältnisse. Eine Sozialkunde, Frankfurt a.M./New York, S. 449-471.

Bach, Maurizio (2014): Die Demokratisierung der Europäischen Union Ideal oder Irrweg?, in: Gesellschaft, Wirtschaft, Politik. Sozialwissenschaften für politische Bildung 1, S. 65-77.

Bach, Maurizio (2014a): Paradoxes Europa: Zur (Eigen-)Dynamik der Eurokrise, in: Thilo Fehmel/Stephan Lessenich/Jenny Preunkert (Hg.), Systemzwang und Akteurswissen. Theorie und Empirie von Autonomiegewinnen, Frankfurt a.M., S. 159-174.

Beckert, Jens/Eckert, Julia/Kohli, Martin/Streeck, Wolfgang (Hg.) (2004): Transnationale Solidarität. Chancen und Grenzen, Frankfurt a.M. /New York.

Duchêne, François (1994): Jean Monnet. The First States man of Interdependence, New York/London.

Grimm, Dieter (2013): Zum Stand der demokratischen Legitimation der Europäischen Union nach Lissabon, in: Hans Michael Heinig/Jörg Philipp Terhechte (Hg.), Postnationale Demokratie, Postdemokratie, Neoetatismus. Wandel klassischer Demokratievorstellungen in der Rechtswissenschaft, Tübingen, S. 105-122.

Haltern, Ulrich (2007): Europarecht. Dogmatik im Kontext, Tübingen.

Heidenreich, Martin (Hg.) (2014): Krise der europäischen Vergesellschaftung? Soziologische Perspektiven, Wiesbaden.

Illing, Falk (2013): Die Euro-Krise. Analyse der europäischen Strukturkrise, Wiesbaden.

Lepsius, M. Rainer (2013): Die Europäische Union als rechtlich konstituierte Verhaltensstrukturierung, in: ders., Institutionalisierung politischen Handelns. Analysen zur DDR, Wiedervereinigung und Europäischen Union, Wiesbaden, S. 204-221.

Luhmann, Niklas (2000): Die Politik der Gesellschaft, Frankfurt a.M.

Scharpf, F. W. (2012): Die Eurokrise: Ursachen und Folgerungen, in: Zeitschrift für Staats- und Europawissenschaften 10.3, S. 324-337.

Streeck, Wolfgang (2012): Gekaufte Zeit. Die vertagte Krise des demokratischen Kapitalismus, Frankfurt a.M.

Touraine, Alain (2010): Après la crise, Paris. 
Viehoff, Reinhold/Segers, Rien T. (Hg.) (1999): Kultur. Identität. Europa. Über die Schwierigkeiten und Möglichkeiten einer Konstruktion, Frankfurt a.M.

Vobruba, Georg (2005): Die Dynamik Europas, Wiesbaden.

Vobruba, Georg (2007): Die Dynamik Europas, 2. aktualisierte Auflage, Wiesbaden. 



\section{Ambivalenzen der Krise}

Währung, Konflikt und europäische Integration

GEORG VOBRUBA

\section{EINLEITUNG}

Krisen sind offene soziale Konstellationen. Das bedeutet: Das zentrale Merkmal von Krisen ist, dass für Akteure, die Krisen beobachten und in ihrem Kontext handeln, stets mehrere Entwicklungsverläufe möglich sind. Dazu kommt das Bewusstsein, dass der Verlauf der Krise vom Handeln von Akteuren - allerdings keineswegs zwingend vom eigenen Handeln - abhängt. Der Akteursbezug und die Offenheit der Konstellation sind historisch relativ neue Merkmale des Verständnisses von Krisen. Es lohnt, darauf kurz einzugehen, um Besonderheit von Krisen und die theoriestrategische Bedeutung sozialwissenschaftlicher Krisenforschung deutlich zu machen.

Ich werde einleitend sehr knapp skizzieren, warum Krisen im modernen sozialwissenschaftlichen Denken als offene Konstellationen konzipiert werden müssen. Dann werde ich die Hauptcharakteristika der Eurokrise knapp beschreiben und anschließend die Unterscheidung zwischen Geld und Währungen einführen, um die sozialen Implikationen des Wegfallens des Wechselkursmechanismus durch die Institutionalisierung der gemeinsamen Europäischen Währung zeigen zu können. Im nächsten Schritt will ich die komplexe Konfliktkonstellation schildern, die sich vor dem Hintergrund der gemeinsamen Währung aus der Eurokrise und dem Eurokrisenmanagement ergibt. Daran anschließend geht es um die Frage, ob in der Eurokrise die Bedingungen dafür erfüllt sind, dass Konflikte gesellschafts- 
bildend wirken. Abschließend greife ich das Problem von Krisen als sozial offene Konstellationen noch einmal auf.

\section{KRisen Als Offene Konstellationen}

Dem traditionalen geschichtsphilosophischen Denken sind Krisen in die historische Entwicklung eingebaute Schubphasen. Sie mögen die eine oder andere unmittelbare Wirkung in der Gesellschaft haben, letztlich aber geht ihr Effekt im Telos der Geschichte auf. Krisen sind dem traditionalen Geschichtsverständnis Episoden der „Selbstläufigkeit des Geschehens“ (Koselleck 1973: 111), das auf einen Endzweck der Geschichte zustrebt. In der Logik einer absolutistisch-vormodernen Weltinterpretation ist das Ziel der Geschichte schon im absoluten Anfang und Ursprung der Welt beschlossen. „Die Zukunft war nichts, wofür man hätte Sorge tragen können oder müssen. Denn was immer geschah, lag schon irgend beschlossen in der Vergangenheit. Nur die Praxis ließ in der Sorge für das Nächstgelegene ein kleines Stück Zukunft erkennen“ (Dux 1989: 352). Sofern das traditionale Denken über Geschichte überhaupt handelnde Subjekte einbaut, sind sie diesem Geschehen ein- und untergeordnet. Ihr Handeln ist darum von politischer Verantwortung letztendlich entlastet (Koselleck 1973: 112). Dieses Geschichtsverständnis löste sich mit dem absolutistisch-vormodernen Weltbild im Übergang zur Moderne auf. Mit dem Verfall der Geltung jedes denkbaren absoluten Bezugspunkts der Geschichte öffnete sich dem Bewusstsein Zukunft als Möglichkeitenraum gesellschaftlicher Entwicklungen. Etwa seit der Mitte des 18. Jahrhunderts etablierte sich die Verwendung des Krisenbegriffs im Sinne einer ,auf Entscheidungsalternativen verschiedener Handlungsträger zulaufende(n) Situationserfassung “ (Geschichtliche Grundbegriffe 1982: 624). Das sich damit abzeichnende neue Krisenverständnis ist Ausdruck des Strukturwandels der Weltbilder im Umbruch zur Moderne. Karl Marx' Verständnis von Krise steht in charakteristischer Weise zwischen Tradition und Moderne: „Er operierte einerseits mit einem systemimmanenten Krisenbegriff, indem er die iterative Struktur ökonomischer Krisen aufzeigte. Andererseits kannte er einen systemsprengenden Krisenbegriff, den er aus anderen - ehedem theologischen - Prämissen ableitete und der die Weltgeschichte auf eine letzte große Krise zutreiben ließ“" (Koselleck 2010: 213). Das Krisenverständnis folgt dem Wandel der 
Weltbilder und trägt selbst zu ihm bei. Einerseits muss sich das Verständnis von Krisen ändern, sobald es im Weltbild der Moderne unmöglich geworden ist, Gesellschaft und ihre Entwicklung von einem absoluten Bezugspunkt und voraussetzbaren Endzweck her zu denken. Andererseits ist die Verbreitung des Krisenbegriffs selbst eine Voraussetzung dafür, dass im Denken über Politik und gesellschaftliche Entwicklung Handeln zunehmend zentral wird.

Unter einer Krise versteht man in der Moderne eine Konstellation, in der ein Systembestand mit mehr Problemen konfrontiert ist, als er in seinem status quo zu lösen vermag, so dass unter Zeitdruck Veränderungen vorgenommen werden müssen, um den Systembestand zu erhalten; und in der ungewiss ist, ob dies gelingt.

Die Zentralität von Handeln für den Krisenverlauf bedingt das moderne Verständnis von Krisen als offene soziale Konstellationen. Mit der Relevanz von Handeln in Krisen werden zugleich die Kriseninterpretationen der Handelnden für das Krisenverständnis zentral. „Erst wenn die Gesellschaftsmitglieder Strukturwandlungen als bestandskritisch erfahren und ihre soziale Identität als bedroht fühlen, können wir von Krisen sprechen.“ (Habermas 1973: 12) Das also sind die konstitutiven Bestandteile des Krisenbegriffs: Die Überforderung der Problemlösungskapazität eines Systembestandes, Zeitdruck, relevante Akteure und deren handlungsleitende Kriseninterpretationen und Offenheit der Konstellation.

Von einer Krise ist soziologisch dann die Rede, wenn sich diese Merkmale einer Konstellation beobachten lassen. Mit anderen Worten: Krisen sind in der Praxis beobachtete und damit auch immer schon interpretierte Sachverhalte (Bohmann/Vobruba 1994: 95ff.), Thema der Soziologie werden Krisen in der Perspektive der Beobachtung zweiter Ordnung (Vobruba 2009). Dass Krisen offene Konstellationen sind bedeutet, dass in ihrem Verlauf über ihren Ausgang prinzipiell nichts Definitives gesagt werden kann. Das gilt sowohl für die in die Krisen involvierten Akteure als auch für die soziologische Beobachtung der Krise. Für die soziologische Krisenbeobachtung und -interpretation birgt dies ein erhöhtes „Risiko der Diagnose“ (Kaufmann 2012). Dieses Risiko dokumentiert das unvermeidliche Mindestmaß, in dem die soziologische Krisenbeobachtung und -interpretation selbst in eine Krise involviert ist. Meist freilich geht die Kriseninvolviertheit krisensoziologischer Beiträge darüber hinaus, indem sie versuchen, an den Kämpfen um angemessene Kriseninterpretation (bemerkens- 
werter Weise weniger: um Krisenlösungen) selbst teilzunehmen. Ob das gelingt, und welche Wirkungen in Krisen es tatsächlich hat, ist freilich eine empirische krisensoziologische Frage.

\section{Zum VerLaUf der EUROKRISE}

Soweit es sich um ökonomische Aspekte handelt, herrscht über die Ursachen und den Verlauf der Eurokrise weitgehend Einigkeit. Ab 2007 wurden die Probleme der Immobilienfinanzierung in den USA manifest, Immobilienfinanzierer gerieten durch Schuldnerausfälle in Schwierigkeiten, die Investmentbank Lehmann Brothers wurde insolvent. Sowohl die Signalwirkung dieser Vorgänge als auch reale Aktivaverluste führten zu sprunghaft zunehmendem Risikobewusstsein und Vertrauensverlusten der Gläubiger (Preunkert 2014) und zu restriktiver Kreditvergabe der Banken weltweit und insbesondere in der Eurozone. Für die gemeinsame europäische Währung bedeutete dies das Ende der Zinskonvergenz, welche die Entwicklung der Mitgliedsländer der Eurozone etwa seit 2000 bestimmt hatte. Die Angleichung der Zinsen für Staatsanleihen der Euroländer seit 1999 auf niedrigem Niveau (vgl. z.B. SVR 2010/11: 82) hatte zu hohen Schuldenständen und $\mathrm{zu}$ raschen Wohlstandssteigerungen insbesondere in den südlichen Euroländern geführt. Das abrupte Ende der Phase der Zinskonvergenz brachte öffentliche und private Schuldner jener Euroländer, deren Rückzahlungsfähigkeit plötzlich bezweifelt wurde, in (Re-)Finanzierungsschwierigkeiten. Zum einen konnten jene Euroländer, die bereits vor der Krise hohe öffentliche Schuldenquoten hatten und deren Rückzahlungsfähigkeit plötzlich in Zweifel stand, fällig werdende Schulden nicht mehr zu tragbaren Zinsen refinanzieren. Zum anderen gerieten Banken durch notleidende Kredite in Schwierigkeiten und mussten, da sie als „,systemrelevant“ angesehen wurden, um den Preis erhöhter Staatsverschuldung stabilisiert werden, was wiederum die von Banken gehaltenen älteren Staatspapiere entwertete. Die Folge war zum einen, dass Teufelskreise zwischen Bankenproblemen und Staatsverschuldung in Gang gerieten; und zum anderen, dass seit 2009 in rascher Folge unterschiedliche Kombinationen von Politik zur Wiederherstellung der Kreditierungsbereitschaft potentieller Gläubiger - meist „Stabilisierung des Gläubigervertrauens“ genannt - und Disziplinierung des Ausgabeverhaltens der Schuldner diskutiert und zu implemen- 
tieren versucht wurden. Zwei spezifische Probleme dominierten das Eurokrisenmanagement und bestimmten maßgeblich den Krisenverlauf.

Erstens. Die beiden Ziele: Wiederherstellung der Kreditierungsbereitschaft und Disziplinierung des Ausgabeverhaltens stehen zueinander in Widerspruch (Vobruba 2012: 138ff.). Dazu kommt, dass diese Ziele in der Eurokrise nicht anonymen Marktkräften überlassen werden können, sondern dass Marktzwänge teils als politische Instrumente eingesetzt und teils politisch ersetzt werden müssen, um sie zu verfolgen. Es waren ja gerade die jahrelangen falsche Risikoeinschätzungen der Gläubiger, also ein Versagen der Finanzmärkte, die eine Flut an billigem Geld ausgelöst und damit die Eurokrise vorbereitet hatten. Das Eurokrisenmanagement stand also vor einem Dilemma: Die Verfolgung des Ziels der Disziplinierung der Kreditaufnahme durch den Markt erfordert, Risiken politisch nicht aufzufangen, also Rückzahlungserwartungen von Gläubigern zu enttäuschen. Und umgekehrt bedeutet die politische Erfüllung der Rückzahlungserwartungen zwecks Stabilisierung des Gläubigervertrauens, die Disziplinierungseffekte des Marktes auszuhebeln. Die politische Instrumentalisierung von Marktzwängen ebenso wie ihr Ersatz durch Politik haben zur Folge, dass die Zwänge plötzlich auftreten, dass sie durchgreifende Wirkungen auf die Institutionen und Lebensverhältnisse in den Schuldnerländern haben, und dass sie auf politische Entscheidungen, teils aus nationalen teils aus übernationalen Zusammenhängen, zurückführbar sind. Maßnahmen des Krisenmanagements zwecks Wiederherstellung der Kreditierungsbereitschaft mussten als einseitige politisch gewollte Privilegierung von Banken- und Gläubigerinteressen, Maßnahmen zur Disziplinierung des Ausgabeverhaltens in den Schuldnerstaaten als Eingriffe in die Lebensverhältnisse und als auswärtige Einmischung in die inneren Angelegenheiten einzelner EuroMitgliedsländer wahrgenommen werden. Darum bewirkt sowohl die politische Instrumentalisierung als auch die politische Ersatzvornahme von Finanzmarktzwängen in der Eurokrise einen Politisierungsschub im Verhältnis zwischen der Bevölkerung und den politischen Institutionen der Eurozone (Rauh/Zürn 2014; Vobruba 2014).

Zweitens. Die Eurokrise ist nicht nur eine Krise der (Finanz-) Ökonomie. Die Wiederherstellung der Kreditierungsbereitschaft und die Disziplinierung des Ausgabeverhaltens verursachen hohe soziale Kosten in Form von Einkommenseinbußen, Arbeitslosigkeit, scheiternden Einstiegen in die Berufsbiographie, Kürzungen von Sozialtransfers. Im ökonomisch 
dominierten Krisendiskurs werden diese sozialen Folgen als transitorische Kosten des Krisenmanagements aufgefasst: Sie erscheinen als unvermeidbare Begleiterscheinungen der ökonomischen Krisenbekämpfung, die mit deren Erfolg wieder behoben sind. Tatsächlich jedoch zeichnet sich eine charakteristische Spaltung des Krisenverlaufs ab. Die ökonomischen und insbesondere die auf den Finanzmarkt bezogenen Indikatoren weisen nach mehreren Jahren Krise und Krisenmanagement wieder in Richtung Normalität. Die sozialen Kosten von Krisen und Krisenmanagement dagegen bleiben auf hohem Niveau erhalten, sie folgen also nicht dem ökonomischen Krisenverlauf (Tsobanoglou/Petropoulos 2014). Die ökonomisch-finanztechnische und die arbeitsmarkt- und sozialpolitische Hälfte der Eurokrise driften auseinander. „Das Vertrauen der Investoren kommt zurück“, es bleibt aber „,eine breite Verunsicherung in unseren Bevölkerungen“ (Schäuble 2013: 22; vgl. Preunkert/Vobruba 2013). Unklar ist dabei mindestens Dreierlei. Erstens: Welche sozialen Folgeprobleme der Eurokrise und des Eurokrisenmanagements werden durch die ökonomische Normalisierung zeitverzögert abgebaut, und welche sozialen Folgeprobleme verfestigen sich irreversibel? Zweitens: Welche Folgen hat das Auseinandertriften von ökonomischen und sozialen Aspekten der Eurokrise? Insbesondere, welche Rückwirkungen haben die sich verfestigenden sozialen Probleme auf den ökonomischen Krisenverlauf und in der Folge für den Europäischen Integrationsprozess? Drittens: Welcher politische Integrationsdruck, insbesondere in Richtung transnationaler Lastenteilung der sozialpolitischen Krisenfolgen, ergibt sich aus der Eurokrise?

Hier geht es um die letztgenannte Frage.

\section{GeLD UND WÄHRUNG}

Um gesellschaftsbildende Effekte der Eurokrise zu untersuchen, muss man zwischen Geld und Währung unterscheiden. Dies erfordert eine kurze Begründung, denn diese Unterscheidung wird, wenn ich recht sehe, üblicherweise nicht getroffen. Soweit sich die Soziologie für soziale Ursachen und Folgen von Geld interessiert, geht es ganz überwiegend um Geld an sich, sei es als „Symbol“, als „Sprache“ oder als „Medium“, nicht aber um Zahlungsmittel in ihren jeweiligen konkreten institutionellen Einbettungen (Simmel 1989; Parsons 1978). Der hohe Abstraktionsgrad des Begriffs 
„Geld“ verhindert, eine handlungstheoretisch basierte Theorie zu entwickeln, welche sich darauf einstellt, dass „Zahlung und Nichtzahlung“ (Luhmann 1989: 53) in der Gegenwart weltweit unter hoch institutionalisierten Bedingungen stattfinden. Man verständigt sich nicht mittels „Sprache“, sondern in konkreten Sprachen (Gerhards 2010: 55ff.), und man zahlt nicht mit „Geld“, sondern in bestimmten Währungen. Dies erfordert von der Soziologie, den Gebrauch von Geld in jenem institutionellen Rahmen zu beobachten, welcher den Umgang mit Geld reguliert und an dem sich geldbezogenes Handeln zu orientieren hat. Geld in seinem institutionellen Rahmen bezeichnet man als Währung. Darum spreche ich im Folgenden nicht von Geld, sondern von Währungen im Kontext der Eurokrise.

Der geläufige institutionelle Rahmen einer Währung ist der Nationalstaat. Wenn in der sozialwissenschaftlichen Literatur meist auch dann von Geld gesprochen wird, wenn eine spezielle Währung gemeint ist, so liegt dies daran, dass die nationalstaatliche Rahmung des Geldes bisher zu selbstverständlich war, um die Differenz für bemerkenswert zu halten. Aber spätestens die Einführung der postnationalen Währung Euro hat dieser Begriffspraxis die Grundlage entzogen.

Die Tatsache, dass nationalstaatlich verfasste Währungen in der Mehrzahl auftreten, hat einen grundlegend ambivalenten Effekt. Dies liegt daran, dass, sobald es zwischen den nationalen Ökonomien Austausch gibt, Relationen zwischen einzelnen Währungen entstehen und sich somit in irgendeiner Form ein Wechselkursmechanismus etabliert. Hier liegt der Kern der Ambivalenz von nationalstaatlichen Währungen. Einerseits impliziert der Wechselkursmechanismus, dass eine Währung selbst als Handelsobjekt behandelt werden kann, also der sozial folgenreichen Fiktion unterworfen wird, eine Ware zu sein (Polanyi 1978: 102ff.). Daran kann Spekulation anknüpfen, welche die monetäre Abbildung realer Knappheitsverhältnisse stört, mit destruktiven Wirkungen auf die Realökonomie und die Lebensverhältnisse. Andererseits aber bietet der Wechselkursmechanismus den national gerahmten Ökonomien einen gewissen Schutz vor Konkurrenz. Zumindest so lange sich Veränderungen von Währungsrelationen in einem gewissen Rahmen halten, kann der internationale Konkurrenzdruck auf eine leistungsschwächere Ökonomie samt sozialen Folgenproblemen wie Betriebsschließungen und Arbeitslosigkeit durch die Abwertung ihrer Währung vermindert werden. 
Die sozialen Folgen der gemeinsamen europäische Währung sind dazu spiegelbildlich ambivalent: Einerseits bedeutet die Einführung der gemeinsamen Währung die Abschaffung des intraeuropäischen Devisenmarktes, und eine stabilere globale Devisenmarktposition als nationale Währungen. Der Euro ist im Vergleich zu den in ihm aufgegangenen nationalen Währungen wesentlich geringerem Abwertungs- oder Aufwertungsdruck ausgesetzt. Dieser Effekt war schon lange vor der Einführung der gemeinsamen Währung Bestandteil des integrationspolitischen Kalküls (Commission 1990). Als Indikator dafür, dass dieses Kalkül aufgegangen ist, kann man den stabilen Außenwert der gemeinsamen Währung während der gesamten Eurokrise nehmen. Andererseits bedeutet der Euro die Preisgabe des Wechselkursschutzes zwischen den Mitgliedsländern der Eurozone und damit eine Verschärfung der transnationalen Konkurrenz zwischen Unternehmen und unter den Anbietern von Arbeitskraft. Einen Lohndisziplinierungseffekt erwartete die Europäische Kommission von einer Währungsunion bereits 1990. „A credible monetary union will affect the behaviour of wagebargainers. They will be more careful about risking becoming uncompetitive, given that devaluation will not be an option" (Commission 1990: 24; dazu Spahn 2013). Also lässt sich in losem Anschluss an Karl Polanyi (1977) die Ambivalenzdiagnose für die Währungsintegration in der folgenden Formel komprimieren: Die Integration mehrerer nationalstaatlicher Währungen in einem gemeinsamen Währungsraum schwächt die Wirksamkeit der Warenfiktion für Geld und verstärkt sie für Arbeitskräfte. Eine Konsequenz aus dieser Überlegung ist, dass das Lamento über den Wegfall des Wechselkursschutzes und die Plädoyers für eine Rückkehr zu nationalen Währungen zumindest einseitig sind, weil sie die skizzierte grundlegende Ambivalenz übersehen. Zur Unhaltbarkeit solcher Positionen trägt weiter bei, dass die Bedeutung des Schutzes durch die gemeinsame Währung gegen Spekulationen unterschätzt wird, dass die Möglichkeiten des Schutzes nationaler Ökonomien, Arbeitskräfte und Konsumenten durch Wechselkursänderungen überschätzt werden, und dass nicht gesehen wird, dass die Kosten einer Auflösung der gemeinsamen Währung die der NichtEinführung weit übersteigen.

Wie werden durch die Eurokrise die gesellschaftsbildenden Effekte der gemeinsamen Währung manifest? (Vobruba 2014). Durch den Wegfall der Möglichkeit von Wechselkursanpassungen entstehen neue und intensivere Kooperations- und Konkurrenzverhältnisse. Die gemeinsame Währung be- 
deutet einerseits eine Senkung der Transaktionskosten und ermöglicht damit gesteigerten Austausch und intensivere Kooperation, andererseits den Verlust des Schutzeffektes von Wechselkursänderungen (Abwertungen) für leistungsschwächere Ökonomien und darum mehr Konkurrenz. Mit der gemeinsamen Währung entfällt die Möglichkeit, „die Folgen der Integrationspolitik durch Abwertung der Währungen der Mitgliedsländer bewältigen zu lassen“ (Lepsius 2013: 192). Der soziale Effekt des Übergangs von variablen Wechselkursen zu fixen Währungsrelationen oder einer gemeinsamen Währung besteht darum darin, dass Indifferenz zwischen den am Arbeitsmarkt teilnehmenden Teilen der Bevölkerungen durch höhere Konsensanforderung und gesteigerte Konflikte ersetzt wird. Dabei ist zu beachten, dass in diesen Zusammenhang ein Selbstverstärkungsmechanismus eingebaut ist. Die gemeinsame Währung führt zu verschärfter Konkurrenz, dies erfordert als Selbstbehauptungsstrategie mehr Spezialisierung, und dies wiederum steigert die Arbeitsteilung, den Austausch und damit die wechselseitige Abhängigkeit (Münch 2009: 48ff.).

Diese gesellschaftsbildenden Wirkungen der gemeinsamen Währung haben sich in der Eurokrise in spezifischer Art und Weise manifestiert. Staaten geraten in die Rolle von Bürgen, entweder unmittelbar, oder indem Garantieinstitutionen geschaffen werden, an denen die Mitglieder der Eurozone beteiligt sind für Schulden anderer Staaten. Und über den Umweg dieser Staatsbürgschaften geraten die Bevölkerungen unterschiedlicher Mitgliedsländer als Steuerzahler, Transferleistungsempfänger etc. miteinander in (Verteilungs-)Konflikte. Im Einzelnen bedeutet das Folgendes.

Staaten werden zu Bürgen, weil sie Teilhaber von Institutionen sind, die Garantien für Schuldner, die als ,systemrelevant“ angesehen werden, übernehmen müssen. Im Zuge der Eurokrise haben bestehende Institutionen, insbesondere die EZB, Garantieaufgaben übernommen, und es entwickeln sich neue spezielle Garantieinstitutionen, ESFS und EMS. Die öffentliche Garantieerklärung des Präsidenten der EZB Mario Draghi (2012) gilt als Wendepunkt der Eurokrise: ,the ECB is ready to do whatever it takes to preserve the euro. And believe me, it will be enough."

In der akuten Phase der Eurokrise wurde die Notwendigkeit von transnational wirksamen Garantien mit dem „Ansteckungsargument“ (Vobruba 2012: 72ff.) begründet. Ein Bankrott eines Euromitglieds ebenso wie einer systemrelevanten Bank könne nicht zugelassen werden, da dies das Misstrauen potentieller Gläubiger so steigere, dass der gesamte gemeinsame 
Währungsraum getroffen werde. Zur Leitmetapher des Krisenmanagements wurde das Ansteckungsargument, weil man seine empirische Triftigkeit in der Praxis nicht testen konnte. Denn hat die Ansteckung erst einmal stattgefunden, ist es zu spät.

Transnational wirksame Garantien, für die in letzter Konsequenz staatliche Budgets haften, involvieren zwingend die Verteilungsinteressen der Zahler von Steuern und Empfänger von geldwerten staatlichen Leistungen aller Art. Darum entstanden durch die Garantien neue länderübergreifende Konfliktlinien. Sie führten gemeinsam mit den bestehenden, national gebundenen Konflikten, zu einer komplexen Konfliktkonstellation (Vobruba 2014a).

\section{EINE KOMPLEXE KONFLIKTKONSTELLATION}

Diese Konstellation lässt sich als Kombination von zweierlei Konfliktlinien beschreiben. Zum einen wirken weiterhin die Verteilungskonfliktlinien innerhalb der einzelnen Mitgliedsländer. Diese Konfliktlinien verlaufen im Wesentlichen zwischen den Beziehern niedrigerer und höherer Einkommen und sind entlang der Unterscheidung zwischen Arbeit und Kapital stabil institutionalisiert. Zum anderen entstehen neue Konfliktlinien, die zwischen wettbewerbsstarken und wettbewerbsschwächeren Ländern verlaufen. Indem Staaten in die Rolle von Bürgen für die Verschuldung anderer Staaten genötigt werden, die EZB Garantieaufgaben übernimmt und neue Garantieinstitutionen entstehen, kommen breite Mehrheiten in den wettbewerbsstarken Ländern als Steuerzahler als „guarantors of last resort“ ins Spiel. Zugleich werden durch Auflagen, die mit Kreditvergabe und Bürgschaften verbunden sind, die Lebensverhältnisse breiter Mehrheiten in den wettbewerbsschwächeren Ländern beeinträchtigt. Die Konflikte, die daraus entstehen, haben kein eindeutiger Gegenüber und sind kaum institutionalisiert. Dies lässt sich anhand der Konstruktion der Adressaten von Protest gegen die Austeritätspolitik im Zuge der Eurokrise ablesen (vgl. Petropoulos 2014: 351ff.; Rodriguez 2014: 520ff.). Der Protest richtet sich teils gegen „die Reichen“, „die Banken“, „das Kapital“ „die Korrupten“ im eigenen Land (traditionelle Konfliktlinie); teils gegen „die Troika“, „,den IMF“, ,die Kommission der EU“" und gegen die Hegemonie der Kernländer der EU und Eurozone, insbesondere gegen Deutschland (neue Konfliktlinie). 
Wieder sieht man den ambivalent gesellschaftsbildenden Effekt des Euro. Die gemeinsame Währung impliziert einerseits einen sozialen Integrationsschub. Die wechselseitige Indifferenz zwischen nationalen Bevölkerungen, die wesentlich durch die Möglichkeiten von Veränderungen der Währungsrelationen abgesichert war, wird von verdichtete Kooperation und intensiveren Konflikt abgelöst. Die Verdichtung der Kooperation lässt sich an der Ausweitung der Handels- und Leistungsbilanzvolumina seit der Einführung des Euro ablesen. Zwar entwickelten sich bis zum Ausbruch der internationalen Finanzkrise 2007 erhebliche Handelsungleichgewichte, die nur durch Kapitalimporte verdeckt wurden. Aber am Befund der Kooperationsverdichtung ändert das nichts: Arbeitsteilung und Austausch haben seit der Einführung der gemeinsamen Währung zugenommen. Die Intensivierung von Konflikt ergibt sich aus der Eurokrise und dem Eurokrisenmanagement. Aber selbst dieser Aspekt von Gesellschaftsbildung ist uneindeutig: Einerseits birgt die gemeinsame Währung die Möglichkeit, dass zwischen den Mitgliedsländern und innerhalb der Mitgliedsländer soziale Spannungen entstehen, welche den Bestand der EU gefährden. Es scheint zwar nicht sehr wahrscheinlich zu sein, dass aus integrationsskeptischen Stimmungen durchsetzungsfähige politisch Positionen werden (Gerhards/ Lengfeld 2013), aber auszuschließen ist es nicht. Andererseits geraten die Bevölkerungen der Mitglieder der Eurozone miteinander in „Streit“ - mit potentiell gesellschaftsbildenden Effekten (Simmel 1992: 284ff.).

Um diese These weiter zu verfolgen, ist es erst einmal erforderlich, die übliche Gleichsetzung von Gesellschaftsbildung, sozialer Integration und Homogenität zu überwinden (Vobruba 2010).

Dabei geht es nicht darum, soziologisch einen Begriff von Gesellschaft zu definieren, um dann die Realität daran zu messen. Vielmehr ist es sinnvoll, ausgehend von einem heuristischen Gesellschaftsverständnis herauszufinden, ob sich Verhältnisse entwickeln, die in der Gesellschaft selbst als Gesellschaftsbildung beobachtet und interpretiert werden. Dafür ist es keineswegs zwingend, dass im Verhältnis zwischen Bevölkerung und Institutionen Zufriedenheit und innerhalb der Bevölkerung Harmonie dominieren muss. Vielmehr wären dies überaus unwahrscheinliche Fälle, also keineswegs sinnvolle Kriterien für gelungene Gesellschaftsbildung. Man wird also jedenfalls mit Konflikten rechnen und die soziologische Begrifflichkeit auf Gesellschaftsbildung mit oder gar durch Konflikt - im Sinn von Georg 
Simmel - einstellen müssen. Die These lautet allerdings nicht einfach, dass Konflikte Gesellschaft schaffen. Es ist komplizierter.

Für die Frage, ob die Eurokrise zur Gesellschaftsbildung beiträgt, ist das Zusammenwirken von Konflikten und ihren Konfliktrahmen (Fehmel 2014) entscheidend. Georg Simmel sieht Konflikte unter der Bedingung als sozialintegrativ an, dass ,die Gegner ein Gemeinsames haben, über dem sich erst ihr Kampf erhebt.“ (Simmel 1992: 310) Die Frage ist, was als ein solches „Gemeinsames“ fungieren kann. Man kann, wenn ich recht sehe, diese Idee allgemeiner fassen und institutionentheoretisch nutzen. Konflikte sind gesellschaftsbildend, wenn sie sich in einem Rahmen abspielen, den sie selbst nicht angreifen können. Bei Simmel besteht dieser Rahmen im Wesentlichen aus Einstellungen, Orientierungen, Wertüberzeugungen, welche alle Konfliktparteien teilen. Meine These ist, dass Institutionen analoge Effekte haben können, wenn sie von den Konfliktparteien akzeptiert werden oder doch hingenommen werden müssen (Vobruba 2014).

\section{GeSELLSChAFTSBILDUNG}

Um die gesellschaftsbildenden Effekte der Eurokrise zu untersuchen, muss man also Entwicklungen auf zwei Ebenen ins Auge fassen: Erstens neue Konfliktverhältnisse in der Bevölkerung und zweitens die Stabilität bestehender Institutionen und krisenbedingte Institutionenbildung.

$\mathrm{Zu}$ den Konflikten: Eine sehr allgemeine Diagnose der Effekte von transnationalen Integrationsprozessen könnte lauten, dass sie mehr Homogenität im Großen und mehr Heterogenität im Kleinen bewirken. Empirische Evidenz dafür gibt es etwa in der Dimension von materieller Ungleichheit. Jedenfalls bis zum Beginn der Eurokrise kam es zum Abbau von Ungleichheit zwischen den Ländern bei gleichzeitiger Zunahme von Ungleichheit innerhalb der Länder (Münch/Büttner 2006: 80f.). Für den Fall der Währungsunion lässt sich die allgemeine Diagnose so konkretisieren: Einerseits entwickelt sich mehr Homogenität im Großen, mit der Folge, dass die gemeinsame Währung global in eine starke Position gerät, die unter anderem die Chance der Entwicklung zur Reservewährung impliziert, samt allen Vorteilen, die dieser Status bietet. Andererseits entwickelt sich mehr Heterogenität im Kleinen, woraus sich eine Vielzahl an Interessenpositionen und Konfliktlinien ergibt, die sich im Wesentlichen durch fol- 
gende Merkmale auszeichnen: Vielfalt der Inhalte, Unklarheit über die Adressaten von Forderungen, instabile Trägerschaft. Die Konfliktkonstellation ist insgesamt gekennzeichnet „von Konfliktlagen, bei denen (anders als im nationalstaatlich verfassten industriellen Konflikt, bei föderalen BundLänder-Konflikten, im Parteienwettbewerb usw.) nicht feststeht wer sich mit wem im Interessenkonflikt befindet und an welchen Verhandlungstischen der Konflikt nach welchen Regeln und zwischen welchen repräsentativen Kollektivakteuren auszutragen ist“ (Offe 2001: 431). Daraus aber lässt sich keineswegs eindeutig auf ein besonderes sozial desintegratives Potential von Konflikten im EU- oder Euro-Rahmen schließen (Kiess 2013). Im Gegenteil. Konsequenz der komplexen Konfliktkonstellation, welche die Eurokrise manifest gemacht hat, ist, dass die sich gegen die Europäische Integration richtenden Interessen nur schwach organisationsfähig und darum auch kaum politikfähig sind.

Zur Institutionenstabilität und -bildung: Tatsächlich hat die Eurokrise politische Institutionen in Europa kaum geschwächt. Auf der nationalstaatlichen Ebene finden wir kaum Krisenwirkungen auf Institutionen. Der Einfluss nationalstaatlicher Institutionen auf die EU-Ebene hat sich eher noch verstärkt. Das kommt unter anderem in der Klage über die Dominanz der intergouvernementalen Ebene beim Eurokrisenmanagement zum Ausdruck. Noch dazu bringt die Eurokrise einen Institutionalisierungsschub mit sich (Heidenreich 2014). Wo sich Kompetenzverluste nationalstaatlicher Institutionen registrieren lassen, sind diese in aller Regel auf explizite oder implizite Kompetenzübertragungen an die EU-Ebene zurückzuführen. Das gilt sowohl für nationale Notenbanken als auch für nationale Höchstgerichte. Solche Kompetenzverschiebungen werden als umwegige Absicherung nationalstaatlicher Souveränität interpretiert.

Auf EU-Ebene hat die Eurokrise dazu geführt, dass bestehende Institutionen zusätzliche Aufgaben übernehmen und dass neue Institutionen entstehen und ,that much more of what is national sovereignty is going to be exercised at supranational level“" (Draghi 2012). Dazu zählen die von der Kommission vorgeschlagenen „Stabilitätsbonds“, also die Möglichkeiten der Vergemeinschaftung von Staatshaftungen, der Vorschlag der französische „Groupe Eiffel Europe“ (SZ 15./16.2.2014: 9), welche die Weiterführung der Euroländer zu einem politisch integrierten Kerneuropa mit eigenen Organen der politischen Willensbildung vorschlägt, oder die Aufwertung des Europäischen Parlaments durch die Konzentration des Wahlkampfs 
2014 auf Spitzenkandidaten. Ob diese Entwicklungen die Gesellschaftsbildung zu EU-institutionellen Bedingungen vorantreiben? Das ist die Frage nach der Entwicklung des Verhältnisses von sozialen Konflikten und Institutionen. Werden die Konflikte im Rahmen der Institutionen ausgetragen, handelt es sich um Gesellschaftsbildung. Hebeln die Konflikte die Institutionen aus, handelt es sich um Desintegration durch die Eurokrise. Vor dem Hintergrund des eingangs skizzierten Begriffs von Krise und des modernen Verständnisses von offener Zukunft lässt sich diese Frage nicht eindeutig beantworten. Die Soziologie kann nur die Ambivalenzen der Eurokrise zeigen und registrieren, dass diese ihr selbst Grenzen setzt.

\section{ScHLUSS}

In der europapolitischen Diskussion taucht immer wieder das kritische Argument auf, die Europäische Integration werde als alternativenloses Projekt verfolgt, dem Integrationsverständnis liege also eine Teleologie zu Grunde. Ob die Soziologie sich diese Kritik zu eigen machen soll, hängt davon ab, an wen sie adressiert ist. Als Kritik an Überzeugungen, die sie in der Praxis vorfindet, geht sie daneben. Wenn die Europäische Integration von Akteuren in der (politischen) Praxis teleologisch interpretiert wird, so muss die Soziologie dies als empirisches Datum nehmen und zu anderen praktisch wirksamen Interpretationen der europäischen Integration in Relation setzen. Denn zur Mehrdeutigkeit von Krisen gehört auch, dass es unterschiedliche, konkurrierende Interpretationen über die Krisenfolgen gibt.

Sofern aber soziologische Ansätze selbst teleologisch unterlegt sind, trifft die Kritik. Als Theoriekonzept kann sich die Soziologie eine teleologische Auffassung der europäischen Integration deshalb nicht zu eigen machen, weil sie damit dem Eigensinn der Leute den Raum nimmt, die Empirie alternativer Möglichkeiten der Interpretationen und des Handelns in der Europäischen Integration und damit auch die Eurokrise prinzipiell offene Konstellation nicht erfassen kann. Man kann sich dies an der Mehrdeutigkeit des Begriffs „Notwendigkeit“" klar machen (Vobruba 2009: 44f.): Die Europäische Integration mag angesichts der kriegerischen Vergangenheit, zwecks Selbstbehauptung in der Globalisierung, zur Verteidigung zentraler europäischer Werte und noch aus vielen anderen guten Gründen notwendig sein. Das kann man behaupten und dafür muss man von Fall zu Fall sorg- 
fältig argumentieren. Notwendigkeiten, auf die man auf diese Weise kommen kann, sind aber im Sinn von „,erforderlich“, nicht von ,zwingend“ zu verstehen. Krisen sind Phasen potentiell beschleunigten sozialen Wandels. Sie müssen als offene soziale Konstellationen konzipiert werden, um dem Eigensinn der im Krisenkontext Handelnden theoretisch Raum zu bieten (Vobruba 2014b: 273ff.). Dass Krisen sozial offene Konstellationen sind, ist die Konsequenz eines posttraditionalen Geschichtsverständnisses und begründet die theoriestrategische Relevanz soziologischer Krisenforschung. Helmut Fleischer fasst das Verhältnis von sozialem Wandel und Handeln im posttraditionalen Verständnis von Geschichte so: „Historische Fortschritte sind jeweils praktisch notwendig, weil Menschen sich im Hinblick auf Möglichkeiten höherer Bedürfnisbefriedigung mit dem bisherigen Stand nicht mehr abfinden.“ Und darum gilt: „Die Verwirklichung des praktisch Notwendigen ist durch nichts anderes als durch die Dispositionen und Qualifikationen der dafür engagierten Menschen gewährleistet" (Fleischer 1972: 148, 149). Die Europäische Integration ist kein teleologischer Prozess, der objektiven historischen Gesetzmäßigkeiten folgt, denn ,objektive historische Notwendigkeiten" gibt es nicht.

\section{LITERATUR}

Bohmann, Gerda/Vobruba, Georg (1994): Krisen und ihre Interpretationen, in: Georg Vobruba, Gemeinschaft ohne Moral, Wien, S. 95-129.

Commission (1990): Commission of the European Communities, One Market, One Money - An Evaluation of the Potential benefits and Costs of Forming an Economic an Monetary Union. European Economy 44.

Draghi, Mario (2012): Speech by Mario Draghi, President of the European Central Bank at the Global Investment Conference in London 26 July 2012. https://www.ecb.europa.eu/press/key/date/2012/html/sp120726. en.html. [Letzter Zugriff: 05.03.2015.]

Dux, Günter (1989): Die Zeit in der Geschichte. Ihre Entwicklungslogik vom Mythos zur Weltzeit, Frankfurt a.M.

Fehmel, Thilo (2014): Konflikttheorie und Gesellschaftsbildung. Europäische Integration durch soziale Konflikte, in: Thilo Fehmel/Stephan Lessenich/Jenny Preunkert (Hg.), Systemzwang und Akteurswissen. 
Theorie und Empirie von Autonomiegewinnen, Frankfurt a.M., S. 133157.

Fleischer, Helmut (1972): Marxismus und Geschichte. Frankfurt a.M.

Gerhards, Jürgen (2010): Mehrsprachigkeit im vereinten Europa, Wiesbaden.

Gerhards, Jürgen/Lengfeld, Holger (2013): Wir, ein europäisches Volk?, Wiesbaden.

Geschichtliche Grundbegriffe (1982): Artikel „Krise“, in: Otto Brunner/ Werner Conze/Reinhard Koselleck (Hg.), Geschichtliche Grundbegriffe. Band 3, Stuttgart, S. 617-650.

Habermas, Jürgen (1973): Legitimationsprobleme im Spätkapitalismus, Frankfurt a.M.

Heidenreich, Martin (2014): Eurokrisen und Vergesellschaftung. Die krisenhafte Europäisierung nationaler Fiskalpolitiken. Eine Einführung, in: Martin Heidenreich (Hg.), Krise der europäischen Vergesellschaftung?, Wiesbaden, S. 1-28.

Hofmann, Andreas/Wessels, Wolfgang (2013): Tektonische Machtverschiebungen. Die Krise als Auslöser und Verstärker des institutionellen Wandels, in: Zeitschrift für Politik 2, S. 220-241.

Kaufmann, Franz-Xaver (2012): Als Soziologen tragen wir nicht das Risiko des Handelns, aber wir tragen das Risiko der Diagnose, in: Soziologie. Forum der deutschen Gesellschaft für Soziologie 41.4, S. 425-436.

Kiess, Johannes (2013): European integration, interest groups and institutional sets of conflict. Serie Europa - European series 5. http://www.unileipzig.de/leus/wp-content/uploads/2013-05-Kiess-European-integrationinterest-groups-and-institutional-sets-of-conflict.pdf. [Letzter Zugriff: 23.02.2015.]

Koselleck, Reinhard (1973): Kritik und Krise, Frankfurt a.M.

Koselleck, Reinhard (2010 [1985]): Einige Fragen an die Begriffsgeschichte von Krise, in: Reinhard Koselleck, Begriffsgeschichten, Frankfurt a.M., S. 203-217.

Lepsius, M. Rainer (2013): Institutionalisierung politischen Handelns. Analysen zur DDR, Wiedervereinigung und Europäischen Union, Wiesbaden.

Luhmann, Niklas (1989): Die Wirtschaft der Gesellschaft, Frankfurt a.M.

Münch, Richard (2009): Das Regime des Liberalen Kapitalismus. Inklusion und Exklusion im neuen Wohlfahrtsstaat, Frankfurt a.M. 
Münch, Richard/Büttner, Sebastian (2006): Die europäische Teilung der Arbeit. Was können wir von Emile Durkheim lernen?, in: Martin Heidenreich (Hg.), Die Europäisierung sozialer Ungleichheit. Zur transnationalen Klassen- und Sozialstrukturanalyse, Frankfurt a.M., S. 65-107.

Offe, Claus (2001): Gibt es eine europäische Gesellschaft? Kann es sie geben?, in: Blätter für deutsche und internationale Politik 4, S. 423-435.

Parsons, Talcott (1978): Action Theory and the Human Condition, New York.

Petropoulos, Nicholas P. (2014): A Sociopolitical Profile and the Political Impact of the Greek Indignados. An Exploratory Study, in: Georg O. Tsobanoglou/Nicholas P. Petropoulos, (Hg.), The Social Impacts of the Dept Crisis in the Eurozone, Athens, S. 463-519.

Polanyi, Karl (1977 [1944]): The Great Transformation, Wien.

Preunkert, Jenny (2014): Vertrauen in der Krise - Vertrauen als Verantwortungszuschreibung, in: Thilo Fehmel/Stephan Lessenich/Jenny Preunkert (Hg.), Systemzwang und Akteurswissen. Theorie und Empirie von Autonomiegewinnen, Frankfurt a.M., S. 175-195.

Preunkert, Jenny/Vobruba, Georg (2013): Die beiden Hälften der Eurokrise, in: Gegenworte 30. Herbst 2013. Berlin-Brandenburgische Akademie der Wissenschaften, Berlin, S. 21-25.

Rauh, Christian/Zürn, Michael (2014): Zur Politisierung der EU in der Krise, in: Martin Heidenreich (Hg.), Krise der europäischen Vergesellschaftung?, Wiesbaden, S. 121-145.

Rodriguez, Ariadna (2014): The M-15 Spanish Movement and its Projection in the Media Communication, in: George O. Tsobanoglou/Nicholas Petropoulos (Hg.), The Social Impacts of the Eurozone Debt Crisis, Athen, S. 520-530.

Schäuble, Wolfgang (2013): Kein deutsches Europa!, in: Süddeutsche Zeitung, 20./21.7.2013, S. 22.

Simmel, Georg (1989 [1900]): Philosophie des Geldes, Frankfurt a.M.

Simmel, Georg (1992 [1908]): Soziologie, Frankfurt a.M.

Spahn, Peter (2013): „One Market, One Money“ - Zwei Jahrzehnte später, in: List Forum 39.1, S. 1-15.

SVR (2010/11): Sachverständigenrat zur Begutachtung der gesamtwirtschaftlichen Situation, Jahresgutachten 2011/12. Chancen für einen stabilen Aufschwung. http://www.sachverstaendigenrat-wirtschaft.de/ aktuellesjahrsgutachten-2010-110.html. [Letzter Zugriff: 23.02.2015.] 
Tsobanoglou, George O./Petropoulos, Nicholas (Hg.) (2014): The Social Impacts of the Eurozone Debt Crisis, Athen.

Vobruba, Georg (2009): Die Gesellschaft der Leute, Wiesbaden.

Vobruba, Georg (2010): Gesellschaftstheoretische Grundlagen der Europasoziologie. Die soziologische Beobachtung der Gesellschaft in der Europäischen Integration, in: Monika Eigmüller/Steffen Mau (Hg.), Gesellschaftstheorie und Europapolitik. Sozialwissenschaftliche Ansätze zur Europaforschung, Wiesbaden, S. 431-470.

Vobruba, Georg (2012): Der postnationale Raum. Transformation von Souveränität und Grenzen in Europa, Weinheim/Basel.

Vobruba, Georg (2014): Gesellschaftsbildung in der Eurokrise, in: Martin Heidenreich (Hg.), Krise der Europäischen Vergesellschaftung?, Wiesbaden.

Vobruba, Georg (2014a): The Europeanization of Distributional Conflicts within the Eurocrisis, in: Georg O. Tsobanoglou/Nicholas P. Petropoulos (Hg.), The Social Impacts of the Dept Crisis in the Eurozone. Athens, S. 57-68.

Vobruba, Georg (2014b): Autonomiegewinne und Gesellschaftskritik, in: Thilo Fehmel/Stephan Lessenich/Jenny Preunkert (Hg.), Systemzwang und Akteurswissen. Theorie und Empirie von Autonomiegewinnen, Frankfurt a.M., S. 265-281. 


\title{
Europäische Krisenpolitik auf dem Prüfstand
}

\author{
Die Europäische Integration
}

aus wirtschaftshistorischer Sicht ${ }^{1}$

WERnER PLUMPE

I.

Die Geschichte der europäischen Integration wird in der Regel als Erfolgsgeschichte erzählt, vor allem als wirtschaftliche Erfolgsgeschichte, die sich in Folge kluger und aus historischer Erfahrung getroffener Entscheidungen ergeben habe (vgl. Loth 2014; vgl. auch Mittag 2008). Der Zweite Weltkrieg habe endgültig gezeigt, dass das durch zahlreiche Nationalstaaten gekennzeichnete Europa, sollte es nicht zusammenarbeiten, zu verheerenden Konflikten neige. Und die Zusammenarbeit sei nicht nur politisch klug; sie zahle sich zusätzlich wirtschaftlich aus. So seien allen Teilnehmerstaaten auch in einem ganz ordinär materiellen Sinne Profiteure der europäischen Einigung, die in dieser Logik dann auch gar nicht weit genug gehen kann, bedingen sich hiernach doch das politisch Sinnvolle und das ökonomisch Erfolgreiche gegenseitig - und zwar genau in der Form der supranationalen Organisation, die die Europäische Union mittlerweile angenommen hat. Liest man einen Satz der Bundeskanzlerin Angela Merkel so, dann ist die europäische Integration nach Brüsseler Art deshalb alternativlos, weil es kein vergleichbares Erfolgsmodell gibt. Aus der zunächst durch das Leid

1 Der Stil des Vortrags vom Mai 2014 in Aachen ist weitgehend beibehalten. 
des Krieges geprägten Bereitschaft zur Zusammenarbeit ist unter der Hand eine Art Sachzwang geworden, denn von der einmal eingeschlagenen Straße der Integration kann man in dieser Sicht nur unter erheblichen Wohlstandsverlusten und politischen Risiken abweichen. ${ }^{2}$

In dieser Sachzwanglogik war allerdings die Euro-Krise nicht vorgesehen. Sie konnte im strengen Sinne auch gar nicht passieren, war doch die weitere Vertiefung der europäischen Union zur Währungsunion in den 1990er Jahren gerade damit begründet worden, dass derartige Krisen zukünftig ausgeschlossen seien (vgl. Tietmeyer 2005). Dass die Politik auf sie zunächst überrascht, fast panisch und dann durch konsequentes Vorantreiben der institutionellen und finanziellen Integration reagiert hat, zeigt auch, dass hier ein Denken vorherrscht, das nach dem Motto funktioniert, es könne doch nicht sein, was nicht sein dürfe. Die Euro-Krise ist in dieser Sicht nicht die Folge der Währungsunion, sondern Ausdruck der Tatsache, dass diese noch nicht vertieft genug ist (vgl. Bofinger 2012). Daher wird die Euro-Krise als vermeidbarer Schaden angesehen - nach der Logik der bisherigen Selbstsicht eben insbesondere als Integrationsmangel: Hätte Europa die angemessenen institutionellen Strukturen, dann würde es zu derartigen Krisen nicht kommen bzw. man könne sehr viel effektiver und schneller reagieren. Nun könnte man mit Karl Kraus ironisch sagen, die EU-Integration stelle sich hier als Therapie für eine Krankheit dar, die sie selbst ist - aber wie dem auch sei!

Ist das Argument, die europäische Integration á la Brüssel sei die einzige politisch und ökonomisch sinnvolle Art, mit den Problemen des Kontinents umzugehen, richtig, bleibt zur Reparatur der bestehenden Institutionen und zu ihrem Ausbau im Grunde keine Alternative. Ist aber die andere Vermutung stichhaltig, ohne die eigentümliche Form der forcierten Integration insbesondere seit den 1990er Jahren hätte es die letzte Krise gar nicht bzw. in einem ganz anderen Ausmaß gegeben, dann ist in der Tat zu fragen, ob nicht die gegenwärtige weitere Forcierung der Integration die strukturellen Schwierigkeiten nur weiter verschärft; eine Problematik, die allein deshalb nicht aktuell akut ist, weil die EZB mit der Geldspritze bereit steht. Man kauft sich Zeit, wie es der Kölner Politökonom Wolfgang Streeck treffend gesagt hat (vgl. Streeck 2013). Die Entwicklung der nächsten Jahre

2 Diese im Wesentlichen politische Argumentation muss hier im Einzelnen nicht nachgewiesen werden; sie dürfte jedem Zeitungleser hinreichend bekannt sein. 
wird zeigen, ob die Strategie der forcierten Integration wirklich trägt - oder nur solange durchgehalten werden kann, wie die Staaten des Nordens zu Transfers und die EZB zur Schuldenfinanzierung bereit ist. In Griechenland scheint man das, folgt man den Beobachtungen des ehemaligen ChefVolkswirtes der Deutschen Bank Mayer, bereits für Realität zu halten (vgl. Mayer 2014). Die hohen Staatsschulden, glaubt man dort, seien unproblematisch, das Schlagwort heißt ,japanisiert“, da sie bei den Zentralbanken und der EZB lägen, die das Geld aber gar nicht einforderten. Reformdruck besteht nicht mehr. Während die Finanzkrise „,neutralisiert“, ,,japanisiert“ scheint, nehmen die Strukturprobleme weiter zu. Warten wir es also ab.

\section{II.}

In den folgenden Überlegungen will ich mich nicht mit der Zukunft beschäftigen, sondern mit der Vergangenheit, also mit der Frage, ob der derzeitige Integrationsmodus sich in der Tat wirtschaftshistorisch bewährt hat bzw. welche wichtigen ökonomischen und politischen Faktoren den Integrationsprozess bestimmten. Vorderhand scheint die Erfolgsgeschichte zu stimmen. Die Nachkriegszeit war insbesondere für Westeuropa eine Phase der überaus stürmischen wirtschaftlichen Entwicklung. Man spricht für die Zeit zwischen dem Kriegsende und den frühen 1970er Jahren auch von den „trente glorieuses“. Westeuropa holte nicht nur den Produktivitätsrückstand gegenüber den USA, der nach 1914 entstanden war, zu großen Teilen wieder auf, sondern erlebte einen bis dato beispiellosen Anstieg des Wohlstandsniveaus (vgl. Lindlar 1997). Die Wachstumsraten sind zwar seit den 1970er Jahren niedriger, doch in den 1990er Jahren kamen die Erfolgsgeschichten der neuen EU-Länder, namentlich Irlands, Spaniens und Portugals hinzu. Selbst Griechenland erzielte in jenen Jahren hohe Wachstumsraten. In einem Beitrag zur Cambridge Economic History of Modern Europe kommen Barry Eichengreen und Andrea Boltho daher auch insgesamt zu einem positiven Urteil über die ökonomische Bedeutung der Integration. Grob gesprochen, gehen sie davon aus, dass das BIP in Europa ohne die EU um 5\% niedriger läge, doch weisen sie selbst daraufhin, wie schwer die Bedeutung und Wirkung von Institutionen zu beurteilen ist, denn die ökonomischen Akteure würden ihre Chancen in jedem Fall suchen und - finden (vgl. Eichengreen/Boltho 2010). Gegenüber der großen Erfolgsgeschichte 
sind sie deutlich skeptischer, aber immerhin bestreiten sie sie nicht. Nun ist ihre Geschichte der europäischen Integration vor der Finanzkrise und dem Zusammenbruch der Erfolgsländer Irland, Spanien, Portugal und Griechenlang geschrieben worden. Ob heute, angesichts eines mittlerweile jahrelangen Stagnierens zahlreicher europäischer Volkswirtschaften, zum Teil gar eines Schrumpfens der Wirtschaftsleistung noch von einer erfolgreichen Entwicklung die Rede sein würde, ist zumindest offen. Und auch der „Erfolgsfaktor" Währungsunion, auf den man seinerzeit noch glaubte, setzen zu können, hat erkennbar seine Probleme: Ohne Draghis „dicke Bertha“ wäre der Euro höchstwahrscheinlich bereits Geschichte. Dass die neue europäische Währung zumindest in ihrer jetzigen Form aus eigener Kraft lebensfähig ist, glauben nicht einmal ihre glühendsten Anhänger. ${ }^{3}$

Und auch andere Gesichtspunkte stimmen zumindest skeptisch, was eine positive ökonomische Bedeutung der Integration angeht. Die höchsten Wachstumsraten erzielte Westeuropa in den 1950er und 1960er Jahren, als das Integrationsniveau und auch die Handelsverflechtung noch relativ niedrig waren. Das Integrationsniveau nahm in den Jahren nach 1950 sukzessive zu; der Grad der westeuropäischen Handelsverflechtung stieg von 49,3 $\% 1950$ auf 67,3\% 1972 und schließlich auf 72,2\% 1990 und 76,6\% 2008 (Eichengreen/Boltho 2010: 270). Wenn man will, kann man mit dieser intensiveren Verflechtung die Wohlstandserfolge korrelieren, doch ist Vorsicht am Platz. Für die 1950er und 1960er Jahre mag das gelten, doch seither wachsen andere Volkswirtschaften und andere Regionen mit niedrigeren regionalen Integrationsraten deutlich schneller. Seit den 1960er Jahren sinkt Westeuropas Anteil an der Wirtschaftsleistung der Welt kontinuierlich von mehr als $30 \%$ auf mittlerweile etwa 20\%. ${ }^{4}$ Die konventionelle Geschichte der EU als ökonomischer Erfolg würde mithin nur dann zutreffen, wenn man unterstellt, ohne die Integration hätte Westeuropa noch schlechter abgeschnitten, als es im weltweiten Vergleich seit den 1980er Jahren ohnehin der Fall ist. Dann bliebe aber die Frage, was Westeuropas Wachstumsschwäche im Vergleich mit den USA und asiatischen Staaten denn nun bestimmt hat. Nein, der Rückgang der Wachstumsraten in Westeuropa lässt

3 Vielmehr werden wirtschaftspolitische und institutionelle Änderungen beschworen, um den Euro zu stabilisieren, von dem man doch bei seiner Einführung so Großes erwartet hat; zu dieser Position noch einmal Bofinger 2012.

4 Daten bei Maddison 2007. 
sich mit anderen Gründen gut erklären, ebenso wie der Aufschwung in den Nachkriegsjahrzehnten kein Rätsel ist (Vgl.vgl. Crafts/Toniolo 2010). Die Bedeutung der Integration hierfür war ökonomisch wahrscheinlich eher zu vernachlässigen (vgl. Plumpe/Steiner 2008). Die Entwicklung und der Strukturwandel, die sich in dieser Zeit feststellen lassen, hätten auch ohne die europäische Integration stattgefunden. Die für den europäischen Kontinent, aber auch Großbritannien typischen Strukturmerkmale und Besonderheiten sind ohnehin viel älteren Datums als die europäische Integration, die, so mein nächster Punkt, viel stärker auf diese Strukturen reagierte, als sie selbst zu prägen.

\section{III.}

Die Grundlagen der gegenwärtigen wirtschaftlichen Regionalstrukturen in Europa wurden in den Jahrzehnten vor dem Ersten Weltkrieg gelegt, damals unter britischer Dominanz, die freilich langsam verblasste. Nimmt man nur Großbritannien, Deutschland und Frankreich, so entfiel auf sie vor 1914 mit 36\% der Weltindustrieproduktion etwa so viel wie auf die USA. In Europa wiederum war Deutschland das ökonomische Schwergewicht, das um die Jahrhundertwende Großbritannien wirtschaftlich überholt hatte. Auf diese vier Länder entfiel vor 1914 auch fast die Hälfte des Welthandels; hier behauptete Großbritannien noch einen knappen Vorsprung vor Deutschland und den USA, während Frankreich seit den 1880er Jahren kontinuierlich zurückgefallen war. Gliedert man den Außenhandel weiter auf, so zeigt sich schon vor 1914 das auch heute bekannte Muster: Deutschland ist Exportweltmeister, Großbritannien das Zentrum der Weltfinanz und die USA in jeder Hinsicht bedeutend, aber viel stärker auf ihren in der Tat großen Binnenmarkt orientiert als auf den Welthandel. Im Welthandel zeigte sich die Stärke vor allem der jungen, modernen Industrien, die ihren Schwerpunkt in Deutschland hatten, namentlich des Maschinenbaus, der chemischen Industrie, der Elektrotechnik und der Feinmechanik und Optik. Zwar spielte das Land im Textilhandel vor 1914 keine große Rolle, doch dominierte es den Weltmarkt bei Chemikalien, Farbstoffen und Pharmazeutika fast nach Belieben, im Bereich der Elektrotechnik, der Feinmechanik und Optik und des Maschinenbaus entfielen etwa 50\% des Welthandels auf deutsche Unternehmen. Das Beispiel der Glühbirnen ist vielsagend: Zwar 
einem US-Patent folgend, beherrschte die Firma Osram den Welthandel faktisch vollständig, während der größte Produzent, die USA, an ihrem rasch wachsenden Binnenmarkt im Grunde erst einmal genug zu tun hatten. Die großen Wirtschaftsnationen handelten auch vor 1914 bereits im Wesentlichen untereinander. Zwar spielte der Rohstoff- und Zwischenprodukthandel eine große Rolle. Die afrikanischen Exporte nahmen im 19. Jahrhundert sehr rasch zu, und auch andere Weltgegenden lieferten wichtige Rohstoffe und Agrarprodukte. Doch der Handel fand im Kern zwischen den entwickelten Staaten statt. Die Kunden der deutschen Industrie lebten in Frankreich, Italien, Spanien, Österreich-Ungarn, Russland, vor allem aber in den USA und Großbritannien. Nur ein Beispiel: In den USA gab es etwa vor 1914 keine Farbenindustrie. Alle dort genutzten Farben stammten aus Deutschland oder wurden in deutschen Unternehmen vor Ort hergestellt. ${ }^{5}$

Diese Abhängigkeiten und ihre Nutznießer wurden durchaus aufmerksam verfolgt. Eine Politik des Freihandels betrieb allein das Vereinigte Königreich, das sich seine chronisch negative Handelsbilanz mit seinen europäischen Partnern aber wegen der großen Überschüsse, die im Kolonialhandel insbesondere mit Indien erwirtschaftet wurden, mühelos leisten konnte. Alle anderen großen Staaten versahen hingegen ihre nationalen Industrien mit Schutz, die USA und Frankreich recht drastisch, Deutschland eher moderat. Der verbreitete Protektionismus war aber zu keinem Zeitpunkt prohibitiv. Vor dem Ersten Weltkrieg entwickelte sich der Welthandel rascher als die Warenproduktion. Die Verflechtung nahm mithin zu. Dazu trug auch der Goldstandard bei, dem sich nach und nach alle großen Handelsnationen angeschlossen hatten. Wechselkursschwankungen gab es insofern nur sehr begrenzt und auch der Wert von Auslandsinvestitionen unterlag keinem Wechselkursrisiko. ${ }^{6}$ Die Welt vor 1914 funktionierte derart gut und reibungslos, dass sich niemand einen langen Krieg, der den mühselig erreichten Wohlstand gefährden musste, vorstellen konnte (vgl. Torp 2005).

5 Eine gute Geschichte der Weltwirtschaft fehlt im deutschen Sprachraum bis heute, Hinweise bei Fischer 1979. Im englischen Sprachraum ist das anders; vgl. Findlay/O'Rourke 2007, siehe auch Fischer 1973-1984. Der Band zur Geschichte der Weltwirtschaft vor 1914 fehlt hier leider.

6 Zum Goldstandard vgl. Eichengreen 2008. 


\section{IV.}

Doch waren die anfänglichen Hoffnungen auf einen kurzen Krieg nach dessen Ausbruch rasch zerstoben. Der lange Krieg zerstörte das Weltwirtschaftssystem zeitweilig, und seine Folgen machten es sehr viel krisenanfälliger (vgl. Feinstein/Temin/Toniolo 1997). Für Europa wurde die in Versailles entworfene Nachkriegsordnung, die an die Stelle der Pax Britannica der Vorkriegszeit treten sollte, entscheidend. Die Siegermächte befanden sich dabei von Anfang an in einem letztlich unlösbaren Dilemma. Wollte man von Deutschland große Reparationsleistungen und einen Ausgleich für die interalliierten Schulden, so musste das Land wirtschaftlich leistungsfähig sein und die für den Schuldendienst notwendigen Devisen im Außenhandel verdienen können. John Maynard Keynes sah das sehr klar, doch hielten sich die alliierten Regierungen nicht an seine Ratschläge, die von Deutschland große Reparationssummen verlangten, andererseits aber weder ihre Märkte für deutsche Produkte öffneten noch Deutschland überhaupt wirtschaftlich wieder auf die Beine kommen lassen wollten, um seinen politischen und militärischen Wiederaufstieg zu verhindern. Das war nun paradox, die Kuh zugleich melken zu wollen und verhungern zu lassen. ${ }^{7}$ Aus französischer Sicht hatte das eine gewisse Räson, zumal die Amerikaner sich 1919 rasch aus Europa zurückzogen und keine unmittelbare Verantwortung für den europäischen Wiederaufbau und die Stabilisierung des Systems von Versailles übernahmen. Den Vertrag ratifizierten sie erst gar nicht und dem Völkerbund traten sie nicht bei. Überdies zog man die eigenen Schutzzollmauern in bis dato ungekannte Höhen und bestand darauf, dass Großbritannien und Frankreich ihre Rüstungsschulden aus dem Krieg bezahlten. Lediglich kurzfristige Kredite war man zu vergeben bereit, doch selbst deren Bedienung konnte nicht durch Exporte in die USA verdient werden. Die USA waren nach 1918 der mit Abstand stärkste Spieler, doch weigerten sie sich, Verantwortung zu übernehmen; Sie beschränkten sich auf „Dollardiplomatie“ im eigenen Interesse (vgl. Ziebura 1984).

In Europa herrschten Verbitterung und Misstrauen, die die wirtschaftlich desaströsen Kriegsfolgen weiter verstärkten. Ein von Krise zu Krise taumelndes Deutschland konnte weder umfangreiche Reparationen noch irgendeinen anderen Beitrag zum wirtschaftlichen Wiederaufbau in Europa

7 Vgl. hierzu die Beiträge in Boemeke/Feldman/Glaser 1998. 
leisten, im Gegenteil wurde das schwer verschuldete Land zum Krisenfaktor Nr. 1. Großbritannien ächzte unter dem zur Wiederherstellung des Londoner Finanzplatzes wieder aufgenommenen Goldstandard. Frankreich ging es in der zweiten Hälfte der 1920er Jahre zwar wirtschaftlich besser, doch war, von kurzfristigen Hoffnungen abgesehen, die Angst vor einem zunächst wirtschaftlich und dann politisch wiedererstarkenden Deutschland viel zu groß (vgl. Kraus 2013). Deutschland machte für seine Probleme das Versailler System verantwortlich und zerfiel innerlich; in der Weltwirtschaftskrise profitierten hiervon vor allem die Nationalsozialisten. Das Weltwirtschaftssystem war aber bereits zuvor zusammengebrochen, als ausgehend von Österreich und Deutschland 1931 zusätzlich eine Finanzkrise ausbrach, in deren Folge der Goldstandard zerbrach und eine Flucht in den Protektionismus einsetzte: „Beggar-thy-neighbour policy“ hat man das genannt. ${ }^{8}$ Aufrüstung und Krieg setzten hierunter einen fast folgerichtigen Schlussstrich. Der Weltkrieg selbst führte dann allerdings erneut zu einem Integrationsschub; unter deutscher militärischer Besatzung und entsprechendem Zwang entstand eine intensive Rüstungskooperation, die für die betroffenen Länder eine janusköpfige Bedeutung hatte (vgl. Klemann/ Kudryashov 2012). In Deutschland jedenfalls machte sich bereits lange vor Kriegsende eine Europaeuphorie breit, die ein geeintes Europa als Bollwerk gegen amerikanischen Kapitalismus und sowjetischen Bolschewismus beschwor und dabei - Rainer Hank hat jüngst darauf hingewiesen - zahlreiche institutionelle Entwicklungen, die später für die europäische Integration wichtig wurden, bereits gedanklich vorwegnahm (vgl. Hank 2013).

\section{V.}

Die Gründung der europäischen Institutionen nach 1945, insbesondere die Einrichtung der Europäischen Gemeinschaft für Kohle und Stahl, wird gemeinhin der Europaidee und der Klugheit von Schumann und Monnet zugeschrieben sowie der Bereitschaft Konrad Adenauers, die Bundesrepublik nach der Katastrophe des Krieges fest in den Westen einzubinden. Das ist nicht falsch, aber bestenfalls die halbe Wahrheit (vgl. Gehler 2010). Für Frankreich war es nach 1945 alles andere als selbstverständlich, eine wirt-

8 Als Überblick vgl. jetzt Hesse/Köster/Plumpe 2014. 
schaftliche, geschweige denn eine politische Kooperation mit einem wie auch immer gearteten Deutschland einzugehen. Man setzte vielmehr auf dessen Zerschlagung und dauerhafte Niederhaltung bzw. Kontrolle, wofür nach der bedingungslosen Kapitulation des Dritten Reiches nun auch die Voraussetzungen existierten (vgl. Kipping 1996). Am Anfang stand auch keineswegs eine Art gemeinschaftlicher Institutionenbildung, sondern das Ruhrgebiet sollte selbst nach einer Wiederherstellung deutscher Staatlichkeit dauerhaft internationaler Kontrolle unterworfen sein. Dazu diente das 1949 von den USA, Großbritannien, Frankreich und den Beneluxstaaten verabschiedete Ruhrstatut, auf dessen Basis eine internationale Ruhrbehörde zur Kontrolle des Ruhrgebietes eingerichtet wurde. Nach ihrer Gründung trat die Bundesrepublik trotz massiver innenpolitischer Kritik der Ruhrbehörde bei und hatte schließlich drei von 15 Stimmen in deren Rat, doch war nach der massiven Kritik in Deutschland - Schumacher sprach von Adenauer als dem Kanzler der Alliierten; Adenauer verteidigte sich, hätte er nicht dem Petersberger Abkommen über den Abschluss der Demontagen und dem Ruhrstatut zugestimmt, wäre es zu massiven Demontagen deutscher Industrieanlagen gekommen - nicht damit zu rechnen, dass sich die Bundesrepublik auf Dauer mit dieser einseitigen Kontrolle abfinden würde (vgl. Lüders 1988).

Dabei war die Ruhrbehörde bereits ein Zugeständnis insbesondere der USA an Frankreich, das sich nur schwer damit abfinden konnte, dass nicht nur ein neuer westdeutscher Staat gebildet, sondern dieser auch noch in den westeuropäischen Wiederaufbau einbezogen werden sollte. Wie war es dazu gekommen?' Mit Kriegsende fiel Deutschland auch als Wirtschaftsmacht aus. Das Land wurde vollständig besetzt und auch sein Außenhandel strikt kontrolliert. Nach dem Zusammenschluss der britischen und amerikanischen Zone zur Bizone wurde die Joint Export Import Agency (JEIA) gebildet, die den deutschen Außenhandel restriktiv handhabte, vor allen Dingen aber eine Dollarklausel besaß, wonach Exporte in US-Dollar zu bezahlen waren. Die Folge war, dass Deutschland als Wirtschaftspartner für die westeuropäischen Länder vollständig ausfiel, deren wichtigster Handelspartner es trotz aller Turbulenzen aber traditionell gewesen war. Westeuropa musste jetzt durch eigenen Export in die USA erst die Dollars verdienen, mit denen man Güter aus Deutschland oder eben auch direkt aus den USA

9 Vgl. zum Folgenden Buchheim 1990. 
hätte beziehen können. Das war für die kleineren westeuropäischen Staaten kaum akzeptabel. Die Niederlande verharrten folgerichtig bis zur Öffnung der westdeutschen Wirtschaft 1949 in einer schweren Rezession. Für Frankreich schien das leichter hinnehmbar zu sein, doch machte sich auch hier die Dollar-Lücke bald schmerzhaft bemerkbar. Wie nach dem Ersten Weltkrieg wurde sehr schnell klar, dass ohne Westdeutschland an den Wiederaufbau Westeuropas nicht zu denken war, was freilich die für Frankreich unangenehme Folge hatte, dass auch Westdeutschland davon profitieren würde. Diese Lage bedingte die französische Verzögerungshaltung, die schließlich von den USA, die an einem prosperierenden, antikommunistischen Westeuropa ein vitales Interesse hatten, mit dem Marshall-Plan und dem Ruhrstatut aufgeweicht und gebrochen werden konnte. ${ }^{10}$ Dass Frankreich dann von sich aus vorschlug, die Kontrolle der Schwerindustrie zu multilateralisieren, um sie so auf Dauer aufrechterhalten zu können, war zweifellos ein Akt der Klugheit, folgte aber weniger einer wie auch immer gearteten Europaidee, sondern klaren machtpolitischen Kalkül: Wenn wir Deutschland schon nicht klein halten können, müssen wir es dauerhaft kontrollieren (vgl. Kipping 1996). Dieses Motiv schien noch einmal bei der Gründung der Währungsunion 1992 durch, als sich mit der deutschen Wiedervereinigung erneut das Problem einer möglicherweise un- oder nur wenig kontrollierten deutschen Machtentfaltung stellte. Doch war das Konzept der EGKS und später das der Römischen Verträge viel angemessener als die Währungsunion, die von den Partnern sehr viel mehr verlangte und noch verlangt.

\section{VI.}

Denn die EWG/EG als stabiles ökonomisches Bündnis separater Wirtschaftsgebiete und verschiedener Staaten funktionierte auch deshalb so reibungslos, weil es zumindest teilweise auf eine Art ökonomisches PlusSummen-Spiel hin angelegt war, das ansonsten den jeweiligen Partner in seiner je nationalen Eigenart in Ruhe ließ. Da Westdeutschland vor allem an Marktzugang und Zollfreiheit interessiert war, Frankreich vor allem Schutz und Förderung für seine Landwirtschaft suchte, war die EWG nicht

10 Zum Marshall-Plan vgl. Hardach 1994. Ferner Daniel 1982. 
spannungsfrei, ${ }^{11}$ zumal sich ihre Lasten von Anfang an ungleich verteilten, doch war in der Struktur der Sechs klar, dass Frankreich politisch dominierte, Deutschland ökonomisch profitierte und - was ja gar nicht selbstverständlich war - gleichberechtigt einbezogen wurde. Schon de Gaulles Widerstand gegen eine britische Mitgliedschaft zeigt aber, dass es Frankreich stets um mehr oder anderes ging als nur um möglichst große ökonomische Effizienz (vgl. Steininger 1996). Zu einer dauerhaften Gewichtsverschiebung in der EWG kam es aber erst durch den Zerfall des Systems von Bretton Woods, wodurch der US-Dollar seine Funktion als Leitwährung verlor. ${ }^{12} \mathrm{Da}$ in Europa keine floatenden Währungen akzeptabel schienen, entstand zunächst die Währungsschlange, dann das EWS, mit denen die Währung in einer vergleichsweise engen Bandbreite aneinander gekoppelt und die jeweiligen Zentralbanken verpflichtet wurden, diese Bandbreite durch ihre Geld- und Zinspolitik zu verteidigen. Nun wurden die Konflikte härter, zumal die Bundesbank aufgrund des wirtschaftlichen und finanziellen Gewichtes der Bundesrepublik und ihrer ausgeprägten Stabilitätstradition rasch in eine Art Ankerposition rückte, an der sich die anderen Zentralbanken zu orientieren hatten. Dieser Zustand war trotz der Erweiterungserfolge der 1970er und 1980er Jahre insbesondere aus französischer Sicht nur schwer akzeptabel, sodass Überlegungen in der alten Tradition aufkamen, das System durch einen Währungsverbund bzw. eine gemeinsame Währung zu multilateralisieren. Vor dem Fall der Mauer kam es aber nicht mehr zu einem entsprechenden Schritt.

\section{VII.}

Das Experiment der Wirtschafts- und Währungsunion, vor allem die deutsche Bereitschaft, die D-Mark und die starke Stellung der Bundesbank aufzugeben, waren wohl der Preis, der für die Wiedervereinigung zu zahlen war, um ein wirtschaftlich und finanziell noch größeres Deutschland für

11 Interessant etwa die Position Ludwig Erhards, der in der EWG stets eine Art Wettbewerbsverhinderungsinstitut befürchtete; vgl. Hentschel 1998, insbesondere Kapitel 5.

12 Vgl. hierzu Tietmeyer 2005, wo die Entwicklung der Währungsregelungen seit den 1970er Jahren dargestellt wird. 
Frankreich überhaupt akzeptabel zu halten (vgl. Rödder 2009). Ökonomische und finanzielle Überlegungen spielten hingegen eine geringere Rolle; ansonsten hätte bereits das Stöhnen zahlreicher Zentralbanken unter den Vorgaben der Bundesbank bzw. der Zerfall der Währungsschlange und die wiederholten Krisen des EWS warnen müssen. Denn ob nun Bundesbank oder nicht: Eine gemeinsame Währungs- und Zinspolitik musste unter Umständen desaströse Folgen haben, denn ihre Probleme waren gerade nicht eine Folge der Dominanz der Bundesbank, sondern der wirtschaftlichen Heterogenität der europäischen Staaten. Doch das Gegenteil trat ein. ${ }^{13}$ Der Euro wurde durch seinen Effekt, die Zinsen für die große Mehrzahl seiner Mitgliedsstaaten drastisch zu senken, zu einer vermeintlichen Erfolgsgeschichte, ohne dass man begriff, wie sehr die Staaten und ihre Projekte nunmehr genau von diesen niedrigen Zinsen abhängig wurden, da der Verschuldungsgrad von Staaten, Banken, Unternehmen und Privathaushalten unter diesem System bis dato unbekannte Ausmaße erreicht hatte. Im Gegenteil galt die Schuldenwirtschaft lange Zeit als geradezu formidable Möglichkeit der Wohlstandssteigerung, der sich nur Dummköpfe verweigerten. Das Festhalten an einer eher haushälterischen Strategie, das Bestehen auf industriellen Kernen musste sich nun den Vorwurf der Rückwärtsgewandtheit gefallen lassen - die Bundesrepublik, die auch wegen der Folgen der Wiedervereinigung am großen schuldenfinanzierten Boom der Jahre nach der Jahrtausendwende nicht teilnahm, war plötzlich der kranke Mann Europas. Dass die meisten Boomländer in diesen Jahren dramatisch an Wettbewerbsfähigkeit verloren: Wen störte es, solange der Wohlstand durch Kredite spielend zu finanzieren war. Alles schien vereinbar: Unterschiedliche Länder, unterschiedliche Wettbewerbsfähigkeiten, unterschiedliche Inflationsraten etc. pp. Die EU war schließlich derart vernebelt, dass sie sich mit ihrer Lissabon-Strategie ernsthaft vornahm, die Wirtschaftsleistung ihrer Teilregionen rasch auf hohem Niveau anzugleichen und zugleich weltweit wirtschaftlich führend zu sein. 2000 wurde in Lissabon wahrhaftig beschlossen, innerhalb von zehn Jahren „die Union zum wettbewerbsfähigsten und dynamischsten wissensbasierten Wirtschaftsraum in der Welt zu machen“ (Europäisches Parlament 2000).

13 Die Literatur zur Euro-Krise ist so umfassend und vielfältig, dass sie hier nicht zitiert werden kann. Verwiesen sei daher nur auf Sinn 2014. 
Was daraus seit 2008 geworden ist, ist bekannt. Nicht nur mussten zahlreiche europäische Banken mit großen Milliardensummen vor dem Bankrott geschützt werden; nein, ganze Staaten waren und sind allein nicht mehr handlungsfähig. Griechenland hat trotz Schuldenschnitten eine Schuld, die es nicht tragen kann - aber heute glaubt, vernachlässigen zu können, weil die Gläubiger ein Interesse daran haben, das Land zahlungsfähig zu halten. Im Jargon der Bankenkrise ist Griechenland damit eine Art Zombie-Staat geworden - ganz analog zu den Banken, die unter regulären Marktbedingungen von ihren Schuldenlasten längst erdrückt worden wären. Was nach der Finanzkrise zu erkennen war, ist die Rückkehr der unterschiedlichen Zinssätze und deren überaus dramatische Folgen für Staaten, Banken und Unternehmen, die sich auf niedrige Zinsen eingestellt hatten, ja auf diese angewiesen sind. Steigen die Zinsen, drohen harte Sanierungsprogramme, im Grenzfall der Bankrott und der Ausschluss aus der Eurozone. Also müssen die Zinsen niedrig gehalten werden, um jeden Preis, obwohl alle Teilnehmer wissen, dass es gerade die unnatürlich niedrigen Zinsen waren, die das Desaster erst ausgelöst haben. Nein: Die Währungsunion, eingeführt aus dem Geist der multilateralen, gegenseitigen Kontrolle zur Ermöglichung wirtschaftlicher Kooperation, mit dem Westeuropa nach dem Krieg gut gefahren ist, hat den Bogen ökonomisch letztlich überspannt, da sie die Kooperation autonomer Akteure durch ein Zwangssystem der Anpassung ersetzt hat, in dem es nur noch Gewinner und Verlierer gibt, was freilich mit dem bis heute an Nationalstaatlichkeit gebundenen Demokratieprinzip unvereinbar ist. Damit das nicht auseinanderfliegt, muss die EZB die Zinsen niedrig halten.

\section{VIII.}

Die vorstehenden Überlegungen enthalten mehrere Aussagen. Der wesentliche Befund lautet, dass die EWG-/EU-Staaten nicht wegen ihrer Integration wirtschaftlich erfolgreich sind, sondern andersherum die enge wirtschaftliche Integration in Europa ${ }^{14}$ nach 1945 die politische Kooperation

14 Diese ist ganz generell ohnehin nicht das Ergebnis politischer Entscheidungen, sondern ökonomischer Verhältnisse, die den Handel von Nachbarn aus vielerlei, nicht zuletzt Transportkostengründen begünstigen. In der Außenhandelstheorie 
geradezu erzwang, die dann wiederum auch durchaus ökonomisch positive Folgen hatte. Der Mechanismus, dass es gerade Europas ökonomische Integration war, die die politische Zusammenarbeit erzwang, wurde freilich im Laufe der Zeit verdrängt, weil die Wahrnehmung seiner Realität angesichts des schönen Scheins der Kooperation zu verstörend gewirkt hätte! Der Zusammenhang von unvermeidbarer ökonomischer Kooperation und politischer Kontrolle wurde mit der Geschichte von der „großen Idee Europa“ wirksam camoufliert, zumal sie an unterschiedliche Traditionsbestände anknüpfen konnte und insofern keineswegs eine semantische Innovation darstellte. So konnte sich schließlich auch die Vorstellung einer vermeintlich gültigen Reihenfolge verfestigen, politische Integration ziehe ökonomische Prosperität in jedem Fall nach sich. Diese im Grunde ja nicht einmal völlig falsche Überzeugung war dann aber auch das Schmiermittel einer Währungsunion, die nun freilich weit über das hinausging, was bislang an politischer Kooperation und ökonomischer Integration stattgefunden hatte. Deren Kritiker wiesen genau auf diese Punkte hin, wurden aber bestenfalls aus politischen Gründen ernst genommen, während ihre ökonomischen Argumente vom Tisch gewischt wurden. Die Maastricht-Kriterien dienten dann vor allem zur Beruhigung der deutschen Öffentlichkeit. Doch der mit der Währungsunion in Gang gesetzte Mechanismus bekam sehr rasch viel dramatischere Dimensionen, als man sich zunächst auch nur vorstellen wollte. Niedrige Zinsen und leichte Finanzierbarkeit, sich aufblähende Schuldenhaushalte schienen angesichts boomender Wirtschaft hinnehmbar - bis zur Finanzkrise. Seither ist die Party vorbei, und nun zeigt sich, dass mit der Währungsunion nicht einfach ein weiterer Schritt getan wurde, sondern de facto eine ganz neue Stufe der Integration ausgelöst wurde, die man - in kleinerem Maßstab - schon 1990 in der DDR beobachten konnte. Mit der einheitlichen Währung und dem einheitlichen Binnenmarkt entstand (in Europa allerdings bei Fortbestand der Nationalstaaten) ein einheitliches Wirtschaftsgebiet, das sich nun allein nach den jeweiligen Kostenstrukturen und Angebot und Nachfrage regional neu gruppiert. Diese regionale Gruppierung hat mit nationalen Grenzen, die gleichwohl immer noch über die Legalität und Legitimität politischen Handelns entscheiden, nichts mehr zu

wird daher auch von „Gravität“ gesprochen, deren Vorteile Politik nicht schaffen, wie Europa in der ersten Hälfte des 20. Jahrhunderts gezeigt hat, aber massiv stören kann. Vgl. Krugman/Obstfeld/Melitz 2012: 39-44. 
tun. Im Gegenteil, die jeweiligen Staaten geraten jetzt mit ihren nationalen institutionellen Traditionen und Verhältnissen massiv unter Druck, sollten diese sich nicht am Markt bewähren. Politische Entscheidungen und Marktentwicklungen treten in unmittelbare Konkurrenz, wobei keineswegs die demokratische Mehrheitsentscheidung die Oberhand behält. Und es sind die Staaten, in denen sich ökonomisch erfolgreiche Regionen finden, auch nur vorderhand glücklich, denn sie müssen in Form von Transferleistungen das jetzt für Europa insgesamt leisten, was - um im Vergleich zu bleiben die Bundesrepublik bereits für ihre neuen Länder leistete und noch leistet. Für die deutsche Exportwirtschaft, die sich schon seit den 1880er Jahren über die Weltmärkte und die dortigen Konkurrenzverhältnisse definierte, ist das nur begrenzt eine Bedrohung, eher eine große Chance - ob das für Staat und Gesellschaft ebenso zutrifft, sei dahingestellt. Noch ist der Prozess nicht abgeschlossen. In wirtschaftshistorischer Sicht ist aus dem alles in allem sinnvollen Prozess der ökonomischen Zusammenarbeit souveräner Staaten mit dem Übergang zur Währungsunion und zum einheitlichen Markt ein Risikospiel geworden, dessen Ausgang offen ist, denn die Niedrigzinspolitik der EZB ist vielleicht schlau für heute, aber nicht klug für immer.

\section{LITERATUR}

Boemeke, Manfred/Feldman, Gerald D./Glaser, Elisabeth (Hg.) (1998): The Treaty of Versailles. A Reassessment after 75 Years, Cambridge.

Bofinger, Peter (2012): Zurück zur D-Mark? Deutschland braucht den Euro, München.

Broadberry, Stephen/O'Rourke, Kevin H. (Hg.) (2010): The Cambridge Economic History of Modern Europe. Volume 2: 1870 to the Present, Cambridge.

Buchheim, Christoph (1990): Die Wiedereingliederung Westdeutschlands in die Weltwirtschaft 1945-1958, München.

Crafts, Nicholas/Toniolo, Gianni: Aggregate Growth, 1950-2005, in: Broadberry/O'Rourke, The Cambridge Economic History of Modern Europe. Volume 2: 1870 to the Present, S. 296-332.

Daniel, Ute (1982): Dollardiplomatie in Europa. Marshallplan, Kalter Krieg und Außenwirtschaftspolitik 1945-52, Düsseldorf. 
Eichengreen, Barry ( $\left.{ }^{2} 2008\right)$ : Globalizing Capital. A History of the International Monetary System, Princeton.

Eichengreen, Barry/Boltho, Andrea (2010): The Economic Impact of European Integration, in: Broadberry/O'Rourke, The Cambridge Economic History of Modern Europe. Volume 2: 1870 to the Present, S. 267-295.

Feinstein, Charles H./Temin, Peter/Toniolo, Gianni (1997): The European Economy between the Wars, Oxford.

Findlay, Ronald/O'Rourke, Kevin H. (2007): Power and Plenty. Trade, Ware, and the World Economy in the Second Millenium, Princeton.

Fischer, Wolfram (Hg.) (1973-1984): Geschichte der Weltwirtschaft im 20. Jahrhundert. 5 Bände, München.

Fischer, Wolfram (1979): Die Weltwirtschaft im 20. Jahrhundert, Göttingen.

Europäisches Parlament (2000): http://www.europarl.europa.eu/summits/ lis1_de.htm vom 23./24. März 2000. [Letzter Zugriff: 18.02.2015.]

Gehler, Michael ( $\left.{ }^{2} 2010\right)$ : Europa. Ideen - Institutionen - Vereinigung, München.

Hank, Rainer (2013): Wir Europäer. Nach der verlorenen Unschuld, in: Merkur. Deutsche Zeitschrift für Europäisches Denken 67, S. 872-885.

Hardach, Gerd (1994): Der Marshall-Plan. Auslandshilfe und Wiederaufbau in Westdeutschland 1948-1952, München.

Hentschel, Volker (1998): Ludwig Erhard. Ein Politikerleben, Berlin.

Hesse, Jan-Otmar/Köster, Roman/Plumpe, Werner (2014): Die große Depression. Die Weltwirtschaftskrise 1929-1939, Frankfurt a.M..

Kipping, Matthias (1996): Zwischen Kartellen und Konkurrenz. Der Schuman-Plan und die Ursprünge der europäischen Einigung 1944-1952, Berlin.

Klemann, Hein/Kudryashov, Sergei (2012): Occupied Economies. An Economic History of Nazi-occupied Europe, 1939-1945, London/New York.

Kraus, Hans-Christof (2013): Versailles und die Folgen. Außenpolitik zwischen Revisionismus und Verständigung 1919-1933 (= Deutsche Geschichte im 20. Jahrhundert, Band 4), Berlin.

Krugman, Paul/Obstfeld, Maurice/Melitz, Marc ( $\left.{ }^{9} 2012\right)$ : Internationale Wirtschaft. Theorie und Politik der Außenwirtschaft, München.

Lindlar, Ludger (1997): Das mißverstandene Wirtschaftswunder. Westdeutschland und die westeuropäische Nachkriegsprosperität, Tübingen. 
Loth, Wilfried (2014): Europas Einigung. Eine unvollendete Geschichte, Frankfurt a.M.

Lüders, Carsten (1988): Das Ruhrkontrollsystem. Entstehung und Entwicklung im Rahmen der Westintegration Westdeutschlands 1947-1953, Frankfurt a.M..

Maddison, Angus (2007): Contours of the World Economy, 1-2030 AD. Essays in Macro-Economic History, Oxford.

Mayer, Thomas (2014): Die Griechen sind entspannter. Die Geldgeber drängen nicht mehr so, in: Frankfurter Allgemeine Sonntagszeitung, 04.05.2014, S. 29.

Mittag, Jürgen (2008): Kleine Geschichte der europäischen Integration. Von der Europaidee bis zur Gegenwart, Münster.

Plumpe, Werner/Steiner, André (2008): Dimensionen wirtschaftlicher Integrationsprozesse in West- und Osteuropa nach dem Zweiten Weltkrieg, in: Jahrbuch für Wirtschaftsgeschichte/Economic History Yearbook 2, S. 21-38.

Rödder, Andreas (2009): Deutschland einig Vaterland. Die Geschichte der Wiedervereinigung, München.

Sinn, Hans-Werner (2014): Gefangen im Euro, München.

Steininger, Rolf (1996): Großbritannien und de Gaulle. Das Scheitern des britischen EWG-Beitritts im Januar 1963, in: Vierteljahreshefte für Zeitgeschichte 44, S. 87-118.

Streeck, Wolfgang (2013): Gekaufte Zeit. Die vertagte Krise des demokratischen Kapitalismus. Frankfurter Adorno-Vorlesungen 2012, Berlin.

Tietmeyer, Helmut (2005): Herausforderung Euro. Wie es zum Euro kam und was er für Deutschlands Zukunft bedeutet, München.

Torp, Cornelius (2005): Die Herausforderung der Globalisierung. Wirtschaft und Politik in Deutschland 1860-1914, Göttingen.

Ziebura, Gilbert (1984): Weltwirtschaft und Weltpolitik 1922/24-1931. Zwischen Rekonstruktion und Zusammenbruch, Frankfurt a.M. 



\section{Euro-Krise und internationale Finanzkrise}

Die Finanzialisierung der Wirtschaft

als politische Herausforderung für Europa ${ }^{1}$

\section{CHRISTOPH DEUTSCHMANN}

\section{Die Spaltung der europäischen GeselLschaFt}

Die Finanzkrise ist zur Zeit aus den Schlagzeilen verschwunden. Europa und die Weltwirtschaft, so heißt es, seien ,über den Berg“. Irland, Spanien und Portugal sind an die Kapitalmärkte zurückgekehrt. Es gibt zwar neue Probleme in einer Reihe von Schwellenländern (Brasilien, Türkei, Südafrika, Indien, Russland); dazu kommen die politisch durch den UkraineKonflikt verursachten Irritationen. Aber das Management der Finanzkrise selbst wird, auch in Europa, als insgesamt erfolgreich bewertet. Die Wachstumsprognosen sind wieder positiv, sogar in den südeuropäischen Krisenländern wird wieder ein leichtes Wirtschaftswachstum (einige Zehntel hinter dem Komma) festgestellt.

Man sollte sich durch solche Meinungen, deren Zweckoptimismus nicht zu überhören ist, nicht zu sehr beeindrucken lassen. Auch wenn die Rezession überwunden scheint und die Situation sich speziell in Deutschland günstig darstellt, ist das wirtschaftliche Wachstum in Europa, Nordamerika und Japan noch immer schwach. Die Staatsverschuldung ist in vielen Län-

1 Überarbeitete und aktualisierte Version eines Aufsatzes, der zuerst in: Sozialer Fortschritt 63.1-2 (2014), S. 2-7 erschienen ist. 
dern auf nie gekannte Höhen geklettert. In der Euro-Zone betrug sie 2013 92,6 Prozent des Bruttoinlandsprodukts; gleichzeitig haben die Bruttokapitalbildung und die Wirtschaftsleistung das Vorkrisenniveau noch nicht wieder erreicht. Die Arbeitslosigkeit ist, vor allem in den süd- und westeuropäischen Krisenländern, bedrückend hoch geblieben. Indizien für die Fortdauer der Krise sind vor allem die Anleihekäufe und die anhaltend ultralockere Geldpolitik der Notenbanken. Die Realzinsen sind negativ, d.h. konventionelle Geldanlagen auf Spar- oder Geldmarktkonten oder in Anleihen verlieren an Wert. Die finanziellen Rettungsmaßnahmen der Notenbanken und der Staaten nach 2008 haben zwar einen Kollaps des globalen Finanzsystems verhindert. Die Folge der Rettungsmaßnahmen war aber, dass die Banken und Staaten noch heute auf einem Berg von faktisch uneinlösbaren Vermögensforderungen sitzen. Ein neues starkes Wachstum der Realwirtschaft, das aus der Krise herausführen könnte, ist zumindest in den entwickelten Ländern nicht in Sicht.

Die Diskussion darüber, wie es zu dieser Krise kommen konnte, bleibt daher unvermindert aktuell. Es haben zwar in den letzten Jahren Dutzende von Konferenzen, Symposien, Vorträgen, Talkshows zum Thema stattgefunden. Trotzdem hat man nicht das Gefühl, dass die vielen, oft heftig geführten Debatten nennenswert zur Klärung der zentralen Fragen beigetragen hätten, im Gegenteil. Das hängt damit zusammen, dass die Diskussion - vor allem in Europa - auf die staatliche und institutionelle Ebene fixiert ist, auf ,Gläubiger'länder hier, ,Schuldner'länder da. Das trägt auch zum Wiederaufleben innereuropäischer Nationalismen bei. Die Expertenkontroversen um das Für und Wider der europäischen Gemeinschaftswährung oder um den ,richtigen“ Weg zur Euro-Rettung haben die in der Krise zu Tage getretenen sozialen Verwerfungen in ganz Europa weitgehend aus dem Blick verschwinden lassen. Wirtschaftlich ist Europa heute dank des gemeinsamen Binnenmarktes stärker integriert denn je zuvor. Zugleich aber ist die europäische Gesellschaft (vor allem im Süden und Westen des Kontinents) so tief gespalten wie nie. Um ein realistisches Bild der Krise zu gewinnen, müsste der Blick viel stärker auf die sich quer durch Europa ziehenden sozialen Polarisierungen und Konflikte gerichtet werden.

Im Folgenden werde ich die These entwickeln und begründen, dass die Euro-Krise in erster Linie gerade nicht auf die vieldiskutierten (und nicht zu leugnenden) Widersprüche in der institutionellen Konstruktion der Gemeinschaftswährung zurückzuführen ist. Sie ist vielmehr eine Folgewir- 
kung der internationalen Finanzkrise, die ihrerseits vor allem auf die exzessiv angewachsenen Ungleichheiten in der Verteilung der Vermögen und Einkommen, in Europa wie anderswo, zurückgeht. Wer nach Auswegen aus der Krise sucht, muss hier ansetzen und nach Wegen für einen (wenigstens) europaweit koordinierten Abbau der völlig überbewerteten Vermögensforderungen suchen.

\section{NARRATIVE DER KRISENERKLÄRUNG}

Auf den ersten Blick stellt die Überschuldung der Staaten und der Banken das Hauptproblem der Krise dar. Nur in acht Staaten der EU-27 lag der Schuldenstand des Staates im Jahr 2013 noch unter der in den MaastrichtVerträgen festgelegten Grenze von 60 Prozent des Bruttoinlandsprodukts. In den anderen Ländern lag er zum Teil weit darüber, in Frankreich z.B. bei 96,6 Prozent, in Italien bei 135,6 Prozent; Spitzenreiter war Griechenland mit rund 174,1 Prozent. Auch Deutschland verfehlte mit einem Schuldenstand von 77,3 Prozent den Maastricht-Grenzwert deutlich. Die hohen Staatsschulden beschneiden die staatlichen Handlungsspielräume und wirken zusammen mit der noch viel höheren Verschuldung der Banken lähmend auf die Konjunktur. Je mehr der Schuldenabbau zur obersten Priorität für Staaten, Haushalte und Unternehmen wird, desto stärker droht die Wirtschaft in eine Abwärtsspirale zu geraten. Zwar bedeutet die Höhe der Staatsverschuldung nicht schon automatisch ein Problem für die Refinanzierung. Deutschland z.B. hat eine nur wenig geringere Gesamtverschuldung als Spanien, muss aber praktisch keine Zinsen an den Kapitalmärkten bezahlen, während von Spanien zeitweise 5 oder 6 Prozent gefordert wurden. Der für die Höhe der Zinsen entscheidende Faktor sind die Ratings der Finanzmarktagenturen, die nach wenig durchsichtigen Kriterien erfolgen. Die Höhe der Staatsverschuldung ist dabei nur ein Faktor unter anderen. Die stark verschuldeten USA und auch Japan mit einer Schuldenquote von über 200 Prozent z.B. erhalten zwar keine Spitzenbewertungen mehr, aber noch immer gute Noten. Es trifft aber zu, dass die wachsende Staatsverschuldung die Regierungen erpressbar gegen den Druck der Kapitalmärkte gemacht hat. Das gilt insbesondere für die Euro-Länder, deren Regierungen das Problem nicht einfach durch Geldschöpfung der eigenen Zentralbank lösen können. 
Wie ist es zu der heutigen hohen Verschuldung der Euro-Staaten gekommen? An diesem Punkt gehen die Meinungen weit auseinander. Eine verbreitete, unter Ökonomen und Journalisten beliebte Erzählung lässt sich so zusammenfassen: Erstens: Demokratien können mit Geld nicht umgehen. Die Regierungen wollen sich ihrer Klientel erkenntlich zeigen, indem sie Geschenke und sogenannte „Wohltaten“ an ihre Wähler verteilen. Gleichzeitig scheuen sie sich, die Wähler durch höhere Steuern zu belasten und neigen daher zum Schuldenmachen. Zweitens: In einem System nationaler Währungen und flexibler Wechselkurse gibt es einen eingebauten Korrekturmechanismus gegen ausufernde staatliche wie private Schulden: Exzessive staatliche Haushaltsdefizite führen genau wie Defizite der Leistungsbilanz zu einer Abwertung der Währung. Die Folge ist eine Erhöhung der Kapitalmarktzinsen sowie eine Erhöhung der Importpreise, die die Beteiligten zur Disziplin zwingt und auf den Pfad der Tugend zurückführt. Drittens: Genau dieser Korrekturmechanismus ist durch die Einführung der gemeinsamen Währung im Euroraum beseitigt worden. Unterschiede im nationalen Haushaltsgebaren und auch in der Wettbewerbsstärke der nationalen Volkswirtschaften können auf der Ebene der Devisenmärkte nicht mehr korrigiert werden. Die Folge sind ausufernde Leistungsbilanzdefizite und staatliche Haushaltsdefizite der wirtschaftlich schwächeren Länder. Die politische Folgerung aus diesem Narrativ lautet: „Wir“, gemeint ist die Regierung des momentan wirtschaftlich starken Deutschland, haben keinen Grund, für die Versäumnisse der Anderen zu haften oder zu zahlen, und die europäischen Verträge lassen das auch nicht zu. Die „,no-bail-out“-Klausel der Maastricht-Verträge sollte strikt angewandt werden. Letztlich müssen wir uns mit dem Gedanken vertraut machen, dass die Einführung des Euro ein politisch vielleicht verständlicher, aber ökonomisch verhängnisvoller Irrweg war, der lieber früher als später wieder rückgängig gemacht werden sollte.

Die Zunft der Ökonomen hat in den letzten Jahren viel Kritik aufgrund ihres Versagens bei der Prognose und Diagnose der internationalen Finanzkrise einstecken müssen. Nun endlich scheinen wenigstens einige von ihnen mit ihren Prognosen einmal richtig zu liegen, und man kann ihre Genugtuung darüber verstehen. Haben sie nicht schon immer vor der Einführung des Euro gewarnt? Und wären wir heute nicht in einer besseren Lage, wenn wir schon damals mehr auf die Stimme der Wissenschaft gehört hätten? Bei allem Verständnis für die Seelenlage unserer eurokritischen ökonomischen 
Kollegen: Ich fürchte, nein. Bei näherem Hinsehen spricht wenig dafür, dass es Europa heute besser ginge, wenn wir damals auf die Kollegen Starbatty, Hankel und ihre Mitstreiter gegen das Euro-Projekt gehört und den Euro nicht eingeführt hätten. Noch weniger ist die Rückkehr zu nationalen (oder gespaltenen) Währungen heute eine realistische Option, um aus der Krise herauszukommen. Das ist näher zu begründen.

\section{Die KLUfT ZWISCHEN ÖKONOMISCHER UND POLITISCHER INTEGRATION}

Zunächst muss daran erinnert werden, dass der Beschluss von damals 12 europäischen Ländern zur Einführung einer gemeinsamen Währung (der Name Euro wurde erst später eingeführt) im Vertrag von Maastricht im Jahr 1992 nicht nur auf ökonomische Beweggründe zurückging, sondern im Kern eine politische Entscheidung war. Sie hing zusammen mit der durch die deutsche Wiedervereinigung und den Fall des Eisernen Vorhangs geschaffenen neuen Situation in Europa. Schon vor der Wiedervereinigung war die DM aufgrund der wirtschaftlichen Stärke Westdeutschlands die heimliche Leitwährung Europas gewesen. Die anderen Länder standen in ihrer Geld- und Wirtschaftspolitik faktisch unter dem Diktat der Bundesbank, das schon damals oft als drückend empfunden wurde. Mit der Vereinigung drohte diese deutsche Dominanz für die Nachbarn, vor allem für Frankreich, vollends unerträglich zu werden. Der Preis für die Zustimmung der Nachbarn zur Wiedervereinigung war die Europäisierung der D-Mark in Form der gemeinsamen Währung, die den Zentralbanken der anderen Länder wenigstens formal die Möglichkeit der Mitbestimmung über die europäische Geld- und Währungspolitik geben sollte. Das war ein Experiment, über dessen ökonomische Unausgegorenheiten schon in den Neunziger Jahren heftig gestritten wurde. Aber die Politiker haben sich damals mit guten Gründen dafür entschieden, die politische Gestaltung Europas nicht allein von der Logik des ,ökonomischen Sachverstandes“ abhängig zu machen; allerdings wurde das wohl nicht deutlich genug ausgesprochen. Aufgrund des politischen Kompromisscharakters der Euro-Konstruktion war im Grunde von vorn herein klar, dass der Euro nicht so „hart“ wie die DM sein konnte, und auch die Europäische Zentralbank nicht einfach eine Kopie der Deutschen Bundesbank. Nur die deutsche Politik hielt bis vor kur- 
zem an dieser Lebenslüge fest. Unter dem Druck der aktuellen Krise ist die schon immer latente Politisierung der europäischen Währung manifest geworden; insbesondere mit der Einrichtung des ESM und der gegen das Votum der Bundesbank getroffenen Entscheidung der EZB, Staatsanleihen hochverschuldeter Euro-Länder auf dem Sekundärmarkt zu kaufen.

Aber der Euro war nicht nur ein politisches Projekt. Er hat vielmehr maßgeblich dazu beigetragen, dass das Vorhaben des europäischen Binnenmarktes zu einem Erfolg wurde. Auf wirtschaftlicher Ebene ist Europa in den letzten fünfzehn Jahren eng zusammengewachsen. So ist die Exportquote Deutschlands zwischen 1991 und 2013 von 25,7 auf 50,6 Prozent gestiegen, und 57, 5 Prozent der deutschen Exporte gingen (bei nur leicht abnehmender Tendenz) 2013 in die Länder der EU-27 (IW 2014: Tabellen 2.4., 4.2.). Zeitweise war der Trend zur europainternen Integration der Märkte sogar noch stärker als der zur Globalisierung, wie Neil Fligstein (2010) gezeigt hat. Die Integration erstreckt sich nicht nur auf die Produktund Dienstleistungsmärkte, sondern auch auf die Kapitalmärkte und zunehmend auch die Arbeitsmärkte. Auch die Produktionslogistik ist europäisiert worden; nicht nur große, sondern auch mittelständische Unternehmen haben ihre Fertigungsketten grenzüberschreitend organisiert: Teil A wird in Frankreich gefertigt, Teil B in Spanien, und zusammengebaut wird das Ganze vielleicht in der Slowakei. Nach einer Studie des Ifo-Instituts ließ sich im Verarbeitenden Gewerbe Deutschlands beobachten, dass inländisches Outsourcing in den Jahren 1995 bis 2008 immer stärker vom Offshoring, also dem Zukauf von Vorleistungen aus dem Ausland, verdrängt wurde. So stieg der Offshoring-Anteil am Produktionswert in diesem Zeitraum von 13 auf 23 Prozent an (Aichele et al. 2013: 18). Ob ein Produkt ,,made in Germany" ist, oder griechisch, französisch, italienisch usw. lässt sich oft gar nicht mehr so leicht feststellen. Man kann nicht behaupten, dass das immer sehr sinnvoll war. Es gibt zweifellos auch absurde Formen dieser Arbeitsteilung (z.B. wenn Nordseekrabben in Malta oder Portugal gepult und dann nach Deutschland zurückgeschickt werden). Es sollen hier keine Detailberechnungen darüber angestellt werden, wie groß die Ökonomisierungs- und Wohlfahrtsgewinne genau waren, die der größere europäische Binnenmarkt den Unternehmen und auch der Bevölkerung eingebracht hat. Aber kaum jemand zweifelt heute mehr daran, dass es diese Gewinne gegeben hat. Die gemeinsame Währung hat diese Entwicklung gefördert. Schon vor der Einführung des Euro hat man deshalb versucht, die gegenseitigen 
Schwankungen der europäischen Währungen durch Festlegung von Bandbreiten (die sog. „Europäische Währungsschlange“) unter Kontrolle zu halten. Das lud bereits damals die Finanzmärkte zu spekulativen Attacken ein, und es gelang daher mehr schlecht als recht. Der frühere Finanzminister Theo Waigel hat mit Recht daran erinnert, dass das europäische Währungssystem schon vor der Euro-Einführung immer wieder krisengeschüttelt war, und er hält die heutige Krise für keineswegs die schlimmste. Wer das bezweifelt, sollte das Buch von Martin und Schumann über die „Globalisierungsfalle“ (1996) wieder zur Hand nehmen.

Selbst wenn die wahrscheinlich katastrophalen unmittelbaren Konsequenzen einer Abschaffung des Euro halbwegs beherrschbar wären: Es würde nur dieser frühere Krisenzustand wieder hergestellt, von dem außer den Hedgefonds und der Finanzindustrie, die nicht zufällig immer gegen den Euro opponiert haben, niemand profitieren würde. Die Finanzmärkte würden erst recht Ping-Pong mit den europäischen Währungen spielen. Aufgrund der stark gestiegenen Masse des vagabundierenden Kapitals würden die spekulativen Bewegungen noch heftiger ausfallen als früher und die Zentralbanken zu massiven Interventionen zwingen. Die deutsche Bundesbank würde in eine ähnliche Lage geraten wie heute die schweizerische und müsste unentwegt Geld schöpfen, um einen Anstieg der DM ins Uferlose abzuwehren. Das würde kaum geringere Inflationsgefahren heraufbeschwören als die heutige Politik der EZB. Umgekehrt müssten auch die Defizitländer harte Sparmaßnahmen durchsetzen, um die Kapitalflucht zu stoppen und einen Fall ihrer Währung ins Bodenlose zu verhindern. Die Unternehmen wären mit kaum kalkulierbaren Wechselkursrisiken konfrontiert, die sie zu teuren Absicherungsgeschäften zwingen würden. Das wiederum würde zu einem Rückbau des europäischen Binnenmarktes, zu einem Wiederaufleben der innereuropäischen Protektionismen und einer verlustreichen Re-Nationalisierung der Volkswirtschaften führen.

Die Vorstellung von einer angeblich problemlosen Regulierung von Differenzen der Wettbewerbsfähigkeit durch Auf- und Abwertungen, wie sie auch Wolfgang Streeck (2013: 246) vertritt, ist realitätsfern. Sie vernachlässigt die fortgeschrittene Integration der Güter- und Kapitalmärkte in Europa und die stark gestiegene Masse und Volatilität der transnationalen Kapitalströme. Die nationalen Zentralbanken stehen unter ständiger Beobachtung durch die Kapitalmärkte und können über Auf- oder Abwertungen keineswegs „frei“ entscheiden. Gerade im internationalen Wettbewerb zu- 
rückfallende Länder bekommen den Druck der Märkte zu spüren. Wenn ein Land abwertet, mag es zwar Vorteile in Gestalt preisgünstigerer Exporte haben. Die gleichzeitige Erhöhung der Importpreise verteuert jedoch aus dem Ausland bezogene, kurzfristig nicht substituierbare Vorleistungen, darunter auch lebenswichtige Importe (z.B. Energie, Medikamente, Technologie). Sie heizt die interne Inflation an und macht so die auf den Exportmärkten gewonnenen Vorteile wieder zunichte. Außerdem wirkt sich die Abwertung nicht nur auf die Produkt- und Dienstleistungsmärkte, sondern auch auf die Kapitalmärkte aus. Das Kapital wandert ab und lässt sich, wenn überhaupt, nur mit drastischen Zinserhöhungen wieder anlocken. Wer die Rückkehr zu separaten Währungen fordert, sollte das deshalb gleich mit der Forderung nach Wiedereinführung von Kapitalverkehrskontrollen verbinden und damit den europäischen Binnenmarkt insgesamt aufkündigen. Die Folgen einer Abwertung für die öffentlichen Haushalte und die Privatwirtschaft wären jedenfalls kaum weniger schmerzhaft als die der heutigen Sparauflagen der „Troika“ in den Krisenländern. Alle diese Überlegungen sprechen dagegen, dass die Schwierigkeiten heute geringer wären, wäre der Euro nicht eingeführt worden. Und noch illusionärer wäre es, sich von einer Abschaffung des Euro und einer Re-Nationalisierung der Währungen eine Lösung der Probleme zu erhoffen. Im Gegenteil, die Krise würde wahrscheinlich gänzlich außer Kontrolle geraten, zumal die Schulden der Defizitländer wohl größtenteils abgeschrieben werden müssten.

Es war gerade der Erfolg des Binnenmarktprojekts, der die Kluft zwischen den Integrationsniveaus von Wirtschaft und Politik verschärft hat. Während die Wirtschaft längst auf europäischer und zum Teil auf globaler Ebene integriert und vernetzt ist, hat die Politik nicht gleichgezogen und operiert selbst in Europa noch immer in einem überwiegend nationalstaatlichen Horizont. Dieses Hinterherhinken der Politik bildet den Kern der Probleme, und in ihm ist auch die viel beschworene „Krise der Demokratie“, d.h. die Abhängigkeit der Regierungen von den europäisch und global mobilen Wirtschafts- und Finanzakteuren begründet. Transnational bewegliche Akteure haben immer auch andere Optionen; sie können dort investieren und Steuern zahlen, wo es für sie am günstigsten ist und die Standortkonkurrenz zwischen den nationalstaatlichen Regimes ausnutzen. Das war im Prinzip schon früher so; schon in der Mitte der neunziger Jahre hat der damalige Bundesbankpräsident Tietmeyer die Finanzmärkte als vierte Gewalt im Staat bezeichnet, von der die Politik in umfassender Weise abhängig sei; 
nur die Politiker hätten es noch nicht gemerkt. Heute tritt diese Abhängigkeit richtig hervor, und nun endlich scheinen es auch die Politiker (und manche Wissenschaftler) zu merken.

Das Nebeneinander von europäischer bzw. globaler Wirtschaft und nationaler Politik lässt Interessenkonflikte gerade auch bei normalen Bankkunden entstehen, über deren Komplexität sie sich selbst oft gar nicht im Klaren sind, und die quer zu den nationalstaatlich fixierten Wahrnehmungsschemata der Politiker und Experten stehen. Diese Konflikte können sich sogar durch ein und dieselbe Person hindurch ziehen; ich will das an einem fiktiven Beispiel erläutern. Stellen wir uns einen Wähler der eurokritischen „Alternative für Deutschland“ vor, der die Einrichtung des ESM und die ESM-Interventionen z.B. zugunsten Spaniens kritisiert. Derselbe Eurokritiker hat aber vielleicht nur vergessen, dass er vor 20 Jahren eine Kapitallebensversicherung abgeschlossen hat. Das Versicherungsunternehmen wiederum hat sein Geld in spanischen Bankanleihen anlegt. Diese Banken hatten damals einen hervorragenden Ausblick, weil sie in dem aufblühenden Immobiliengeschäft engagiert waren. Nun müssen sie gerettet werden. So wohnen zwei Seelen in der Brust unseres Eurokritikers: Als Staatsbürger ist er gegen Finanzhilfen für Spanien, als Versicherter muss er der spanischen Regierung dankbar sein und Finanzhilfen für sie unterstützen. Solange das Integrationsgefälle zwischen Wirtschaft und Politik in Europa fortbesteht, wird es unvermeidlich zur Entstehung solcher widersprüchlicher Interessenlagen kommen. Es gibt nur zwei Auswege: Entweder die Wirtschaft müsste wieder auf das Niveau der Politik gebracht, also re-nationalisiert werden, mit der Re-Nationalisierung der Währung als erstem Schritt. Europa würde sich damit auf den Weg zurück in die 1930er Jahre machen. Das wird niemand im Ernst wollen können. Also bleibt - hier ist Habermas, Offe und Altvater zuzustimmen - nur der zweite Weg, nämlich dass die Politik der Wirtschaft nachzieht und sich zumindest auf europäischer Ebene stärker integriert, so mühevoll das gegenwärtig auch erscheinen mag.

\section{UND DIE INTERNATIONALE FINANZKRISE?}

Kritikwürdig ist aber vor allem die übliche Erklärung der exzessiven Staatsverschuldung aus den angeblich eingebauten Rationalitätenfallen demokratischer Politik. Es mag zwar sein, dass demokratische Regierungen 
manchmal der Versuchung unterliegen, sozialpolitisch sinnvolle Umverteilungsmaßnahmen zu überziehen. Richtig ist auch: Wenn ein Staat so wenig wie in Griechenland (z.T. auch Italien) fähig oder bereit ist, seinen Steuergesetzen auch gegenüber den Vermögenden Geltung zu verschaffen, gleichzeitig sich aber umfangreiche öffentliche Ausgaben leistet, dann kann das auf die Dauer nicht gut gehen, unter welchem Währungsregime auch immer. Aber die heutige Überschuldung der Euro-Staaten en bloc aus der Rationalitätenfallen-Theorie zu erklären, läuft auf eine Halbwahrheit hinaus, die durch beständige Wiederholung nicht wahrer wird. Die spanische und die irische Regierung waren Musterbeispiele solider Haushaltsführung, bevor sie ihre Banken retten mussten und tief in die roten Zahlen gerieten. Auch in Deutschland ist die Gesamtverschuldung der Gebietskörperschaften aufgrund der Ausgaben zur Bankenrettung (IKB, Hypo Real Estate, West LB usw.) um rund 8 Prozentpunkte angestiegen, und diese Bankenrettung war nicht die erste. Das Land Berlin verdankt seine hohe Verschuldung vor allem den Kosten für die Rettung der Berliner Landesbank in den neunziger Jahren. Last, but not least muss daran erinnert werden, dass die Verschuldung nicht aus dem Ausgabenverhalten allein erklärt werden kann, sondern immer das Resultat zweier Faktoren ist: Ausgaben und Einnahmen. Die staatliche Steuerbasis aber ist während der letzten zwanzig Jahre nicht nur in Griechenland, sondern in vielen OECD-Ländern durch zielstrebige Lobbyarbeit der Finanzindustrie und einen internationalen Steuersenkungswettlauf bei den Kapital- und Unternehmenssteuern beständig unterminiert worden. Dieser Wettlauf wurde durch den neoliberalen mainstream in der veröffentlichten Meinung begrüßt und gefeiert. In den größten 20 OECD-Ländern sank der durchschnittliche Satz der Unternehmensbesteuerung zwischen 1985 und 2009 von 44 auf 29 Prozent, der Spitzensatz der Einkommenssteuer sank von durchschnittlich 65 auf 46 Prozent (Genschel/Schwarz 2011: 356). Darüber hinaus wurden die staatlichen Haushalte durch die jahrzehntelang augenzwinkernd tolerierte Steuerhinterziehung der Reichen, durch undurchschaubare Steuernachlässe und die Steuervermeidungspolitik transnationaler Konzerne in die Schuldenfalle getrieben. Die Regierungen mussten öffentliches Vermögen privatisieren und immer mehr Geld an den Kapitalmärkten aufnehmen. Wiederum profitierten die Investoren in Form eines stetig wachsenden Stroms von Zinszahlungen aus Steuergeldern (Streeck 2013: 79f.). 
Die Argumente der mainstream-Ökonomen folgen dem Glaubenssatz: Marktversagen kann es nicht geben, oder: der Markt hat immer recht. Also muss nach anderen Krisenerklärungen gesucht werden, und dafür bietet sich der klassische Prügelknabe „Staat“ allemal an. Vor dem offensichtlichen Versagen der Selbstregulierungskräfte der Finanzmärkte verschließt man fest die Augen. In Wirklichkeit pfeifen es die Spatzen von den Dächern, dass die Überschuldung der Staaten vor allem eine Hinterlassenschaft der internationalen Banken- und Finanzkrise ist. Diese Krise war nicht nur ein auf individuelles Fehlverhalten der Bankvorstände und der staatlichen Regulierungsinstanzen zurückzuführender „Betriebsunfall“. Sie war vielmehr der Kulminationspunkt einer sich über Jahrzehnte hinweg aufbauenden Strukturveränderung der entwickelten westlichen Volkswirtschaften, für deren Bezeichnung sich in der politisch-ökonomischen Literatur der Begriff „Finanzialisierung“ eingebürgert hat (ausführlicher: Lounsbury/Hirsch 2010; Deutschmann 2011; Heires/Nölke 2014). Gemeint ist der schon in den 1980er Jahren einsetzende Aufstieg des Finanzsektors (Banken, Investmentfonds, Versicherungen, Immobilienwirtschaft) zum führenden Wirtschaftssektor; eine Entwicklung, die sich nicht nur in den USA und Großbritannien zeigte, sondern auch in Westeuropa. Hinter dem Aufstieg der Finanzindustrie wiederum stand das Wachstum der privaten Finanzvermögen. Die Vermögen sind nicht nur weitaus ungleicher verteilt als die Einkommen. Sie sind auch schon seit Jahrzehnten wesentlich stärker gestiegen als das nominale Bruttosozialprodukt und die Arbeitseinkommen (Sassen 2005). In Westdeutschland z.B. verfügten die privaten Haushalte im Jahr 1960 über ein Nettogeldvermögen von 132 Mrd. DM. 1977 war diese Summe auf 1 Billion DM gestiegen, 1986 auf zwei Billionen, 1991 (Gesamtdeutschland) auf drei und 1998 auf 5,3 Billionen DM. Heute kann man knapp denselben Betrag ansetzen - allerdings nicht in DM, sondern in Euro (Stein 2004; Grabka 2011). Diese Entwicklungen zeigen sich nicht nur in Deutschland und Europa, sondern weltweit. Die globalen Vermögensbestände (Aktien, Anleihen, Kredite) sind von 12 Billionen \$ (120 Prozent des Bruttosozialprodukts der Welt) im Jahr 1980 auf 212 Billionen \$ (356 Prozent des Bruttosozialprodukts der Welt) im Jahr 2010 gestiegen (Bieling 2013: 287; McKinsey 2011: 2; parallele Befunde auch bei Piketty 2014). Sogar mitten in der Finanzkrise - im Jahr 2009 - ist die Zahl der Millionärshaushalte weltweit um nicht weniger als 14 Prozent gegenüber dem Vorjahr weiter gestiegen. Weltweit gehören knapp 1 Prozent aller 
Haushalte zu diesem exklusiven Kreis; sie verfügen über 38 Prozent des global verwalteten Vermögens (FAZ vom 11.6. 2010). Auch in Deutschland, wo die Zahl der Vermögensmillionäre im Jahr 2010 auf rund 950.000 stieg (Grabka 2011), war eine parallele Entwicklung zu beobachten. Mit der Zunahme der Finanzvermögen wachsen auch die aus diesen Vermögen fließenden Einkommen (Zinsen, Dividenden), über die es keine verlässlichen statistischen Daten gibt.

Man sollte sich klarmachen, was es bedeutet, wenn die Finanzvermögen ${ }^{2}$ über Jahrzehnte hinweg weitaus stärker steigen als die Leistung der Gesamtwirtschaft. Finanzvermögen - diese Binsenweisheit kann nicht oft genug wiederholt werden - sind immer auch Schulden. Wertpapiere gleichgültig ob Aktien oder Anleihen - sind immer nur genau so viel wert, wie sich seriöse Schuldner finden, die das Kapital nachfragen, einsetzen und in der Lage sind, es mit Zins und Zinseszins zu bedienen. Wenn die Vermögen und mit ihnen auch die von der Gesellschaft direkt oder indirekt zu tragenden Zinsen und Dividenden über lange Zeit hinweg überproportional zunehmen, dann setzt das eine entsprechende Zunahme der Schuldner bzw. ihrer Nachfrage nach Kapital voraus - wohlgemerkt: der ,guten“, zahlungsfähigen Schuldner, denn an Leuten, die einfach nur Geld brauchen, herrscht natürlich nie Mangel. Gefordert wäre eine rasante Zunahme gewinnversprechender Investitionen und Projekte. Die Schuldner müssten Tag und Nacht arbeiten; am Ende müssten alle Lebensbereiche kommerzialisiert werden. In der Tat wurde die Öffentlichkeit lange Zeit durch die Rhetorik vom ,unternehmerischen Selbst“, vom Ruck, der durch Deutschland gehen müsse usw. traktiert. Aber diese Rhetorik ist wirklichkeitsfremd, zumal angesichts der Alterung der Bevölkerung und der faktisch immer größeren Schwierigkeiten von Unternehmensgründungen. Es kann nicht die gesamte Bevölkerung Tag und Nacht rotieren, nur um die Ansprüche der Eigentümer zu bedienen. So ergibt sich das Dilemma, dass ein ständig wachsendes Angebot an anlagesuchenden Finanzvermögen auf eine stagnierende oder gar schrumpfende Nachfrage von der Seite zahlungsfähiger Schuldner stößt.

Wären die Kapitalmärkte so allwissend, wie die berühmte Theorie ,effizienter" Märkte behauptet hatte, hätte es zum Aufbau dieser Vermögens-

2 Auf die in der Studie von Piketty (2014) zusätzlich erfassten öffentlichen und privaten Sach- und Immobilienvermögen gehe ich hier nicht ein. 
blase nie kommen können. Längst hätte es eine Gegenbewegung mit sinkenden Dividenden, Zinsen und fallenden Börsenkursen geben müssen solange, bis ein realistisches, der tatsächlichen Kapitalnachfrage entsprechendes Bewertungsniveau erreicht ist. Aber so funktionieren reale Märkte nicht. Die Banken und Fonds haben vielmehr eine eindrucksvolle Kreativität bei der Verschleierung des sich anbahnenden Ungleichgewichts entwickelt und lange Zeit damit enorme spekulative Profite erzielen können. Seit der Finanzkrise stehen die Bankvorstände unter heftiger öffentlicher Kritik. Ihnen wird Gier, Skrupel- und Verantwortungslosigkeit vorgeworfen, und diese Vorwürfe sind zum großen Teil nicht falsch. Aber dennoch greift die rein moralische, auf individuelles Fehlverhalten zielende Kritik zu kurz. Sie übersieht, dass wir es mit einem Aggregatproblem, mit einem strukturellen Überfluss an Anlage suchendem Kapital an den Märkten zu tun haben, das auf makroökonomische Ursachen in Gestalt der völlig aus dem Ruder gelaufenen Ungleichheit der Einkommens- und Vermögensverteilung zurückgeht. Es führt fast zwangsläufig auf der Seite der Banken und Investmentfonds zu kreativen Tricks mit dem Ziel, das ihnen überreichlich zuströmende Kapital dennoch in den Markt zu drücken. Es geht also nicht allein um individuelles Fehlverhalten der Finanzmanager, so weit verbreitet dieses auch war. Man darf nicht vergessen, dass die Banken und Fonds um die Gunst des Anlegerpublikums konkurrieren müssen und einer ständigen Bewertung ihrer ,performance“ ausgesetzt sind. Die populäre Kritik an der „Gier“ der Bankvorstände ist von projektiven Zügen nicht frei. Die Gier ist ja ein Problem nicht nur der Manager, sondern auch ihrer Kunden, von denen viele geradezu ein „Recht“ auf Rendite für sich in Anspruch nehmen (Deutschmann 2008).

Die kreativen Tricks der Banken bestanden, wie heute klar ist, in der Entwicklung verschiedener Arten von „Finanzinnovationen“. Dazu gehörten vor allem Derivate (Optionen, Futures, Zertifikate), die ursprünglich sinnvolle realwirtschaftliche Absicherungsfunktionen auf liberalisierten Devisenmärkten erfüllten, sich dann aber spekulativ verselbständigten. Kapital wurde hier nicht mehr in reale Vermögenswerte, sondern in „Wetten“ auf andere Finanztitel investiert. Eine andere „Innovation“ waren Kreditverbriefungen (CDO's), die eine rasante Konjunktur erlebten, weil sie eine sorgfältige Prüfung der Bonität des Kreditnehmers entbehrlich machten. Weil die Schuldverschreibungen sogleich wieder verkauft werden konnten, drückte man ein oder beide Augen zu, wenn es um die Einschätzung der 
Zahlungsfähigkeit des Kreditnehmers ging. Es galt hier die „Greater FoolTheory“ (Lanchester 2012): Wer diese Papiere kaufte, war zwar ein Dummkopf. Aber er konnte immer damit rechnen, dass es noch größere Dummköpfe gab, die sie ihm wieder abkaufen. Was die SubprimeHypotheken in den USA waren, waren spanische oder irische Immobilienanleihen oder griechische Staatspapiere in Europa. Die Überschuldung der staatlichen Haushalte geht keineswegs allein auf die Verfallenheit der Regierungen an die Droge Kredit zurück. Sie ist vielmehr auch eine Folge des Anlagedrucks an den Kapitalmärkten. Die Privatwirtschaft allein ist ja längst nicht mehr in der Lage, Renditen in jener Höhe und in jenem Umfang zu liefern, wie sie die Finanzinvestoren und ihre Kunden erwarten. Der Griff nach Staatsschulden als Renditequelle - darauf hat Christian v. Weizsäcker aufmerksam gemacht - ist für die Investoren längst unentbehrlich geworden. Es sind die Kapitalmärkte, die der Droge Staatskredit verfallen sind. Wo sonst sollen Versicherungen und Pensionskassen mit ihrem Geld hin? Das Ergebnis jedenfalls war eine spekulative Aufblähung der Vermögenswerte, die einen trügerischen Optimismus entstehen ließ und das tatsächliche Ungleichgewicht an den Märkten völlig unkenntlich machte.

So kam es zu der Situation, wie wir sie heute haben. Es haben sich Vermögensansprüche aufgebaut, die so umfangreich sind, dass sie weder konsumiert, noch investiert werden können. Wir haben es nicht mit einer normalen zyklischen Krise zu tun, sondern mit den Folgen einer über Jahrzehnte hinweg aufgestauten Überliquidität an den Kapitalmärkten. Die Forderungen der Vermögenseigentümer, zu denen nicht nur spekulierende Milliardäre gehören, sondern auch die Kunden von Pensionsfonds und Lebensversicherungen, haben längst jedes realistische Maß überschritten. Das Volumen der nicht gedeckten Forderungen ist derart angeschwollen, dass man sie nicht mehr einfach abschreiben konnte, ohne einen allgemeinen $\mathrm{Zu}$ sammenbruch der Märkte zu riskieren. Die Staaten sahen sich deshalb gezwungen, mit umfangreichen „Rettungspaketen“ zu intervenieren. Damit erreichten sie zwar eine kurzfristige Stabilisierung der Lage, aber um den Preis, dass sie sich selbst zu Geiseln der Märkte machten. Die Finanzindustrie und ihre Kunden haben es geschafft, ihr eigenes Problem auf die Staaten abzuwälzen und es als ein Problem der staatlichen Haushalte erscheinen zu lassen. Hier, und nicht bloß in der widersprüchlichen institutionellen Konstruktion des Euro oder in den Unterschieden der nationalen Wettbewerbsfähigkeit, liegt der Kern der Euro-Krise. Nicht nur in Europa hat die 
Ungleichheit der Vermögen ein Ausmaß erreicht, das sich unter keinem Gesichtspunkt mehr rechtfertigen lässt, erst recht nicht unter dem der Produktivität. Der Finanzmarkt-Kapitalismus hat nicht das Unternehmertum gefördert, wie immer behauptet wurde, sondern einer Herrschaft der Finanzrentiers über die Unternehmer den Weg gebahnt. Er hat das Wirtschaftswachstum nicht angetrieben, sondern immer stärker beeinträchtigt. Statt die Chancengleichheit und die soziale Aufstiegsmobilität zu fördern, kam es im Gegenteil zur Blockierung der Aufstiegswege und zur Etablierung einer Finanzaristokratie, die ihren Reichtum kaum mehr der eigenen Leistung, sondern immer mehr den wachsenden umfangreicheren Erbschaften (rund 170 Milliarden Euro jährlich in Deutschland, vgl. Beckert 2004) verdankt.

\section{Realistische und VERnÜnftige Antworten AUF DIE KRISE}

Faktisch laufen die staatlichen Rettungsaktionen auf nationaler und europäischer Ebene auf den Versuch einer künstlichen Stabilisierung der in einem jahrzehntelangen Prozess aufgepumpten Vermögensblase und einer völlig aus dem Ruder geratenen Vermögensverteilung hinaus. Das wird kaum funktionieren können. Zwar versucht man auch diesmal wieder, die Bevölkerung zahlen zu lassen, insbesondere über die mit den ESM-Krediten verknüpften Kürzungsauflagen. Aber selbst das wird in der heutigen extremen Situation nicht mehr helfen. Die Schulden verschwinden ja nicht, wie sich in Griechenland, Spanien und anderen Ländern zeigt, sondern wachsen aufgrund der depressiven Folgewirkungen der Sparauflagen nur noch weiter. Vermögensforderungen, die nicht mehr eingetrieben werden können, müssen abgeschrieben werden. So wenig, wie man einen Bock mit Gewalt melken kann, kann man Geld, das einfach nicht vorhanden ist, durch „Austeritätspolitik" herbeischaffen. Genauso wenig hilfreich ist die Idee einer „Vergemeinschaftung“ der Schulden, die ja die Schulden auch nicht beseitigen, sondern nur umverteilen würde. Um die Blockierung des ökonomischen Kreislaufs zu beseitigen, ist es vielmehr unabdingbar, die Erwartungen der Vermögenseigentümer auf den Boden der Realität herabzuholen; es geht also primär gar nicht um ein Problem der „Gerechtigkeit“, erst recht nicht um die Bedienung von „Neidgefühlen“. Europa wird um eine neue 
und massive Abschreibung der Vermögen wie der Schulden nicht herumkommen. Die Frage ist nicht ob, sondern nur, wie es zu dieser Korrektur kommt. Hier sehe ich drei Optionen: Eine weder realistische noch vernünftige, eine realistische, aber wenig vernünftige, und eine vernünftige, aber (zur Zeit jedenfalls) noch wenig realistische.

Die erste Option (Option 1) wäre, dass es, aufgrund welcher Ereignisverkettungen auch immer, doch noch zu einer ,marktwirtschaftlichen“ Lösung kommt, also zu einem neuen Crash, der dann wahrscheinlich auch mit einem Auseinanderbrechen des Euro verbunden wäre. Zwar „will“ niemand einen solchen Zusammenbruch. Aber er wäre die billigend in Kauf genommene implizite Konsequenz einer dezidiert „ordnungspolitischen“ Position, wie sie in Deutschland von einigen Ökonomen und den DMNationalisten der „Alternative für Deutschland“ vertreten wird. Leisten kann sich eine solche ökonomische Gesinnungsethik nur, wer keine politische Verantwortung trägt und für die Folgen nicht geradestehen muss. Eine solche Option wäre aufgrund ihrer völlig unabsehbaren ökonomischen, politischen und gesellschaftlichen Folgen mit vernünftigen Argumenten nicht zu rechtfertigen. Sie wäre aber auch angesichts der erklärten Haltung der EZB nicht realistisch. Die politisch Verantwortlichen versuchen, den Zusammenbruch um nahezu jeden Preis zu vermeiden. Um dennoch zu einer Entwertung der Vermögen zukommen, verfügen sie wiederum über zwei Optionen: eine realistische, aber kurzsichtige und wenig vernünftige (Option 2), und eine vernünftige, aber zur Zeit noch wenig realistisch erscheinende (Option 3).

Die realistische Option 2 ist die sog. „Monetarisierung“ der Schulden, die Ablösung der Schulden durch die elektronische Notenpresse der EZB. Auch das ist eine Form der Entwertung der Vermögen, zwar nicht direkt, aber indirekt über den politisch bequemeren Weg der Inflationierung. Die Märkte werden durch billiges Geld geflutet, das die Realzinsen negativ werden lässt und so für eine allmähliche Entschuldung sorgt; der Investorenjargon hat dafür das Schlagwort der „finanziellen Repression“ geprägt. Das ist die Politik, die die EZB unter der Führung von Draghi (mit der einsamen Gegenstimme von Weidmann) verfolgt, ebenso wie die britischen, amerikanischen und japanischen Zentralbanken. Sie hat zu dem perversen Resultat geführt, dass die Anleger im Jahr 2012 Spitzengewinne ausgerechnet mit Anleihen europäischer Krisenstaaten (Griechenland und Portugal) erzielen konnten (FAZ vom 4.1.13). Die Geldschöpfung durch die Zentral- 
bank verschafft der Politik eine Atempause, und solange die durch die Zentralbank geschaffene Liquidität im Bankensystem bleibt und nicht auf die Realwirtschaft übergreift, muss es auch nicht zu einer Inflation der Verbraucherpreise kommen. Aber die Probleme sind damit nicht vom Tisch. Sie werden nur latent gehalten; wir müssen uns auf eine lange Zeit der Stagnation und immer wieder sich aufblähende und platzende Finanzmarkt-, Immobilien- und Rohstoffblasen einstellen. Die Rohstoffblasen können am Ende doch zu einer Verbraucherpreisinflation führen. Die Inflationierung der Finanzvermögen führt zu einer Umverteilung des Vermögensbesitzes zugunsten von Aktien, Sachwerten, Immobilien und schädigt damit vor allem die Mittelschichten. Überdies drohen immer neue Marktturbulenzen und mittelfristig eine Destabilisierung der Währung, die die gesamte Bevölkerung trifft. Für die Finanzindustrie läuft die Politik des ,quantitative easing“ auf eine Einladung hinaus, ihre spekulativen Pirouetten in der gewohnten Weise fortzusetzen (Bieling 2013). Diese „Lösung“ ist mit beträchtlichen wirtschaftlichen und sozialen Kollateralschäden verbunden und somit alles andere als rational.

Die andere, zweifellos vernünftigere, aber gegenwärtig noch wenig realistisch erscheinende Lösung (Option 3) bestände in einem kontrollierten, politisch verhandelten Abbau der Vermögen bzw. Schulden, der der Wirtschaft wieder Raum zum Atmen gäbe. Schon lange wird deshalb ein allgemeiner Schuldenschnitt vorgeschlagen (z.B. Harald Hau und Ulrich Hege in der FAZ vom 14.9.12). Das Hauptproblem dabei wäre zu verhindern, dass wiederum die Steuerzahler die Hauptbürde der Entschuldung tragen. Diesem Ziel sollten die 2014 abgeschlossenen Europäischen Vereinbarungen zur Bankenunion und zur Abwicklung maroder Banken dienen. Ein alternativer, ebenfalls viel diskutierter Weg wären direkte steuerliche Zugriffe auf die privaten Vermögen mit dem Ziel der Entschuldung der Staaten. Möglich wären hier eine Zwangsanleihe oder eine einmalige Vermögensabgabe, wie sie das DIW (Bach 2012) angeregt hat, und die GRÜNEN im Wahlkampf von 2013 gefordert haben. Auch eine Erhöhung des Spitzensteuersatzes, der Steuern auf Vermögen und Vermögenseinkommen, sowie eine Finanzmarkttransaktionssteuer wären zweckmäßig. Mit welchen Schritten oder mit welcher Kombination von Schritten die effizientesten Ergebnisse zu erzielen wären, ist noch immer Thema von Diskussionen. Um die zu erwartende Kapitalflucht zu begrenzen, müssten vermögensabschöpfende Maßnahmen möglichst europaweit, idealerweise: G-20 weit 
koordiniert und durchgesetzt werden. Deshalb ist auch die durch die EU angestrebte und z.T. beschlossene Europäisierung der Fiskalpolitik grundsätzlich richtig. Fatal ist nur, wenn die Europäisierung sich, wie gegenwärtig, einseitig an den Interessen der Gläubiger orientiert und allein auf Kürzungen öffentlicher Ausgaben zielt. Das Ziel einer Europäisierung der Fiskalpolitik müsste auch darin bestehen, den Steuersenkungswettlauf bei den Kapital- und Vermögenssteuern zu beenden und überall endlich eine angemessene Besteuerung hoher Einkommen und Vermögen durchzusetzen wenigstens in Europa. Die früher augenzwinkernd tolerierte Steuerhinterziehung und -verlagerung reicher Privatpersonen und transnationaler Konzerne dürfte nicht länger hingenommen werden. Die öffentlichen Haushalte können nicht nur über die Ausgabenseite konsolidiert werden. Sie brauchen auch höhere Einnahmen, die bei jenen geholt werden müssen, die von der Hypertrophie der Vermögen und den staatlichen Rettungsaktionen profitiert haben. Aber jede Politik, die in diese Richtung geht, führt zu heftigen Verteilungskämpfen und härtestem Widerstand der Eigentümer und der Finanzlobby. Um diese Widerstände zu überwinden, braucht es einen langen Atem; über die kurzfristigen Erfolgschancen sollte man sich keine Illusionen machen.

Erste Anzeichen dafür, dass sich ein internationaler politischer Konsens in Richtung der genannten dritten Position entwickeln könnte, sind zwar erkennbar: Die von der Mehrheit der Regierungen der Euro-Gruppe beschlossene Finanzmarkt-Transaktionssteuer, die Fortschritte in der Koordinierung des Kampfes gegen Steueroasen und Steuerflucht, die erstmalige Heranziehung der Gläubiger und Bankenaktionäre zur „Rettung“ des Staates und der Banken im Fall Zyperns. Auch die im Frühjahr 2014 getroffenen Vereinbarungen zur Bankenunion könnten zu einer politisch und sozial verträglichen Entschuldung beitragen, sollte die angekündigte Abwicklung von Banken, die die laufende Bilanzprüfung nicht bestehen, tatsächlich umgesetzt werden. Aber dafür spricht gegenwärtig (September 2014) leider wenig. Die Ankündigung der EZB, von den Banken gehaltene Kreditverbriefungen in großem Umfang aufzukaufen, deutet vielmehr darauf hin, dass die Probleme wie gehabt durch Monetarisierung der Schulden auf die lange Bank geschoben und damit letztlich wiederum dem Steuerzahler zugewiesen werden sollen.

Die Euro-Krise wird nur überwunden werden können, wenn sozial und demokratisch tragfähige Wege zur Entschuldung gefunden werden. Abs- 
trakte Appelle an die europäische Solidarität werden dabei kaum weiterhelfen. Erfolgversprechender wäre es, konkrete Themen und politische Konflikte zu benennen, in deren Austragung Europa auf einer praktischen Ebene zusammenwachsen könnte. Dass die Kosten der Finanzkrise nicht von den Steuerzahlern, sondern von ihren Verursachern zu tragen sind, ist eine legitime Forderung, die in der gesamten europäischen Bevölkerung auf breite Zustimmung stößt. Eine demokratieverträgliche Bankenabwicklung wird nur zustande kommen, wenn der Ministerrat, die EZB und die Kommission in dieser Frage europaweit wesentlich mehr Druck von unten bekommen als bisher. Die Hinterlassenschaften der Finanzkrise werden sich gerade nicht durch Re-Nationalisierung, sondern nur durch eine wirksame transnationale Koordinierung demokratischer Politik unter Kontrolle bringen lassen, bei der auch das Europäische Parlament eine aktivere Rolle als bislang spielen könnte. Entscheidend ist die Behebung des demokratischen Defizits der europäischen Institutionen. Die Schuldenkrise als die zentrale gegenwärtige Herausforderung der europäischen Wirtschaftspolitik wird nicht allein auf der Ebene der Institutionen, sondern nur durch eine demokratische Mobilisierung der europäischen Öffentlichkeit erfolgreich bewältigt werden können. Märkte regulieren sich nicht im Selbstlauf. Ein Versagen der Regulierungsmechanismen der Märkte, wie es in der Finanzkrise wieder zu Tage trat, lässt sich nur durch einen stabilen institutionellen und politischen Rahmen verhindern. Transnational vernetzte Märkte, wie sie in Europa längst Realität sind, verlangen nach einem transnationalen institutionellen Rahmen. Die europäische Integration ist daher keineswegs nur ein abstraktes Elitenprojekt, sondern ist durch den Integrationsvorsprung der Märkte zwingend geboten. Sie muss keineswegs in einen zentralistischen Superstaat münden, sondern ist durchaus als eine intelligente Mischung von zentraler, nationaler und regionaler Koordinierung denkbar (Habermas 2011). Sie ist gleichwohl ein mühevolles, weil historisch innovatives Vorhaben, bei dem dicke Bretter zu bohren und nur langsame Fortschritte zu erwarten sind. Kreative Ideen, nicht der Rückgriff auf scheinbar bewährte Rezepte der Vergangenheit, sind auf diesem Weg gefragt. 


\section{LITERATUR}

Aichele, Rahel/Felbermayr, Gabriel/Heiland, Inga (2013): Neues aus der Basarökonomie, ifo-Schnelldienst 66.6, Ifo-Institut, Berlin, S. 17-28.

Bach, Stefan (2012): Vermögensabgaben - ein Beitrag zur Sanierung der Staatsfinanzen in Europa, in: DIW-Wochenbericht 28, S. 3-11.

Beckert, Jens (2004): Unverdientes Vermögen. Soziologie des Erbrechts, Frankfurt a.M.

Bieling, Hans-Jürgen (2013): European Financial Capitalism and the Politics of (De-)financialization, in: Competition and Change 17.3, S. 28398.

Deutschmann, Christoph (2008): Die Finanzmärkte und die Mittelschichten: der kollektive Buddenbrooks-Effekt, in: Leviathan 4.36, S. 501517.

Deutschmann, Christoph (2011): Limits to Financialization. Sociological Analyses of the Financial Crisis, in: Archives Europèennes de Sociologie LII.3, S. 347-389.

Fligstein, Neil (2010): The Europeanization of Business, in: Jens Beckert/ Christoph Deutschmann (Hg.): Wirtschaftssoziologie. Sonderheft 49 der Kölner Zeitschrift für Soziologie und Sozialpsychologie, Wiesbaden, S. 107-124.

Genschel, Philipp/Schwarz, Peter (2011): Tax Competition: a literature review, in: Socio-Economic Review 9.2, S. 339-370.

Grabka, Markus (DIW/SOEP) (2011): Die Einkommens- und Vermögensverteilung in Deutschland, Kapitalmarktforum 2011, Heinz-Nixdorf Museums-Forum Paderborn, 8. Nov. 2011.

Habermas, Jürgen (2011): Zur Verfassung Europas - ein Essay, Berlin.

Heires, Marcel/Nölke, Andreas (Hg.) (2014): Politische Ökonomie der Finanzialisierung, Wiesbaden.

IW (2014): Institut der deutschen Wirtschaft Köln: Deutschland in Zahlen 2014, Köln.

Lanchester, John (2012): Whoops! Why Everyone Owes Everyone and No One Can Pay, London.

Lounsbury, Michael/Hirsch, Paul M. (Hg.). (2010): Markets on Trial. Sociology of the US Financial Crisis, Part A, B, Bingley.

Martin, Hans-Peter/Schumann, Harald (1996): Die Globalisierungsfalle. Der Angriff auf Demokratie und Wohlstand, Reinbek. 
McKinsey (2011): Roxburgh, Charles/Lund, Susan/Piotrowski, John: Mapping Global Capital Markets 2011; McKinsey Kinsey Global Institute www.mckinsey.com/mgi. [Letzter Zugriff: 05.03.2015.]

Piketty, Thomas (2014): Capital in the Twenty-First Century, Cambridge/ Mass.

Sassen, Saskia (2005): The Embeddedness of Electronic Markets: The Case of Global Capital Markets, in: Karin Knorr-Cetina/Alex Preda (Hg.): The Sociology of Financial Markets, Oxford, S. 17-37.

Statistisches Bundesamt (2012): VGR-Private Konsumausgaben, 4. Vj. 2012.

Stein, Holger (2004): Anatomie der Vermögensverteilung. Ergebnisse der Einkommens- und Verbrauchsstichproben 1983-1998, Berlin.

Streeck, Wolfgang (2013): Gekaufte Zeit. Die vertagte Krise des demokratischen Kapitalismus, Berlin.

SVR (2012): Jahresgutachten des Sachverständigenrates zur Begutachtung der gesamtwirtschaftlichen Entwicklung 2012/13. 



\title{
Die Krise der Demokratie in Europa - und die Krise der Erforschung dieser Krise
}

\author{
THORSTEN THIEL
}

Die Krise der Demokratie in Europa ist oft diagnostiziert worden. So oft, dass über sie zu schreiben, gar nicht mehr so einfach ist. Was soll man zu den Bibliothekskilometern hinzufügen, die aus jedem denkbaren Winkel die europäischen Institutionen, das Zusammenspiel dieser Institutionen, das Verhältnis von EU und Nationalstaaten oder die mal schleichende, mal lautstarke Abkehr der europäischen Bürger von den demokratischen Institutionen vermessen und analysiert haben? Die Schwerpunkte der Diagnosen variieren, auch wer als Bösewicht besetzt wird oder was als strukturelle Unzulänglichkeit erachtet wird, aber dass eine Krise besteht und dass diese die Demokratie - national wie europäisch gesehen - betrifft, wird sehr weit geteilt.

Krisendiagnosen sind dabei stets politisch. Wer von der Krise spricht (oder schreibt), will zum Handeln anregen. Er erachtet eine Situation als untragbar und behauptet, dass der Status Quo nicht fortgeführt werden kann. Krise impliziert Negativität und Bedrohung; von der Krise zu sprechen spitzt eine Situation auf eine Entscheidung hin zu: Entweder muss es Veränderung geben oder aber es droht der Untergang. Eine Krise ist umfassend, sie stellt eine systemweite Bedrohung dar und unterminiert charakteristische Handlungsmuster und Routinen. ${ }^{1}$ Krise suggeriert Dringlichkeit,

1 Dafür, dass Krise gemeinhin als ein sozialwissenschaftlicher Schlüsselbegriff aufgefasst wird, ihr als Selbstbeschreibungsvokabel moderner Gesellschaften ein enorme Bedeutung zukommt und sie im öffentlichen und politischen Diskurs 
sie ist eine Ausnahmesituation und für die Lösung der Krise stehen daher Mittel bereit, die weit über das hinausgehen, was im Normalmodus selbst angelegt ist oder auch nur für möglich erachtet wird. Jede Krisendiagnose hat daher eine performative Kraft: Wird sie geteilt, so ist sie unmittelbar handlungsrelevant.

Es ist diese (potentielle) Macht der Krisendiagnose, die ich im Folgenden mit der Macht dieser speziellen Krisendiagnose, der Krise der europäischen Demokratie, kontrastieren möchte. Ich möchte fragen, ob der allgegenwärtige Krisendiskurs eigentlich noch die Leistung erbringt, die ihm zugeschrieben wird, ob also die Diagnose der Krise der Demokratie in Europa, so wie sie heute gestellt wird, tatsächlich Handlungsanreize schafft und Alternativen denkbar werden lässt.

Meine These ist, zugespitzt, dass die Krise der Demokratie in Europa auch eine Krise der Erforschung dieser Krise ist. Mein Argument lautet, dass die sich immer weiter spezialisierende Europaforschung und die öffentliche Diskussion viel zu weit auseinandergetreten sind, vor allem aber, dass sich der Diskurs über europäische Demokratie konzeptionell erschöpft hat. Er bietet daher wenige oder keine Impulse mehr, um auf die nach wie vor stattfindende und normativ höchst bedeutsame Weiterentwicklung eu-

eines der wichtigsten Signalwörter für die Einordnung politischer Geschehnisse ist, gibt es erstaunlich wenig begriffliche Verständigung über das Konzept ,Krise'. Die enorme politische Kraft des Begriffes, sein Einsatz als narrative Verkürzung sowie die Ausweitung über sämtliche Bereiche der conditio humana, hat - wie schon Koselleck in der bis heute zentralen begriffsgeschichtlichen Studie formuliert hat (Koselleck 1982) - dazu geführt, dass der Begriff ausgeweitet und überstrapaziert ist. Das wissenschaftliche Interesse an der Krisenterminologie ließ nach einem Höhepunkt der Krisentheoretisierung in den 1970er Jahren deutlich nach. In den letzten Jahren kam es jedoch - sicherlich nicht zuletzt bedingt durch die Erfahrung schnell hinter einander auftretender wirtschaftlicher und politischer Großkrisen - zu einer erneuten und sehr intensiven Beschäftigung mit der ,Krise‘ als Konzept (einen guten Einstieg und Überblick geben die folgenden Werke: Friederichs 2007; Mergel 2012; Baumann/Bodoni 2014; Roitman 2014; Schulze 2011; Fenske, et al. 2011; Wengeler/Ziem 2013). Die ,Krise der Demokratie“ stellt in diesem Zusammenhang noch einmal eine besondere Untergattung von Texten dar (vgl. Merkel 2014 für eine empirische Hinterfragung der vielfältigen normativen Krisenkonzepte). 
ropäischer Integration in einer Weise zu reagieren, die Resonanz erzeugen und überzeugende Urteile begründen würde. Dem kann nach meiner Einschätzung entgegengewirkt werden, wenn eine stärkere Einbindung von gegenwärtig in der politischen Theorie diskutierten Ansätzen versucht würde. Das Vokabular moderner politischer Theorie erlaubt es, einen Fokus zu setzen auf Momente des Politischen und Voraussetzungen politischen Handelns, was im Bereich der Europaforschung eine völlig andere Diskussion möglich werden ließe.

Das Folgende soll also ein Versuch sein, eine sehr partielle, aber - wie ich denke - doch wichtige Facette unserer Schwierigkeit des Umgangs mit der Demokratie in Europa aufzudecken. Der Fokus dieser Ausarbeitung liegt dabei allein auf dem wissenschaftlichen (oder noch genauer: dem demokratietheoretischen) Diskurs über die Krise der Demokratie in Europa. Dem Gegenstand, der Krise der Demokratie selbst, nähre ich mich dabei nur indirekt und aus der Perspektive des Beobachters des Beobachters. Doch eben weil dies in der derzeitigen Diskussion nur selten gemacht wird, erhoffe ich mir spezielle Aufschlüsse und ein Überwinden des Problems der von Europa schweren Regalkilometer.

Der Text gliedert sich in drei Teile: Im ersten wende ich mich den Bedingungen normativen Theoretisierens im Europadiskurs zu. Ich beschreibe die zunehmende Spezialisierung der Europaforschung und deren Folgen für die Rolle Politischer Theorie. Anschließend skizziere ich, wie sich die Diagnosen europäischer Demokratie inhaltlich ausdifferenziert haben und arbeite heraus, worin nach meiner Ansicht die konzeptionelle Erschöpfung des Diskurses besteht. Abschließend halte ich ein kurzes Plädoyer für ein alternatives Theoretisieren und damit verbunden einen anderen öffentlichen Diskurs über Europa.

\section{Politische Theorie Und EuRopaforschung}

Die Europaforschung ist ein boomendes wissenschaftliches Feld (Keeler 2005; Rosamond 2007). Ein Feld zudem, dass sich über die Zeit in einer sehr eigenen Weise und mit sehr eigenen Institutionen ausdifferenziert hat. ${ }^{2}$

2 Es sei direkt angemerkt, dass es keine selbstständige und klar abgegrenzte akademische Disziplin „Europaforschung“ gibt und die Rede von einem For- 
Europaforschung ist dabei durch eine stark interdisziplinäre Anlage und eine sehr moderne, netzwerkbasierte Struktur gekennzeichnet. Rechtswissenschaft und Politische Wissenschaft sind in ihr die zentralen Herkunftsdisziplinen, soziologische und historische Ansätze spielen zunehmend und ergänzend eine Rolle. Das Interesse am Phänomen der europäischen Integration und den Institutionen der Europäischen Union bildete sich in Rechtsund Politikwissenschaft schon in den frühen Tagen europäischer Integration heraus. Innerhalb der Politischen Wissenschaft, auf deren Diskurs ich mich hier weitgehend konzentrieren will, ist die Europaforschung vor allem aus den Anstrengungen von zwei Teildisziplinen hervorgegangen: den Internationalen Beziehungen, in denen die Frage nach den Gründen für den Fortgang von internationaler Integration und deren Grenzen das ursprüngliche Erkenntnisinteresse war, und der Vergleichenden Politikwissenschaft, für die das Verständnis der Funktionierens der sich herausbildenden Institutionen zentral ist. Die Evolution der Forschung hat es dabei mit sich gebracht, dass die beiden Ansichten heute an vielen Stellen verbunden sind. So hat sich ein begrifflich und theoretisch eigenständiger Diskurs herausgebildet, der zudem dadurch distinkt wird, dass auch institutionell eine Ausdifferenzierung stattgefunden hat. Die Europaforschung ist sehr viel internationaler orientiert und organisiert als die allgemeine Politikwissenschaft. Sie verfügt über einen Fachdiskurs, der nahezu ausschließlich über englischsprachige Zeitschriften verläuft, mit der Folge, dass die angelsächsisch orientierten Länder und deren Forschungs- und Demokratieverständnisse in der Forschung über die EU eine weit größere Bedeutung haben als im Brüsseler

schungsfeld daher präziser ist. Zum Forschungsfeld „Europaforschung“ gehört zunächst jeder, der den Gegenstand „Europäische Union“ thematisiert. Es existieren zwar immer wieder Ansätze, eine eigenständige Europawissenschaft zu etablieren (etwa: Schuppert, et al. 2005), und gerade im angelsächsischen Raum über das Konzept area study mit dem Unterbereich European Studies existiert eine so benannte disziplinäre Entität (Calhoun 2003), aber die Formierungsversuche müssen noch als unabgeschlossen und uneinheitlich gelten. Inwiefern es zu einer disziplinären Konsolidierung überhaupt kommen wird oder ob die netzwerkartige Struktur erhalten bleibt, die gegenwärtig die bessere Beschreibung ermöglicht, muss offen bleiben. 
politischen Betrieb. ${ }^{3}$ Europaforschung ist zudem häufig in großen Forschungsnetzwerken oder an einzelnen Standorten ausgebaut: Beispiele sind das ARENA Centre for European Studies in Oslo oder in Deutschland das Mannheimer Zentrum für Europäische Sozialforschung. Diese Eigenheiten haben die Europaforschung $\mathrm{zu}$ einem sehr starken und wichtigen Forschungsfeld gemacht. Den aus dem naturwissenschaftlichen Disziplinen entlehnten Forschungsimperativ (kollaborativ, paradigmenorientiert, datengetrieben, global) und den damit verbundenen Förderpraktiken steht Europaforschung sehr viel näher als die eher geisteswissenschaftlich orientierte, althergebrachte Politikwissenschaft, was zu einer Selbstwahrnehmung als Avantgarde führt.

Nachdem seit Mitte der achtziger Jahre und im Zuge externer Ereignisse wie den Schwierigkeiten der Ratifikation des Maastricht-Vertrags die normativ-demokratietheoretische Frage nach der Legitimation europäischen Regierens den Status einer dritten zentrale Diskursarena erhielt (Bellamy/Castiglione 2003), stellte sich nichtsdestotrotz die Frage, ob eine disziplinäre und methodische Erweiterung des Kanons der Europaforschung nötig sei. Das Interesse an Erkenntnissen der Politischen Theorie nahm in der Europaforschung stark zu und auch aus der Öffentlichkeit wurde ein Bedarf nach einer anschlussfähigen, richtungsweisenden Debatte artikuliert. Das Bemühen um ein gesättigtes politik- und demokratietheoretisches Vokabular wurde zunächst stark von Rechtswissenschaftlern bedient (vgl. die wegweisenden Artikel von Grimm [1995] und Weiler [1995]), über die Zeit war aber auch in der politikwissenschaftlichen Linie der Europawissenschaft eine Hinwendung zur Demokratietheorie zu beobachten.

Anders als in der Formierungsphase der Europaforschung, wo Internationale Beziehungen und Vergleichende Politikwissenschaft gleichberechtigt Theorien und Vokabular einspeisten und dann kollaborativ weiterentwickelten, erfolgte in der in viel höherem Maße konsolidierten und institutionell etablierten Europaforschung der Import nicht so sehr durch wechselseitigen Austausch oder die Aufnahme dezidierter Figuren der politischen Theorie in den Diskurs, sondern als eine einseitige Rezeption, Aneignung

3 Der relative Einfluss der USA auf das Forschungsfeld war allerdings in den frühen Jahren deutlich größer und ist im allgemeinen Wachstum des Forschungsfelds und der Professionalisierung der Sozialwissenschaften in Europa spätestens seit der Jahrtausendwende zurückgegangen (Andrews 2012). 
und Weiterentwicklung zentraler Theoreme (das bekannteste, unten noch weiter erörterte Beispiel ist die deliberative Demokratietheorie). Der Import von Theoriefragmenten in die europawissenschaftliche Begriffssprache ließ eine separierte Entwicklung des normativen Vokabulars möglich werden. Stichworte, Theorien und Konzepte des politiktheoretischen Diskurses von Legitimität bis Souveränität - sind somit zwar in der Europaforschung präsent, die Europäische Union ist aber auch heute noch kein wichtiger Gegenstand in der Politischen Theorie. Neuere Entwicklungen und Diskurse wurden nach der Phase der Etablierung des Legitimationsdiskurses nur noch wenig beachtet. ${ }^{4}$

Diese Tendenz wird noch dadurch verstärkt, dass umgekehrt auch auf Seiten politischer Theoretiker und Philosophen zwar ein abstraktes Interesse an der Entwicklung hin zur postnationalen Konstellation zu registrieren ist, der Diskurs sich aber bewusst fernhält von der Komplexität empirischer Institutionen. Politische Theorie neigt stark zum Systematisieren und Gene-

4 Selbstverständlich bestätigen Ausnahmen diese Regel. So lässt sich etwa auf den englischsprachigen Sammelband von Jürgen Neyer und Antje Wiener zu Political Theory of the European Union (Neyer/Wiener 2010) hinweisen (beide Herausgeber sind aber bezeichnenderweise Professoren für Internationale Beziehungen). Auch gibt es enorm wirkmächtige Autoren, die als Politische Theoretiker angesehen werden können oder in diesen Diskursen zentral sind, wie etwa Jürgen Habermas oder Richard Bellamy. Schließlich schwankt der Grad des Einbezugs auch noch nach Politikfeld und Fragestellung; so war etwa in der Auseinandersetzung um den Komplex Identität/Solidarität/Vertrauen das Interesse an politiktheoretischer Beteiligung größer und anhaltender als etwa im Diskurs um institutionelle Reformen. Auch gilt es zu bedenken, dass die hier sehr zugespitzte Verwendung von Unterscheidungen entlang von Subdisziplinzugehörigkeiten weder ein eindeutiges noch ein sonderlich folgenschweres Kriterium für das Vorhandensein von Perspektiven oder die Qualität des Diskurses sein kann. Die Trennung ist weder analytisch scharf noch ließen sich aus ihr kausale Schlüsse ziehen. Die Unterscheidung kann aber einen griffigen Marker setzen, um die Ordnung des Diskurses zugespitzt zu illustrieren und das Feld zu bereiten für einen bisher nur randständigen Lösungsansatz. Ganz in der den Essay rahmenden Logik der Krisendiagnose, versuche ich auf ein entweder-oder zuzuspitzen, wohl wissend, dass die Beschreibung der Realität ein komplexes sowohl-als auch benötigte. 
ralisieren und zur Beschränkung auf abstrakte Begründungsfragen, wie am deutlichsten in der Debatte um ,globale Gerechtigkeit“ ersichtlich wird. Nur so kann weitgehend uninformiert vom realen Funktionieren von Institutionen und deren Aufgaben und Besonderheiten Theorie betrieben werden, was für sich ein Problem darstellt, aber auch den weitgehenden Rückzug von Theoretikern aus aktuellen Debatten zu erklären hilft.

Die Selbst- wie Fremdmarginalisierung politischer Theorie im Europadiskurs ist per se zunächst einmal überhaupt kein Problem. Auch dort, wo politische Theorie sich stark einbringt, ist schließlich nicht gesagt, dass sie überzeugende Ergebnisse produziert, öffentliche Diskurse in Gang bringt oder auch nur diskussionswerte Alternativen aufzeigt. Ich möchte im Folgenden aber zeigen, dass gerade die Europaforschung von einer besseren Kenntnis und einem regen Austausch mit Diskursen in der Politischen Theorie profitieren würde. Die Diskurse über Form und Wesen der Demokratie, die sich in der Politischen Theorie über die letzten zehn, fünfzehn Jahre entwickelt haben, sind dem schematischen Demokratieverständnis der Europaforschung mit ihrer Aufmerksamkeit für Politisierungsprozesse und den vielfältigen Austausch von Bürgern und Institutionen, wie er etwa in republikanischen oder radikaldemokratischen Debatten reflektiert wird, klar voraus und können die etablierten Perspektiven gewinnbringend ergänzen.

Und noch aus einem zweiten Grund erscheint mir eine solche Weiterung des Diskurses angebracht: Die oben beschriebene Ausdifferenzierung und Szientifizierung des Europadiskurses hat eine starke Trennung von Europaforschung und politischer Öffentlichkeit mit sich gebracht. Europa ist im politischen Feuilleton zwar ein ständiges Thema, aber welcher Zwischenruf kommt schon ohne den Hinweis aus, dass viel $\mathrm{zu}$ wenig über Europa nachgedacht und öffentlich geredet wird. Es sind weniger die Europaforscher als vielmehr die allgemeinen Intellektuellen, die hier Stellung beziehen, und für diese gilt oftmals, dass eine weitreichende Lähmung mit Blick auf Fragen des europäischen Regierens zu konstatieren ist. Ursachen hierfür sind viele angeführt worden, so etwa von Georg Vobruba (2007), der die Schwierigkeit der Intellektuellen, eine eigene Position zwischen Affirmation und Populismus zu finden, mit einer gespaltenen Wahrnehmung zwischen positivem Integrationsziel und negativer Institutionensicht begründet. Andere Erklärungen zielen auf das Fehlen einer übergreifenden europäischen Öffentlichkeit oder die Oberflächlichkeit, die die Logik moderner Berichterstattung mit sich bringt. 
Ich denke, dass man auch sehen muss, dass der hochentwickelte Wissenschaftsdiskurs relativ ungeeignet ist, verständlich seine Erörterung der Krise der Demokratie in den öffentlichen Raum zu tragen. Die wenigen etablierten wissenschaftlichen Stimmen im Diskurs - die zudem oft älter und fast immer männlich sind - wirken routiniert und bieten seit Jahren einen sonoren Mix von Appell und Klage. Durch sie findet aber nahezu kein Transfer innovativer Überlegungen in die öffentliche Debatte statt. Jene Wissenschaftler, die ,echte' Europaforschung machen, meiden zumeist die Debatte, oft wohl, weil sie von Vermittlung und Diskussion desillusioniert sind. Es gelingt ihnen nicht überzeugend, die kleinteiligen und stark differenzierenden Erkenntnisse der Europaforschung in eine diskursive Form zu überführen und ein informiertes, aber doch verständliches Vokabular zu entwickeln. Es bedarf daher einer Annäherung von beiden Seiten aus, von Seiten des öffentlichen Diskurses wie seitens der Wissenschaft. Und es scheint mir, dass eine stärkere Einbeziehung moderner politischer Theorie von Wert wäre, weil die dort entwickelten Verständnisse von Demokratie eingängiger erscheinen und mehr Bezug zu gesellschaftlichen Akteuren (jenseits von Politikberatung und strategischer Expertise) mitbringen.

\section{VERSTÄNDNISSE VON DEMOKRATIE IN DER EUROPAFORSCHUNG}

Bevor wir uns aber diesen ergänzenden Perspektiven zuwenden, müssen wir zunächst eine Kategorisierung jener Ansätze versuchen, die im Legitimationsdiskurs der Europaforschung stark sind. Nur so lässt sich verstehen, wie sich die Debatte entwickelt hat, was als Krise der Demokratie in Europa verstanden wird und wo die Grenzen und Einseitigkeiten einzelner Ansätze verlaufen. Um der ungemeinen Vielfalt des höchst produktiven Diskurses Struktur und Halt zu geben, will ich hierfür im Folgenden ein analytisches Raster vorschlagen, das helfen soll, die verhandelten Ansätze entlang zweier grundsätzlicher Unterscheidungen zu sortieren.

Die erste Unterscheidung ist jene zwischen Ansätzen, die normative Erwägungen zum Ausgangspunkt nehmen, und solchen, die mit einer möglichst dichten empirischen Beschreibung europäischen Regierens starten. Mit einer normativen Erörterung zu beginnen bedeutet, dass man zunächst 
grundlegende Überlegungen dazu formuliert, was Demokratie heißt und Kriterien entwickelt, mittels derer die demokratische Legitimität eines politischen Gemeinwesens erörtert werden kann. Diese Standards können abstrakt aus Demokratietheorien oder der Erörterung von Werten und Rechten hergeleitet oder analytisch aus der Untersuchung des ,Kerns' entwickelter demokratischer Systeme gewonnen werden. Wichtig für die Unterscheidung ist allein, dass zunächst die normative Messlatte entwickelt wird. Die EU wird dann (zumindest prinzipiell) nicht als Ausnahme behandelt, sondern an den so identifizierten Maßstäben bemessen. Ansätze, die umgekehrt mit einer empirischen Beschreibung beginnen, betonen, dass es zunächst zu verstehen gilt, was die Europäische Union eigentlich ist, was deren Ziele oder Funktionen sind und wo sie sich von nationalstaatlichen Demokratien und deren Legitimationsanforderungen unterscheidet. Erst dann könne man auf Grundlage eines spezifischen Verständnisses sinnvoll über die Entwicklung adäquater Bedingungen reden und Vorschläge zu Reformen entwickeln.

Die zweite Unterscheidung ist jene zwischen Ansätzen, in denen Demokratie als Kontrolle von Eliten konzipiert wird, und Ansätzen, die die Ermächtigung der Bürger zu politischem Handeln als zentrales demokratisches Gut setzen. Bei ersterem liegt der Fokus auf Institutionen und Mechanismen, Repräsentation wird für unerlässlich gehalten, und die Möglichkeit von deren Missbrauch sowie das Risiko der Aggregation von Macht gelten als zentrale Herausforderungen der Demokratie. Der zweite Ansatz rückt hingegen stärker partizipatorische, gesellschaftliche Aspekte in den Vordergrund, formuliert zudem die Erwartung eines zu entdeckenden oder im Prozess entstehenden Gemeinwohls. Weniger die individuelle ,Freiheit von' als eine (zumindest teilweise) kollektive ,Freiheit zu' gilt als das eigentlich demokratiespezifische Moment.

Kombiniert man nun diese beiden Unterscheidungen, so erhält man eine Vier-Felder-Matrix, in der sich die zentralen demokratietheoretischen Überlegungen der Europaforschung gut sortieren lassen. 


\begin{tabular}{|c|c|c|}
\hline & Normativer Ausgangspunkt & $\begin{array}{l}\text { Empirischer } \\
\text { Ausgangspunkt }\end{array}$ \\
\hline Kontrolle & $\begin{array}{l}\text { Institutionen-basierte } \\
\text { Theorien } \\
\text { - Liberale Grundannahmen } \\
\text { - Demokratiedefizit }\end{array}$ & $\begin{array}{l}\text { EU als Zweckverbund } \\
\text { - Legitimation auch } \\
\text { losgelöst von De- } \\
\text { mokratie möglich }\end{array}$ \\
\hline $\begin{array}{l}\text { Ermächti- } \\
\text { gung }\end{array}$ & $\begin{array}{l}\text { Demos-basierte Theorien } \\
\text { - Bürgerschaftliche } \\
\text { Aktivität } \\
\text { - Gemeinwohl/ } \\
\text { Öffentlichkeit }\end{array}$ & $\begin{array}{l}\text { Europäische } \\
\text { Governance } \\
\text { - Deliberative } \\
\text { Verhandlungs- } \\
\text { demokratie }\end{array}$ \\
\hline
\end{tabular}

Auf der linken Seite der Matrix finden sich jene Ansätze, die unmittelbar auf demokratietheoretische Debatten zugreifen. Hier sind besonders zwei Debatten in der Europaforschung wichtig geworden, die anhand ihres ,Ergebnisses ' unterschieden werden können: die Debatte um das Demokratiedefizit und die Debatte um den fehlenden Demos. In der Debatte um das Demokratiedefizit ist die Auseinandersetzung fokussiert auf die institutionelle Qualität europäischer Institutionen. Es wird verhandelt, inwiefern die europäischen Institutionen in der gleichen Weise das Ziel der demokratischen Kontrolle von Eliten ermöglichen bzw. ob diese sogar zu einer Unterminierung der nationalen Demokratie beitragen. Hierfür werden detaillierte Analysen einzelner europäischer Institutionen (vor allem zu Parlament und Kommission, jüngst aber auch verstärkt zum Europäischen Rat sowie zum Europäischen Gerichtshof) bzw. von deren Zusammenspiel unternommen. Insbesondere das Verhältnis zur nationalen Demokratie, zu Parlamenten oder sogar zu den Eingriffsmöglichkeiten einzelner Bürger steht im Vordergrund (beispielhaft für solche Argumentation sind etwa: Grande 1996; Decker 2000; Lord/Beetham 2001). Das Verhältnis von supranationalen und intergouvernementalen Elementen steht im Blickpunkt und wird mal mehr, mal weniger kritisch hinterfragt und zu bewerten gesucht. Besonders viel Augenmerk liegt dabei auf der Frage, ob europäisches Regieren als Immunisierungsstrategie von politischen Eliten (oder Bürokratien) gegenüber der europäischen Bürgerschaft oder nationalen Anliegen zu werten ist.

Demos-basierte Theorien auf der anderen Seite verstehen Demokratie sehr viel emphatischer als eine Form der Selbstregierung eines Kollektivs. 
Die Frage hier ist daher, inwiefern es überhaupt möglich ist, die Heterogenität der europäischen Bürgerschaft (mitsamt der zusätzlichen Instanz staatlicher Willensbildung) in einen gemeinsamen Politikprozess zu übersetzen. Typische Debatten in diesem Kontext drehen sich um die Entstehung bzw. das Vorhandensein von Solidarität und Vertrauen oder um die Möglichkeit der Herstellung eines übergreifenden öffentlichen Raums. Das Ergebnis solcher Erörterungen ist dabei meist, dass es der EU an der Selbstidentifizierung der europäischen Bürger als Gemeinschaft und der damit verknüpften intrinsischen Bereitschaft füreinander einzustehen mangelt (neben Grimm und Weiler, die weiter oben schon angeführt wurden, ist insbesondere Kielmansegg 2003 einschlägig für diese Position). Dies kann entweder als substantieller Mangel (Simson 1991) oder als Problem eines defizitären Prozess der Öffentlichkeitsbildung gedeutet werden (dass hier gerade die aktuelle Krise aber eine neue Wahrnehmung geschaffen haben könnte, zeigt Eder 2014). Das Fehlen eines europäischen Demos stelle ein nachhaltiges Hindernis für jedwede Form europäischer Demokratisierung dar, da ohne Demos auch institutionelle Reformen stets als usurpatorisch empfunden werden müssten. Die Position mündet daher meist in Plädoyers, die Rolle der nationalstaatlichen Demokratie wieder zu stärken und europäische Politikdynamiken zu begrenzen.

Eine besondere Variante dieser Theorielinie stellt der Ansatz von Jürgen Habermas dar. Dessen Verständnis von europäischer Demokratie setzt zwar den Aspekt bürgerschaftlicher Ermächtigung ins Zentrum, er ist jedoch sehr viel optimistischer an der Möglichkeit orientiert, Solidarität durch die Einrichtung eines mehr Repräsentation ermöglichenden politischen Prozesses aufzubauen (Habermas 1998, 1999a, 1999b, 2011, 2014). Habermas übersieht keineswegs, dass es eine Fülle von Problemen gibt, er setzt allerdings darauf, dass - analog zur bundesrepublikanischen Verfassungsgeschichte und dem Modell des Verfassungspatriotismus - eine katalysatorische Wirkung eintreten kann. So fordert er etwa in seiner Auseinandersetzung mit Wolfgang Streecks Krisenhypothese einer notwendig scheiternden, weil dem Kapitalismus gegen die Demokratie zum Sieg verhelfenden Supranationalisierung (Streeck 2013a, 2013b) gerade nicht das europä- 
ische Projekt aufzugeben, sondern in der Krise die Chance zur ReDemokratisierung zu sehen (Habermas 2013). ${ }^{5}$

Sieht man von Habermas' oft kritisiertem optimistischen Ansatz ab, sind die Positionen, die zunächst normativ die Maßstäbe bestimmen und dann auf die EU blicken, überwiegend kritisch. Demokratiedefizit und NoDemos-Hypothese werden zudem einander nicht ausschließend und oft kombiniert verwendet und meist dafür benutzt, die im Nationalstaat herausgebildete Demokratie als bestmögliche Realisierung des Prinzips der Selbstregierung vorzustellen und deren möglichst weitgehende Schonung zu verlangen. Viele Autoren ergänzen die eigenen Überlegungen aber trotzdem sodann um Erörterungen, wieso europäische Integration zu begrüßen oder zumindest nicht zurückzudrehen ist. Das zugleich als potentiell progressiv gewertete europäische Projekt mit all seinem instrumentellen Nutzen zu verwerfen, scheint trotz einer prinzipiell skeptischen normativen Erörterung zu verlustreich. Das mündet in die sich stark selbst zurücknehmende Position, die die Feuilletondebatte um Europa prägt. Demokratiedefizit und No-Demos-Hypothese (bzw. deren argumentative Bausteine) sind zu festen Paradigmen geronnen. Sie werden zwar jeweils in die Tiefe entwickelt und empirisch differenziert (etwa wenn es um die Erforschung der Stärke/Schwäche des Europäischen Parlaments geht), kaum aber werden einmal normative Diskurse jenseits dieser Grundunterscheidung angestellt.

Während in der öffentlichen Debatte die beiden Positionen den allergrößten Teil der Aufmerksamkeit konsumieren, ist in den Auseinandersetzungen der spezialisierten wissenschaftlichen Europaforschung auch die rechte Seite der Matrix von großer Bedeutung. Auch auf dieser lässt sich die Unterscheidung von auf Kontrolle abzielenden, individualistisch-liberal begründeten Ansätzen und stärker partizipatorischen Ansätzen einziehen,

5 Habermas ist in vielerlei Hinsicht ein nahezu idealtypisches Beispiel dafür, was ich in diesem Text als mögliche Leistung politischer Theorie einfordern möchte. Sein Ansatz schöpft direkt aus politischer Theorie und Philosophie, ihm gelingt die Verbindung von Öffentlichkeit und Europaforschung und seine Positionierung hat in vielerlei Hinsicht die fest gezogenen Linien der Debatte ins Rutschen gebracht. Inhaltlich unterscheidet sich seine Theorieentwicklung allerdings in wichtigen Details von Aspekten, die ich in der europäischen Debatte für entscheidend halte, wie ich an unterschiedlichen Stellen entwickelt habe (Thiel 2008, 2012). 
was wiederum zur Unterscheidung von zwei inhaltlichen Positionen führt: Die erste sieht in der EU einen Fall, der einer besonderen Legitimation bedarf, die zweite verweist auf die sich herausbildenden Governance-Praktiken als chancenreiche Uminterpretation demokratischer Prinzipien.

Der erste Ansatz ist vor allem mit den Schriften von Giandomenico Majone (Majone 1994, 1998, 2006) und Andrew Moravcsik (Moravcsik 2002, 2006) verknüpft. Beide argumentieren, dass das pathetische Demokratieverständnis der Debatte den Zweck europäischen Regierens verkenne und die EU den demokratischen Nationalstaat nicht doppeln müsse, um Legitimität (in normativer wie empirischer Hinsicht) erfolgreich beanspruchen zu können. Zu viel Ähnlichkeit sei angesichts des mangelnden Interesses der Bürger an Europa sogar kontraproduktiv, würde weitere Europäisierung doch zu einer ungesunden Machtverlagerung führen. Stattdessen plädieren sie für eine abgestufte Legitimationstheorie, die sich aus der Betrachtung der Geschichte, vor allem aber der Zwecke der Integration entwickelt und jeweils spezifisch fragt, welche Formen der Legitimierung für welche Form der Leistungserbringung am ehesten passend sind. Legitimierungsforderungen werden somit nach Aufgaben und Handlungslogiken erörtert, und der Blick liegt weit mehr auf dem Output-Moment (sowie faktischer Akzeptanz) als auf Input-Elementen (wie aktiver Beteiligung oder prozeduraler Offenheit). Demokratie könne so sogar dann gestärkt werden, wenn die Einflussmöglichkeiten gar nicht steigen, wohl aber die Rationalität und Nachkontrolle (Keohane et al. 2009).

Auf eine nochmal andere Logik setzen jene Ansätze, die nicht die funktionalen, sondern die prozeduralen Besonderheiten europäischen Regierens hervorheben. Hier tritt insbesondere die deliberative Aushandlungslogik überstaatlicher Politik ins Blickfeld, die einen verbesserten Einbezug von Zivilgesellschaft und Experten mit sich zu bringen verspricht. In diesen Diskursen verschwindet die Fixierung auf die Kerninstitutionen europäischer Integration, und der Politikprozess als Ganzer wird wichtiger. Während die Governance-Konzeption dabei zunächst eine allein beschreibende und somit wertneutrale Positionierung entwickelte, kam es bald zu einer Verquickung mit Legitimationskonzepten und -diskursen. Insbesondere die gegenüber dem Nationalstaat gestiegenen Einwirkungsmöglichkeiten der Aushandlungsprozesse und die damit einhergehende verbesserte Rationalität werden als demokratietheoretisch relevant identifiziert. Versatzstücke deliberativer Demokratietheorie sind für diese Erörterung entscheidend, da 
sie begründen helfen, wieso es nicht vorrangig eines aggregativen oder identitätsabbildenden Mechanismus der Repräsentation bedarf, sondern im Erhöhen von Beteiligungschancen und in der Strukturierung des Austauschs selbst schon ein demokratisierendes Element enthalten sein kann. Horizontalität und Deliberation werden so zu wichtigen, fast schon mit Demokratie synonym verstandenen Schlagwörtern in der Debatte (Cohen/ Sabel 1997; Joerges 2000; Neyer 2006, 2009; Sabel/Zeitlin 2008). ${ }^{6}$

Die Diskussionen um die Krise der Demokratie in Europa haben seit dem Aufkommen der Legimationsforderungen an europäische Politik meist eine der vier vorgestellten Grundpositionen zum Ausgangspunkt genommen. Idealtypisch zugespitzt ist somit das analytische Spektrum der Demokratiediskussionen in der Europaforschung umrissen (eine ausführlichere und sehr viel differenziertere Rekonstruktion habe ich an anderer Stelle vorgenommen: Thiel 2012). Welche Theorieansätze dabei als besonders überzeugend gelten und wie sich die Ansätze miteinander kombinieren lassen, ist steten Konjunkturen unterworfen. Seit dem Ende ihrer Formierungsphase ist es aber in dieser Debatte mehr oder weniger dabei geblieben, dass die demokratietheoretischen Prämissen selbst nicht mehr groß zum Thema werden. Wichtiger ist deren Operationalisierung sowie die Bändigung von Komplexität und Ambivalenz. Dies hat den Effekt hervorgebracht, den ich weiter oben als ,konzeptionelle Erschöpfung ' bezeichnet habe. Selbst als höchst einschneidend eingeschätzte Entwicklungen wie die Eurokrise oder der Lissabon-Vertrag führen nicht mehr zu inspirierenden demokratietheoretischen Debatten. In ihnen wird vielmehr nur die Krisendiagnose aus der Perspektive der etablierten Paradigmen aktualisiert, und weil man ohnehin nicht an eine Lösung glaubt, läuft die Diskussion schon im Moment ihrer Anrufung leer. Dadurch wird der eingangs beschriebene Effekt erzielt, dass die Beschreibung der Krise zugleich überall und doch so

6 Theorien dieser Richtung haben relativ klar ihren Scheitelpunkt überschritten und sind nach einer intensiven Diskussion um die Jahrtausendwende heute eher auf dem Rückzug. Dies liegt sowohl an einer gewissen empirischen Ernüchterung und einer wahrgenommenen ,Wiederkehr' des Staates und hierarchischer Organisationsformen von Politik, aber natürlich auch an einer mittlerweile sehr etablierten Kritik der blinden Flecken solcher Ansätze, die oft elitistisch überformt sind und Partizipation mit Technokratie verwechseln (eine umfassende Kritik liefert: Niesen 2008). 
kraftlos ist. Die Ansätze sind in allen Richtungen durchdekliniert, doch aus ihnen selbst lässt sich nur wenig an Ideen zur politischen Reform ziehen. Das Scheitern des Verfassungsprozesses gilt hierfür als der endgültige Beleg, zeigt er doch, dass die Kritiken zwar richtig, aber die Situation trotzdem in hohem Maße unabänderlich ist. Der Ausweg der Forschung besteht darin, immer stärker auf den empirischen Feinschliff zu setzen. Das ändert aber wenig, da so zwar die Differenzierung steigen mag, jedoch keine Brücke zu einem öffentlichen Verstehen geschlagen wird.

\section{EIN ANDERER EUROPADISKURS IST MÖGLICH}

Wenn das hier gezeichnete Bild der Krise der Erforschung der Krise europäischer Demokratie stimmig ist, stellt sich abschließend die Frage, was für alternative Möglichkeiten des Nachdenkens über demokratische Standards und Entwicklungen denkbar sind und wie sich die Routinen durchbrechen lassen, die zur konzeptionellen Erschöpfung der Europaforschung geführt haben.

Es geht mir an dieser Stelle nicht darum, eine eigene substantielle Demokratietheorie ins Spiel zu bringen, die aus sich heraus einen anderen Blick, andere Wertungen oder andere Lösungsansätze hervorbringen würde und zugleich den Spagat zwischen öffentlichem Diskurs und wissenschaftlicher Komplexität bewältigen könnte (wäre dies gefordert, so würden meine Erwägungen in Richtung eines pluralistischen Republikanismus gehen, den ich an anderer Stelle und mit mehr Platz zu plausibilisieren versucht habe: Thiel 2011, 2012). Vielmehr möchte ich im Einklang mit der oben gegebenen Diagnose, die sich auf Strukturen der Forschung und die Herausbildung von Perspektiven fokussierte, nur in die Richtung weisen, aus der, meiner Einschätzung nach, eine Restrukturierung und damit Auffrischung des Diskurses erfolgen kann.

Und hier kommt die moderne Politische Theorie ins Spiel. In diesem von der Europaforschung weitgehend unbeachteten Zweig der Politikwissenschaft ist es in den vergangenen Dekaden zu einer höchst anregenden Auseinandersetzung über die Veränderung der Bedeutung und die richtige Konzeptionalisierung von Demokratie gekommen. Der Hintergrund pluraler, sich zudem global öffnender Gemeinwesen hat eine Vielzahl von Gewissheiten erschüttert und ein neues Nachdenken darüber ausgelöst, was es 
ausmacht und heißt, in einer Demokratie zu leben und politische Repräsentation zu erfahren. Die zeitweilige Hegemonie deliberativ-demokratischer Ansätze, denen eine Aussöhnung zwischen liberalen und partizipatorischen Sichtweisen auf Demokratie gelungen schien, ist nach (und vielleicht auch als Folge von) deren ,Erwachsen-Werden` zu Ende gegangen (für - allerdings affirmative - Periodisierungen der Entwicklung vgl. Bohman 1998; Mansbridge et al. 2012; Elstub 2010; vgl. ferner den Text von Buchstein/Jörke 2003, der die Entwicklungsoptionen in der Demokratietheorie nachzeichnet). In der politischen Theorie der letzten Dekade ist ein neues Interesse an Konflikt und Kontestation erwacht. Radikaldemokratische und republikanische Theorien sind die augenfälligsten Protagonisten dieser Entwicklung (sehr einflussreiche Texte in der Debatte sind etwa: Mouffe 2007, 2014; Agamben et al. 2012; Tully 2008a, 2008b. Zudem sind mittlerweile Sammelbände und Überblickswerke erschienen, die den Trend nachzuvollziehen suchen: Flügel et al. 2004; Marchart 2010).

Anders als in den Demokratietheorien, die das Fundament des normativen Europadiskurses bilden, liegt der Fokus solcher Ansätze auf gesellschaftlichen Kräften, auf deren Entwicklung und Zusammenspiel. Auch wird der Erhalt oder sogar die Verstärkung von Pluralität betont, nicht deren Vermittlung oder Auflösung. Somit steht auch nicht die Suche nach den Schwellenwerten legitimer Herrschaft im Vordergrund, sondern das Nachdenken über die Möglichkeiten der Hinterfragung von Herrschaft und die Chancen permanenter Erneuerung. Dementsprechend wichtig wird der Begriff des ,Politischen', der als Bezeichnung für eine gute und intensive Auseinandersetzung und die Möglichkeit von Veränderung in vielen Theorien einen ähnlich positiven Klang hat wie der Begriff der Demokratie in der klassischen Debatte. So wird ein anderer normativer wie analytischer Maßstab für die Messung der Qualität einer Ordnung benannt, der sich allerdings häufig explizit mit der Demokratie verbindet, aber eben nicht in der Konzipierung einer kollektiven, sich souverän behauptenden Gemeinschaft.

Die auf das Politische abzielenden Demokratietheorien haben nicht nur deshalb Aufmerksamkeit gefunden, weil sie mit ihrer Rückwendung zu Kritik und Ereignis in einem zunehmend szientistischen Wissenschaftsumfeld einen romantisch-nostalgischen Impuls bedienen, sondern auch als Zeitdiagnosen ihre ganz eigene Aktualität gewonnen. So stellen sie eine wichtige Reflexionsfolie - und gelegentlich auch den Stichwortgeber - für die Ent- 
wicklung neuer Protestkulturen dar, die vom Weltsozialforum bis zu Occupy reichen und die Schaffung von Alternativität zum Gebot der Stunde erklären. Mit Hilfe dieser Theorien und ihrer Vokabulare lassen sich Phänomene wie Populismus (und dessen Ambivalenz) oder auch die Gefahren der Entpolitisierung durch technokratische Mechanismen adäquat erfassen und debattieren. Wo viele klassische Demokratietheorien nur auf die Möglichkeiten schauen, wie Herrschaft legitimiert werden kann, sind diese neueren Theorien an der Praxis von Herrschaft und Widerstand interessiert. Sie suchen nach Bedingungen (institutioneller, aber vor allem auch gesellschaftlicher Art), die ein Offenhalten des Politischen möglich machen und damit gerade die Erfahrung von Herrschaft, die in Ohnmacht wurzelt, identifizieren können. Nicht einfach die Realisierung eines Mehrheits- oder eines Gemeinwillens bringt insofern die demokratische Qualität einer Ordnung zum Ausdruck, sondern zuallererst das Entstehen, die Offenheit und die Dynamik eines politischen Prozesses selbst. Nur wenn politische Auseinandersetzung gesucht wird und wenn Räume zur Verfügung stehen, in denen ein Austausch über politische Veränderung möglich ist, ergibt sich überhaupt die Chance, dass Bürger sich Politik aneignen, was Voraussetzung des klassischen Versprechens der Demokratie ist.

Wie aber lässt sich an diese Diskussionen im Kontext der Europaforschung anschließen? Auf durchaus einfache Weise, - und zwar deswegen, weil es bereits eine Vielzahl guter Beschreibungen der Ambivalenzen der Demokratie in Europa und der gefährlichen Tendenz zur Aushöhlung oder Halbierung von demokratischen Entwicklungen gibt (jüngst etwa: Mair 2013; Brunkhorst 2013). Diese Untersuchungen konzentrieren sich schon längst nicht mehr auf institutionelle Details oder die essentialistische Unmöglichkeit von Demokratie oberhalb des Nationalstaats, sondern gehen systematisch der Frage nach, wie Politik erfahren wird und welche SchlieBungsprozesse stattfinden. Sie tun dies jedoch häufig noch, ohne selbst den Anspruch zu formulieren, über den demokratietheoretischen Status von Oppositionsbildung für demokratisches Regieren nachzudenken (eine neue und wichtige Arbeit in dieser Hinsicht ist: Ley 2014)

Und es gibt noch einen weiteren empirischen Anknüpfungspunkt. Er besteht in der Tatsache, dass die Forschungspraxis der Europaforschung dem politiktheoretischen Diskurs viel näher ist, als sie sich selbst eingesteht, und zwar mit Blick auf die wachsende Politisierung der Europäischen Union (Zürn 2006; Zürn et al. 2007; de Wilde 2011). In dieser Literatur 
wird der allgemeine Trend zur konfrontativen Auseinandersetzung beschrieben und der Druck erörtert, unter den das europäische Gemeinwesen gerät, das in Teilen darauf ja auch schon reagiert, wie sich etwa in der Umgestaltung der Europawahl zeigt, die zumindest in Deutschland einen deutlichen Aufmerksamkeitsschub gebracht hat. Diese Literatur kommt oft noch beschreibend oder spekulierend daher, sie könnte aber viel stärker zum Ausgangspunkt für normatives Räsonieren werden, wenn sie sich von der Vorstellung einfacher institutioneller Reformen lösen würde. Anders als in der Literatur der neunziger Jahre kann es nämlich nicht darum gehen, in der Politisierung die Idee der Integration durch Konflikt zu beschwören. Es muss vielmehr über die Kapazität von Institutionen nachgedacht werden, Konflikte auszuhalten und zu repräsentieren. Auch dies unterscheidet sich von den Konzepten von Kontrolle und Ermächtigung, die den klassischen normativen Europadiskurs fundieren, und es weicht ebenso ab von der Idee der Aushandlung oder der funktionalen Rationalität, wie sie aus der stärker analytischen Europaforschung hervorgegangen sind.

Gerade weil diese Diskurse in der Europaforschung bereits existieren und zunehmend Aufmerksamkeit finden, liegt eine stärkere Interaktion von Politischer Theorie und Europaforschung nahe. In einer gemeinsamen Anstrengung wäre es möglich, den Teufelskreis zunehmender Szientifzierung und paralysierender Ohnmachtserfahrung aufzubrechen. Während die Natur und Vielschichtigkeit der Probleme der Demokratie in Europa der Idee einer ,Lösung ' entgegenstehen, lässt sich so doch ein Impuls gewinnen, um der Krisensituation zu begegnen und neue Optionen zu artikulieren. Über die Krise darf nicht nur lamentiert werden, sondern die Wissenschaft muss auf sie mit einer diskursiven Öffnung reagieren, die andere Formen von Bürgerbeteiligung ins Blickfeld rückt. Politische Theorie kann an dieser Stelle einen wichtigen Beitrag leisten und ihre gesellschaftliche Funktion als eine aktivierende, kritische Kraft erfüllen - eine Aufgabe aber, die sie bald angehen muss, da die Krise (und erst recht deren Permanenz) immer auch die Möglichkeit des Scheiterns impliziert. 


\section{LITERATUR}

Agamben, Giorgio/Badiou, Alain/Bensaid, Daniel/Brown, Wendy/Nancy, Jean-Luc/Ranciere, Jacques/Ross, Kristin/Žižek, Slavoj (2012): Demokratie? Eine Debatte, Berlin.

Andrews, David M. (2012): The Rise and Fall of EU Studies in the USA, in: Journal of European Public Policy 19.5, S. 755-775.

Baumann, Zygmunt/Bodoni, Carlo (2014): State of Crisis, Cambridge.

Bellamy, Richard/Castiglione, Dario (2003): Legitimizing the Euro-polity and its Regime: The Normative Turn in EU Studies, in: European Journal of Political Theory 2.1, S. 7-34.

Bohman, James (1998): The Coming of Age of Deliberative Democracy, in: The Journal of Political Philosophy 6.4, S. 400-425.

Brunkhorst, Hauke (2013): Von der Krise zum Risiko und zurück. Marxistische Revisionen, in: Rahel Jaeggi/Daniel Loick (Hg.), Nach Marx, Berlin, S. 412-444.

Buchstein, Hubertus/Jörke, Dirk (2003): Das Unbehagen an der Demokratietheorie, in: Leviathan 31.4, S. 470-495.

Calhoun, Craig (2003): European Studies: Always Already There and Still in Formation, in: Comparative European Politics 2.1, S. 5-20.

Cohen, Joshua/Sabel, Charles (1997): Directly-Deliberative Polyarchy, in: European Law Journal 3.4, S. 313-342.

de Wilde, Pieter (2011): No Polity for Old Politics? A Framework for Analyzing the Politicization of European Integration, in: Journal of European Integration 33.5, S. 559-575.

Decker, Frank (2000): Demokratie und Demokratisierung jenseits des Nationalstaats. Das Beispiel der Europäischen Union, in: Zeitschrift für Politikwissenschaft 1.2, S. 585-629.

Eder, Klaus (2014): The EU in search of its people. The birth of a society out of the crisis of Europe, in: European Journal of Social Theory 17.3, S. 219-237.

Elstub, Stephen (2010): The Third Generation of Deliberative Democracy, in: Political Studies Review 8.3, S. 291-307.

Fenske, Uta/Hülk, Walburga/Schuhen, Gregor (2011): Die Krise als Erzählung. Transdisziplinäre Perspektiven auf ein Narrativ der Moderne, Bielefeld. 
Flügel, Oliver/Heil, Reinhard/Hetzel, Andreas (2004): Die Rückkehr des Politischen, Darmstadt.

Friederichs, Jürgen (2007): Gesellschaftliche Krisen. Eine soziologische Analyse, in: Helga Scholten (Hg.), Die Wahrnehmung von Krisenphänomenen. Fallbeispiele von der Antike bis in die Neuzeit, Köln, S. 1328.

Grande, Edgar (1996): Demokratische Legitimation und europäische Integration, in: Leviathan 24.3, S. 339-360.

Grimm, Dieter (1995): Braucht Europa eine Verfassung?, München.

Habermas, Jürgen (1998): Die postnationale Konstellation und die Zukunft der Demokratie, in: ders., Die postnationale Konstellation, Frankfurt a.M., S. 91-169.

Habermas, Jürgen (1999a): Braucht Europa eine Verfassung? Eine Bemerkung zu Dieter Grimm, in: ders., Die Einbeziehung des Anderen, Frankfurt a.M., S. 185-191.

Habermas, Jürgen (1999b): Der europäische Nationalstaat unter dem Druck der Globalisierung, in: Blätter für deutsche und internationale Politik 46.4, S. 425-436.

Habermas, Jürgen (2011): Zur Verfassung Europas, Berlin.

Habermas, Jürgen (2013): Demokratie oder Kapitalismus? Vom Elend der nationalstaatlichen Fragmentierung in einer kapitalistisch integrierten Weltgesellschaft, in: Blätter für deutsche und internationale Politik 58.5, S. 59-70.

Habermas, Jürgen (2014): Zur Prinzipienkonkurrenz von Bürgergleichheit und Staatengleichheit im supranationalen Gemeinwesen, in: Der Staat 53.2, S. 167-192.

Joerges, Christian (2000): Transnationale „deliberative Demokratie“ oder „deliberativer Supranationalismus“? Anmerkungen zur Konzeptualisierung legitimen Regierens jenseits des Nationalstaats bei Rainer Schmalz-Bruns, in: Zeitschrift für Internationale Beziehungen 7.1, S. 145-161.

Keeler, John (2005): Mapping EU Studies: The Evolution from Boutique to Boom Field 1960-2001, in: Journal of Common Market Studies 43.3, S. 551-582.

Keohane, Robert O./Macedo, Stephen/Moravcsik, Andrew (2009): Democracy-Enhancing Multilateralism, in: International Organization 63.1, S. $1-31$. 
Kielmansegg, Peter Graf (2003): Integration und Demokratie, in: Markus Jachtenfuchs/Beate Kohler-Koch (Hg.), Europäische Integration, Opladen, S. 49-85.

Koselleck, Reinhart (1982): Krise, in: Otto Brunner et al. (Hg.), Geschichtliche Grundbegriffe. Historisches Lexikon zur politisch-sozialen Sprache in Deutschland, Stuttgart, S. 617-650.

Ley, Isabelle (2014): Opposition im Völkerrecht. Ein Beitrag zu den legitimationstheoretischen Grundlagen internationaler Rechtserzeugung und ihrer Anwendung, Heidelberg.

Lord, Christopher/Beetham, David (2001): Legitimizing the EU: Is there a Post-Parliamentary Basis for Its Legitimation?, in: Journal of Common Market Studies 39.3, S. 443-462.

Mair, Peter (2013): Ruling the Void. The Hollowing-Out of Western Democracy, London.

Majone, Giandomenico (1994): The Rise of the Regulatory State in Europe, in: West European Politics 17.3, S. 77-101.

Majone, Giandomenico (1998): Europe's ,Democratic Deficit‘. The Question of Standards, in: European Law Journal 4.1, S. 5-28.

Majone, Giandomenico (2006): The Common Sense of European Integration, in: Journal of European Public Policy 13.5, S. 607-626.

Mansbridge, Jane/Bohman, James/Chambers, Simone/Christiano, Thomas/ Fung, Archon/Parkinson, John/Thompson, Dennis F./Warren, Mark E. (2012): A Systemic Approach to Deliberative Democracy, in: Jane Mansbridge/John Parkinson, Deliberative Systems: Deliberative Democracy at the Large Scale, Cambridge, S. 1-26.

Marchart, Oliver (2010): Die politische Differenz: Zum Denken des Politischen bei Nancy, Lefort, Badiou, Laclau und Agamben, Berlin.

Mergel, Thomas (2012): Krisen verstehen. Historische und kulturwissenschaftliche Anmerkungen, Frankfurt a.M.

Merkel, Wolfgang (2014): Demokratie und Krise. Zum schwierigen Verhältnis von Theorie und Empirie, Wiesbaden.

Moravcsik, Andrew (2002): In Defence of the ,Democratic Deficit': Reassessing Legitimacy in the European Union in: Journal of Common Market Studies 40.4, S. 603-624.

Moravcsik, Andrew (2006): What Can We Learn from the Collapse of the European Constitutional Project?, in: Politische Vierteljahresschrift 47.2, S. 219-241. 
Mouffe, Chantal (2007): Über das Politische, Frankfurt a.M.

Mouffe, Chantal (2014): Agonistik - Die Welt politisch denken, Berlin.

Neyer, Jürgen (2006): The Deliberative Turn in Integration Theory, in: Journal of European Public Policy 13.5, S. 779-791.

Neyer, Jürgen (2009): Die Stärke deliberativer politischer Theorien und das Elend der orthodoxen Demokratietheorie. Eine Replik auf Marcus Höreth, in: Zeitschrift für Politikwissenschaft 19.3, S. 331-358.

Neyer, Jürgen/Wiener, Antje (2010): Political Theory of the European Union, Oxford.

Niesen, Peter (2008): Deliberation ohne Demokratie? Zur Konstruktion von Legitimität jenseits des Nationalstaats, in: Regina Kreide/Andreas Niederberger (Hg.), Transnationale Verrechtlichung. Nationale Demokratien im Kontext globaler Politik, Frankfurt a.M., S. 240-259.

Roitman, Janet (2014): Anti-Crisis, Durham.

Rosamond, Ben (2007): European Integration and the Social Science of EU Studies: The Disciplinary Politics of a Subfield, in: International Affairs 83.2, S. 231-252.

Sabel, Charles/Zeitlin, Johannes (2008): Learning from Difference: The New Architecture of Experimentalist Governance in the EU, in: European Law Journal 14.3, S. 271-327.

Schulze, Gerhard (2011): Krisen. Das Alarmdilemma, Frankfurt a.M.

Schuppert, Gunnar Folke/Pernice, Ingolf/Haltern, Ulrich (2005): Europawissenschaft, Baden-Baden.

Simson, Werner von (1991): Was heißt in einer europäischen Verfassung „Das Volk“?, in: Europarecht 26.1, S. 1-18.

Streeck, Wolfgang (2013a): Gekaufte Zeit. Die vertagte Krise des demokratischen Kapitalismus, Berlin.

Streeck, Wolfgang (2013b): Was nun, Europa? Kapitalismus ohne Demokratie oder Demokratie ohne Kapitalismus, in: Blätter für deutsche und internationale Politik 58.4, S. 57-68.

Thiel, Thorsten (2008): Braucht Europa eine Verfassung? Einige Anmerkungen zur Grimm-Habermas-Debatte, in: Mandana Biegi et al. (Hg.), Demokratie, Recht und Legitimität im 21. Jahrhundert, Wiesbaden, S. 163-179.

Thiel, Thorsten (2011): Die Europäische Union - eine republikanische Ordnung?, in: Rolf Gröschner/Oliver Lembcke (Hg.), Freistaatlichkeit. Theorie und Tradition des Republikanismus, Tübingen, S. 245-269. 
Thiel, Thorsten (2012): Republikanismus und die Europäische Union Eine Neubestimmung des Diskurses um die Legitimität europäischen Regierens, Baden-Baden.

Tully, James (2008a): Public Philosophy in a New Key. Vol. I: Democracy and Civic Freedom, Cambridge.

Tully, James (2008b): Public Philosophy in a New Key. Vol. II: Imperialism and Modern Freedom, Cambridge.

Vobruba, Georg (2007): Kritik der Europakritik. Die intellektuelle Perspektive auf die europäische Integration, in: Osteuropa 57.7, S. 3-12.

Weiler, Joseph H.H. (1995): Does Europe Need a Constitution? Demos, Telos and the German Maastricht Decision, in: European Law Journal 1.3, S. 219-258.

Wengeler, Martin/Ziem, Alexander (2013): Sprachliche Konstruktionen von Krisen. Interdisziplinäre Perspektiven auf ein fortwährend aktuelles Phänomen, Bremen.

Zürn, Michael (2006): Zur Politisierung der Europäischen Union, in: Politische Vierteljahresschrift 47.2, S. 242-251.

Zürn, Michael/Binder, Martin/Ecker-Ehrhardt, Matthias/Radtke, Katrin (2007): Politische Ordnungsbildung wieder Willen, in: Zeitschrift für Internationale Beziehungen 14.1, S. 129-164. 



\section{Res Publica Europae}

Ein bürgerbasiertes Konzept, die politische Integration Europas zu überdenken ${ }^{1}$

ULRIKE GUÉROT

\section{EINLEITUNG - KURZE GESCHICHTE DES EUROPÄISCHEN INTEGRATIONSDISKURSES}

Die Geschichte der politischen Integration Europas ist lang - so lang, dass ganze Studiengänge sich ausschließlich mit ihr beschäftigen und Bibliotheken leicht zu füllen sind. Dabei hat es in den vergangen Jahrzehnten immer wieder besonders drängende Fragen gegeben: Politische Handlungsmöglichkeiten (Hix/Hoyland 1999, 2011) Europas und damit verbunden die Frage nach dem Spannungsverhältnis zwischen Wirtschaftsunion und einer politischen Union; Europäischer Förderalismus, also die Frage nach der prinzipiellen Grundordnung (Wallace 1996; Risse-Kappen 2008); oder Identitäts- und Kulturfragen (vgl. Anderson 1991).

Das Scheitern der europäischen Verfassung 2005 durch die beiden Referenden in den Niederlanden und in Frankreich hat die akademische Auseinandersetzung stimuliert. Insbesondere in Deutschland war die Debatte dominiert von juristischen Argumenten und von detailreichen Diskussionen über die Vor- und Nachteile einer Verfassung sowie die Unterschiede zwischen der Europäischen Union (EU) als „Staatenbund“ oder „Bundesstaat“.

1 Dieser Artikel hätte ohne die wertvolle Mithilfe meiner Mitarbeiterin Victoria Kupsch nicht verfasst werden können. Ihr gilt größter Dank! 
Der politikwissenschaftliche Diskurs konzentrierte sich indes mehr auf Fragen der Regierungsoptionen in einem Mehrebenensystem, ausgehend von neo-funktionalistischen Theorien der Marktintegration und ihren spill-over Effekten auf die politischen Bereiche (Jachtenfuchs 1996, 2010; Scharpf 2002). Bis heute ist die Gemeinsamkeit dieser beider Diskurse über die Gestaltung der Zukunft der Europäischen Union, dass ihre Existenz den meisten Bürgerinnen der europäischen Mitgliedsstaaten - damit den BürgerInnen der EU - gänzlich unbekannt ist.

Erst mit der Eurokrise 2008 wurden die institutionellenn Defizite der EU, insbesondere der Eurozone, deutlich und für größere Teile der Bevölkerung sichtbar. Durch diese neue Aufmerksamkeit bzw. Betroffenheit der europäischen BürgerInnen durch ein dysfunktionales Wirtschafts- und Währungssystem mit erheblichen sozialpolitischen Defiziten begann sodann eine politische Diskussion in Europa: anti-europäischer Populismus wurde zu einem der wesentlichsten Merkmale in mehreren EU Mitgliedsstaaten, insbesondere in Griechenland, Frankreich, Ungarn, Italien, den Niederlanden oder Finnland (Fieschie et al. 2013; Grabow/Hartleb 2013). Vereinfacht gesagt, war die Eurokrise jener ,Moment der Wahrheit', in dem erkennbar wurde, dass der Vertrag von Maastricht schlicht unvollständig war. Mit ihm war eine Währungsunion ohne einen politischen Gegenpart und vor allem ohne eine Fiskalunion geschaffen worden. Diese Defizite waren denjenigen, die an dem Entwurf des Maastrichter Vertrages gearbeitet hatten, bereits 1992 bewusst. $^{2}$ Es bedurfte aber offenbar einer Eurokrise, um die systemischen Mängel der gemeinsamen Währung schmerzhaft zu erfahren und die krude Realität des Euro als „,verwaiste Währung“ - also einer Währung ohne Demokratie - offen zu legen (Pisany-Ferry 2008).

Nach der akuten Krisenphase verlagerte sich die Diskussion dann von rechts- oder politikwissenschaftlichen Fragen auf die - fehlende - soziale und politische Dimension Europas, insbesondere innerhalb der Eurozone. So entstand die sogenannte Euro-governance oder auch Eurorettungspolitik, die zugleich zu einer Institutionalisierung der ,Unionsmethode‘ wurde. Entscheidungen wurden vermehrt als Konsens zwischen den Regierungen der Mitgliedsstaaten außerhalb der bestehenden EU-Verträge getroffen - mit dem vielfach kritisierten Effekt, dass europäische Gemeinschaftsorgane, insbe-

2 Vgl. hierzu Schwarz (2012) und die dazugehörige Diskussion zur „Krönungstheorie". 
sondere das Parlament und die Kommission, geschwächt wurden. ${ }^{3}$ Das Demokratiedefizit bei wichtigen politischen Entscheidungen wurde somit spätestens ab 2010 sichtbar (Guérot 2013a), ebenso wie die langen Schatten, die es auf die demokratischen (Priester 2014) sowie die soziale Strukturen der Eurozone (Tsoukalis 2013) warf. Lösungen für die politische und finanzielle Krise Europas zu finden, wurde vor allem der Europäischen Zentralbank (EZB) und dem Krisenmanagement Mario Draghis überlassen, dessen Worte „die EZB ist bereit zu tun was immer notwendig ist, um den Euro zu retten. Und glauben Sie mir, es wird reichen “4 wohl in keinem Geschichtsbuch über die EU fehlen werden. Versteht man Souveränität im Sinne von Carl Schmitt, ist diese Aussage essentiell: Wenn der Souverän derjenige ist, der über den Ausnahmezustand entscheidet (Schmitt 1923), dann war die EZB der Souverän der Eurozone (und könnte als solcher auch heute noch gesehen werden). Die Zwickmühle des Systems der Euro-governance wird hier sichtbar: Das Euro-System erwies sich als unfähig, auf politischem Weg die notwendigen Lösungen zu finden und diese rechtlich abzusichern und musste darum die politische Steuerung - bzw. sprichwörtlich die Euro-Rettung - an die EZB abgeben. Ein Zustand, der - obgleich Draghis' Worte die erhoffte EuroRettung brachten und daher als solche nicht zu kritisieren sind - aus demokratietheoretischer Perspektive unhaltbar ist.

Dieses Problem - zusammen mit den vielfältigen Ursprüngen der Eurokrise, die weit über einfache Formeln eines verschwenderischen europäischen Südens als Hauptursache für die Schuldenkrise hinausgehen - wurde in der Literatur vielfach analysiert. ${ }^{5}$ Dabei ist die Vielschichtigkeit der Faktoren, die die beklagenswerten Politikbeschränkung auf EU-Ebene beeinflussen - vor allem das Fehlen einer europäischen Exekutive - deutlich herausgearbeitet worden (Veron 2012). Jüngste Forschungsergebnisse beto-

3 Rede von Angela Merkel vor dem Europakolleg in Brügge 02. November 2010. http://www.bundeskanzlerin.de/ContentArchiv/DE/Archiv17/Reiseberichte/be2010-11-02-bruegge-europakolleg.html. [Letzter Zugriff: 12.03.2015]

4 Rede von Mario Draghi bei der Global Investment Konferenz in London am 26. Juli 2012. Verbatim of the remarks made by Mario Draghi. (in Englisch) Verfügbar über die EZB unter http://www.ecb.europa.eu/press/key/date/2012/html/ sp120726.en.html. [Letzter Zugriff am 12.03.2015]

5 In Deutschland insbesondere von Wolfgang Streeck (2013) sowie Daniela Schwarzer und Guntram Wolff (2013). 
nen und belegen zudem die tiefe Verwobenheit der Finanzmarkt-, Bankenund Eurokrise, die mithin weit mehr ist als eine ,Staatsschuldenkrise“ und vor allem auch nicht als solche begonnen hat, sondern vielmehr in eine solche umgedeutet wurde (Simmerl 2013; Offe 2012).

Einerseits begründet sich die vermehrte wissenschaftliche Auseinandersetzung und Antwortensuche in der fehlerhaften politischen Ökonomie Europas (Beck 2012; Habermas 2011c; Menasse 2012). Die Betrachtung der institutionellen Beschaffenheit der EU hat starke Kritik an den technokratischen Strukturen der EU und ihren sozialen und demokratischen Mängel hervorgebracht (Brunkhorst 2014). Andererseits gab es eine wachsende Literatur, die argumentierte, dass die Abwicklung des Euro unausweichlich ist - oder zumindest das Scheitern des Euro in seiner derzeitigen Form feststellte (Geppert 2013; Heisbourg 2013). Europa und der Euro wurden also zunehmend für das Defizit an demokratischen Strukturen und sozialer Politik herangeführt. Demokratie als topos wurde somit im Zuge der Krisen zentraler Bestandteil der Auseinandersetzung mit Europa und hat die zuvor dominante Frage über die Integration Europas abgelöst. Kurz: Durch die Eurokrise wurde aus einer vorgängigen Integrationsdebatte eine europäische Demokratiedebatte.

Dieser Artikel wird in den nächsten Schritten daher nicht die Ursprünge der rechtlichen, ökonomischen und politikwissenschaftlichen Diskussion über die Integration Europas zurückverfolgen, sondern zielt darauf ab, die aktuelle Debatte, politische Trends und die Dynamiken im öffentlichen Politikdiskurs über die europäische Integration und mithin ihren Wandel zu einer Debatte über europäische Demokratie abzubilden.

Im Folgenden wird daher das Konzept der Res Publica Europae vorgestellt, das im wesentlichen zum Ausdruck bringen will, dass es heute (und in Zukunft) nicht mehr um die Vereinigung von Staaten (,Vereinte Staaten von Europa"), sondern um die Vereinigung von BürgerInnen in Europa geht, also - im Sinne einer gemeinsamen europäischen Sache (res publica europae) aller europäischen BürgerInnen, um eine „Europäischen Republik“. Diese konzeptionelle Verschiebung beruht auf dem Eingeständnis der kontraproduktiven Rolle der Nationalstaaten im politischen System der EU und insbesondere innerhalb der Eurozone; oder, um die Analyse von Ulrich Beck zu teilen: Der Integrationsprozess Europas bzw. die europäische Demokratie kann dann nicht gelingen, wenn die Autorität über den Grad der Integration bei den Staaten verbleibt. Kern dieser These ist, dass das euro- 
päische Projekt den europäischen BürgerInnen als Souverän des Prozesses zurück gegeben werden muss. ${ }^{6}$

\section{NACH DER KRISE: EUROPÄISCHER POPULISMUS UND DIE DEBATTE ÜBER ,MEHR ODER WENIGER“ EUROPA}

Die europäische Politik nach der Krise befindet sich also in einer Sackgasse. Neben den bereits genannten Gründen liegt das vor allem auch an der wachsenden Zahl von BürgerInnen, die die demokratischen und sozialen Missstände erkannt haben und ihre Unzufriedenheit artikulieren. Daraus entstanden ist eine ungesunde und polarisierende Debatte über ,mehr oder weniger“ Europa - bei der die Befürworter von „weniger Europa“ derzeit scheinbar überzeugender sind und Wahlerfolge einfahren. Von Marine Le Pen in Frankreich über Syriza in Griechenland, True Fins in Finnland bis hin zu Geert Wilders in den Niederlanden: An anti-europäischem Populismus mangelt es dieser Tage nicht. Auch in Deutschland, wo die Abwesenheit populistischer Stimmen politische Analysten lange rätseln und auf die Stabilität des deutschen Parteiensystems verweisen ließ, gewinnt die Alternative für Deutschland (AfD) inzwischen mehr und mehr an Stimmen und Anhänger, wie die jüngsten Wahlen in drei Bundesländern gezeigt haben, in denen die AfD jeweils auf einen Stimmenanteil von mehr als $10 \%$ gekommen ist. Während populistische Bewegungen von rechts sich ideell auf Konzepte von Souveränität und Nationalstaatlichkeit konzentrieren, zielt linke populistische Kritik vor allem auf die unsoziale Natur der Eurogovernance. Der Euro-Populismus in Nordeuropa ist vor allem eine Reaktion auf die sogenannte „Transferunion“, während der Euro-Populismus in Südeuropa insbesondere die sozialen Konsequenzen der Austeritätspolitik anprangert. ${ }^{7}$ Es ist daher unschwer zu erkennen, dass die pro-europäischen

6 Als juristischen Hintergrund wird hier auf die Arbeiten des Staatsrechtlers Hans Kelsen rekurriert, wonach Souveränität ein individualisierbares Konzept ist. Es geht also nicht um „Volks“-Souveränität. Siehe dazu Brunkhorst 2013 sowie Somek 2007.

7 Speech by president of the parliamentary group of SYRIZA-USF, Alexis Tsipras. „Europe is on the edge“, in London on March 15, 2013 http://www.syn.gr/ gr/keimeno.php?id=31419. [Letzter Zugriff: 12.03.2015]. „It is widely accepted 
Argumente, also eine bejahende Erzählung Europas, erheblich unter Druck geraten sind und derzeit von zwei Seiten zeitgleich angegriffen werden: von populistischen, anti-europäischen Linken wie Rechten. Die Konfrontationslinie innerhalb der Europa-Diskussion verläuft damit entlang eines europäischen „Mainstreams“, der das derzeitige Euro-Governance-System - und mithin die beschriebenen technokratischen Strukturen - verteidigt bzw. verteidigen muss, und einer rechts- wie linkspopulistischen systemischen Opposition gegen das derzeitige Euro-Govenance-System bzw. die Politik in Europa. Mithin verläuft die Trennlinie dieser (Euro-Populismus-)Diskussion auch nicht entlang von Landesgrenzen, sondern quer durch die einzelnen EU-Länder und ihre Parteienfamilien hindurch.

Noch wesentlicher ist: Das „Pro-Europa“-Argument kann im Grunde deshalb nicht mehr überzeugen, da es versucht, ein mit systemischen Mängeln behaftetes, brüchiges, juristisch zwar absolut legitimes, aber eben intuitiv als undemokratisch und unsozial empfundenes System zu verteidigen. Es ist in der Tat sehr schwierig bis unmöglich, das derzeitige europäische System bzw. die aktuelle Euro-Governance unter Anlegung von demokratietheoretischen Kriterien zu verteidigen. Es läuft im Grunde darauf hinaus, ein politisches System zu verteidigen, in dem das Europäische Parament, eigentlich die souveräne Vertretung der BürgerInnen, nur minimale Rechte hat - so hat das Europäische Parlament z.B. kein Initiativrecht - und im Grunde nicht als kontrollierende Legislative fungieren kann. Innerhalb der Euro-Governance lag die eigentliche Entscheidungskompetenz, z.B. über die griechischen bail-out-Pakete, fast allein beim Deutschen Bundestag. Dies hat indes genau das Problem aufgeworfen, nämlich dass die Entscheidungen des deutschen Bundestags, einem nationalen Parlament, Auswirkungen über die nationalen Landesgrenzen hinaus - nämlich auf die ganze Eurozone - hatten, und mithin europäische BürgerInnen getroffen haben, die ihrerseits kein Wahlrecht zum Bundestag und mithin keine Stimme hatten. Diese Nicht-Kongruenz von demokratisch gewählten Entscheidungsträgern und Betroffenen ist die Essenz des europäischen Demokratiedefi-

that the strategy of European Elites and the Greek government cannot provide a viable prospect of exit from the crisis. The only thing that austerity has accomplished is to plunge Europe into economic depression and to throw Greece in an unprecedented humanitarian crisis. Austerity is leading the Greek economy and society down a catastrophic path.“ 
zits. De facto ist der Bundestag zu einer Art „US-Kongress“ für die Eurozone mutiert, in dem er für die ganze Eurozone entschieden hat, ohne von allen BürgerInnen der Eurozone gewählt worden zu sein (vgl. Somek 2014: 688).

Zudem ist die Rolle des Europäischen Rates bei den europäischen Governance-Entscheidungen undurchsichtig und die Rolle großer EUMitgliedsländer wie Deutschland und Frankreich bei EU-Entscheidungen problematisch dominant, was Probleme für die kleineren Mitgliedstaaten in den Entscheidungsprozessen aufwirft.

Auch dies macht es schwer, heute noch einfach für Europa, gar für „mehr Europa“ zu sein. Dem politischen System Europas fehlt de facto eine parlamentarische Opposition im klassischen Sinne und mithin weitgehend die Möglichkeit der Reversibilität von Entscheidungen. Das Europäische Parlament stimmt meistens in der Formation einer ,großen Koalition ‘ von $70 \%$ ab, da es einer Institutionenlogik und keiner (partei-)politischen Logik folgt: es braucht eine Zweidrittel-Mehrheit, um den Europäischen Rat zu überstimmen. Letztlich führt dies innerhalb des Europäischen Parlamentes zu einer Aufweichung der traditionellen Parteigrenzen, die den politischen Prozess innerhalb der EU für die BürgerInnen aber dadurch weniger einsehbar macht. Letztlich ist die Europäische Kommission der tatsächliche Agenda-Setter, indem hier die meisten Gesetzesinitiativen vorbereitet werden und sie zusätzlich über das „Europäische Semester“ bestimmt. All dies und die Rolle der Troika sind wohl die wichtigsten Zutaten für die ,europäischen Technokratie‘ im Eurokrisen-Management und haben konsequenterweise die Ressentiments der betroffenen BürgerInnen befördert. De facto wurde über die Eurokrise ohne wirklich legitimierte demokratische Entscheidungsfindung eine angebotsorientierte Sparpolitik in europäischen Verträgen zementiert und damit fast irreversibel gemacht.

Das EU-Regierungssystem entspricht in seiner Anlage als sui generis System mit seiner triangulären Beziehung zwischen Rat, Kommission und Parlament nicht dem, was die BürgerInnen intuitiv als undemokratisch wahrnehmen, weil nämlich das EU-System nicht dem klassischen demokratischen System einer Gewaltenverteilung entspricht. Das Europäische Parlament ist im Wesentlichen nicht ,,politisiert“ und stimmt zu über 90\% in den Abstimmungen mit „,70\% + “ Mehrheiten ab, um den Europäischen Rat überstimmen zu können (Maurer 2013). Natürlich ist dieses EU-System im (verfassungs-)rechtlichen Sinne nicht ,undemokratisch“, haben die europä- 
ischen Staaten diese Strukturen doch über Jahrzehnte in immer wieder neuen, ratifizierten Verträgen festgelegt. Dennoch ist das Ergebnis recht weit entfernt von einer Demokratie im Sinne von Montesquieu's Gewaltenteilung zwischen Legislative und Exekutive. Die Politisierung und mithin Demokratisierung der EU ist also der Schlüssel für die endgültige Überwindung der derzeitigen Eurokrise.

In diesem Zusammenhang erscheint es fast überflüssig darauf hinzuweisen, dass, während die demokratischen Mitentscheidungsmöglichkeiten der EU-BürgerInnen in der EU-Governance beschränkt sind, das europäische System indes vor allem für LobbyistInnen ideale Mitsprachemöglichkeiten einräumt, die das System zu ihrem Nutzen beeinflussen und so oft zu den tatsächlichen Souffleuren Brüsseler Politik werden. Vom Verbraucherschutz über Steuerfragen bis hin zur Energiepolitik sind für jedes Politikfeld InteressensvertreterInnen in den Brüsseler Fluren unterwegs. Der Einfluss gut organisierter Lobbygruppen ist gegenüber dem Einfluss nichtorganisierter BürgerInnen, die ihre Interessen im europäischen Alltag nicht so gut vertreten können, übermächtig. Die europäischen BürgerInnen können ihren sozialen und sonstigen Interessen kaum gemeinsam Ausdruck verleihen, da sie transnational nur gering organisiert sind. Der unterschiedliche Organisationsgrad zwischen den professionellen Interessenvertretern und den eigentlich zu repräsentierenden BürgerInnen ist immens. Hinzu kommen die Sprachenvielfalt sowie das Fehlen einer gesamteuropäischen Öffentlichkeit; die Sprachbarriere im Sinne von Ludwig Wittgenstein „Die Grenze meiner Sprache ist die Grenze meiner Welt“ wird zur eigentlichen Hürde bei der europäischen BürgerInnenvertretung (Grimm 1995; Guérot 2012).

Die mithin problematische Organisation demokratischer Prozesse auf der horizontalen Ebene in Europa führt dazu, dass Europadiskussionen letztlich immer zu vertikalen Konfrontationen zwischen der europäischen Ebene und den Nationalstaaten führen. Die technokratische Struktur der EU von heute bietet einen hervorragenden Nährboden für anti-europäischen Populismus. BürgerInnen, die mit europäischen Beschlüssen oder Richtlinien unzufrieden sind, bleibt mangels demokratischer Mitsprache und der Möglichkeit, Entscheidungen systemisch zu revidieren, im Grunde keine andere Wahl, als gegen die EU als Ganzes zu sein.

Konsequenterweise gibt es andauernde Kritik gegen die ,Brüsseler Bürokratie“ und ,Überregulation“ aus Brüssel. Verkannt wird dabei, dass nicht 
„Brüssel“, also die europäischen Institutionen oder Beamten, sondern Lobbygruppen und deren zugehörige Unternehmen vielfach die wahren Initiatoren $^{8}$ europäischer Regulierungspolitik sind. Die inzwischen mehr als berühmte ,Gurkenkrümmung' ist das beste Beispiel dafür, denn tatsächlich ging der Impuls für die Gurkenkrümmungsrichtlinie (EWG, Nr. 1677/88) nicht von einem regelungswütigen Beamten der Europäischen Kommission aus, sondern von einem Zusammenschluss von Bauern- und Handelsverbänden, die den Platz der Transportkisten optimaler nutzen wollten und so eine einheitliche Krümmung definieren wollten. Als die Kommission wegen der übermäßigen Kritik an der Regulierung über die Krümmung von Gurken die Aufhebung der Verordnung von 1989 beschloss, war der Widerstand der Industrie erheblich. Vor allem der deutsche Bauernverband, aber auch die europäischen Verbände Copa-Cogeca und Freshfel wurden letztlich nur wegen der nationalen Scharmützel von Horst Seehofer überwunden, denn schließlich sah man auch in Bayern ein, dass sich generelle europäische Bürokratiekritik nicht mit konkreter Interessenpolitik von Bauernverbänden vereinbaren lässt. ${ }^{9}$ Zudem wird die Eigenverantwortung nationaler Regierungen bei solchen Regulierungsprozessen schlichtweg unterschlagen. Jedem Regelungsvorschlag der Europäischen Kommission geht eine umfassende Bedarfsanalyse voraus, für die sogenannte Weiß- und Grünbücher verfasst werden. $\mathrm{Zu}$ jedem Zeitpunkt könnten sich nationale Administrationen gegen vermeintliche ,Brüsseler Regelungswut' wehren, anstatt den schwarzen Peter auf Brüssel abzuschieben. Die nationalen Regierungen haben die Möglichkeit, zu diesen Weiß- und Grünbüchern Position zu beziehen. Allzu oft bleibt diese Möglichkeit jedoch ungenutzt. Brüssel ist dann umso mehr der ideale Sündenbock. Gerade so wird aber der Eindruck von ,Brüssel“ als einer undurchsichtigen Struktur gefördert, was dem anti-europäischen Populismus mühelos in die Hände spielt. Die Absurdität von Normen wie dem Grad der Gurkenkrümmung ist genau das, worauf die oft kenntnislose Stammtisch-Kritik aufbaut, um den ,Regulationswahn“ der EU anzuprangern. Diese Beispiele treffen dann auf die begründeten Vorbehalte der BürgerInnen über die europäische Demokratie und überspannen so den Bogen des Akzeptablen. Enttäuschung über das

8 Studie über Lobbying in der Europäischen Union http://corporateeurope.org/ sites/default/files/attachements/financial_lobby_report.pdf.

9 Siehe hierzu auch Kremer 1992. 
europäische Projekt und Abkehr von Brüssel sind die Folge. Das Bürokratieargument ist damit eines der schlagkräftigsten Argumente der Populisten gegen Europa und ölt jede ,weniger Europa“-Diskussion. Gleich danach rangiert die oft irreführende Diskussion über das „Subsidiaritätsprinzip“.

Hinter diesem zunächst so eingängigen wie mittlerweile vertrauten Wort - Subsidiarität - verbirgt sich im Europadiskurs ein doppelter Irrtum. Zum einen entstammt der Begriff der katholischen Soziallehre (NellBreuning 1980) und wurde dort verwendet, um die Beziehung zwischen dem Individuum und der Gesellschaft - und die Grenzen der Verantwortung - zu definieren. Dies entspricht mitnichten seiner heutigen Verwendung in Europadiskussionen, die vor allem den Kontext von MehrebenenRegierungssystemen aufspannt: Die jeweils höhere Ebene soll nur machen, was die jeweils untere Ebene nicht kann. Letzteres ist im deutschen Sprachgebrauch eine föderale Gliederung, nicht originär ein subsidiäres System. Zum zweiten wird der Subsidiaritätsbegriff immer weiter ausgedehnt, um de facto regionale oder nationale „kulturellen Unterschiede“ aus einem einheitlichen europäischen Rechtsrahmen herauszulösen, und Ausnahmetatbestände geltend zu machen. Im Zusammenspiel mit den ohnehin problematischen horizontalen Strukturen der europäischen Demokratie wird das Subsidiaritätsprinzip zur Rechtfertigung für nationale oder gar regionale Eigeninteressen: Es werden „Kompetenzkataloge“ entwickelt, in denen bestimmte Länder ihre Kerninteressen verankert sehen wollen und die daher von niemand anderen berührt werden dürfen. ${ }^{10}$ Meistens geht es dabei dann aber wahrlich nicht um ,politische Kerninteressen“ oder strategische Notwendigkeiten. In den politisch hoch aufgehängten „Kompetenzkatalogen“ geht es profan um normannische Äpfel oder niederländische Milch in Schulen. Die Verbindung zur Subsidiaritätsdebatte liegt da, wo die BürgerInnen aufgrund der Defizite der horizontalen Demokratiegestaltung in Europa - es ist für die BürgerInnen nicht mehr erkennbar, wo europäische Politik gemacht wird und von wem - nach dem Subsidiaritätsprinzip rufen (müssen), um wieder Einfluss auf die Entscheidungsprozesse zu gewinnen. Der Ausweg könnte auch hier eine Verbesserung der europäischen Demokratie sein, anstatt den einheitlichen europäischen Rechtsraum durch subsidiäre Ausnahmetatbestände zu zerpflücken. Wenn Schulen in der Normandie z.B. eher mit Übersee-Äpfeln als mit eigenen versorgt werden, liegt dies

10 Z.B. die Kompetenzkataloge der britischen und niederländischen Regierung. 
unter Umständen an einem Handelsabkommen der EU mit Ländern, deren Äpfel billiger produziert werden als die lokalen. Nun haben aber die BürgerInnen der betroffenen EU-Regionen fast keinen Einfluss auf diese Handelsabkommen, sie stimmen nicht darüber ab. Genau daraus entsteht die Dysfunktionalität der europäischen Demokratie, die den Ruf nach Subsidiarität und ,weniger Europa“ laut macht.

Die einzige Möglichkeit, diese ungesunde Dichotomie zwischen „mehr oder weniger" Europa zu überwinden, kann daher nur sein, die öffentliche Debatte zu einer Debatte über ein ,anderes Europa " umzusteuern und die Diskussion aus ihrer vertikalen Struktur - Europa vs. (subsidiäre) Nationalstaaten - in eine horizontale Struktur zu bringen: Wie gestalten wir gemeinsam eine andersartige europäische Demokratie?

Fragestellungen wie ,mehr EU oder mehr Mitgliedstaaten“, „,mehr EUKompetenzen oder mehr Subsidiarität“ richten ihr Augenmerk stets und ausschließlich auf die Schwierigkeiten des Mehrebenen-Regierungssystems der EU und die nach wie vor fehlende Verbindung zwischen den nationalen Parlamenten und dem Europäischen Parlament. Die Aufrechterhaltung der Dichotomie zwischen Nationalstaat und EU kann aber nicht zielführend sein. Die tatsächliche Frage für die zukünftige Europadiskussion muss daher jene nach einer besseren Verknüpfung der nationalen mit der europäischen Legislative sein, also die Schaffung einer ,verschränkten Legitimität“" zwischen nationalen Parlamenten und dem europäischen Parlament. Nur so würden beide Parlamentsebenen, die letztlich die BürgerInneninteressen vertreten, nicht mehr gegeneinander ausgespielt. Mit anderen Worten: es bedarf des Nachdenkens über die Ausgestaltung eines europäischen Zwei-Kammern-Systems, damit Entscheidungen über gemeinsame Prioritäten der EU-BürgerInnen durch eine, verschränkte' Legislative getroffen werden können, damit eine res publica europae für das europäische Gemeinwohl demokratisch einstehen kann.

Die entscheidende Frage wäre dann, wie man eine richtiggehende, mehrsprachige europäische Demokratie gestalten könnte - zunächst für die Eurozone - und zwar mit einer Gewaltenteilung, die es BürgerInnen ermöglichen würde, ihre Interessen in einem transnationalen Rahmen zu äußern. Die nationalen Politikräume würde de-homogenisiert: Es ginge nicht mehr um die deutsche oder die französische Meinung - aggregiert über die nationalstaatliche Stimme im Europäischen Rat -, sondern, jenseits von nationalen Grenzen, um die Meinung europäischer BürgerInnen zu einem be- 
stimmten politischen Thema. Indes gibt es keine einfache Antwort auf die Frage einer europäischen Demokratie und ihren möglichen Organisationsformen. Wie Wolfgang Streeck zu Recht hervorhebt (Streeck 2013), würde in einer solchen ,jakobinisch-unitaristischen“ europäischen Demokratie die Dominanz der Deutschen ein erhebliches Problem darstellen. Man müsste also einen geeigneten Weg finden, den Schutz von ,Minderheiten“ zu sichern. $^{11}$

Hier zeigt sich zudem, dass die Frage der Neugestaltung der europäischen Institutionen eine grundlegende Frage aufwirft, nämlich wie das Europäische Parlament ggf. so verändert werden könnte, dass es dem Prinzip „one man one vote“ entspricht. Bei welcher Kammer würde, anders formuliert, in einem neuartigen Zweikammersystem der Proportionalitätsfaktor und bei welcher der Gleichheitsfaktor berücksichtigt? Die Tatsache, dass das Europäische Parlament in seiner jetzigen Form nicht dem Prinzip ,one man one vote" entspricht, ist eines der wichtigsten Argumente des Bundesverfassungsgerichts für seine Auffassung, dass es noch nicht im traditionellen Sinn demokratisch sei. Darum wurde anlässlich der Ratifizierung des Lissabonner Vertrags das sogenannte „Integrationsverantwortungsgesetz“ eingeführt, durch das der Bundestag als eigentlicher Träger der Legitimität de facto beauftragt wurde, den europäischen Integrationsprozess zu überwachen.

Aus der ,mehr-oder-weniger-Europa“ Matrix auszubrechen, durch die permanent diskursiv die Nationalstaaten gegen die europäische Ebene gegeneinander ausgespielt werden, würde bedeuten, alternative Konzepte wie etwa das einer „Demoikratie“ (Nikolaidis 2013) zu betrachten, um sich aus festgefahrenen Diskussionen über das fehlende europäische Staatsvolk herauszulösen. Demoi - als Plural von Demos - ist der Versuch, alle europäischen Völker gleichsam additiv als europäisches Staatsvolk zu verstehen, die ihre europäische polity, ihr politisches System, gemeinsam begründen.

11 Allerdings nur, wenn man sich, wie offensichtlich Streeck, beim Minderheitenschutz auf nationale oder gar ,ethnische' Kriterien beruft, die einen solchen Minderheitenschutz begründen würden; nicht, wenn man einem transnationalen europäischen Bürgerbegriff das Prinzip der politischen und sozialen Gleichheit zugrunde legt. 
Das Fehlen eines einzelnen Demos ist eines der klassischen (juristischen und konservativen) Argumente gegen die Möglichkeit einer Politisierung Europas, ${ }^{12}$ da Demos stets in Verbindung mit nationalen Grenzen und damit nationaler Souveränität verstanden wird. Der europäischen Realität, in der wirtschaftliche Probleme (z.B. Steuerharmonisierung für Unternehmen) oder soziale Probleme längst grenzüberschreitend wahrgenommen werden, wird dies indes nicht mehr gerecht. Einen pan-europäischen, also transnationalen europäischen Parlamentarismus zu schaffen, der die althergebrachten Grenzen der bisherigen (nationalstaatlichen) Demokratie und seiner Souveränitätsansprüche öffnet, wäre eine Antwort darauf, den realen Lebenswelten und den sozialen Bedürfnissen der BürgerInnen zu entsprechen. Demoikratie - in Verbindung mit der Kelsen'schen Idee einer Individualisierung des Prinzips der Souveränität, die eben nicht nur kollektiv, als Volkssouveränität, sondern von den europäischen Bürgern einzeln delegiert und ausgeübt werden kann - könnte ein neues theoretisches Konzept sein, um gemeinen einen transnationalen politischen Körper in Europa zu bilden.

Die De-Homogenisierung und De-Strukturierung der national konturierten Debatten in politischen Überzeugungen einzelner europäischer BürgerInnen wäre somit ein Schlüsselelement für die europäische Demokratie und die Politisierung des europäischen Projektes. Die meisten Diskussionen über strittige Themen in Europa verlaufen längst nicht mehr entlang nationaler Grenzen- oder Diskussionslinien. Zum Beispiel gibt es in der Energiepolitik nicht einfach die französische Position (Kernenergie) oder die deutsche Position (erneuerbare Energien) oder die polnische Position (Kohle), sondern eine Vielzahl von nationalen Akteuren mit unterschiedlichen Positionen. In Frankreich sind viele BürgerInnen für erneuerbare Energien, während andererseits einige deutsche Unternehmen durchaus froh wären, an der Kernenergie noch länger festhalten zu können und auch in Polen viele kleine und mittlere Unternehmen in erneuerbare Technologien investieren: Die Aggregation nationaler Positionen durch die Vertretung der Staaten im Rat schafft also originär das Problem. Staaten ersetzen de facto Wahlkreise (Somek 2014). Die Rubicon-Frage für den aktuellen politischen Stillstand der europäischen Integration ist also, ob die EU sich in ein vollständig demokratischen System umwandeln ließe, mit einem erhöhten Maß

12 So auch jüngst Grimm 2014. 
an Politisierung ihrer Schlüsselinstitutionen und mit einer transnationalen Meinungsbildung der europäischen BürgerInnen.

\section{DER ENTWURF EINES ANDEREN EUROPA UND Die Probleme moderner Demokratie}

Das derzeitige Problem der europäischen Demokratie und des aktuellen Anti-Euro-Populismus wurzelt, wie oben dargelegt, in Teilen in der derzeitigen Technokratiefalle der EU. Andererseits aber in der schwierigen Aufgabe der Schaffung einer gemeinsamen europäischen Öffentlichkeit und Medienlandschaft, die natürlich an Sprachbarrieren der BürgerInnen scheitert. Europa, genauer die Eurozone, kämpft derzeit mit einer dysfunktionalen Demokratie, für die indes eine Vielzahl von Faktoren ausschlaggebend ist, u.a. eine sich verändernde Medienlandschaft, die Effekte des Internets, die Globalisierung, steigende soziale Ungleichheiten etc., die keineswegs Europa und seine Demokratie alleine betreffen.

Die moderne Demokratie sieht sich derzeit an vielen Orten und Stellen der Welt unter Druck und in einer Belastungsprobe. So kann die Analyse des suboptimalen institutionellen Aufbaus der EU nur ein Faktor unter den vielen Gründen für Anti-Euro-Populismus sein. Die akademische Forschung über die eigentliche Bedrohung der modernen Demokratie hat in den letzten Jahren zugenommen: So werden Prinzipien der partizipativen Demokratie, Funktionen der Evaluierung und Kontrolle und das Problem der mangelnden Effizienz ausgiebig diskutiert (Keane 2009). Zudem befasst sich mittlerweile ein ganzer Forschungszweig mit Fragen der „Postdemokratie“ (Crouch 2009; Habermas 2011b). In den Worten von Pierre Rosanvallon unterscheiden wir heute zwischen „Demokratie als ein Regime der Volkssouveränität und der Demokratie als eine Gesellschaft von Gleichen“ (Rosanvallon 2013: 83) und haben damit das Verständnis von Demokratie auf ihren formalen Charakter (,Wahlen“) reduziert, wobei immer mehr verkannt wird, dass Demokratie im Grunde auf „einem sozialen Körper“ basiert (Rosanvallon 2013: 48). Grob gesagt lässt sich aus Studien längst erkennen, dass ökonomisch benachteiligte BürgerInnen schlicht deshalb nicht wählen gehen, weil sie nicht mehr daran glauben, dass sie mit ihrer Stimmabgabe ihre eigenen Lebenssituation verbessern können (Bühlmann et al. 2008). Damit schreitet de facto die Aushöhlung der partizipati- 
ven Demokratie voran. In den Worten von Colin Crouch: „Man kann abstimmen, aber man hat keine Wahl“. Dieses Phänomen trifft in besonderem Maße auf die europäische Politik zu, da die Abstimmungs- und Beteiligungsmöglichkeiten der BürgerInnen noch reduzierter sind als auf der nationalstaatlichen Ebene. Mehr noch: Im April 2012 wurden beispielsweise alle verfügbaren politischen Kräfte mobilisiert, um in Griechenland ein angekündigtes Referendum zu verhindern, da begründetermaßen damit gerechnet werden musste, dass sich die BürgerInnen gegen die Austeritätspolitik der Troika aussprechen würden (Habermas 2011a). Die BürgerInnenmeinung wurde also von der Exekutive bewusst ausgegrenzt, was Jürgen Habermas als Exekutivföderalismus bezeichnet hat.

In globaler Perspektive befindet sich die Demokratie heute - in Europa und anderswo - unter gesellschaftlichem Druck. Dabei lassen sich grob vier Metatrends kategorisieren, die bei der generellen Bedrohung der Demokratie auch für andere Teile der Welt relevant sind:

- Demokratie und Effizienz: In China z.B. können Flughäfen ohne aufwendige Bürgerbeteiligung schneller gebaut werden.

- Demokratie und Digitalisierung: Der Einfluss des Internets auf die repräsentative Demokratie.

- Demokratie und die soziale Krise: Welchen Gleichheitsgrundsatz können moderne Demokratien noch einlösen?

- Demokratie und Demographie bzw. Generationendynamiken: Die Jugend ist in alternden Gesellschaften strukturell entmachtet.

Viel von dem latenten oder offenen Populismus dieser Tage und der Malaise der europäischen Gesellschaften lässt sich auf einen oder mehrere dieser Metatrends zurückführen. Daran lässt sich aber ebenso erkennen, dass nicht alle derzeitigen Defizite des politischen Systems der EU in ihren defizitären Strukturen begründet liegen. Die Diskussion über eine moderne europäische Demokratie im 21. Jahrhundert muss daher mit Blick auf diese globalen Trends geöffnet werden. Erst dann ist es möglich, die Frage zu beantworten, ob Europa für diese Fragen bzw. Metatrends das Problem oder nicht eher die Lösung ist. 


\section{Die Idee einer Res Publica Europae und DIE EUROPÄISCHE DEMOKRATIE}

Die Idee, die Europäische Union von einer Staaten- in eine BürgerInnenunion umzuwandeln, ist nicht neu, aber sie gewann durch die Eurokrise erheblich an Dynamik - und zwar sowohl in der akademischen wie auch politischen Diskussion. Die Kernidee der hier vorgeschlagenen res publica europae ist es, das Konzept der „Vereinigten Staaten von Europa“ hin zu einer „Europäischen Republik“ zu entwickeln. Das zentrale Argument dafür ist anzuerkennen, dass, ,solange die Nationalstaaten die Autorität über den Grad der europäischen Integration haben“ (Beck 2012: 33), eine gemeinsame, transnationale Demokratie in Europa nicht funktionieren kann. Der Europäische Rat und seine Rolle im politischen System der EU sind de facto die größte Hürde für eine wirkliche politische Union. Erneut plädierte darum jüngst Jürgen Habermas für den Ausbau der EU zu einer supranationalen Demokratie (Habermas 2014).

Erstmalig formulierte Stefan Collignon die Idee einer Europäischen Republik (2002) und etablierte so die Idee, dass ,Euroland“ als eine aggregierte Wirtschaft, als ein Wirtschaftsraum mit einer volkswirtschaftlichen Gesamtrechnung verstanden werden sollte. Demzufolge müsste die ,Euroland'-Volkswirtschaft so organisiert werden, dass die einzelnen Mitgliedsstaaten nicht in eine Konkurrenz um Steuern, Sozialleistungen, Exporte und Arbeitskräfte verfallen, sondern auf der Grundlage gleicher fiskalischer und sozialer Regeln wirtschaften. Auf der Basis des eigentlich schon jetzt geltenden politischen und sozialen Gleichheitsgrundsatzes europäischer Bürger im Maastrichter Vertrags müsste perspektivisch eigentlich auch eine gleiche Besteuerung (z.B. Einkommenssteuer) und ein gleicher Zugang zu sozialen Rechten (z.B. ein europäisches Bürgergeld) für alle europäischen Bürger durchgesetzt werden. Dieser Ansatz einer res publica europae durch die politische Ökonomie wurde in der Zeit des europäischen Verfassungskonvents 2003 durch juristische Studien über die rechtlichen Möglichkeiten, Europa republikanisch zu denken, erweitert. Wie Armin von Bogdandy ausführt (2005), ist der Begriff der Republik ein bereits im Mittelalter verwendeter Rechtsbegriff für die grenzüberschreitende Ausübung hoheitlicher Gewalt - genau das, was die Eurozone heute brauchen würde. Das essentielle Problem der Eurozonen-Governance ist heute, dass der Grundsatz der Solidarität nach wie vor an den Begriff der Souveränität und damit an na- 
tionale Grenzen gebunden ist (Guérot 2013b). Mit anderen Worten: die Steuergelder des einen Landes können - zumindest derzeit - nicht zur finanziellen Unterstützung eines anderen Landes (beispielsweise zur Bankenrettung) innerhalb der EU genutzt werden, ohne dabei den Grundsatz ,keine Besteuerung ohne Repräsentation“ zu verletzen (Kadelbach 2006). Alle aktuellen Diskussionen über die griechischen Rettungspakete, das ESM (den Europäischen Stabilitätsmechanismus) oder den OMT (Outright Monetary Transaction)-Beschluss der Europäischen Zentralbank stoßen sich an dieser verfassungsrechtlichen Grenze. In Deutschland gilt dies umso mehr, da das Verfassungsgericht in Karlsruhe die öffentliche Euro-Rettungsdebatte dominiert - bis hin zu einem Grad, der einmal getroffene Entscheidungen quasi unanfechtbar macht (Kundani 2014). Alle aktuellen Probleme der Bankenunion bzw. der Eurorettungs-Diskussion wurzeln in dieser Sackgasse: eine europäische Haftungsgemeinschaft, de facto ein Eurozonen-Budget, so notwendig es ökonomisch wäre, ist politisch weder durchsetzbar noch vorgesehen. Haftung und Verantwortlichkeit innerhalb der Eurozone liegen mithin nicht auf der gleichen Ebene. Diese Logik findet sich in der OMT-Entscheidung von Karlsruhe, der problematischen Diskussion über die EZB als einem, lender of last resort ${ }^{\star}$ und schließlich den Schwierigkeiten bei der Schaffung eines Single Resolution Fund (SRF) im Rahmen der Bankenunion, also einer gemeinsamen Bankeneinlage bei der Sitzung des Europäischen Rates im März 2014. ${ }^{13}$ Der Eurozone fehlt eine vollständige, horizontale Demokratie mit Gewaltenteilung, die eine Entfaltung des Prinzips ,,no taxation without representation“ und damit eine gemeinsame parlamentarische Verantwortung als Grundlage für eine Haftungsgemeinschaft innerhalb der Eurozone überhaupt erst möglich machen würde.

Zuletzt hat das Konzept Europas als Republik von politikwissenschaftlicher Seite zusätzlichen Auftrieb bekommen, vor allem bei der Betrachtung des europäischen Integrationsprozesses durch die Linse der Demokratietheorie, besonders Konzepte der liberalen, kommunitären oder deliberativen Demokratietheorien (Thiel 2012).

Im Kern geht es um die Entstehung eines politischen „Wir“ in Europa, das konstitutiv für eine neue Form der europäischen Demokratie sein könn-

13 Beschluss des Europäischen Rats. 21. März 2014. Verfügbar unter: http://www. consilium.europa.eu/uedocs/cms_data/docs/pressdata/en/141749.pdf. 
te. Die Hürden zu diesem Wir und einer kollektiven Identität als Grundlage für diese europäische Demokratie sind vielfältiger Natur. Ebenso komplex ist die Diskussion über die (un)mögliche Politisierung Europas. Demokratie umfasst letztlich weit mehr als die Institutionen und das politische System. Sie beruht auch auf länderspezifischen Eigenheiten, auf kulturellen Traditionen und Klientelismen - wie beispielsweise soziale Transferleistungen zwischen gesellschaftlichen Gruppen organisiert werden - und bezieht sich damit auf weitaus mehr als eine rein rechtliche oder wirtschaftliche Logik. Was Demokratie ausmacht, findet sich vor allem im Bereich des Sozialen, jenseits der Orte für formelle Beteiligung (Rosanvallon 2013: 33). Genau das macht die Schaffung einer europäischen Demokratie mit einer inneren Balance zwischen kulturell bedingten disketionären Spielräumen und einem einheitlichen rechtlichen Rahmen so schwierig.

Die Idee, dass Europa unter einem politisch-kulturell allgemeingültigen Demokratiemodell vereint werden könnte, das von allen europäischen BürgerInnen gleichermaßen akzeptiert würde, scheint relativ unmöglich. Der 2005 wegen der beiden Referenden in den Niederlanden und in Frankreich gescheiterte europäische Verfassungsprozess hat gezeigt, dass die Idee einer europäischen Verfassung vorerst obsolet ist, besonders da die politischen Diskurse seit der Euro-Krise noch stärkere Renationalisierungstendenzen aufweisen. Und dennoch: wie jüngere Studien belegen, haben die europäischen Bürger in ihrer Mehrheit das Prinzip der politischen und sozialen Gleichheit in Europa längst akzeptiert (Gerhards/Lengsfeld 2013). Darauf ließe sich der Wunsch nach einer neugestalteten europäischen Demokratie begründen.

Die Frage des ,europäischen Hamiltonian Moment" (McCormick 2012; The Economist 2012) - nämlich ob die europäische Schuldenkrise analog zum 19. Jahrhundert in den USA, wo der amerikanische Bürgerkrieg letztlich zu einer Haftungsunion führte - ein ähnliches Ergebnis zeitigen könnte, steht für die EU an diesem Punkt aus und bleibt zu beantworten: es geht nach wie vor um die Frage der Überwindung nationalstaatlicher (Haushalts-) Souveränität innerhalb von Euroland. De facto würde die Neugründung Europas als Republik aber eine constitutante erfordern, in der die europäischen Bürger genau dies mandatieren. Ein Schritt auf diesem Weg wäre ein europaweites Referendum, in dem das Ergebnis der Abstimmung nicht mehr auf nationaler Basis ausgezählt würde. Das wäre bereits ein verfas- 
sungsrechtlicher und politischer Quantensprung in Europa; leider ist ein solcher in naher Zukunft nicht sehr wahrscheinlich.

Allerdings nimmt die politische Dynamik für solche Ideen stetig zu. So hat Bundespräsident Joachim Gauck in seiner Europarede von 2013 bereits die Worte einer europäischen res publica genutzt und eben nicht die Formulierung der sonst vielbemühten „Vereinigten Staaten von Europa“ gewählt. $^{14}$

Wenig später wurde das „Manifest für die Begründung einer Europäischen Republik“ (Menasse/Guérot 2013) - zunächst auf Deutsch - veröffentlicht, aber schon bald in weitere europäische Sprachen übersetzt. Das rechtliche Konzept einer res publica europae wurde in weiteren Artikeln (Bogdandy/Guérot 2013) schließlich vertieft. Im Januar 2014 schickte die Europäische Bewegung Italien einen offenen Brief an Ministerpräsident Letta, in dem sie sich offen für die Schaffung einer Europäischen Republik aussprach. Die Formel der res publica europae birgt eine Chance, die derzeit im System angelegten systemischen Defizite Europas zu überwinden, indem sie einen Neuentwurf Europas ermöglicht. Nicht umsonst ist die Republikidee, wie eine neue Habilitationsschrift erarbeitet hat, das wohl tragfähigste politische und verfassungsrechtliche Konzept der europäischen Geistesgeschichte (Nowrot 2014). Europa könnte sich dies zunutze machen.

Auf den Punkt gebracht könnte das Konzept einer res publica europae für die Eurozone auf den folgenden Merkmalen beruhen: In einer rechtlichen oder institutionellen Perspektive könnte ein vollständiges parlamentarisches System mit einer Zweikammer-Struktur entstehen, in der das europäische Parlament volles Initiativrecht hätte und in der damit die Legitimität der nationalen Parlamente und des europäischen Parlaments ,kombiniert' (Pernice 2013) bzw. ,verschränkt' werden könnten. Damit wäre es möglich, die Blockadestruktur des Europäischen Rates zu überwinden und die angestrebte Verschiebung des politischen Systems hin zu einer horizontalen Demokratie auf dem Grundsatz der Gewaltenteilung zwischen Legislative und Exekutive zu ermöglichen (Kadelbach 2006). Legislaturperiode und Haushaltszyklus der EU würden aufeinander abgestimmt werden, parlamentarische Verantwortung und Haftung auf gleicher politischer Ebene

14 Joachim Gauck, Rede zu Perspektiven der europäischen Idee, Februar 2013. http://www.bundespraesident.de/SharedDocs/Reden/DE/Joachim-Gauck/Reden/ 2013/02/130222-Europa.html. [Letzter Zugriff: 12.03.2015] 
angelegt. Dieses neue europäische Parlament (,Eurozonenparlament“) hätte volle Budgethoheit über die Ausgabenstruktur der Eurozone.

In wirtschaftlicher und sozialer Sicht würde zum einen die Finanzkraft der Eurozone, also ihr gemeinsames Budget, erhöht werden und zugleich würden gemeinsame automatische Stabilisatoren, wie z.B. eine gemeinsame europäische Arbeitslosenversicherung, geschaffen werden. In sozialen und steuerlichen Angelegenheiten würden gleiche Rahmenbedingungen etabliert, etwa eine einheitliche Unternehmenssteuer (um das Steuershopping großer Konzerne innerhalb Europas zu verhindern ${ }^{15}$ ), aber auch eine einheitliche Einkommens- oder Vermögenssteuer in der ganzen Eurozone. Innerhalb der Eurozone würde durchgesetzt, dass auf der Basis einer gleichen und unteilbaren europäischen Unionsbürgerschaft die gleichen Rechte und der gleiche Zugang zu sozialen Sicherungsleistungen für alle Eurozonen-BürgerInnen unabhängig von ihrem „Heimatland“ bestehen. Die volle Portabilität von sozialen Versicherungsleistungen, insbesondere im Gesundheitsbereich oder für Rentenzahlungen, würde gewährleistet. Eine solche demokratische und soziale europäische Demokratie müsste natürlich auch das Recht haben, eigene Steuern zu erheben.

Dies würde die Mobilität in Europa erhöhen und gleichzeitig Arbeitsmigration basierend auf Lohndumping vermindern; also auch den (Lohn-) Wettbewerb der Mitgliedstaaten untereinander (Faist 2013). Europa als politische Union wäre sozial(er). Der Idee einer res publica europae liegt die Analyse zugrunde, dass das eigentliche Einkommensgefälle in Europa de facto nicht entlang nationalstaatlicher Grenzen verläuft, sondern vielmehr entlang eines Zentrum/Peripherie-Gefälles auf der einen Seite und einem Stadt/Land-Gefälle auf der anderen Seite. Fiskalischer Ausgleich in Europa müsste daher im Grunde nicht zwischen Nationen, also einem vermeintlich wohlhabenden Deutschland und einem vermeintlich armen Griechenland verhandelt werden, sondern zwischen Wachstumsregionen und strukturschwachen Regionen. Letztere sind in fast allen Euroländern meistens ländliche Gebiete oder Gebiete in der europäischen Peripherie. Jenseits dieses regionalen Faktors geht es in der Eurokrise mehr um die Austragung und Verhandlung von Klassenkonflikten, denn um nationale Konflikte ent-

15 Ein Thema von aktueller politischer Brisanz seit Bekanntwerden der Steuerhinterziehungsmodellen von Luxemburg, in die der neue EU-Kommissionspräsident Jean-Claude Juncker verwickelt ist. 
lang von Ländergrenzen: sowohl in Deutschland (etwa die Lidl-Verkäuferin) wie in Griechenland (etwa der Hafenarbeiter) haben durch die systemischen Mängel der Euro-Governance jeweils die kleinen Arbeiter, Sparer und Angestellten verloren; die (Export-)Industrie, die Banken oder die Reeder haben gewonnen. Aufgrund fehlender Parameter einer europäischen Demokratie ist Euroland aber nicht in der Lage, diese regionalen und Klassenkonflikte politisch in einem transnationalen Rahmen aufzulösen, sondern verfällt immer wieder in eine Land-gegen-Land Debatte, bei der gegenseitige Schuldzuweisungen die Schlagzeilen bestimmen. Wären wir in der Lage, beim europäischen Politik-Design die nationalstaatlichen Grenzen als entscheidende Konturierung des Diskurses wegzulassen, könnte dieser ,strukturelle Denkfehler' gleichsam mental und emotional beseitigt werden, dann könnte sich das politische Projekt Europa neue wirtschafts- und sozialpolitische Mechanismen und Instrumente erschließen, die auf politische und soziale Gleichheit der Unionsbürger zielen und damit die Akzeptanz Europas fördern würden.

Die regionale Komponente Europas im institutionellen Aufbau mitzudenken hieße auch, den bereits existierenden Realitäten und ihren Dynamiken gerechter zu werden. Statt sich auf die ,Wiedererlangung der Wettbewerbsfähigkeit‘ entlang nationaler Grenzen zu konzentrieren, und zwar unabhängig von geographischen Elementen oder anderen Faktoren wie etwa der Bevölkerungsdichte, könnten so einerseits transnational gleiche rechtliche und soziale Rahmenbedingungen für die europäischen BürgerInnen geschaffen werden; andererseits könnte die europäische Wirtschaftspolitik sensibel und differenziert auf den Unterschied zwischen Wachstumsregionen und strukturschwachen Regionen eingehen, ohne eindimensional nur das Exportwachstum von europäischen Volkswirtschaften fördern zu wollen: Griechenland etwa wird nicht Exportweltmeister im Maschinenbau und sollte es auch nicht werden, da wir die griechischen Inseln als Urlaubsziele brauchen - aber Brandenburg oder Mecklenburg-Vorpommern werden eben sowenig Exportweltmeister. Ebenso kann man bestreiten, dass Slowenien überhaupt eine , unabhängige“ nationale Volkswirtschaft ist, da sie im wesentlichen von einigen großen deutschen Konzernen abhängt und 
zum Cluster der deutschen Automobilindustrie gehört. ${ }^{16}$ Das derzeitige europäische Politik-Design, z.B. die ganzen makroökonomischen EurokrisenProgramme der EU (,Two-Pack', Six-Pack'), ist so zweifelhaft in seiner Ausrichtung und Wirkung, da es immer noch von allein nationalen Zuständigkeiten ausgeht und dabei die Verflechtungen der industriellen Wertschöpfungsketten in Europa übersieht.

Die res publica europae würde es erlauben, die europäischen Politiken auf transnationale, industrielle Cluster auszurichten, anstatt eine zwischenstaatliche Konkurrenz z.B. in der Chemieindustrie innerhalb der Eurozone zu befördern. Dies wäre eine Grundlage für eine volkswirtschaftliche Gesamtrechnung in Europa. Dafür wäre es indes notwendig, von der Einteilung der Eurozone in Schuldner- und Gläubigerländer abzulassen (Soros 2013). Der populäre Diskurs, demzufolge die Euroländer in einem Standortwettbewerb zueinander stehen, ist irreführend. Die Eurozone müsste vielmehr als eine aggregierte und gemeinsame Volkswirtschaft verstanden werden, die sich einen neuen contrat social gibt und die sowohl ihr Verhältnis zwischen Markt und Staat als auch das Verhältnis zwischen Arbeit und Kapital auf europäischer Ebene neu ordnet, so dass eine europaweite Distribution des aggregierten Gewinns gelingen kann. Derzeit ist der Reichtum innerhalb der Eurozone sehr ungleich verteilt (EU Observer 2013; Europäische Kommission 2014). So hat 2012 eine McKinsey-Studie festgestellt, dass der aggregierte Gewinn für die Eurozone in den vergangenen zehn Jahren rund $300 \mathrm{Mrd}$. Euro betragen hat, von denen rund die Hälfte nach Deutschland ging, ein Viertel nach (Nord-)Italien und nur das restliche Viertel in die anderen Euro-Länder. Es ist kein Wunder, dass Euroland unter den daraus resultierenden sozialen Ungleichheiten leidet: EuroGewinne und Euro-Belastungen werden eben nicht durch demokratische politische Arbitrage - arm/reich, jung/alt, Arbeit/Kapital - innerhalb von Euroland verteilt, sondern entlang nationaler Grenzen ,verhandelt'. Sowohl das Verhältnis von Markt und Staat wie auch das Verhältnis von Arbeit und Kapital sind dysfunktional innerhalb der Eurozone, da es eben keine gemeinsame politische Verhandlungsebene (z.B. keine einheitliche europäische Tarifpolitik) gibt. Die europäische Wirtschaftsordnung hat sich ver-

16 Vergleiche Zoltán Pogátsa/Cristian Ghinea, „What kind of capitalism for eastern Europe?" (2011), http://www.eurozine.com/articles/2011-01-12-pogatsa-en.html. [Letzter Zugriff: 19.02.2015]. 
selbständigt, das Wirtschaftliche (europäische Ebene) und das Soziale (nationale Ebene) sind entkoppelt. Auch hier zeigt sich wieder, dass das Fehlen eines handlungsfähigen europäischen Exekutivorgans, also einer Regierung, und eines starken gemeinsamen und transnationalen Euro-Parlaments die Demokratie in der Eurozone aushöhlt und stets national konturierte und oft Lobby-gesteuerte - Ergebnisse produziert werden, anstatt für alle europäischen Bürger gute transnationale Lösungen im Sinne des europäischen Gemeinwohls zu ermöglichen. Derzeit besteht keine Möglichkeit, dieses Defizit und damit auch die europäische Verteilungsungleichheit zu überwinden. Nur das Konzept einer res publica europae, einer transnationalen europäischen Demokratie, jenseits von nationalen Grenzen, wäre letztlich die Lösung der augenblicklichen Malaise Europas!

\section{LITERATUR}

Action Committee for European Democracy (2007): A New Treaty and Supplementary Protocols. Explanatory Memorandum, 4-06-2007. http:// www.eui.eu/Documents/RSCAS/Research/ACED/ACED2007NewTrea tyMemorandum-0406.pdf. [Letzter Zugriff: 10.03.15]

Anderson, B. (1991): Imagined Communities: Reflections on the Origin and Spread of Nationalism, London.

Auer, S. (2013): The End of the European Dream, in: Eurozine, 22 February. http://www.eurozine.com/articles/2013-02-22-auer-en.html. [Letzter Zugriff: 23.02.15.]

Beck, U. (2012): Das deutsche Europa, Berlin.

Bogdandy von, A. (2005): Die Europäische Republik, in: APuZ 36, S. 21-27. Bogdandy von, A./Guérot, U. (2013 ): Eine neue Leitidee - die europäische Republik, in: Frankfurter Allgemeine Zeitung 219, 20 September. http:// www.faz.net/aktuell/politik/staat-und-recht/europaeische-union-unddeutschland-eine-neueleitidee-die-europaeische-republik-12581462.html. [Letzter Zugriff: 23.02.15.]

Brunkhorst, H. (2014): Das doppelte Gesicht Europas, Berlin.

Bühlmann, M./Merkel, W./Weßels, B./Müller, L. (2008): The Quality of Democracy. Democracy Barometer for Established Democracies. Zürich: National Centre of Competence in Research Democracy of the Swiss National Science Foundation, Working Paper 10a. 
Collignon, S. (2002): The European Republic, London.

Crouch, C. (2009): Post-Democracy, Cambridge.

Diez, T. (1996): Postmoderne und europäische Integration Die Dominanz des Staatsmodells, die Verantwortung gegenüber dem Anderen und die Konstruktion eines alternativen Horizonts, in: Zeitschrift für Internationale Beziehungen 2, S. 25-281.

Engemann, C. (2003): Electronic Government. Vom User zum Bürger. Zur kritischen Theorie des Internets, Bielefeld.

EU-Observer (2013): Germany to Face EU Trade Surplus Probe.13 November. http://euobserver.com/news/122093. [Letzter Zugriff: 23.02.15].

Europäische Kommission (2014): Exportstärke ist gut, Binnenkonjunktur zu schwach. 6 March. http://ec.europa.eu/deutschland/press/pr_releases/ 12152_de.htm. [Letzter Zugriff: 23.02.15.]

European Constitutional Group (1993): A Proposal for a European Constitution, London.

Faist, T. (2013): Soziale Ungleichheiten durch soziale Sicherung in Europa, in: Leviathan 41.4, S. 574-598.

Fieschi, C./Morris, M./Caballero, L. (Hg.) (2013): Populist Fantasies: European Revolts in Context, London.

Gerhards, Jürgen/Lengsfeld, Holger (2013): Wir, ein europäisches Volk? Sozialintegration und die Idee der Gleichheit aller europäischen Bürger, Wiesbaden.

Geppert, D. (2013): Ein Europa das es nicht gibt - die fatale Sprengkraft des Euro, Berlin.

Glienicker Gruppe (2013): Aufbruch in die Euro-Union. ZEIT Online, October. http://www.glienickergruppe.eu. [Letzter Zugriff: 23.02.15.]

Grabow, K./Hartleb, F. (2013): Europa - nein danke? Studie zum Aufstieg rechts- und nationalpopulistischer Parteien in Europa. Konrad Adenauer Stiftung e.V., Sankt Augustin. http://www.kas.de/wf/doc/kas_36200544-1-30.pdf. [Letzter Zugriff: 23.02.15.]

Grimm, D. (1995): Braucht Europa eine Verfassung?, in: Juristenzeitung 50.12, S. 581-591.

Grimm, D. (2014): Europa ja, aber welches?, in: Merkur 68.12, S. 10451058.

Groupe Eiffel (2014): Pour une communauté politique de l'Euro. February, http://www.groupe-eiffel.eu. [Letzter Zugriff: 20.02.15.] 
Gründiger, W. (2014): Renten für die Babyboomer, in: ZEIT Online, 7. April. http://www.zeit.de/politik/deutschland/2014-04/rente-mit-63-teuerunsozial. [Letzter Zugriff: 20.02.15.]

Guérot, U. (2012): Is Europe the New Babel? The Role of Language in Building a Transnational Democracy. Lecture at the New York University, 18. May, 2012.

Guérot, U. (2013a): Europa zwischen Demokratie und Legitimationsdefizit, in: APuZ 6-7, February. http://www.bpb.de/apuz/154376/zur-zukunftder-europaeischendemokratie. [Letzter Zugriff: 23.02.15.]

Guérot, U. (2013b): Zwischen Haushalts- und Legitimationsdefizit: Zur Zukunft der europäischen Demokratie, in: APuZ 6-7, S. 3-10.

Habermas, J. (1999): The European Nation State and the Pressure of Globalization, in: New Left Review 235, S. 6-59.

Habermas, J. (2011a): Rettet die Würde der Demokratie, in: Frankfurter Allgemeine Zeitung, 4 November. http://www.faz.net/aktuell/feuilleton/ euro-krise-rettet-die-wuerde-der-demokratie-11517735.html. [Letzter Zugriff: 19.02.15.]

Habermas, J. (2011b): Europe's Post-democratic Era, in: Guardian, 10. November. http://www.theguardian.com/commentisfree/2011/nov/10/ jurgen-habermas-europe-post-democratic. [Letzter Zugriff: 19.02.15.]

Habermas, J. (2011c): Zur Verfassung Europas, Berlin.

Habermas, J. (2014): Warum der Ausbau der Europäischen Union zu einer supranationalen Demokratie nötig und wie er möglich ist, in: Leviathan 42.4, S. 524-539.

Heisbourg, F. (2013): La fin du rêve européen, Paris.

Hix, S./Hoyland, B. (1999 und 2011): The Political System of the European Union, London.

Jachtenfuchs, M. (1996): Conceptualizing European Governance, in: K. E. Jørgensen (Hg.), Reflective Approaches to European Governance, London, S. 39-50.

Jachtenfuchs, M. (2010): Der Wandel des regulativen Mehrebenensystems in der EU, in: Der moderne Staat 3.1, S. 109-124.

Kadelbach, S. (2006): Vorrang und Verfassung: Das Recht der Europäischen Union im innerstaatlichen Bereich, in: C. Gaitanides/S. Kadelbach/G. C. Rodriguez (Hg.), Europa und seine Verfassung, BadenBaden, S. 219-234.

Keane, J. (2009): Death and Life of Democracy, London. 
Kremer, U. (1992): Die Gurkennorm und ihre Hintermänner. Anmerkungen zur Brüsseler Bürokratie, in: Neue Züricher Zeitung Folio, http://folio. nzz.ch/1992/oktober/die-gurkennorm-und-ihre-hintermanner. [Letzter Zugriff: 19.02.15.]

Kundani, H. (2014): Even Germany's Intellectual Elite is Falling Out of Love with the EU, in: EU-Observer, 28. März 2014.

Maurer, A. (2013): Der Preis der Stärke, in: FAZ, 20 October. http:// www.faz.net/aktuell/politik/die-gegenwart/europa-der-preis-der-staerke12625868.html. [Letzter Zugriff: 23.02.15.]

McCormick, D. (2012): Europe Needs its Own Fiscal Union Moment, in: Financial Times, 20 June. http://www.ft.com/cms/s/0/40c037ea-baf311e1-b445-00144feabdc0.html. [Letzter Zugriff: 23.02.15.]

Menasse, R. (2012): Der Europäische Landbote, München.

Menasse, R./Guérot, U. (2013): Es lebe die europäische Republik! in: Frankfurter Allgemeine Zeitung, 28 March. http://www.faz.net/aktuell/ wirtschaft/eurokrise/zukunft-europas-es-lebe-die-europaeischerepublik-12126084.html. [Letzter Zugriff: 22.02.15.]

Meyer, T. (2004): Die Identität Europas, Frankfurt a.M.

Morozov, E. (2011): The Net Delusion: How Not to Liberate the World, in: The Guardian, 9 January.

Nell-Breuning, O. von (1980): Gerechtigkeit und Freiheit. Grundzüge katholischer Soziallehre, München.

Neyer, J. (2013): Globale Demokratie, Baden-Baden.

Nikolaidis, K. (2013): European Demoicracy and its Crisis, in: JCMS 51.2. http://www.sant.ox.ac.uk/people/knicolaidis/00NicolaidisJCMS2013Demoicracy.pdf. [Letzter Zugriff: 23.02.15.]

Nowrot, K. (2014): Das Republikprinzip in der Rechtsordnungengemeinschaft. Methodische Annäherungen an die Normalität eines Verfassungsprinzips, Jus Publicum. Bd. 237, Tübingen.

Offe, C. (2012): 2 1/2 Theories on Democratic Capitalism, in: IWMpost, 109, S. 2-4.

Pernice, I. (2013): The Autonomy of the EU Legal Order - Fifty Years After Van Gend. Walter Hallstein-Institut, WHI-Paper 08.

Piketty, T. (2014): Capital in the 20th Century, Harvard.

Piris, J. C. (2013): The Future of Europe: Towards a Two-Speed EU?, Cambridge. 
Pisany-Ferry, J. (2008): Une Monnai orpheline, in: Le Monde, 27 May. http://www.lemonde.fr/idees/article/2008/05/27/la-monnaie-orphelinepar-jean-pisaniferry_1050264_3232.html. [Letzter Zugriff: 23.02.15.]

Pogátsa, Z./Ghinea, C. (2011): What kind of capitalism for eastern Europe? http://www.eurozine.com/articles/2011-01-12-pogatsa-en.html. [Letzter Zugriff: 19.02 .15$.

Priester, K. (2014): Governance in Europa: Auf dem Weg in die Postdemokratie?, in: Blätter für deutsche und internationale Politik 4, S. 99-110.

Progressive Centre (2012): Why Social Democratic Parties Can No Longer Cater to their Electorate?, London.

Risse-Kappen, T. (2008): Exploring the Nature of the Beast: International Relations Theory and Comparative Policy Analysis Meet the European Union, in: Journal of Common Market Studies 34.1, S. 53-80.

Rosanvallon, P. (2013): The Society of Equals, Harvard.

Schmitt, C. (1923): Soziologie des Souveränitätsbegriffs und politische Theologie, in: Melchior Palyi (Hg): Hauptprobleme der Soziologie. Erinnerungsgabe für Max Weber, München/Leipzig.

Schwarz, H. P. (2012): Helmut Kohl. Eine politische Biografie, München.

Schwarzer, D. und Wolff, G. B. (2013): Memo to Merkel: Post-election Germany and Europe. Bruegel Policy Brief, 2013/05. http://www. bruegel.org/publications/publication-detail/publication/794-memo-tomerkel-post-election-germany-andeurope. [Letzter Zugriff: 22.02.15.]

Simmerl, G. (2013): Der Diskurs der Krise. Eurozone und deutsche Öffentlichkeit 2009-2012. Master-Arbeit, Humboldt Universität zu Berlin.

Somek, A. (2007): Kelsen lives, in: The European Journal of International Law 18.3, S. 409-451.

Somek, A. (2011): Europe: Political, Not Cosmopolitan, Discussion Paper SP IV 803, WZB Berlin, S. 21.

Somek, A. (2013): Sozialpolitik in Europa: Von der Domestizierung zur Entwaffnung, Beiheft 1. Europarecht 49.

Somek, A. (2014): The Darling Dogma of Bourgeois Europeanists, in: European Law Journal 20.5, S. 688.

Soros, G. (2013): How to Save the European Union from the Euro Crisis. Speech delivered at the Center for Financial Studies, Goethe University in Frankfurt, Germany. 9. April. http://www.georgesoros.com/interviewsspeeches/entry/how_to_save_the_european_union_from_the_euro_ crisis/. [Letzter Zugriff: 23.02.15.] 
Soros, G./Schmitz, G. P. (2014): The Tragedy of the European Union: Why Germany Has to Save the Euro in Order to Save Itself, München.

Stiglitz, J. (2011): The Price of Inequality: How Today's Divided Society Endangers Our Future, New York.

Streeck, W. (2013): Gekaufte Zeit, Berlin.

The Economist (2012): The Future of the EU (2). Don't Count on a Hamilitonian Moment. 28 May. http://www.economist.com/blogs/charlemagne/ 2012/05/future-european-union-part-2. [Letzter Zugriff: 23.02.15.]

Thiel, T. (2012): Republikanismus und die Europäische Union. Eine Neubestimmung des Diskurses um die Legitimität europäischen Regierens, Baden-Baden.

Tsoukalis, L. (2013): Euro Zone Crisis Management and the New Social Europe, in: Columbia Journal of European Law 20, S. 31-76.

Veron, N. (2012): The Challenges of Europe's Fourfold Union. Bruegel Policy Contribution, 2012/13. http://www.bruegel.org/publications/ publication-detail/publication/741-the-challenges-of-europes-fourfoldunion. [Letzter Zugriff: 23.02.15.]

Wallace, H./Wallace, W. (Hg.) (1996): Policy Making in the European Union, Oxford.

Wüllenweber, W. (2012): Die Asozialen. Wie Ober- und Unterschicht unser Land ruinieren - und wir davon profitieren, München. 


\section{Krise und Partizipation in der Europäischen Union}

Für eine neue Politik der Bürgerbeteiligung am Beispiel der Energiepolitik

JAN-HENDRIK KAMLAGE UND PATRIZIA NANZ ${ }^{1}$

Die Europäische Union (EU) galt lange als friedens- und wohlstandsicherndes Referenzprojekt einer postnationalen und grenzüberschreitenden politischen Ordnung. Der damit verbundene Optimismus ist einer vorwiegend pessimistischen Sichtweise gewichen. Die EU steckt seit über einem Jahrzehnt in einer tiefgreifenden und existenzbedrohenden Krise, die in ihrer Komplexität kaum noch zu überblicken ist und sich einfachen Lösungen weitgehend entzieht: Bankenkrise, Staatsschuldenkrise, Immobilienkrise, ökonomischer Niedergang, soziale Spaltung zwischen reichem Norden und armen Süden und die Verelendung von Teilen der Bevölkerungen in einigen EU-Staaten. Eine wesentliche Ursache der Krise liegt für viele Beobachter in der fehlerhaften Einführung der Währungsunion, die den Schritt zu einer wirtschaftspolitischen Union unterließ und so eine effektive politische Koordinierung der sehr unterschiedlichen ökonomisch-kulturellen Ausgangs- und Wettbewerbsbedingungen der Mitgliedsstaaten unmöglich machte (vgl. u.a. Streeck 2013b, Offe 2013).

1 Unser Dank geht an Alexander Nolte für die tatkräftige Unterstützung zu diesem Beitrag. 
Die Folgen sind desaströs. Die öffentlichen Haushalte vieler Staaten sind hoffnungslos überschuldet - sicherlich auch aufgrund der zum Teil unverantwortlichen Politik und Misswirtschaft der nationalen Regierungen. Wirklich dramatisch entwickelten sich die Schuldenstände in Irland, Portugal, Griechenland und anderswo allerdings erst in Folge der Wirtschaftsund Bankenkrise, die diese Länder im Herbst 2008 mit großer Härte traf. Die internationalen Finanzmärkte entzogen den Staaten anschließend das Vertrauen, die Kosten für die staatliche Kreditversorgung stiegen enorm an. Um die Staatsinsolvenzen zu verhindern und um die Gläubiger und Exportinteressen zu schützen, entschieden sich Regierungen in Brüssel, Berlin und Paris im Frühjahr 2010 zur „Rettung um jeden Preis“ (Scharpf 2014). Der Europäische Fiskalpakt und die so gennannten ,,austerity measures““2 zwingen die Schuldenstaaten heute zu rigorosen Kürzungen der Staatsausgaben. Der Ausweg über Neuverschuldung, Besteuerung der Vermögenden und Abwertung der Währung, um die eigene Wettbewerbsfähigkeit zu erhöhen und so die negativen Handelsbilanzen auszugleichen, bleibt dabei versperrt (ausführlich dazu Offe 2013). Die Folge: Eine Demontage des Sozial- und Steuerstaates durch die „Politik des Schuldenstaates“ (Streeck 2013a) zulasten der schwachen Staaten und Bevölkerungen. Es häufen sich soziale Unruhen in Griechenland, Spanien, Italien und Portugal. Mehr noch: Antieuropäische rechts- oder linkspopulistische Bewegungen in Frankreich, Deutschland, Ungarn, Italien, Dänemark, Griechenland, den Niederlanden und anderen Ländern der Europäischen Union werden immer stärker. Unsicherheit, Armut, soziale Spaltung, Entsolidarisierung und Fremdenfeindlichkeit untergraben die Fortentwicklung des Europäischen Projektes (Beck 2012). Droht am Ende ein „Kapitalismus ohne Demokratie“, wenn wir uns nicht von der gemeinsamen Währung trennen und den geordneten Rückzug in den demokratischen Nationalstaat antreten, wie Wolfgang Streeck es prophezeit (2013a)? ${ }^{3}$ Klar ist: Aus einer Krise der suprastaatlichen Institutionen der EU, die gerne auch akademisch euphemistisch als ,demokratisches Defizit" betitelt wird, ist eine umfassende Legitimationskrise gewor-

2 Die Maßnahmen sehen vor allem Kürzungen von Sozialleistungen, Renten und Gehältern im öffentlichen Dienst vor.

3 Lutz Wingert arbeitet die Argumentation von Streeck prägnant auf in seinem Artikel „Eurokapitalismus ohne Demokratie“ in der Süddeutschen Zeitung (Wingert 2013). 
den, die das politische Projekt der EU im Ganzen zu Fall bringen kann. Ein Austritt Griechenlands aus der Union könnte dabei den Startpunkt markieren, dem sich Großbritannien nach dem geplanten Referendum im Jahr 2017 anschließen und weitere Mitgliedsstaaten Südeuropas folgen könnten (Streeck 2015). Die Wahlen in Griechenland drohen dabei als Fanal in die Geschichte einzugehen, das den europaweiten Zusammenschluss der Linksund Rechtspopulisten gegen den äußeren Feind in Brüssel und die technokratischen Eliten der EU ankündigt. ${ }^{4}$

Die Europäische Politik krankt zugleich an der strukturell unzureichenden demokratischen Rückbindung an die europäische Bevölkerung (Inputlegitimität) sowie an der mangelnden Fähigkeit der Europapolitik, die drängenden ökonomischen und finanzpolitischen Probleme effektiv zu lösen (Outputlegitimität). Beide Legitimationsdefizite verstärken sich gegenseitig und stellen die besondere Gefahr der heutigen Situation dar. Die mangelnde Inputlegitimation der Union wurde lange Zeit durch die Outputlegitimation überdeckt, die durch die Regierungen der Mitgliedsstaaten getragen wurde (Scharpf 2014: 3). Mit der zunehmenden politischen Regulierung auf der transnationalen Ebene geht allerdings eine schleichende Entdemokratisierung der Bürgerschaften einher, wenn nicht zugleich eine entsprechende demokratische Mitsprache und Beteiligung gewährleistet ist. ${ }^{5}$ Die aktuelle Krise zeigt, dass der technokratische und exekutivlastige Regierungsstil der deutsch-europäischen Sparpolitik an sein Ende gekommen ist. Viele Beobachter teilen die Meinung, dass das, was kurz- und mittelfristig der EuroKrise begegnen könnte, etwa eine Transferunion oder eine solidarische

4 Ende Januar 2015 ging die Linkspopulistische Syriza mit ihrem charismatischen Parteichef Tsipras als deutlicher Wahlsieger (36 Prozent der Stimmen) aus den Parlamentswahlen hervor. Dem Wahlsieg vorrausgegangen war ein Wahlkampf, der sich explizit gegen Europa und die Sparpolitik der Troika wandte. Direkt nach dem Wahlsieg bildete Syriza eine Koalition mit der rechtspopulistischen Partei die Unabhängigen Griechen, die sich in der Ablehnung der Europäischen Politik gefunden haben (Kolb 2015).

5 Grundsätzliche Einwände gegen die Demokratisierbarkeit der EU hegt Michael Greven. Seiner Meinung nach übersteigt ein funktional ausdifferenziertes Regierungssystem wie die Europäische Union mit all ihren Institutionen und Akteuren sowie seiner Komplexität die kognitiven und motivationalen Fähigkeiten der Bürger zur Mitsprache und Beteiligung (Greven 2003: 86 ff). 
Haftung für die Schulden wie Eurobonds, Schuldenerlasse oder -aufschübe, die Solidarität der Bevölkerungen der Geberländer überstiege und auf demokratischem Weg nicht durchzusetzen wäre (Offe 2013). ${ }^{6}$ Deutsches Steuergeld für Griechenland, Spanien und Portugal? Die Hetze des Boulevards auf die faulen „Pleite-Griechen“, die uns das „Geld wegnehmen“, wäre wohl nur ein Vorgeschmack auf die Kampagne, die folgte, wenn weitere Milliarden zur Rettung der Schuldenstaaten nötig wären. Auf der anderen Seite tragen aber auch die Bevölkerungen der Schuldenstaaten die existenzbedrohende Reformpolitik der Troika aus Kommission, EZB und IWF nicht mehr länger mit. Wie nun weiter, Europa?

\section{VERÄNDERTE BEDINGUNGEN DEMOKRATISCHER HERRSCHAFTSAUSÜBUNG IN DER EU}

Die Zeiten, in denen der „technokratische Konsens der Eliten“ (Milward 1992) und die stillschweigende Zustimmung der Bevölkerungen (Lindberg/ Scheingold 1970) den Prozess der europäischen Integration getragen haben, sind letztlich schon seit Maastricht Geschichte (Eichenberg/Dalton 2009). ${ }^{7}$ Die EU ist seitdem eine suprastaatliche Ordnung mit weitrechenden

6 Diese vielfach gehörte Position wird allerdings auch in Frage gestellt. Hepp und andere Autoren arbeiten in einer transkulturellen qualitativen Studie die „Bürgerperspektive“ auf die EU-Finanzkrise in sechs EU-Ländern heraus. Daraus geht hervor, dass die Befragten sich als Europäische Bürger verstehen, die die Krise und ihre Ursachen kaum verstehen und nachvollziehen können. Gleichzeitig fühlen sie sich betroffen und entwickeln Lösungsvorschläge, die je nach Standpunkt entweder die nationale Verantwortung der Schuldenstaaten in den Mittelpunkt rücken, die europäische Solidarität zwischen den Staaten und Menschen und weitere Schritte der intensivierten Integration als Lösungsweg sehen oder aber die Solidarität zwischen den Schuldenstaaten und Europa neu verhandeln wollen (Hepp et al 2013).

7 Damals entschieden sich die Dänen in einem Referendum gegen den MaastrichtVertrag, und auch die Franzosen waren kurz davor, die Gründung der Europäischen Union zu verhindern. Der Hinweis der Dänen, dass auch die Union der Zustimmung der Bevölkerungen der Mitgliedsstaaten bedarf, wirkte wie ein heilsamer Schock. Damals wurde klar, dass die EU mit steigender Integrations- 
Kompetenzen und einer politischen Autorität, die weit in die Lebenswelt der Bürger hineinreicht (Rauh/Zürn 2014). Mit zunehmender Integrationsund Eingriffstiefe wuchs auch die Politisierung weiter Teile der Bevölkerungen und die Kritik an der EU-Politik, die deren Handlungsmöglichkeiten heute drastisch einschränkt (Hooghe/Marks 2009). Die Menschen wollen sich nicht mehr ohne weiteres durch eine ferne Exekutive in Brüssel oder durch die Staats- und Regierungschefs hinter verschlossenen Türen regieren lassen. Die Euro-Krise hat diese Wahrnehmungen noch verschärft. Die nationalen und europäischen Politiker mit dem ,Zuchtmeister Deutschland“ haben weitreichende Entscheidungen getroffen und Risiken auf sich genommen, die nicht ausreichend an Parlamente und öffentliche Willens- und Meinungsbildung zurückgebunden waren, wie die Kritik an den Maßnahmen zum Euro-Rettungsschirm zeigen (Müller 2013; Mehr Demokratie 2012). Die Erkenntnis, dass eine erfolgreiche Fortführung des Einigungsprozesses gerade in der Krise nur durch die aktive Einbindung und $\mathrm{Zu}$ stimmung der europäischen Bevölkerungen möglich ist, scheint sich allerdings bei vielen Staats- und Regierungschefs nach wie vor nicht durchgesetzt zu haben. Überdeutlich wird dieser Umstand durch die Tatsache, dass die Regierungen der Schuldenstaaten den ihnen auferlegten Sparpaketen zugestimmt haben, die Bevölkerungen aber nicht (Beck 2012: 12). Mehr noch: Die von der deutschen Regierung dominierte Top-down Politik der europäischen Eliten provoziert erhebliche Widerstände und Spannungen in den Gesellschaften der Schuldenstaaten und destabilisiert die Regierungen. Ein Gefühl der Ohnmacht und Wut greift allenthalben um sich. Den antieuropäischen Parteien und Kräften ist es vielfach gelungen, von diesen Stimmungen in den Gesellschaften zu profitieren. Immer mehr Europäer entziehen der Union ihre Unterstützung, viele gehen in den lautstarken Protest.

Die Legitimationskrise verschärft sich mit jedem weiteren Integrationsschritt durch die Praxis des Schweigens und Umgehens der (nationalen) Öffentlichkeiten durch die europäischen Eliten (Brunkhorst 2014). Die aktuelle Situation Griechenlands macht diesen Zusammenhang deutlich. Weder die Politik der Troika selber noch die ,,austerity measures“ im Land waren

tiefe und Einflussnahme auf die nationale Politik und das Leben ihrer Bürger mehr für ihre Akzeptanz in den Bevölkerungen tun muss. Weitere Integrationsschritte, so schon die damalige die Erkenntnis, würden zukünftig nicht mehr ohne breite öffentliche Zustimmung möglich sein. 
ausreichend durch die Bevölkerungen getragen. Die Folgen der Politik: Die Arbeitslosigkeit ist seit 2008 von 7,8 Prozent auf heute fast 30 Prozent gestiegen. Die Jugendarbeitslosigkeit liegt bei nahezu 60 Prozent. Die Zahl von schweren Depressionen hat sich seit Ausbruch der Krise 2007 verdoppelt, die Säuglingssterblichkeit ist enorm angestiegen (Karanikolos et al. 2013). Die Wut der Bevölkerung über die einseitige Sparpolitik hat in den Wahlen im Januar 2015 den Sieg für die antieuropäischen links- und rechtspopulistischen Kräfte gebracht. Auch die Wahlen zum Europäischen Parlament 2014 waren durch Erfolge europafeindlicher Parteien und eine sehr geringe Wahlbeteiligung geprägt. Und das, obwohl die EU größere Anstrengungen als je zuvor unternommen hat, Sympathien zu gewinnen. Zum ersten Mal wurde versucht, einen echten europaweiten Wahlkampf zu organisieren, und das Europaparlament betrieb eine aktive Kommunikationspolitik, insbesondere über die sozialen Netzwerke, um die Menschen für die Wahlen zu interessieren. Die verschiedenen Fernsehdebatten zwischen den Kandidaten der europäischen politischen Parteien - zweifellos ein Fortschritt in den Bestrebungen, einen breiten öffentlichen Raum zu schaffen - waren nach allgemeiner Einschätzung ziemlich glanzlose, elitäre Veranstaltungen. Das Publikum bekam nicht den Eindruck, dass die wichtigsten Kandidaten echte Alternativen vertraten. Eher schien es, als lasse die Brüsseler Politik nur eine Alternative zu: entweder Zustimmung zu dem bestehenden Projekt der Mitte-Rechts- und Mitte-Links-Parteien (verkörpert durch die beiden Spitzenkandidaten Jean-Claude Juncker und Martin Schulz) oder die totale Abkehr davon und Hinwendung zu den europafeindlichen Parteien. Andere Parteien fielen offenbar nicht ins Gewicht. All das hat jedenfalls nicht dazu beigetragen, das Projekt Europa für die Bürgerschaft attraktiv zu machen. Die Unterstützung für die EU schwindet in den letzten Jahren rasant. Laut Eurobarometer-Umfrage ,,Vertrauen in die Europäische Union“"gaben im Mai 2006, also noch vor der Krise, 57 Prozent der Bürger in Europa an, dass sie der EU vertrauen. Im November 2014 lag dieser Wert nur noch bei 37 Prozent und nur wenige Monate zuvor sogar auf seinem Tiefststand von 31 Prozent. Dramatisch sanken dabei die $\mathrm{Zu}$ stimmungswerte in den Krisenländern. In Griechenland beispielweise fiel das Vertrauen von 63 Prozent auf 23 Prozent, in Spanien von 65 Prozent auf 30 Prozent und in Italien von 58 Prozent auf 29 Prozent im gleichen Zeitraum (Eurobarometer 2015). 
Wie reagiert nun die politische Elite in Europa auf diese Entwicklungen? Es spricht einiges dafür, dass die Angst vor der ,,irrationalen Volkswut" die Verantwortungsträger eher lähmt und sie von Strukturreformen des politischen Systems abhält. Das hat nach der Europawahl 2014 auch das unrühmliche Geschacher zwischen Parlament und Rat um die Nominierung des Kommissionspräsidenten Junker eindrucksvoll gezeigt (Habermas 2014). Die langfristigen Kosten für einen solch elitären und technokratischen Regierungsstil sind hoch: Ohne ausreichende Akzeptanz bei den Bürgern ist die Union am Ende zum Scheitern verurteilt. Es wird daher Zeit, dass die veränderten Bedingungen der europäischen Herrschaftsausübung von den Regierenden zur Kenntnis genommen und der Regierungsstil diesen veränderten Bedingungen angepasst wird.

\section{DER UMGANG MIT DER LEGITIMATIONSKRISE: MEHR ODER WENIGER DEMOKRATISIERUNG FÜR DIE EU?}

Welche Möglichkeiten gibt es, das politische Projekt Europa erfolgreich fortzusetzen? Vereinfacht lassen sich zwei Standpunkte in der Debatte unterscheiden. Die erste Gruppe von Autoren spricht sich für eine umfassende Demokratisierung der Europäischen Union aus (Habermas 2011; Beck 2013; Brunkhorst 2014). Mehr Europa als Antwort auf die Krise durch eine Demokratisierung von unten als Gegenmodell zur nicht ausreichend legitimierten, wenig transparenten, technokratischen und exekutivlastigen Politik der europäischen Eliten in Kommission, Rat und EZB. Habermas und anderen schwebt dabei eine radikale Neuordnung der EUInstitutionen vor. Ihre Vision ist, die EU zu einem ,entstaatlichten supranationalen demokratischen Gemeinwesen“ mit Hilfe eines Verfassungskonvents umzubauen. Die Argumentation lebt von der Attraktivität des Normativen - und von der Alternativlosigkeit des Faktischen. Diese Autoren sehen ein Zurück zum Nationalstaat als wenig aussichtsreich an, weil unter Bedingungen der Denationalisierung und Globalisierung der Einfluss der Einzelstaaten wie ein Sandkorn in einer Sanduhr untergehe und der Sozialstaat nur auf der europäischen Ebene gegen den Kapitalismus bestehen könne (Brunkhorst 2014; Zürn 1998; Habermas 1998). Weitgehend offen bleibt allerdings, wie ein „Europa der Bürger“ und eine gemeinsame Ver- 
fassungsgebung etabliert und wie zentrale politisch-kulturelle Voraussetzungen für eine transnationale Demokratie - die wechselseitige Anerkennung als politische Gleiche, eine gemeinsame Identität, transnationale Solidarität und ein kollektiver Willens- und Meinungsbildungsprozess vermittelt über europäische Parteien und eine entsprechende Medienöffentlichkeit - geschaffen werden können (zum Aspekt der Sozialintegration vgl. Gerhards/Lengfeld 2014).

Die zweite Gruppe von Autoren hingegen schlägt als Lösung der europäischen Krise einen Rückzug in den Nationalstaat vor, weil die europäische Politik gegenüber den Finanz-, Güter- und Arbeitsmärkten immer mehr an Einfluss verliere und langsame ausgehöhlt werde. Macht, Status und Klientelismus schirmten die Märkte von der wirksamen demokratischen Kontrolle und Regulierung eines sozialen Europas ab, das allein in der Lage wäre, die Konflikte zwischen Arbeit und Kapital zu befrieden und für eine Umverteilung von oben nach unten zu sorgen. Die Europäische Integration hat nach Ansicht von Fritz Scharpf (Steinbeis 2011) bisher vor allem daraus bestanden, die politische Handlungsfähigkeit der Mitgliedsstaaten einzuschränken - mit dem Ziel, die ökonomischen Freiheiten (Waren, Dienstleistungen, Arbeitskräfte und Kapital) zu erhöhen. In der Europäischen Integration ein demokratisches Projekt zu sehen, widerspricht demzufolge der Logik des ökonomischen Vergemeinschaftungsprozesses. Mehr noch: Würde man die EU demokratisieren, so Scharpf, träten die fundamentalen ökonomischen und kulturellen Unterschiede der einzelnen Staaten vom Arbeitsmarkt bis hin zu den Gesundheitssystemen wirkungsmächtig zu Tage und würden eine demokratische Regulierung auf EU-Ebene sprengen (Steinbeis 2011). In der „neoliberalen Währungsunion“ sehen Scharpf und Streeck ein „Programm zur Zwangsvereinheitlichung der Wirtschafts- und Lebensweisen der europäischen Völker“ (Streeck 2013b: 83). Dementsprechend sehen sie keine Möglichkeiten, die Europäische Union zu demokratisieren. Es bleibt eine „Fassadendemokratie“ (Streeck), die durch postdemokratische Institutionen und Akteure den Imperativen und dem Einfluss des Geldes und der Märkte unterliege. Um eine demokratisch egalitäre und soziale Politik zu gewährleisten, die den Kapitalismus zu zähmen im Stande ist, plädieren Streeck und Scharpf dafür, sich aus der Währungsunion zu verabschieden und sich auf die einzig demokratisch legitimierte und funktionierende Einheit, den Nationalstaat zurückzuziehen. Ein solcher Rück- 
zug dient dazu, Zeit zu gewinnen und „Barrikaden gegen den technokratischen Fortschritt" (Streeck 2013b) aufzubauen.

Die Stärke dieser Position liegt in der präzisen und kritischen Analyse der Krisen mit ihren dramatischen ökonomischen und sozialen Folgen. Die Schlussfolgerungen erscheinen uns allerdings vor dem Hintergrund einer sich immer stärker vernetzenden und interdependenten Weltwirtschaft und vor dem Hintergrund globaler ökologischer Herausforderungen wenig erfolgsversprechend. Vieles spricht hier für die Analyse der ersten Gruppe von Autoren, dass nämlich der einzelne Nationalstaat unter dem Wettbewerbsdruck des Kapitalismus, der Logik des globalen Marktes und der existenzbedrohenden Ressourcenausbeutung der Erde nicht mehr der richtige Ort ist, um die Interessen einer Weltbürgerschaft zu durchzusetzen. Offensichtlich ist allerdings auch, dass die Europäische Union den Anspruch, den Kapitalismus sozialpolitisch und ökologisch einzubetten, bisher nicht entschlossen verfolgt. Es braucht vielmehr einen radikalen Wandel, der von der europäischen Bevölkerung getragen wird. Die Frage lautet: Wie könnte ein solcher Wandel aussehen und welche demokratischen Innovationen könnten ihn unterstützen?

Eine pragmatische Zwischenposition in der Debatte vertritt Jürgen Neyer. Er sieht die Chance der Demokratisierung der EU darin, die umfassende Mehrebenenstruktur und das System der zusammengesetzten Repräsentation der Europäischen Union weiterzuentwickeln. Sein Vorschlag ist, die transnationale Zusammenarbeit der nationalen und regionalen Parlamente als institutionelle Brücke weiter auszubauen, um so den Parlamentarismus und damit die kollektive Willens- und Meinungsbildung in der europäischen Politik in seiner vertikalen Dimension zu stärken (Neyer 2013). Die Grundannahme dahinter lautet, dass die historisch gewachsenen Nationalstaaten, die einzige legitime Organisationform darstellen, weil sie über ausreichende kulturell-politische Voraussetzungen für eine demokratische Herrschaftsausübung verfügen und handlungsfähig sind. Die seit 1989 bestehende Konferenz der Europaausschüsse der nationalen Parlamente (Cosac) könnte, so die Idee, zu einem ,kontinuierlich tagenden interparlamentarischen Verfassungskonvent" umgebaut werden, der das europäische Primärrecht weiterentwickelt (Neyer 2013). Dieser Vorschlag erscheint uns sinnvoll, um den vertikal verankerten Parlamentarismus in der EU zu stärken und die Mehrebenenstruktur der EU besser zu nutzen und damit die Europapolitik näher an die Bürger heranzutragen. Aber die EU wird sich 
wohl nie zu einem rein parlamentarischen politischen System entwickeln. Die komplexe, fragmentierte und oft schwer zu durchschauende politische Struktur, die schwache Ausprägung einer gemeinsamen Identität, die fehlende europäische Parteien- und Medienöffentlichkeit trüben das Bild von einer parlamentarisch-repräsentativen Union nach wie vor ein. Und solche Bemühungen um mehr Demokratie in der EU trügen auch den veränderten Partizipationswünschen eines wachsenden Teils der Bürger in Europa nicht Rechnung. Wie aus den meisten Umfragen hervorgeht, reicht es ihnen heute nicht mehr, nur bei den Wahlen ihre Stimme abzugeben und ansonsten die Macht an die politischen Vertreter zu delegieren. Immer mehr Bürger verlangen Mitsprache auch zwischen den Wahlterminen. Sie bedienen sich neuer Mittel der politischen Partizipation und fordern direktere Formen der Beteiligung. Aus unserer Sicht lassen sich im System der zusammengesetzten Repräsentation der EU weitere Stellschrauben der direkten Bürgerbeteiligung mit Legitimationspotentialen identifizieren, die bislang ungenutzt sind.

\section{AUSBAU DER PARTIZIPATIVEN DEMOKRATIE IN DER EU - FÜR EINE DEMOKRATISIERUNG ,VON UNTEN““}

Seit Lissabon ist die partizipative Demokratie im Vertragswerk der EU verankert und neben der repräsentativen Demokratie fester Bestandteil der EUPolitik geworden. Dieser Grundsatz suggeriert, dass die Bürger der EU schon heute ihr Leben als politische Gleiche selbstbestimmt gestalten und auf die Politik der Union unmittelbar einwirken können. Die Verfassungswirklichkeit sieht anders aus (Kohler-Koch 2011b: 243ff.). Die Institutionen Rat, Kommission und Parlament dominieren das politische Geschehen als Ausdruck einer, wenn auch kaum entwickelten repräsentativen Demokratie. Eine unmittelbare Beteiligung ${ }^{8}$ der Bürger ist begrenzt auf das 2011

8 Der Begriff „Bürgerbeteiligung“ umfasst all jene Handlungen und Verhaltensweisen, die Bürger freiwillig und mit dem Ziel verfolgen, Entscheidungen auf den verschiedenen Ebenen des politisch-administrativen Systems zu beeinflussen (vgl. Kaase 2003). Unter „,neuen“ oder dialogorientierten Formen der Bürgerbeteiligung werden im Folgenden (noch) nicht verfasste, unkonventionelle Formen politischer Beteiligung verstanden; im Gegensatz zu verfassten, gesetz- 
eingeführte direkt-demokratische Instrument der Europäischen Bürgerinitiative, die allerdings mit hohen institutionellen Hürden versehen wurde. Die Etablierung und Institutionalisierung einer partizipativen Demokratie steht dagegen noch aus. „Partizipativ“ bedeutet seit dem White Paper on Governance (2001) nichts weiter als dass die Kommission die organisierte Zivilgesellschaft konsultiert. Industrieverbände, Umweltverbände, Vereine, Lobbygruppen, Gewerkschaften und Experten werden sowohl bei der Politikformulierung z.B. in formalisierten Verhandlungssystemen und informellen Netzwerken auf der suprastaatlichen Ebene, als auch bei der Umsetzung von Politiken wie etwa die regionale Zivilgesellschaft in der Europäischen Regionalpolitik beteiligt (Kamlage 2011). Lange Zeit galt dies als Lösung für das demokratische Defizit der Kommission: Durch die Einbeziehung organisierter Interessen sollte der „Motor der europäischen Gesetzgebung“ ohne eigene Legitimationskette in die Bevölkerung auskommen können (Kohler-Koch 2011a: 8). Viele Beobachter stellen sich heute allerdings die Frage, ob und inwieweit solche Konsultationsmechanismen im Governancesystem der Kommission überhaupt einen demokratischen Mehrwert liefern und zur Legitimation der EU beitragen. Kohler-Koch und andere Autoren kommen zu einer gemischten Bilanz. Die Konsultationen erhöhen grosso modo die Responsivität der Kommission, verbreitern die Wissensbasis für Entscheidungen und sorgen für eine Repräsentation vielfältiger Interessen der Stakeholder im politischen Prozess. Kritisch gesehen wird, dass es den zivilgesellschaftlichen Organisationen kaum gelingt, als „Transmissionsriemen“ in die Gesellschaft zu fungieren (Steffek/Nanz 2008). Vielmehr sind die europäischen Governancesysteme vielfach auch Einfallstore für Lobbyinteressen, die im Kampf um Macht und Einfluss die weniger stark organisierten Interessen verdrängen.

Die Frage also bleibt: Welche Formen der Partizipation könnten die Demokratisierung der EU tatsächlich vorantreiben und die Distanz zwischen EU-Institutionen und Bürgerschaft verringern? Wir schlagen vor, eine unmittelbare Beteiligung der Bürger in transnationalen dialogorientierten Beteiligungsverfahren zu etablieren. In dialogorientierten Beteiligungsverfahren werden Bürger idealerweise frühzeitig im politischen Prozess zu-

lich geregelten Formen wie die Anhörungen im Rahmen von Planfeststellungsund Raumordnungsverfahren oder klassische Beteiligungsmechanismen der direkten Demokratie wie Referenden, Volksentscheide und Bürgerbegehren. 
sammengebracht. Im Mittelpunkt der Beratungen steht der Austausch von Argumenten mit dem Ziel einer konsensualen Entscheidungsfindung. In Diskussionen wägen die Beteiligten alternative Positionen ab, unter der Prämisse, dabei andere Standpunkte zu berücksichtigen (Fung 2003: 340), und ringen gemeinschaftlich um Lösungen für eine verantwortungsbewusste Zukunftspolitik - jenseits von kurzfristigen (Wahlkampf-)Interessen. Dialogorientierte Beteiligungsverfahren sind auf die Unterstützung von Moderatoren und ggf. von Experten aus Wissenschaft und Praxis angewiesen. Sie ermöglichen einen differenzierten, gemeinwohlorientierten Willensbildungsprozess in einem relativ geschützten Raum, - geschützt vor medialer Kommerzialisierung und dem Druck mächtiger Lobbyinteressen. Bürgerschaftliche Partizipation kann so einen wichtigen Gegenpol zu dominierenden organisierten Interessen bilden (Fung/Wright 2004). Widerstreitende Positionen können integriert und Partikularinteressen eingedämmt werden. Dadurch können Polarisierungen und Konflikte reduziert und national geprägte Debatten und Sichtweisen aufgebrochen werden. Solche Beteiligungsverfahren liefern selbst zu hochkomplexen Themen, wie zum Beispiel Chancen und Grenzen des Nutzens von Nanotechnologie, qualitativ hochwertige Ergebnisse (Powell/Kleinman 2008). Indem sie divergente Perspektiven und Informationen einspeisen, verbessern sie die Grundlage politischer Entscheidungen und erhöhen deren Tragfähigkeit in der Bürgerschaft. Zudem wird dialogorientierten Verfahren das Potential zugeschrieben, das oft gering geschätzte Wissen der Bürger in den politischen Prozess einzubeziehen und dabei die bürgerschaftliche Kompetenzen der Beteiligten zu fördern (Sintomer 2007; Blondiaux 2008).

Immer häufiger nutzen Bürger in Europa dialogorientierte Partizipationsangebote, um ihre Anliegen zu artikulieren und Einfluss zu nehmen auf kommunale, regionale oder nationale Politik. Seit den neunziger Jahren ist eine starke Verbreitung von innovativen Formen der Bürgerbeteiligung weltweit zu beobachten (Particepedia 2015). Eine beachtliche Anzahl von neuen, dialogorientierten Beteiligungsverfahren belegt diesen Trend - vom Verfassungskonvent in Irland und Island über die Konsensuskonferenzen zur Abschätzung von Technikfolgen in Dänemark bis hin zu lokalen Initiativen zur Förderung bürgerschaftlichen Engagements in benachteiligten Quartieren vieler Städte. Auch die Europäische Kommission und das Parlament haben eine Vielzahl von Projekten unterstützt, um zu testen, welche Verfahren und Methoden für transnationale und mehrsprachige Bürgerbe- 
teiligung geeignet sind (Kies/Nanz 2013). Nach den gescheiterten Referenden über den EU-Verfassungsvertrag in Frankreich und den Niederlanden 2005 und dem dramatischen Verlust an Zustimmung in der Bevölkerung entwickelte Kommissarin Margot Wallström eine Kommunikationsstrategie unter dem Label „Plan D“ für Demokratie, Dialog und Diskussion, Debating Europe und die Initiative e-Europe. Im Zuge dieser Strategie wurden beispielsweise die European Citizens Consultations, Europolis und IdealEU Prozesse durchgeführt. Ziel dieser Initiativen war, die europäischen Bürger als kritische Gesprächspartner zu adressieren und sie nicht länger als ein abstraktes Massenpublikum zu behandeln, dem man mithilfe von klassischen Medien der Public Relation wie Flyer, Fernsehspots und Internetseiten das europäische Projekt anpreist.

Das größte und vielschichtigste Projekt dieser neuen Kommunikationsstrategie waren die Europäischen Bürgerkonferenzen, die erstmals zwischen Oktober 2006 und Mai 2007 stattfanden. An diesem grenzüberschreitenden Großverfahren nahmen etwa 1.800 nach demographischen Kriterien zufällig ausgewählte Bürger aus 27 Mitgliedstaaten teil und berieten über die Zukunft Europas sowie über Einzelfragen aus den Politikbereichen der EU. Diese Konsultationen waren nach der Auftaktveranstaltung in Brüssel als ein dreistufiges Verfahren organisiert: Im ersten Schritt wurden zentrale Konsultationen mit Online-Elementen in den einzelnen Mitgliedstaaten durchgeführt. Im zweiten Schritt wurden ergänzend in verschiedenen Städten der Mitgliedstaaten regionale Bürgerforen veranstaltet, um in einem letzten Schritt die Ergebnisse aus allen Mitgliedstaaten auf der europäischen Ebene zusammenzutragen und dort mit Vertretern der Europäischen Kommission auf einer Abschlussveranstaltung $\mathrm{zu}$ diskutieren (Baumann/Felten et al. 2009). Im Anschluss an die ersten Europäischen Bürgerkonferenzen gab es verschiedene Folgeprozesse, die die Ergebnisse des Verfahrens in die Mitgliedstaaten zurück kommuniziert haben. Im Jahr 2009 wurden erneut Europäische Bürgerkonferenzen veranstaltet, mit dem Ziel eine transnationale Beteiligungspraxis der Bürger in Europa zu etablieren. Wie häufig bei solchen Beteiligungsangeboten wurde deren Organisation und Umsetzung durch eine zivilgesellschaftliche Organisation geleistet, die belgische König-Baudouin-Stiftung. Die Beteiligungsangebote kamen bei den Bürgern insgesamt sehr gut an. Sie bekundeten große Zufriedenheit, dass man sie eingeladen hatte, ein oder zwei Tage lang über Europafragen zu diskutieren, fühlten sich besser informiert, standen dem euro- 
päischen Projekt grundsätzlich positiver gegenüber und hatten teilweise ihre Ansichten im Laufe der Diskussion geändert. Hingegen äußerten sich viele enttäuscht, dass die Experimente keinen Einfluss auf die politisch Verantwortlichen hatten (Kies/Nanz 2013).

Bis 2010 fanden 23 transnationale Bürgerbeteiligungsverfahren statt, an denen nach Schätzungen insgesamt ungefähr 100.000 Europäer beteiligt waren (Yang 2013). Die Zahlen verdeutlichen, dass die öffentliche Meinungs- und Willensbildung in der EU durch einen bloß punktuellen Einsatz solcher Verfahren nur im geringen Umfang angestoßen wird (Friederich 2014). Der Einfluss könnte verstärkt werden, wenn die dialogischen Beratungen der Bürgerschaft systematisch weiter entwickelt worden wären und wenn man die Bürgerdialoge an die formale Beratungs- und Entscheidungsprozesse der EU gekoppelt hätte. Der nächste Schritt der europäischen Partizipationsinitiative hätte darin bestehen müssen, Bürgerbeteiligung konsequent dadurch auszuweiten, dass unter den experimentellen Konsultationen diejenigen ausgewählt worden wären, die sich am besten für eine Institutionalisierung geeignet hätten. Doch das ist nicht erfolgt. Das Partizipationsprojekt ist ohne Begründung abgebrochen und durch die Einführung der Europäischen Bürgerinitiative ersetzt worden (Smith 2013: 215). Dieses direkt-demokratische Instrument dient freilich in erster Linie organisierten Interessengruppen, die über die finanziellen und technischen Mittel verfügen, um innerhalb von zwölf Monaten eine Million Unterschriften in sieben Ländern zu sammeln. Es erfüllt mitnichten die Funktionen, die für eine staatsbürgerliche europäische Bewusstseinsbildung und grenzüberschreitende Diskussionen nötig sind, wie dies Bürgerdialoge leisten könnten.

Wir schlagen vor, die abgebrochene partizipative Initiative wieder aufzunehmen und regelmäßig dialogorientierte Bürgerbeteiligungsverfahren über zentrale europäische Fragen auf lokaler, regionaler, nationaler und transnationaler Ebene anzubieten. Die Konsultationen müssten dezentral und das ganze Jahr über mit Gruppen von Teilnehmern stattfinden, die repräsentativ für die verschiedenen Meinungen in der Gesellschaft sind und nach dem Zufallsprinzip auf der Grundlage soziodemografischer Kriterien ausgewählt wurden (zum Beispiel Alter, Bildungsgrad, Geschlecht, Staatsangehörigkeit). Damit dieser Diskussionsprozess nachhaltig wird, schlagen wir weiterhin die dauerhafte Einrichtung einer Konsultative vor: einen europäischen Zukunftsrat (Leggewie/Nanz 20134). Seine Aufgabe bestünde 
darin, dialogorientiertes Agenda-Setting zu betreiben und Parlament, Rat und Kommission zu beraten. Damit hätten die Konsultationen eine feste Struktur und greifbaren Einfluss; der Zukunftsrat könnte seine Arbeit je nach Themenstellung langfristig ausrichten (zwischen zehn und dreißig Jahren) und könnte seinerseits einzelne Beteiligungsverfahren zu dringenden Themen initiieren. Er hätte natürlich keine Entscheidungsbefugnis, aber die politischen und wirtschaftlichen Eliten dürften sein Votum nicht ignorieren. Die drei Institutionen, die in der EU die Entscheidungen treffen das Parlament, die Kommission und der Rat - würden verpflichtet, offiziell zu den Empfehlungen (und Fragen) des Zukunftsrats Stellung zu beziehen. Diese Konsultative verfügt über eigene Ressourcen im Sinne einer Geschäftsstelle und finanziellen Mitteln für Öffentlichkeitsarbeit und Expertenhearings. Besonderes Augenmerk verdient die Verbreitung der Konsultationen in Zusammenarbeit mit den traditionellen und neuen Medien, damit sich eine möglichst große Zahl von Bürgern informieren kann. Die Konsultative würde auch als Anlaufpunkt für die Zusammenführung und Kommunikation der Ergebnisse der einzelnen dialogorientierten Beteiligungsverfahren fungieren - gewissermaßen als „Sprachrohr der Bürger“ Europas. Die partizipative Demokratie könnte so entsprechend dem im Vertragswerk der EU formulierten Grundsatz weiterentwickelt werden.

Klar ist: Sowohl die Konsultative also auch die einzelnen transnationalen dialogorientierten Beteiligungsverfahren verstehen sich als Ergänzungen weiterer Versuche, die europäischen Institutionen zu demokratisieren. Ausgehend von der Beteiligung und Mobilisierung ihrer Bürger, die sich künftig über nationalen Grenzen hinweg über dringliche Fragen austauschen und beraten, könnte die Europäische Gemeinschaft auf eine neue Basis gestellt werden. Wechselseitige Solidarität und Loyalität gegenüber den europäischen Institutionen entwickeln sich nur, wenn sich die gesellschaftliche Integrationskraft von Demokratie weiter entfalten kann. Allerdings bedarf es auch - und das ist zentral - der Erfahrung der teilnehmenden Bürger, dass die Ergebnisse der Konsultationen Eingang finden in die europäischen Entscheidungsprozesse und rückgebunden sind an Kommission, Rat und Parlament. Man darf nicht erwarten, dass sich zum jetzigen Zeitpunkt die Bürger von sich aus und spontan Europa zuwenden werden. Europa kann nur Interesse wecken und Verständnis finden, wenn es auf seine Bürger zugeht und sie in die Lage versetzt, sich über wichtige Fragen der EU-Politik zu informieren und auszutauschen. Auf diese Weise kann 
Europa zeigen, dass es die Anliegen der Menschen ernst nimmt. In einem europäischen Zukunftsrat würde Bürgerbeteiligung institutionalisiert und verbindlich.

\section{DiE EUROPÄISCHE ENERGIEPOLITIK ALS EXPERIMENTIERFELD EINER INSTITUTIONALISIERTEN PARTIZIPATIVEN DEMOKRATIE}

Die gemeinsame Europäische Energiepolitik ist ein zentrales Zukunftsthema der Europäischen Union. Die sich anbahnende umfassende Transformation des Energiesystems, so viel ist jetzt schon absehbar, hat weitreichende Konsequenzen für die Art und Weise, wie wir heute in Europa leben. Wie zur Zeit der Gründerväter der Europäischen Gemeinschaft für Kohle und Stahl ist die Energieversorgung auch heute wieder ein zentrales Thema auf der Europäischen Agenda - der Kampf um Einfluss und Macht in diesem entstehenden Politikfeld ist im vollen Gange (Tosun et al. 2015). Die Russland-Ukraine Krise hat die strategische Bedeutung und Notwendigkeit einer stärker europäisierten Energieversorgung für die Energiesicherheit der Mitgliedsstaaten offensichtlich gemacht. Die Energiepolitik ist aber auch das zentrale Handlungsfeld, wenn es um die Erreichung der Europäischen Klimaschutzziele geht. Der Rat hat sich langfristig drauf verpflichtet, die CO2Emissionen bis zum Jahr 2050 um 80 bis 95 Prozent im Vergleich zum Basisjahr 1990 zu reduzieren (European Commission 2011). Mittelfristig (bis 2020) haben die Staats- und Regierungschef die Senkung der Treibhausgasemissionen um 20 Prozent, den Ausbau des Anteils erneuerbarer Energien auf 20 Prozent und Verbesserung der Energieeffizienz um 20 Prozent beschlossen (Europäische Kommission 2010). 80 Prozent aller klimaschädlichen Treibhausgasemissionen entfallen direkt oder indirekt auf das Energiesystem. Ohne eine schnelle und umfassende Transformation dieses Sektors mit weitreichenden Investitionen in die Infrastruktur besteht also die Gefahr, dass die Klimaschutzziele nicht erreicht werden (Kommission 2010). Die Europäische Union ist der zweitgrößte Energiemarkt der Welt und bezeichnet sich als führend im Management und in der Förderung erneuerbarer Energien (European Commission 2006). Die EU hat eine Vorreiterrolle in der Welt. Der weltweite Klimaschutz, die Dekarbonisierung der Energieversorgung und der Eintritt in ein neues Energiezeitalter der er- 
neuerbaren Energien hängen stark davon ab, ob und inwieweit es gelingt, eine funktionierende europäische Netzinfrastruktur aufzubauen und gleichzeitig den Umbau der Energieversorgung in Richtung Erneuerbarer Energien europaweit zu beschleunigen.

Der schnelle Rückbau der atomaren und fossilen Energieträger ist eine gesellschaftspolitische Großaufgabe. Die deutsche Energiewende hat gezeigt, dass der Umbau der ursprünglich zentralistischen organisierten Energieproduktion zu einer stärker dezentralen, auf regenerative Energieträgern basierenden Produktionsstruktur einhergeht mit der Notwendigkeit eines Ausbaus der Übertragungsnetze und der Einführung neuer Technologien (Kamlage/Fleischer 2014). Mehr noch: Der flächendeckende Ausbau der Erneuerbaren „onshore and offshore“, der weitreichende Aus- und Umbau der Netzinfrastruktur und die Entwicklung und Einführung lokaler Energiespeicher, weitere Technologien wie Smart Grids und Smart Meters bedeuten tiefe und folgenreiche Eingriffe in die Natur und in die Lebenswelt der Bürger (für den Netzausbau vgl. Kamlage/Nanz/Fleischer 2014). Die Energiewende ist ein fundamentaler sozio-technischer Wandel (Grunwald 2014). Politische Weichstellungen mit so langfristigen Folgen für Mensch und die Natur bedürfen einer breiten demokratischen Legitimation. Eine Europäische Energiewende darf nicht den Experten und Eliten überlassen werden, sondern braucht eine aktive Einbindung und Mitsprache der Bürger.

Wir schlagen für die europäische Energiepolitik einen Zukunftsrat (Leggewie/Nanz 2013) vor, der im wesentlichen dialogorientiertes AgendaSetting betreibt und im Erfolgsfall als Konsultative neben Legislative, Judikative und Exekutive einen Platz findet im gewaltenteilig organisierten Willensbildungs- und Entscheidungsprozess der Europäischen Institutionen. Im Unterschied zu punktuellen Debatten oder episodischen Beteiligungsverfahren zum Beispiel um ein konkretes Infrastrukturvorhaben wie den Bau einer Stromtrasse, geht es im Zukunftstrat um umfassende Szenarien und Weichenstellungen auf supranationaler Ebene, aber antizipativ auch darum, mögliche Konflikte zwischen Mitgliedstaaten frühzeitig zu bearbeiten und eine qualifizierte Bürgersicht zu entwickeln.

Die langfristige Bedeutung der europäischen Energiepolitik legt zum einen die Einrichtung eines supranationalen, zahlenmäßig überschaubaren, iterativ arbeitenden Gremiums aus Laienbürgern (Mini-Populus) nahe, das einen Lernprozess über die gesamte Periode in wechselnder Zusammenset- 
zung der Teilnehmer organisiert. Die notwendige Expertise und Informationsquellen für die Beratungen werden über Expertenhearings herangezogen. Für die Zeit der Beratungen werden die teilnehmenden Bürger von ihren beruflichen Verpflichtungen freigestellt und/oder aufwandsentschädigt. Zum anderen liegt es nahe, den Zukunftsrat zur europäischen Energiepolitik durch zahlreiche regionale und lokale Gremien zu unterstützen, die über Weichenstellungen und Infrastrukturvarianten vor Ort beraten, entscheidungsreif machen und bei ihrer Implementierung begleitend evaluieren. Diese Dezentralisierung lässt lokales Wissen in den nationalen und europäischen Planungsprozess einfließen, ohne damit zu einem Hort lokaler Resistenz zu werden, in dem nach dem NIMBY-Prinzip verfahren wird eine Erhöhung der erneuerbare Energie ja, aber keine Stromtrasse in unserer Nähe. Solche (im Einzelfall jeweils nachvollziehbaren und legitimen) Reaktionen werden abgeglichen durch überlokale Abwägungen und Erfordernisse. Um zu einer umfassenden, von breiter Zustimmung getragenen Konzeption der Energiepolitik zu gelangen, sollte es freilich neben den Bürgerdialogen auf lokalen, nationalen und supranationalen Ebenen von diesen informierte Debatten in den breiten nationalen Öffentlichkeiten geben. Dies würde mit Sicherheit zu einer Wiederbelebung des europäischen politischen Projekts beitragen. Natürlich wird die Idee eines Zukunftsrats einen großen Teil der heute maßgeblichen politischen Akteure irritieren. Sie werden argumentieren, Bürgerdialoge seien grade auf europäischer Ebene zu schwierig einzurichten, dazu nicht repräsentativ und teuer, deren Empfehlungen nicht steuerbar und also gefährlich. Wenn die Europäische Union eine direkte Verbindung mit den Bürgern knüpfen will, gibt es aber nur den Weg, ihnen die Gelegenheit zu geben, in einen Dialog zu treten. Die demokratische Legitimität der Europäischen Union und wahrscheinlich sogar ihr Fortbestand hängen von einer stärkeren Einbindung der Bürger ab. Das ist jede Mühe wert.

\section{SCHLUSSFOLGERUNGEN}

Europaweiter Dissens und Protest zeigen: Der technokratische und exekutivlastige Regierungsstil der europäischen Eliten in Rat und Kommission ist an ein Ende gekommen. Die demokratische Selbstbestimmung der Bürgerschaft darf nicht weiter gegen die funktionale Logik der Problemlösungsfä- 
higkeit ausgespielt werden. Andererseits erscheint ein Rückzug in den Container des Nationalstaates besten Falls eine Lösung auf Zeit, die die Augen verschließt vor den globalen gesellschaftspolitischen und ökologischen $\mathrm{He}$ rausforderungen. Ein klares Bekenntnis zur Solidarität zwischen den Mitgliedsstaaten in Form einer Transferunion und/oder der Vergemeinschaftung der Schulden kann dabei ein Weg zur Lösung sein. Ein generelles Umsteuern in der Politik ist ebenso notwendig. Dem „Diktat des Marktes“ und der stark neoliberal imprägnierten Integrationspolitik muss endlich das soziale, ökologische und demokratische Europa als gemeinsame Vision entgegengestellt werden. Es wäre ein Versuch wert zu überprüfen, ob eine solche Neuausrichtung die Zustimmung der Bevölkerung in der EU fände. Neben der Lösung des akuten Problems der Eurokrise steht ein Umbau der Demokratie an, um das strukturelle Problem der fehlenden demokratischen Legitimation anzugehen. Die vertikalen Brücken von den EU-Institutionen in die europäischen Gesellschaften brauchen eine systematische Verstärkung. Wir sehen die Chance im „Europa der Bürger“, das eine direkte und unmittelbare Teilhabe an der europäischen Politik ermöglicht. Der Ausbau der im Lissabonvertrag verankerten partizipativen Demokratie und die Weiterentwicklung der (abgebrochenen) europäischen Partizipationsinitiative bieten dafür geeignete Anknüpfungspunkte. Zentrale Anlaufstelle für dialogorientierte Verfahren zu wichtigen europäischen Themen könnte eine ständige Konsultative aus zufällig ausgewählten Bürgern sein. Ihre Aufgabe bestünde darin, langfristiges Agenda-Setting zu betreiben und Parlament, Rat und Kommission zu beraten. Erprobt werden könnte eine solche Konsultative bei der Entwicklung einer Europäischen Energiepolitik, einem der zentralen Zukunftsfelder der Europäischen Union.

\section{LITERATUR}

Baumann, Mechthild/Felten, Sandra/Stratenschulte, Eckart D. (2009): Empirische Auswertung der Europäischen Bürgerforen 2008/2009. Online verfügbar unter: www.buergerforen.de/fileadmin/medias-buergerforen/ presse/Finale_Auswertung.pdf. [Letzter Zugriff: 06.02.2015.]

Beck, Ulrich (2012): Das deutsche Europa, Berlin.

Beck, Ulrich (2013): Kooperieren oder scheitern. Die Existenzkrise der Europäischen Union, in: Blätter für deutsche und internationale Politik 
(Hg.), Demokratie oder Kapitalismus? Europa in der Krise, Berlin, S. 215-227.

Blondiaux, Loic (2008): Le nouvel esprit de la democratie. Actualite de la democratie participative, Paris.

Brunkhorst, Hauke (2014): Das doppelte Gesicht Europas, Berlin.

Eurobarometer (2015): Homepage des Eurobarometers. Online verfügbar: http://ec.europa.eu/public_opinion/index_en.htm. [Letzter Zugriff: 06.02.2015.]

European Commission (2001): European Governance. A White Paper, 428 final. Online verfügbar unter: http://europa.eu.int/eur-lex/en/com/cnc/ 2001/com2001_0428en01.pdf. [Letzter Zugriff: 06.01.2015.]

European Commission (2006): Green Paper: A European strategy for sustainable, competitive and secure energy. http://europa.eu/legislation_ summaries/energy/european_energy_policy/127062_en.htm. [Letzter Zugriff: 06.02.2015.]

Europäische Kommission (2010): Energie 2020. Eine Strategie für wettbewerbsfähige, nachhaltige und sichere Energie. Online verfügbar unter: http://eur-lex.europa.eu/resource.html?uri=cellar:da308df7-7394-4753aa8f-a70047d99382.0003.03/DOC_1\&format=PDF. [Letzter Zugriff: 04.02.2015.]

European Commission (2011): Energy Roadmap 2050. Online verfügbar unter: http://www.kowi.de/Portaldata/2/Resources/fp7/coop/com-2011Energy-Roadmap-2050-en.pdf. [Letzter Zugriff: 06.02.2015.]

Friedrich, Dawid (2014): Democratic representation in transnational citizens' forums?, in: S. Kröger (Hg.), Political representation in the European Union - Still democratic in times of crisis?, New York, S. 161177.

Fung, Archon (2003): Survey Article: Recipes for Public Spheres: Eight Institutional Design Choices and Their Consequences, in: Journal of Political Philosophy 11.3, S. 338-367.

Fung, Archon/Wright, Eric O. (2004): Deepening Democracy: Institutional Innovations in Empowered Participatory Governance, London.

Gerhards, Jürgen/Lengfeld, Holger (2014): In welchem Maße ist die Europäische Union eine sozial integrierte Gesellschaft?, in: M. Heidenreich (Hg.), Krise der europäischen Vergesellschaftung?, Wiesbaden, S. 201226. 
Greven, Michael Th. (2003): Sind Demokratien reformierbar? Bedarf, Bedingungen und normative Orientierungen für eine Demokratiereform, in: C. Offe (Hg.), Demokratisierung der Demokratie. Diagnosen und Reformvorschläge, Frankfurt a.M./New York, S. 72-91.

Grunwald, Armin (2014): „Technischer Wandel in der Energiewende notwendig, aber nicht hinreichend“, in: Holger Rogall et al. (Hg.), Jahrbuch 2014/2015 Nachhaltige Ökonomie. Im Brennpunkt: Die Energiewende als gesellschaftlicher Transformationsprozess, Marburg, S. 235254.

Habermas, Jürgen (1998): Die postnationale Konstellation. Politische Essays, Berlin.

Habermas, Jürgen (2011): Zur Verfassung Europas - Ein Essay, Berlin.

Habermas, Jürgen (2014): Europa wird direkt ins Herz getroffen, in: Frankfurter Allgemein Zeitung vom 29. Mai 2014. Online verfügbar unter: http://www.faz.net/aktuell/feuilleton/juergen-habermas-im-gespraecheuropa-wird-direkt-ins-herz-getroffen-12963798.html. [Letzter Zugriff: 06.02.2015.]

Hepp, Andreas et al. (2013): I just hope the whole thing won't collapse: „Understanding“ and „overcoming“. TranState Working Papers No. 168, Sonderforschungsbereich fb 597: „Staatlichkeit im Wandel,“ „Transformations of the State“, Bremen.

Hooghe, Liesbet/Marks, Gary (2009): A postfunctionalist theory of European integration: from permissive consensus to constraining dissensus, in: British Journal of Political Science 1, S. 1-24.

Kaase, Max (2003): Politische Beteiligung/Politische Partizipation, in: U. Andersen/W. Woyke (Hg.), Handwörterbuch des politischen Systems der Bundesrepublik Deutschland, Opladen, S. 495-500.

Kamlage, Jan-Hendrik (2011): Demokratische Potenziale zivilgesellschaftlicher Beteiligung im Partnerschaftsmodell der europäischen Regionalpolitik, unv. Dissertation, Universität Bremen.

Kamlage, Jan-Hendrik/Nanz, Patrizia/Fleischer, Björn (2014): Bürgerbeteiligung und Energiewende: Dialogorientierte Bürgerbeteiligung im Netzausbau, in: Holger Rogall et al. (Hg.), Jahrbuch 2014/2015 Nachhaltige Ökonomie. Im Brennpunkt: Die Energiewende als gesellschaftlicher Transformationsprozess, Marburg, S. 195-216. 
Kamlage, Jan-Hendrik/Fleischer, Björn (2014): Kommunen und ihre Bürger als Träger der Energiewende, in: Innovative Verwaltung, Ausgabe 14/1, S. 35-38.

Karanikolos, Marina et al. (2013): Financial crisis, austerity, and health in Europe, in: The Lancet 381.9874, London, S. 1323-1331.

Kies, Raphael/Nanz, Patrizia (Hg.) (2013): Is Europe listening to us? Successes and Failures of EU Citizen Consultations, Farnham.

Kohler-Koch, Beate (2011a): Regieren mit der europäischen Zivilgesellschaft, in: B. Kohler-Koch/Ch. Quittkat (Hg.), Die Entzauberung partizipativer Demokratie. Zur Rolle der Zivilgesellschaft bei der Demokratisierung von EU-Governance, Frankfurt a.M.

Kohler-Koch, Beate (2011b): Zivilgesellschaftliche Partizipation: Zugewinn an Demokratie oder Pluralisierung der europäischen Lobby?, in: B. Kohler-Koch/Ch. Quittkat (Hg.), Die Entzauberung partizipativer Demokratie. Zur Rolle der Zivilgesellschaft bei der Demokratisierung von EU-Governance, Frankfurt a.M.

Kolb, Matthias (2015): Wo der linke Tsipras mit den Rechtspopulisten hin will. Online verfügbar unter: http://www.sueddeutsche.de/politik/ parlamentswahl-in-griechenland-wo-der-linke-tsipras-mit-denrechtspopulisten-hin-will-1.2321071. [Letzter Zugriff: 06.02.2015.]

Leggewie, Claus/Nanz, Patrizia (2013): Neue Formen demokratischer Teilhabe, in: Transit. Europäische Revue 44, S. 72-85.

Lindberg, Leon N./Scheingold, Stuart A. (1970): Europe's Would-Be Polity. Patterns of Change in the European Community, Englewood Cliffs, N.J.

Mehr Demokratie e.V. (2012): Bürger klagen gegen undemokratische Ratifizierung von ESM- und Fiskalvertrag. (Pressemeldung 12.04.2012) Online verfügbar unter: http://www.mehr-demokratie.de. [Letzter Zugriff: 06.02.2015.]

Milward, Alan (1992): The European Rescue of the Nation-State, Routlegde, London.

Müller, Reinhard (2013): Karlsruher Republik im Wandel, in: Frankfurter Allgemeine Zeitung vom 24. Mai 2013, Online verfügbar unter: http://www.faz.net/aktuell/politik/inland/verfassungsgericht-karlsruherrepublik-im-wandel-12191535.html. [Letzter Zugriff: 06.02.2015.] 
Nanz, Patrizia/Fritsche, Miriam (2012): Handbuch Bürgerbeteiligung. Verfahren und Akteure, Chancen und Grenzen. Bundeszentrale für politische Bildung, Bonn.

Neyer, Jürgen (2013): Europa: Integration und Demokratie, in: Frankfurter Allgemeine Zeitung vom 8. April 2013, Online verfügbar unter: http:// www.faz.net/aktuell/politik/die-gegenwart/europa-europa-integrationund-demokratie-12140515.html. [Letzter Zugriff: 04.02.2015.]

Offe, Claus (2013): Europa in der Falle, in: Blätter für deutsche und internationale Politik 1, S. 67-80.

Participedia (2015): Homepage von Participedia. Online verfügbar unter http://www.participedia.net/dehttp://www.participedia.net/de. [Letzter Zugriff: 06.02.2015.]

Peter, Simone/Giegold, Sven (2015): Schluss mit der zynischen PositivRhetorik, in: Süddeutsche Zeitung vom 25. Januar 2015, Online verfügbar unter: http://www.sueddeutsche.de/politik/griechenland-vor-derwahl-schluss-mit-der-zynischen-positiv-rhetorik-1.2319657 [Letzter Zugriff: 02.02.2015.]

Powell, Maria/Kleinman, Daniel L. (2008): Building Citizen Capacities for Participation in Nanotechnology Decision-Making: the Democratic Virtues of the Consensus Conferences Model, in: Public Understanding of Science 17, S. 329-348.

Rauh, Christian/Zürn, Michael (2014): Zur Politisierung der EU in der Krise, in: M. Heidenreich (Hg.), Krise der europäischen Vergesellschaftung?, Wiesbaden, S. 121-145.

Scharpf, Fritz W. (2014): Legitimierung oder das demokratische Dilemma der Euro-Rettungspolitik. Online verfügbar unter: http://www.mpifg.de/ people/fs/documents/pdf/Legitimierung_oder_das_demokratische_ Dilemma_der_Euro-Rettungspolitik.pdf 2014. [Letzter Zugriff: 06.02.2015.]

Sintomer, Yves (2007): Le pouvoir au peuple. Jurys citoyens, tirage au sort et democratie participative, Paris.

Smith, Graham (2013): Designing Democratic Innovations at the European Level: Lessons from the Experiments, in: R. Kies/P. Nanz (Hg.): Is Europe listening to us? Sucesses and Failures of EU Citizen Consultations, Farnham, S. 201-216.

Steffek, Jens/Nanz, Patrizia (2008): Emergent Patterns of Civil Society Participation in Global and European Governance, in: J. Steffek/C. 
Kissling/P. Nanz (Hg.): Civil Society Participation in European and Global Governance: A Cure for the Democratic Deficit? Houndmills/ Basingstoke, S. 1-29.

Steinbeis, Maximilian (2011): Euro-Krise: Man kann Rührei nicht mehr trennen, in: Frankfurter Allgemeine Zeitung vom 29. November 2011. Online verfügbar unter: http://www.faz.net/aktuell/feuilleton/eurokrise-man-kann-ruehrei-nicht-wieder-trennen-11545325.html. [Letzter Zugriff: 03.03.2015.]

Streeck Wolfgang (2013a): Gekaufte Zeit: Die vertagte Krise des demokratischen Kapitalismus, Berlin.

Streeck, Wolfgang (2013b): Vom DM-Nationalismus zum Euro-Patriotismus, in: Blätter für deutsche und internationale Politik 9, S. 75-92.

Streeck Wolfgang (2015): Es ist so weit, in: Die Zeit vom 5. Februar 2015, S. 40.

Tosun, Jale/Biesenbender, Sophie/Schulze, Kai (2014): Energy Policy Making in the EU. Building the Agenda, Wiesbaden.

Wingert, Lutz (2013): Eurokapitalismus ohne Demokratie, in: Süddeutsche Zeitung vom 21. Mai 2013, S. 17.

Yang, Mundo (2013): Europe's New Communication Policy and the Introduction of Transnational Deliberative Citizens' Involvement Projects, in: R. Kies/P. Nanz (Hg.): Is Europe listening to us? Sucesses and Failures of EU Citizen Consultations, Farnham.

Zürn, Michael (1998): Regieren jenseits des Nationalstaates: Globalisierung und Denationalisierung als Chance, Frankfurt a.M. 


\title{
Muss Europa neu begründet werden?
}

\author{
Michael STOLLEIS
}

I.

Europa muss nach Ansicht vieler neu begründet werden. ${ }^{1}$ Meist wird dies so verstanden, dass der nach 1949 und speziell mit den Römischen Verträgen von 1957 begonnene Prozess der wirtschaftlichen und politischen Einigung Europas heute ins Stocken geraten ist und dass es geraten sei, sich erneut und grundsätzlich zu besinnen, in welcher Richtung es künftig weitergehen solle. Die Europäische Wirtschaftsgemeinschaft hat sich über mehrere Zwischenstufen zur Europäischen Union gewandelt, die Zahl der Mitglieder hat sich deutlich erhöht, und es gibt weitere - näher und ferner liegende - Beitrittskandidaten. Die Institutionen haben sich tiefgreifend gewandelt, Europa hat eine aus Verträgen und konsentierten Dokumenten bestehende „Verfassung“, ohne dass man deshalb aber vom einem europäischen Bundesstaat mit klassischer Verfassung sprechen kann. Gewichtige Stimmen warnen sogar vor einer Weiterentwicklung in dieser Richtung, vor allem vor einer weiteren Stärkung des Europa-Parlaments auf Kosten der Kompetenzen der nationalen Parlamente. In der Tat gibt es wachsende Widerstände, zumal von populistischen Parteien, die mit Argumenten gegen „Brüssel“ Wählerstimmen gewinnen möchten, andererseits aber finanzielle

1 Dieser Beitrag ist die etwas veränderte Fassung eines bereits unter dem Titel „Europa als Rechtsgemeinschaft“ in: Stefan Kadelbach (Hg.), Europa als kulturelle Idee. Symposion für Claudio Magris, Baden-Baden 2010, S. 71-81 erschienenen Aufsatzes. 
Unterstützung aus Brüssel einfordern. Auch in Deutschland macht seit der Banken- und Finanzkrise der EU eine neue Partei auf sich aufmerksam, die eine „Alternative“ zur fortschreitenden Homogenisierung Europas und zu den partiellen Verzichten auf klassische Souveränitätsrechte erreichen will. Diese Widerstände sollten aufmerksam studiert werden, auch wenn ihre Argumente sich oft auf Stammtischniveau bewegen; denn die Politik demokratischer Länder reagiert sensibel auf „Stimmungen“, selbst in Ländern wie Deutschland, deren ökonomische und politische Staatsräson von Europa nicht abgekoppelt werden kann.

Ungelöst sind in der Tat Kernfragen der wirtschaftlichen und sozialen Homogenität und die Vereinbarkeit einer nationalen staatstragenden Identität mit einer den Nationalismus programmatisch überschreitenden Europaidee. Dies wird in der Finanz- und Währungspolitik ebenso deutlich wie in der Verteidigungspolitik, in den Standards für eine gemeinsame Gesundheits- und Sozialpolitik, in den drängenden Fragen des europäischen Asyls für Flüchtlinge aus Krisengebieten sowie im noch unerreichten Konsens für eine gemeinsame Einwanderungspolitik. Jede der nationalen Teil-Politiken hat unausweichlich einen europäischen Rahmen, auch wenn es noch keine „Richtlinien“ geben mag. Ein Ausbrechen aus diesem Rahmen ist realpolitisch entweder gar nicht möglich oder doch mit erheblichen politischen Kosten und Risiken verbunden.

All dies ist schon vielfach erörtert worden und findet sich täglich im politischen Netzwerk zwischen Brüssel, Straßburg, Luxemburg und den europäischen Hauptstädten. Dabei schwingt stets der große historische Resonanzraum Europas seit dem Mittelalter, ja der gesamte Mittelmeerraum der Antike mit. Immer wieder wird darauf hingewiesen, in welche Tiefenschichten die heutige europäische Diversität der Sprachen und Kulturen zurückreicht. Dabei ist klar, dass der überaus offene und vielfältig interpretierbare Begriff der „Kultur“ auch die jeweilige „Rechtskultur“ umschließt (Schennach 2014). Und „Rechtskultur“ wiederum ist auch nur ein Sammelbegriff für kollektive Vorstellungen von Recht und Rechtsanwendung, für normative Vorgaben im Umgang mit Recht, für zu Selbstverständlichkeiten geronnene Erwartungen und gewohnheitsmäßige Reaktionen auf größere und kleinere Konflikte, die mit Mitteln des Rechts gelöst werden sollen (Kadelbach 2010).

Der Beitrag eines Rechtshistorikers zur Frage der Neugründung Europas könnte in doppelter Weise ansetzen. 
(1) Er könnte ausgehen von dem Wort des Frankfurter Juristen Walter Hallstein, „Europa muss Rechtsgemeinschaft sein“, ein Wort, das später noch einmal von Jacques Delors aufgenommen wurde. Hallstein gehörte zu den Promotoren des neuen Europa nach dem Zweiten Weltkrieg. Robert Schuman, Alcide de Gasperi, Paul Henri Spaak, Jean Monnet und Konrad Adenauer waren die legendären Gründungsväter. Daneben gab es eine große Anzahl von Juristen und Diplomaten, die in jenen Jahren mit dem Optimismus der Nachkriegsgeneration und des Neuanfangs, Europa auf den Weg brachten. Dieser Weg reicht vom Europarat (1949) über die MontanUnion (1951) zur gescheiterten Europäischen Verteidigungsgemeinschaft (1954), zum Schuman-Plan und schließlich zu den Römischen Verträgen von 1957. Die folgenden Jahre waren von europäischem Optimismus und einem Willen zur Ausfüllung der Verträge bestimmt. Man erwartete eine gegenseitige Stimulierung des freien Warenverkehrs, der Freizügigkeit und des Agrarmarkts, so dass an ein Zurück in voreuropäische Nationalismen nicht mehr zu denken war. Wesentliches Bauelement war das „Recht“, sowohl in der Politik der Kommission als auch in der Rechtsprechung des Europäischen Gerichtshofs, der den Vorrang des europäischen Rechts bei Kollisionen mit nationalstaatlichem Recht durchsetzte. In diesem Zusammenhang fiel Hallsteins Wort, die Europäische Wirtschafts-Gemeinschaft (EWG), wie sie damals noch hieß, sollte „Rechtsgemeinschaft“" werden (Hallstein 1969; Zuleeg 1994: 545ff.).

Das ist die heutige Europäische Union in der Tat auch geworden, eine Rechtsgemeinschaft, gesteuert durch professionell arbeitende Juristen. Sie schufen Institutionen, formulierten Normen aller Art, kümmerten sich um deren Durchsetzung und legten auf diese Weise ein immer dichter werdendes normatives Gespinst über Europa. Wenn wir heute eine Zigarette anzünden, eine Tüte Milch oder einen Fisch kaufen, eine Banane essen oder Speiseeis schlecken, unterliegen wir (oder die von uns geschätzten Produkte) europäischen Normen. Die Europa-Idee ist in die Hände der Bürokratie übergegangen (Stolleis 2011). Zwei Generationen später sehen wir deutlicher als damals, dass das optimistische Programm „Europa muss Rechtsgemeinschaft werden“ auch Schattenseiten im Bewusstsein der Bürger hatte. Populisten in fast allen Länder der Union, etwa in Dänemark, Irland, Niederlanden, Belgien und Frankreich, in der tschechischen Republik und in Polen nutzen das Potential der Affekte gegen die „Bürokraten“ und ihr Recht in Brüssel. 
Im hier gezogenen Rahmen ist es aber nicht möglich, die Realisierung des heutigen Europa Schritt für Schritt nachzuzeichnen. Die Entstehung Europas als Gemeinschaft des geltenden Europarechts ist auf der politischen Ebene und - parallel - auf derjenigen der Wissenschaftsgeschichte des öffentlichen Rechts (Stolleis 2012: 603ff.) kompliziert, aber auch lehrreich und spannend. Es wäre eine Art Verfassungs- und Wissenschaftsgeschichte der „Europäischen Union“ (Zuleeg 1997: 270ff.).

(2) Will man jedoch etwas von der rechtlichen Tiefendimension Europas vermitteln, muss man anders ansetzen. Die Wissenschaftsgeschichte der Rechtsgeschichte zeigt, dass die wohl unausweichliche permanente Einwirkung der äußeren Lage auf die Forschung den Blick nicht nur verengen, sondern auch neue Horizonte öffnen kann. Denn parallel zum Übergang der alten Europa-Idee in die politische Wirklichkeit nach 1945 entdeckte auch die „europäische Rechtsgeschichte“ in den fünfziger Jahren ihre Chance. Sie wandte sich zunehmend von den klassischen nationalstaatlichen Parametern ab und versuchte „europäische“ Rechtsgeschichte zu werden. Das lag für diejenigen auf der Hand, die die Geschichte des römischen Rechts bearbeiteten. Das geschah ohnehin schon immer innerhalb des europäischen Kontextes. Nun aber - nach 1945 - wurden erstmals wirklich europäisch angelegte Geschichten des ius commune geschrieben (Francesco Calasso, Paul Koschaker, Franz Wieacker), es gab ein europäisches Gemeinschaftsprojekt des römischen Rechts im Mittelalter (Ius Romanum Medii Aevi, Milano 1961) und es kam zur Gründung eines Max-Planck-Institut für europäische Rechtsgeschichte 1964 durch Helmut Coing in Frankfurt (Schäfer 2009: 517ff.). Ihrer aller Grundidee lag darin, das mittelalterliche und frühneuzeitliche ius commune als ein verbindendes Element Europas wieder ins Bewusstsein zu heben, weniger um der europäischen Rechtsvereinheitlichung zuzuarbeiten als um die Breite und Tiefe der europäischen Rechtskultur zu erforschen.

Rechtshistoriker erinnern seit der Europaeuphorie der fünfziger Jahre daran, dass Europa vom 13. bis zum 18. Jahrhundert über eine prinzipiell homogene Wissenschaftskultur des Rechts verfügte. Das in den meisten europäischen Gebieten „rezipierte“ römische Recht war „gemeines Recht“ (ius commune). Begonnen hat es, wie wir alle wissen, in Bologna, dann in Padua und Pavia, Prag, Heidelberg, Köln und Wien, in Bourges, Paris und Orléans, später in Uppsala, Krakau und anderswo. Die gelehrte Welt und die Kirche sprachen gemeinsam Latein. Nationale Grenzen gab es noch 
nicht, wohl aber ein dichtes Geflecht von Herrschaftsbeziehungen weltlicher und kirchlicher Herren. Die Bildungslandschaft war frei begehbar. Ausbildungsziele, Methodik, Gegenstände und das Wanderleben der Scholaren waren einheitlich und stilbildend für einen selbstbewussten Juristenstand, der seit dem 15. Jahrhundert überall in städtischen, fürstlichen und königlichen Verwaltungen und Gerichten das Bild bestimmte.

Gleichzeitig erhielt sich aber das überall vorhandene einheimische, lokale Recht. Die Parteien mussten es vor Gericht darlegen - etwa abweichendes Handelsrecht, Dorfrecht, Stadtrecht, Landrecht, lokale Gewohnheiten, Privilegien Einzelner usw. Europa war also rechtlich außerordentlich kompliziert: Es gab Recht, das auf die Person (und nur auf diese) bezogen war. Der Lehensmann, der Kaufmann, der Handwerker, der Bauer, der Priester, der Mönch und die Nonne lebten sämtlich in Sonderrechtskreisen, mit jeweils für sie gültigen Normen. Für die einen war der Lehensherr zuständig, später der Rat der Stadt oder der Landesherr, für die anderen Zunft und Zunftgericht, für wieder andere der Bischof oder der Abt. Darüber lag eine weitgehend einheitliche Rechtsschicht des gelehrten Rechts (in Deutschland auch kaiserliches Recht genannt, um den Legitimationsgrund anzudeuten). Es überlagerte die einheimischen lokalen Rechte, und es war das Recht, das die höheren Gerichte, die mit professionellen Juristen besetzt waren, vor allem anwandten. Dadurch sickerte dieses römische Recht gewissermaßen in die einheimischen Rechte ein, gab ihnen Systematik und Rechtsbegriffe. Im 20. Jahrhundert hat man diesen für das Spätmittelalter und die frühe Neuzeit zentralen Vorgang dann kurzerhand „Verwissenschaftlichung“ genannt (Wieacker 1967: 124ff.).

$\mathrm{Zu}$ diesem Ineinander von einheimischem lokalem Recht und ,wissenschaftlichem" (lateinischem) ius commune kam - um die Komplexität weiter zu steigern - noch das Recht der katholischen Weltkirche hinzu. Es war nach einer Inkubationszeit von fast tausend Jahren im 13. Jahrhundert in der Art eines Gesetzbuchs zusammengefasst worden und galt nun für alle katholischen Christen auf den Gebieten des Eherechts, des kirchlichen Vermögensrechts, des Prozessrechts, der Kirchenstrafen, des Mönchsrechts usw. Auch dieses katholische Kirchenrecht - selbst eine Art Abkömmling wieder des römischen Rechts - prägte die Lebenswelt der Europäer von Norwegen bis Sizilien, von Polen bis Spanien. Es bildete eine parallele Rechtsordnung zum ius civile - und entsprechend promovierte man vielerorts mit dem Titel Dr. utriusque juris, also „beider Rechte“. 
Das Kirchenrecht hat alles weltliche Recht tief durchdrungen und es hatte eine mindestens ebenso starke Klammerfunktion für das ,lateinische Europa“ (vgl. Link 2010: 42ff.). Die lutherische und die calvinistische Reformation haben daran nichts geändert. Das evangelische Kirchenrecht hat die gemeinsamen Grundlagen stets akzeptiert und fortgebildet. Funktional betrachtet bildet das Kirchenrecht aller drei Hauptkonfessionen eine Einheit. Es ist einer der wesentlichen Faktoren europäischer Identitätsbildung geworden. Auch die kirchliche Seite des öffentlichen Lebens wurde ,verrechtlicht“ und „verwissenschaftlicht“. Das Individuum erhielt eine scharf umrissene Rechtsposition, es gab genaue Verfahrensregeln und Prinzipien der Verfahrensgerechtigkeit. Mit Recht spricht man vom römischkanonischen Prozess, der sich überall an den Gerichten durchsetzte. Und vor allem wurde in Europa eingeübt, dass richterliche Entscheidungen als verbindlich anzusehen seien. Selbsthilfe und Gewalt sollten ein Ende haben, wenn eine Sache entschieden war (res iudicata).

Diese komplexe europäische Rechtswelt, in der noch einmal England und das dem Kontinent nähere Schottland, Skandinavien und Polen (ganz zu schweigen vom europafernen orthodoxen Russland und den Ländern unter der Herrschaft von Byzanz!) Sonderrollen spielen, diese Welt wurde mit der Entstehung der Nationalstaaten aufgesprengt. Der Prozess reicht weit in das Mittelalter zurück, wird aber manifest dann im 17. und 18. Jahrhundert. Nun hatten sich europäische Staaten mit festen Grenzen gebildet. Die Staaten pochten auf ihre Souveränität, errichteten Grenzregime, bauten territoriale Verwaltungen auf, schufen Steuersysteme, entwickelten erstmals Handelsbilanzen für ihre Länder und sie ordneten - nicht zuletzt - ihre Justiz. Fast überall rief man nun nach Ordnung des verworrenen Rechts, betonte die Rolle des Gesetzgebers, dessen Gebot nun alles ältere Recht aufheben konnte. Diesem Gesetzgeber traute man dann auch bald die große Ordnung stiftende Tat zu, die Kodifikation. Seit dem 16. Jahrhundert geisterten mannigfache Pläne der Kodifikation durch Europa, immer wieder wurde ein „,neuer Justinian“ beschworen (Conring 1634/1994: 237ff.). Die Juristen entwarfen (auf der Grundlage des römischen Rechts und nach dem Schema des nun überall gelehrten Naturrechts) Einteilungen des Rechtsstoffs und überlegten sich, was in eine Kodifikation gehöre. Am Ende des 17. Jahrhunderts beginnt dann die lange Reihe der Kodifikationen mit Dänemark (1683), zahlreichen Landrechten in Österreich und Deutschland, einer geschlossenen Kodifikation in Bayern (1756), dann Preußen (1794), 
Frankreich (1804), Österreich (1811). Ganz am Ende stehen dann Italien (1865), Deutschland (1896) und die Schweiz (1911). Gegenstand dieser Kodifikationen war durchweg das Privatrecht, daneben das Gerichtswesen mit seinen Prozessordnungen, aber auch das Strafrecht und das Handelsrecht. 1917 mündete auch das Recht der Katholischen Kirche in einen neuen Codex Iuris Canonici.

Dies alles ist im Wesentlichen Gegenstand der sog. Privatrechtsgeschichte sowie der Geschichte des Kirchenrechts. Mindestens der privatrechtsgeschichtliche Teil ist allen Rechtshistorikern geläufig. Es ist sozusagen das dreifache rechtsgeschichtliche Erbe Roms. Zuerst also das juristische Erbe des römischen Rechts, im 6. Jahrhundert noch einmal in Konstantinopel gesammelt und im Hochmittelalter in Europa wiedergefunden und entfaltet. Es ist aber auch das Erbe des römischen Kirchenrechts, das ebenfalls im 12. Jahrhundert in Buchform gegossen und weiterentwickelt wurde, um dann von der katholischen und den protestantischen Kirchen bis in die Gegenwart weitergeführt zu werden. Und es war schließlich (drittens) von hohem Symbolwert, dass das moderne Europarecht des 20. Jahrhunderts wieder mit den Römischen Verträgen von 1957 in Rom seinen Ausgangspunkt genommen hat.

\section{II.}

Es gibt jedoch noch einen zweiten, nicht weniger wichtigen Pfad europäischer Überlieferung und Formung der europäischen Rechtskultur. Wenn Walter Hallstein und Jacques Delors davon sprachen, Europa müsse eine „Rechtsgemeinschaft“ werden, dann war das gewiss nicht im Sinne des privatrechtlichen ius commune und nicht im Sinne eines christlichen Kirchenrechts gemeint, sondern zunächst ganz vordergründig im Blick auf eine Verankerung der verschiedenen Nationalökonomien in einem neuen gemeinsamen Rechtsrahmen. Darüber hinausgehend mochte man an die Bindungskraft von ,Recht“ schlechthin gedacht haben, also an etwas Dauerhaftes, dem sich die Partner unterwerfen, an Institutionen, die nicht vom Wind der Politik bewegt werden, sondern verlässlich als Rechtseinrichtungen stehen. Schließlich könnte man auch an eine künftige Verfassung Europas gedacht haben. 
In diesem weiteren Sinne geht es nun im Folgenden um den eigentlichen heute noch wirksamen Kern Europas. Es handelt sich um das längst verinnerliche, selbstverständlich gewordene, sozusagen sedimentierte Ensemble von Grundregeln oder Grundprinzipien des öffentlichen Rechts. Es ist das Ius Commune Publicum (von Bogdandy/Cruz Villalón/Huber 20072011). Seine Grundprinzipien müssen nicht neu erfunden werden. Sie haben sich über Jahrhundert entwickelt, auch über andere Weltteile ausgebreitet, ohne dort sicherer Besitz geworden zu sein. Sie sind - wie beim Rechtstransfer üblich - umgewandelt worden, haben sich anderen gesellschaftlichen Bedingungen angepasst, haben Gestalt und Funktion verändert. Ebenso sind sie in Europa selbst keineswegs „,sicherer Besitz“, sondern müssen permanent an neue Herausforderungen angepasst, von neuen Generationen erlernt und in krisenhaften Situationen getestet werden. Erinnert sei nur an die Reaktionen auf die Gefahren des internationalen Terrorismus sowie an die Aufnahme von Flüchtlingen aus aller Welt.

1. Vom 16. bis zum 18. Jahrhundert entfaltete sich in ganz Europa das neuzeitliche Natur- und Völkerrecht (ius naturale, ius gentium europaeum). Es bediente sich seiner antiken und mittelalterlichen Quellen, es begleitete die Moderne in doppelter Weise: Einmal die Eroberung der ,ganzen“ Welt (Amerika, Asien, Afrika) durch Spanier und Portugiesen, Niederländer, Franzosen und Engländer. Es ist das Recht der Eroberer, euphemistisch „Recht der Völker“, später ,,international law“ genannt. Zugleich diente das Naturrecht im Inneren dieser europäischen Staaten als die rationale, für alle Gemeinwesen passende Rechtstheorie und entwickelte Schritt für Schritt ein ,ius publicum universale“ (Stolleis 1988: 291ff.). Es bot nun die Möglichkeiten, eine Konstruktion der Herrschaftsverhältnisse im Innern eines Staates zu liefern (vor allem durch die Erfindung des fiktiven Herrschaftsund Unterwerfungsvertrags), Rechte und Pflichten der Individuen ebenso zu definieren wie Rechte und Pflichten des Herrschers. Es bot also die Möglichkeit, den modernen Staat als Rechtsgebilde mit eigenen Grenzen und eigener Souveränität als großes Individuum zu begreifen, das mit anderen Staaten in Rechtskontakt tritt. Rechtsordnung im Innern und Völkerrechtsordnung in den äußeren Beziehungen konnten nun in einer Terminologie beschrieben werden, die für alle gleich war, auch für Christen und Heiden.

2. Ein zweites Element liegt in der Tradition der aristotelischen Politik. Dieses antike Grundwerk politischen Denkens Europas ist bekanntlich im 
Mittelalter wieder entdeckt, ins Lateinische übersetzt und zum festen Element der Grundausbildung an den Universitäten gemacht worden, auch für Juristen. Die protestantischen Länder haben dies im Neo-Aristotelismus des 16. und 17. Jahrhunderts intensiviert. Anhand der Lektüre und der in die hunderte gehenden Kommentierungen von Aristoteles „Politik“ lernte man in ganz Europa die Unterscheidung guter und schlechter Staatsformen, hörte von den Vorzügen der ,gemischten“ Verfassung, definierte das gute Regiment und den Staatszweck „Gemeinwohl“, erörterte die Staatskrankheiten und ihre Heilung.

3. Nimmt man zu Aristoteles' Politik noch die gesamte antike Staatsliteratur, insbesondere Cicero und Tacitus sowie die staatsrechtlichen Bruchstücke des römischen Rechts hinzu, dann hat man die Fragen im Blick, die das europäische politisch-juristische Denken beherrschten: Wie entsteht der Staat und wie lässt er sich legitimieren, welches ist die beste Verfassung, was ist die Souveränität und wer ist Träger der Staatsgewalt, welchen Bindungen unterliegt er, wer hat das Recht der Gesetzgebung, wer darf Steuern erheben und zu welchem Zweck? Diese Debatte war europäisch und überkonfessionell. Sie leistete, was sich für das gesamteuropäische Bewusstsein als zentral erweisen sollte: eine Verständigung über die Elementarsätze einer wissenschaftlichen Politik, über die Rechtsgrundlage legitimer Herrschaft sowie über deren Begrenzung durch übergeordnete Normen, einschließlich des (höchst umstrittenen) Widerstandsrechts gegen den illegitimen Herrscher. Ohne diese gewissermaßen zur Selbstverständlichkeit gewordene Rechtsbindung der Obrigkeit wäre die Verfassungsbewegung des 18. und 19. Jahrhunderts gar nicht denkbar gewesen. Ohne die Lehre von der „respublica mixta“ und ohne die Einübung des Satzes ,rex regnat, sed non gubernat" seit dem 16. Jahrhundert wäre die Trennung von Regierung und Verwaltung, und damit auch die moderne Gewaltentrennungsdoktrin, nicht akzeptiert worden. Ohne die jahrhundertelange Einübung genossenschaftlicher Selbstverwaltung und ohne die Grundidee eines Gesellschaftsvertrags gäbe es keine moderne Demokratie. ,Quod omnes tangit, ab omnibus approbari debetur" (was alle angeht, muss auch von allen gebilligt werden) ist ein zunächst spätantiker, dann mittelalterlicher kirchenrechtlicher und zur Einberufung von Hoftagen auch weltlich genutzter Satz (Kluxen 1983). Dass das Volk die oberste Legitimationsquelle sein solle, wurde von Marsilius von Padua im 14. Jahrhundert formuliert (1324: Teil I, Kap. $\mathrm{XV}, \S \S 2,3$.). Auch wenn man diese Anfänge nicht im Sinne des modernen 
demokratischen Prinzips und der Volkssouveränität lesen darf, ebenso wie 300 Jahre später in der Lehre von der Politik bei Johannes Althusius (Winters 1995: 29ff.), so nehmen doch hier Gedankenströme ihren Ursprung, die später, in ganz anderen Kontexten, herrschend und geschichtsmächtig werden sollten.

4. Ein wesentlicher weiterer und in vielen Facetten schillernder Grundgedanke ist die Verantwortlichkeit der europäischen Obrigkeiten für eine gerechte Sozialordnung. Immer wieder wurde den Herrschenden durch Fürstenspiegel, Tugendlehren, theologisch-moralische Traktate oder Kommentare zur aristotelischen Politik eingeschärft, ihre Aufgabe sei das Gemeinwohl, die ,gute Ordnung“ oder ,gute Policey“, also eine Ordnung, die nicht nur Sicherheit und formale Rechte gewährt, sondern auch einen Ausgleich zwischen Reich und Arm (pauper et potens), Benachteiligten und Begünstigten, Hoch und Niedrig sucht (Simon 2004). Gleichviel, ob das als Gebot der Nächstenliebe, als Satz der praktischen Ethik oder als Kalkül der Machterhaltung begründet wird, gehören Schutz und Fürsorge zu den elementaren Aufgaben des Herrschers oder der entsprechenden Autoritäten. Sie wurden erfüllt durch eine Mischung von Zwang und Fürsorge, indem man ohne Bedenken repressiv intervenierte, etwa durch Ausweisung fremder Bettler oder Krimineller sowie durch Errichtung von Zucht- und Arbeitshäusern, aber auch eine Palette von Hilfsmaßnahmen kannte, für die weltliche und kirchliche Obrigkeiten aktiv waren. Dass sich in Europa ein „Sozialstaat“ mit seinen Paradoxien von Verweigerung und Gewährung entwickelte, während er in anderen Weltgegenden in dieser Form hoheitlicher Umverteilung praktisch unbekannt ist, belegt noch einmal, dass wir es hier mit einem tausendjährigen vormodernen Pflichtenkanon zu tun haben, der im Kontext der Industriellen Revolution und der „Sozialen Frage“ noch einmal an Dynamik gewinnt und zur Ausbildung unterschiedlichster Formen der Bewältigung typischer Lebensrisiken und unvorhersehbarer Einbrüche in die Biographie führt (Maier 2002; Stolleis 2003: 13ff.).

\section{III.}

Richtet man nun den Blick auf die konkreten Elemente des Ius Commune Publicum, dann findet sich so viel und so Grundsätzliches, dass im hier gezogenen engen Rahmen kleine Hinweise genügen müssen: 
1. Zunächst die Idee der Verfassung, weit verstanden als eine Grundentscheidung über den politischen „Status“ in Rechtsform, entweder in grundlegenden Rechtsakten oder in einer einzigen Urkunde (Mohnhaupt 2002). In der heute üblichen Form sind Verfassungen seit dem ausgehenden 18. und im 19. Jahrhundert in Europa und Amerika entstanden und haben sich heute über die ganze Welt ausgebreitet. Es ist signifikant, dass sich diese Verfassungsbewegung parallel zur Kodifikationsbewegung entwickelt, auf diese Weise die schrittweise Trennung von Staat und Gesellschaft sinnfällig machend. Für die zwischenmenschlichen Beziehungen das Zivilrecht, für das Verhältnis zwischen Bürger und Staat das Strafrecht und die Verfassung!

Grundidee der Verfassungen war die Begrenzung der Macht des Herrschers, bald aber auch die Legitimation der gesamten öffentlichen Ordnung. Solche Fundamental- oder Grundgesetze gab es in allen europäischen Ländern, sie regelten die Thronfolge bzw. die Königswahl, sie bestimmten das Verhältnis zu den Landständen, sie legten seit dem 15. Jahrhundert meist auch die Unteilbarkeit des Landes fest und verdrängten das dynastische Erbrecht. In diesem Sinne ist von einer „Verstaatlichung des dynastischen Verbandes" gesprochen worden (R. Vierhaus). Dass die deutsche Verfassung „Grundgesetz“ genannt wird, war einerseits ein Hinweis auf ihren vermeintlichen Charakter als Provisorium, andererseits aber eine Fortsetzung der genannten langen Vorgeschichte.

2. Europäischer ideeller Gemeinbesitz ist auch die Vorstellung, dass es gegenüber dem nun immer stärker werdenden modernen Staat gewisse unantastbare Bereiche geben müsse, also Grundrechte. Grundrechte sind die Antwort auf religiöse Intoleranz, willkürliche Verhaftungen und Verurteilungen, Vertreibungen, Missachtung des Hausfriedens, rechtswidrige Enteignungen, Auswanderungs- und Heiratsverbote, politische Zensur usw. Die langsam entstehende bürgerliche Gesellschaft suchte und fand in diesen Schutznormen ihre Entfaltungsräume gegenüber dem Absolutismus, sie fand in ihnen ihre geistige Identität, lange bevor sie die Chance erhielt, diese Normen in modernen Verfassungen festzuschreiben. Aber Grundrechte für Individuen genügen nicht: Auch Minderheiten sind schutzbedürftig, wenn sie bei Abstimmungen nach „Mehrheit“ ständig unterliegen. Folglich müssen verfahrensrechtliche Sicherungen erfunden werden, mit deren Hilfe Minderheiten der „Diktatur der Mehrheit“ Widerstand leisten können. Dazu zählen etwa Vetorechte in existentiellen Fragen, Zweidrittelmehrheiten für 
grundlegende Änderungen, eine Spaltung des Abstimmungskörpers (itio in partes) und anderes mehr.

Heute sind es auf breiter Front die Rechtsprechung der nationalen Verfassungsgerichte, der Menschenrechtsschutz im Gerichtshof in Straßburg und die Rechtsprechung des Europäischen Gerichtshofs in Luxemburg, die den gemeineuropäischen Grundrechtsstandard für Einzelne und für Gruppen sowie Prinzipien des europäischen Verfassungsstaats modellieren langsam und fallbezogen gewiss, aber sie tun es.

3. Die Liste prinzipieller europäischer Gemeinsamkeiten, die sich insgesamt zu einem Ius Commune publicum zusammenschließen, müsste verlängert werden um Ausführungen zum Föderalismus, dem Gedanken der Gewaltenteilung in großen Flächenstaaten, weiter um die Grundgedanken der Gewaltenteilung in Legislative, Exekutive und Judikative, die - vielleicht über ein Missverständnis Montesquieus über England, vielleicht aber auch über ein Missverständnis der Exegeten Montesquieus! - zum europäischen Gemeinbesitz geworden ist. Eng damit zusammen hängt die Unterscheidung zwischen parlamentarischem Gesetz und administrativer Verordnung - auch sie ein Produkt der Gewaltenteilung und gegenseitigen Kontrolle. Schließlich müsste man unbedingt noch die für Europa so zentrale Tradition des Rechtsschutzes durch richterliche Entscheidung erwähnen; die seit dem Mittelalter in ganz Europa bestehenden großen Gerichtshöfe und ihr professionelles Richtertum sind vielleicht das sprechendste Beispiel für institutionelle Gemeinsamkeiten (Stolleis 2008: 204f.). Das Parlement de Paris, der Große Rat von Mechelen, das englische Krongericht, das schwedische Högsta Domstolen, die spanischen Königsgerichte, das Reichskammergericht in Speyer und Wetzlar, der Reichshofrat in Wien und viele andere bildeten die Spitzen eines unendlich vielfältigen, aber von einem einfachen Grundgedanken beherrschten Rechtsschutz. Dieser Grundgedanke lautet: alle politische Gewalt ist rechtlich gebunden, sie muss „dem Rechte gemäß“ handeln, Schutz gewähren, Rechtsfrieden durch bindenden Entscheidungen stiften. Auf diese Weise sind Landfriedensbrüche, Fehdewesen und unerlaubte Selbsthilfe langsam zurückgedrängt worden. Der „Prozess der Zivilisation“ (Norbert Elias) hat auch die europäische Geschichte der Gerichtsbarkeiten geprägt. Das System ist immer dichter, formelhafter und sicherer geworden. Weitgehend hat sich eine Dreistufigkeit der Instanzen durchgesetzt, die Verfahrensregeln sind im Kern ähnlich, ebenso das Vollstreckungswesen. Ohne Zweifel vermittelt dieser historisch 
gewachsene Standard des Rechtsschutzes einen wesentlichen Teil jener Homogenisierung, die Europa als ideelle Einheit konstituiert.

Die Ergebnisse dieser Skizze lassen sich thesenartig zusammenfassen wie folgt:

1. Die heutigen europäischen Gesellschaften sind geprägt durch jahrhundertelange Erfahrung im Umgang mit einer pragmatischen flexiblen Staatstheorie aristotelischer Herkunft sowie mit weltlichem und kirchlichem Recht aus römischrechtlicher Wurzel. Die Gesellschaften werden als „rechtlich verfasst“ verstanden. Herrschaft muss sich durchweg sowohl als demokratisch wie als ,rechtlich“ legitimieren.

2. Hierauf ruht die europäische Idee des Rechts- und Verfassungsstaats, „wahrscheinlich“, wie Talcott Parsons gesagt hat, „die entscheidende Erfindung der Moderne“. Gewiss werden die Formeln der rule of law, des état de droit, estado de derecho, stato di diritto etc. in Nuancen unterschiedlich verstanden, aber der Kern der Bindung an das demokratisch legitimierte Gesetz ist gleich (Haller 2004: 52ff.). Machtausübung muss kontrolliert werden. Der Bürger muss die Möglichkeit haben, sich gegen staatliche Maßnahmen effektiv zu wehren. Bedenken Sie, in wie vielen Staaten dies nicht möglich ist, und Sie werden ermessen, welche kostbare Errungenschaft eine verwaltungsgerichtliche Anfechtungsklage darstellt! Dass sogar die Machtausübung des gewählten Gesetzgebers über seine Bürger durch ein unabhängiges „Verfassungsgericht“ noch einmal überprüft werden kann, perfektioniert diesen Rechtsstaat. Und wenn alles dies nicht Sicherung genug ist, steht der Straßburger Gerichtshof für Menschenrechte zur Verfügung.

3. Dieser Rechtsstaat ist nach allgemeiner Überzeugung aber nicht nur ein Rechtsschutzstaat für diejenigen, die Rechte haben, sondern auch ein der Gerechtigkeit verpflichteter materialer Rechtsstaat. Wir nennen ihn Sozialstaat und nehmen ihn heute als wesentliche Garantie des sozialen Friedens im kapitalistischen Industriestaat westlicher Prägung wahr. Er verteilt das Sozialprodukt um, sucht strukturelle Defizite und Sonderopfer auszugleichen, Lebensrisiken abzusichern und die Startchancen der Einzelnen jedenfalls ansatzweise zu homogenisieren, nicht nur durch 
materielle Leistungen an die Individuen, sondern genau so über Schulen und Universitäten.

4. Die Legitimation der schwierigen Balance von Rechts- und Sozialstaat, Freiheit, fürsorglicher Lenkung und notwendigem Zwang gelingt unter heutigen (westlichen) Bedingungen nur über Verfahren der Demokratie. Deren Grundgedanke reicht von der griechischen Polis über den mittelalterlichen Satz „Was alle angeht, muss von allen entschieden werden“ bis in die Aufklärung und in die Französische Revolution, in die moderne Verfassungsbewegung und in unsere Tage. Wie man ihn ausgestaltet, ist offen. Wir neigen heute langsam dazu, die strikt repräsentative Ausgestaltung der Demokratie (also eine vierjährige Abkoppelung der Abgeordneten vom jeweiligen Volkswillen) durch Elemente direkter Beteiligung des Volkes zu ersetzen, also durch Volksinitiativen und Volksentscheide bis hin zur Abstimmung über einzelne Vorhaben. Europa ist in seinen Einzelstaaten reich an solchen Modellen, aber die Ebene des geltenden Europarechts haben sie noch nicht erreicht.

\section{IV.}

Wir stehen momentan an einem Kreuzweg der Fortentwicklung Europas. Viele glauben, es sei richtig, den Zusammenschluss Europas zu bremsen, den nationalen Egoismus wieder stärker zu betonen, jedenfalls die Entscheidungsprärogative der nationalen Parlamente zu stärken - verständlich angesichts der europäischen Finanzkrise. Andererseits gibt es aus historischen und pragmatisch-politischen Gründen keine wirklich gangbaren Wege, aus der Europäischen Union wieder auszutreten. Die Folgen einer solchen Rückbewegung, wenn sie überhaupt möglich wäre, könnten verheerend sein, nämlich in Form einer Rückkehr zu den alten Nationalismen, denen Europa um den Preis zweier Weltkriege gerade entronnen ist. Die Empfehlung kann also vernünftigerweise nur lauten, Europa in der Weise auszugestalten, dass seine Institutionen rascher und effektiver handlungsfähig werden und vor allem, dass ihr Mandat über das Europäische Parlament für die Bürger sichtbar und fühlbar an demokratische Wahlen rückgekoppelt wird. Weltpolitisch haben wir gar keine andere Wahl, es sei denn wir 
betrachten uns nur noch als Museumswärter eines museal gewordenen Europa.

Wir bauen dieses künftige Europa mit den historischen Bausteinen, die uns zur Verfügung stehen. Ihre Herkunft wurde historisch skizziert. Dieser Hintergrund ist unser ideenpolitisches Reservoir, unser kultureller Resonanzraum. Selbst diejenigen leben in ihm, die von Geschichte nichts wissen oder wissen wollen. Er umfasst mit starken Modifikationen auch die ursprünglich europäisch geprägten Räume Nord- und Südamerikas. In vergleichbarer Weise leben Chinesen, Japaner, Koreaner und andere Völker Südostasiens im kulturellen Resonanzraum der konfuzianischen Ethik, ihrer Familienstrukturen und der dadurch vermittelten Wertsysteme.

Die europäischen Länder, so verschieden sie sind, haben eine gemeinsame Sprache entwickelt, eine Sprache, die trotz unterschiedlicher Idiome, eine Verständigung über die rechtlichen Grundlagen demokratischer Verfassungsstaaten ermöglicht. Wir wissen, wovon wir reden. Die Verfassungsrichter Europas, die sich regelmäßig treffen, bezeugen es, die aus verschiedenen Nationen kommenden Richter am Europäischen Gerichtshof in Luxemburg ebenso wie die Straßburger Richter am Gerichtshof für Menschenrechte. Sie alle haben, sagen sie, keine Verständigungsprobleme über die Grundlagen ihrer Rechtsvorstellungen. Und in diesem Sinne haben vielleicht auch die Gründer des heutigen Europa ihr politisches Gebilde als „Rechtsgemeinschaft“ verstanden. Europa sollte keine Räuberbande sein, kein Konsortium wirtschaftlicher Egoisten. Leitgedanke war die Hoffnung, man binde sich an sehr alte und gemeinsame Rechtsregeln und gemeinsame materiale Rechtswerte, an einen „ordre public européen“. Das ist bisher bei den Nationen des Kerneuropa so gewesen, bei den neuen Mitgliedern (etwa Rumänien und Bulgarien, die Balkanstaaten und Griechenland) muss vieles von unseren verfassungsrechtlichen Selbstverständlichkeiten, Verfahrensund Fairnessregeln, Parteienwesen, Rechtskontrolle der Verwaltung und Verfassungskontrolle der Gesetzgebung erst eingeübt werden - von der Angleichung der Lebensverhältnisse ganz zu schweigen. Mit anderen Worten: Es gibt einen historischen Fundus, es gibt erprobte Elemente und das Basisprinzip der demokratischen Legitimation des Staatshandelns. Das sind die historischen Reserven. Sie zu besitzen genügt nicht. Wir müssen sie ständig erneuern.

Europa muss nicht neu gegründet oder gar neu erfunden werden. Es kann und muss vielleicht seine Verfassungsgrundlagen, die es bereits hat, 
im Konsens ändern und neuen Bedingungen anpassen. Das wäre nichts Ungewöhnliches und in der momentanen Situation sogar dringend geboten. Das wird extrem schwierig werden. Nationalismen und Egoismen breiten sich aus. Die Distanzen der Volkswirtschaften vergrößern sich - trotz gemeinsamer Währung. Eine Ausweitung der Euro-Zone ist derzeit nicht realistisch; es geht zunächst einmal darum, sie zu stabilisieren. Der Kitt, der die verschiedenen Elemente Europas zusammenhält, heißt einfach „Angst“, und zwar Angst vor den finanziellen Weiterungen, vor dem Verlust der guten Plätze im Wettbewerb der Welt, Angst vor dem Verspielen dessen, was drei Generationen nach dem Zweiten Weltkrieg an Europa aufgebaut haben.

Angst ist aber, wie die Evolutionsbiologen sagen, unverzichtbar als Antrieb zur Vermeidung von Gefahren. Wir brauchen eine gewisse Erschütterung Europas, um zu begreifen, was wir an diesem einzigartigen politischen Zusammenschluss haben. Und wenn wir seine Vorteile behalten wollen, müssen wir energisch einiges ändern: Wir müssen die Währungsunion durch ein schlagkräftiges finanzpolitisches Regime der nationalen Haushalte komplettieren. Das setzt Souveränitätsverzichte und für die Deutschen eine Grundgesetzänderung voraus. Dazu bedarf es einer Zweidrittelmehrheit, die heute noch nicht zu haben ist, an der aber langfristig kein Weg vorbeiführt.

Wir müssen weiter, und dies ebenso dringend, das Europa-Parlament weiter stärken, und zwar durch eine Steuer- und Budget-Verantwortung, Nur dies, so lehrt die Verfassungsgeschichte des 19. Jahrhunderts, führt zu einem wirklichen parlamentarischen System. „Was alle angeht, muss auch von allen entschieden werden“ (Quod omnes tangit - tönt es seit dem Mittelalter). Aber auch nur dies! Was nicht alle angeht, soll in nationaler, regionaler oder kommunaler Verantwortung bleiben.

Es ist der gemeinsame politische und wirtschaftliche Raum, der seine neue, zukunftsfähige innere Ordnung finden muss, um handlungsfähig zu werden. Die Zeiten des Nationalismus sind vorbei. Nur eine europäische Wirtschafts-, Währungs- und Verteidigungspolitik ist in der Lage, die Probleme zu lösen, die uns alle angehen. Die in langer gemeinsamer europäischer Geschichte entwickelten Instrumente für die Umgestaltung liegen bereit, wie zu zeigen versucht wurde: Demokratie, Rechtsstaat und Sozialstaat, Vorrang der Verfassung und Verfassungsgerichtsbarkeit, Gewaltenteilung und Föderalismus, ein maßvoll eingesetztes Subsidiaritätsprinzip 
und größtmögliche Teilhabe der Bürger an den Entscheidungsprozessen. Es ist unser und vor allem unserer Kinder Schicksal, das dabei verhandelt wird.

\section{LITERATUR}

Bogdandy, Armin von/Cruz Villalón, Pedro/Huber, Peter M. (Hg.) (20072011): Handbuch Ius Publicum Europaeum. Bände I-IV, Heidelberg.

Conring, Hermann (1643): De origine iuris Germanici Commentarius Historicus. Dt.: ders. (1994): Der Ursprung des Deutschen Rechts, Frankfurt/Leipzig.

Haller, Gret (2004): Die Grenzen der Solidarität. Europa und die USA im Umgang mit Staat, Nation und Religion, Berlin.

Hallstein, Walter (1969): Der unvollendete Bundesstaat. Europäische Erfahrungen und Erkenntnisse, Düsseldorf/Wien.

Kadelbach, Stefan (Hg.) (2010): Europa als kulturelle Idee. Symposion für Claudio Magris, Baden-Baden.

Kluxen, Kurt (1983): Geschichte und Problematik des Parlamentarismus, Frankfurt a.M.

Link, Christoph (2010): Kirchliche Rechtsgeschichte, 2. Aufl., München.

Maier, Hans (2002): Historische Voraussetzungen des Sozialstaats in Deutschland, Heidelberg.

Mohnhaupt, Heinz/Grimm, Dieter (2002): Verfassung. Zur Geschichte des Begriffs von der Antike bis zur Gegenwart, Berlin.

von Padua, Marsilius (1324): Defensor Pacis (dt. Der Verteidiger des Friedens, Stuttgart 1971).

Schäfer, Frank L. (2009): Visionen und Wissenschaftsmanagement. Die Gründung eines Max-Planck-Instituts für europäische Rechtsgeschichte, in: Zeitschrift für europäisches Privatrecht 3, S. 517-535.

Schennach, Martin P. (2014): Recht - Kultur - Geschichte. Rechtsgeschichte und Kulturgeschichte, in: Zeitschrift für Neuere Rechtsgeschichte 36, S. 1-31.

Simon, Thomas (2004): „Gute Policey“. Ordnungsleitbilder und Zielvorstellungen politischen Handelns in der Frühen Neuzeit, Frankfurt a.M.

Stolleis, Michael (1988): Geschichte des öffentlichen Rechts in Deutschland. Erster Band 1600-1800, München. 
Stolleis, Michael (2003): Geschichte des Sozialrechts in Deutschland, Stuttgart.

Stolleis, Michael (2008): The Profile of the Judge in the European Tradition, in: TRAMES. Journal of the Humanities and Social Sciences 12.2, S. 204-214.

Stolleis, Michael (2011): Freiheit und Unfreiheit durch Recht. TheodorHeuss-Gedächtnisvorlesung 2010, Stuttgart.

Stolleis, Michael (2012): Geschichte des öffentlichen Rechts in Deutschland. Vierter Band: Staats- und Verwaltungsrechtswissenschaft in West und Ost 1945-1990, München.

Wieacker, Franz (1967): Privatrechtsgeschichte der Neuzeit, 2. Aufl. Göttingen.

Winters, Peter Jochen (1995): Johannes Althusius, in: Michael Stolleis (Hg.): Staatsdenker in der frühen Neuzeit, München.

Zuleeg, Manfred (1994): Die Europäische Gemeinschaft als Rechtsgemeinschaft, NJW 1994, S. $545 \mathrm{ff}$.

Zuleeg, Manfred (1997): Ansätze zu einer Verfassungsgeschichte der Europäischen Union, in: Zeitschrift für Neuere Rechtsgeschichte 19, S. $270 \mathrm{ff}$. 


\section{Verzeichnis der Autoren und Herausgeber}

Maurizio Bach, Dr. phil., Professor für Soziologie an der Universität Passau und Mitherausgeber der Zeitschrift für Politik.

Winfried Brömmel, Geschäftsführer der Europäischen Horizonte und Leiter des EUROPE DIRECT Informationsbüros der Stadt Aachen.

Christoph Deutschmann, Dr. phil., Professor (em.) am Institut für Soziologie der Universität Tübingen.

Ulrike Guérot, Dr. phil., Gründerin und Direktorin The European Democracy Lab, Berlin, und Lehrbeauftragte an der Europa-Universität Viadrina Frankfurt (Oder).

Jan-Hendrik Kamlage, Dr. rer. pol., Mitarbeiter am Kulturwissenschaftlichen Institut Essen (KWI) im Forschungsbereich Partizipationskultur.

Helmut König, Dr. phil., Professor für Politische Wissenschaft an der Rheinisch-Westfälischen Technischen Hochschule Aachen mit dem Schwerpunkt Politische Theorie und Ideengeschichte.

Patrizia Nanz, Dr. phil., Leiterin des Forschungsbereichs Partizipationskultur am Kulturwissenschaftlichen Institut Essen (KWI), sowie Gründerin und wissenschaftliche Leiterin des European Institute for Public Participation (EIPP).

Werner Plumpe, Dr. phil., Professor für Wirtschafts- und Sozialgeschichte an der Goethe-Universität Frankfurt am Main. 
Manfred Sicking, Dr. phil., Beigeordneter für Wirtschaftsförderung, Soziales und Wohnen der Stadt Aachen und Honorarprofessor am Institut für Politische Wissenschaft der Rheinisch-Westfälischen Technischen Hochschule Aachen.

Michael Stolleis, Dr. phil., bis zur Emeritierung 2006 Professor für Öffentliches Recht und Rechtsgeschichte an der Johann Wolfgang GoetheUniversität Frankfurt am Main und von 1992 bis 2009 Direktor des MaxPlanck-Instituts für europäische Rechtsgeschichte.

Thorsten Thiel, Dr. phil., Koordinator des Leibniz-Forschungsverbundes „Krisen einer globalisierten Welt“, assoziiertes Mitglied im Exzellenzcluster „Die Herausbildung Normativer Ordnungen“ an der Goethe-Universität Frankfurt am Main.

Georg Vobruba, Dr. iur., bis zur Emeritierung 2013 Professor für Soziologie an der Universität Leipzig und Herausgeber der Zeitschrift „Soziologie. Forum der Deutschen Gesellschaft für Soziologie“. 


\section{Europäische Horizonte}

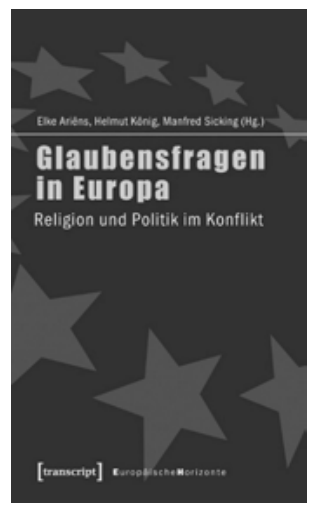

Elke Ariëns, Helmut König, Manfred Sicking (Hg.)

Glaubensfragen in Europa

Religion und Politik im Konflikt

2OII, 232 Seiten, kart., 27,80€,

ISBN 978-3-8376-I707-8

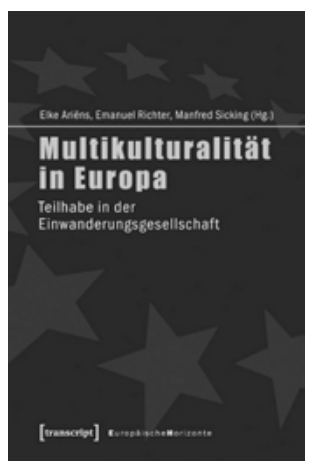

Elke Ariëns, Emanuel Richter,

Manfred Sicking (Hg.)

Multikulturalität in Europa

Teilhabe in der Einwanderungsgesellschaft

(unter Mitarbeit von Eva Onkels und Philip Röhr)

20I2, 234 Seiten, kart., 27,80 €,

ISBN 978-3-8376-2096-2

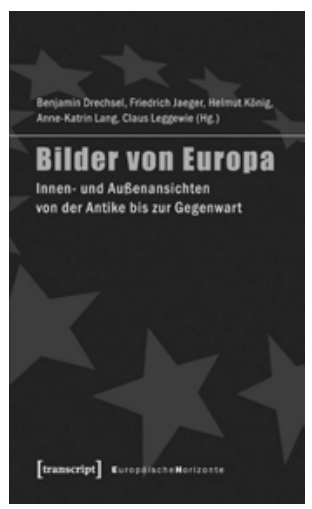

Benjamin Drechsel, Friedrich Jaeger, Helmut König, Anne-Katrin Lang, Claus Leggewie (Hg.)

\section{Bilder von Europa}

Innen- und Außenansichten von der Antike bis zur Gegenwart (unter Mitarbeit von Julia Schmidt sowie Angela und Marcel Siepmann)

20I0, 346 Seiten, kart., zahlr. Abb., 32,80€, ISBN 978-3-8376-I458-9 


\section{Europäische Horizonte}

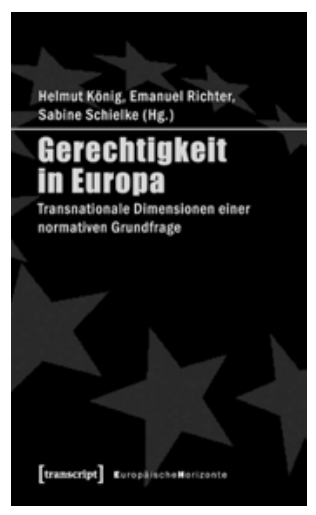

Helmut König, Emanuel Richter,

Sabine Schielke (Hg.)

Gerechtigkeit in Europa

Transnationale Dimensionen

einer normativen Grundfrage

2008, I36 Seiten, kart., $15,80 €$,

ISBN 978-3-89942-768-4

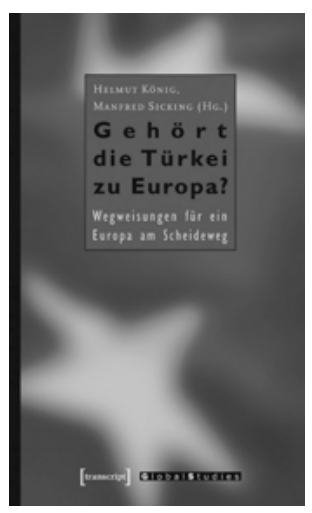

Helmut König, Manfred Sicking (Hg.)

Gehört die Türkei zu Europa?

Wegweisungen für ein Europa am Scheideweg

2005, 222 Seiten, kart., 22,80€,

ISBN 978-3-89942-328-0

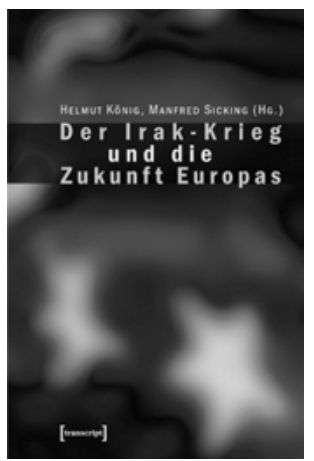

Helmut König, Manfred Sicking (Hg.)

Der Irak-Krieg und die Zukunft Europas

2004, I94 Seiten, kart., 2I,80€,

ISBN 978-3-89942-209-2

Leseproben, weitere Informationen und Bestellmöglichkeiten finden Sie unter www.transcript-verlag.de 